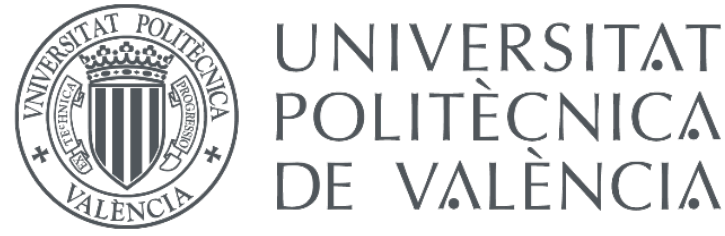

PROGRAMA EN CIENCIA, TECNOLOGÍA Y GESTIÓN ALIMENTARIA

\title{
Sustainability Assessment of Active Packaging Incorporating Nanomaterials
}

Doctoral thesis

By

\section{Hai Zhang}

October 2016 
Directors:

Dr. Mercedes Hortal Ramos

Dr. Maria Jordá Beneyto

The research leading to these results has received funding from the Seventh Framework Program of the European Union under grant agreement No. 290098 "NewGenPak" Project.

The research has been carried out in the ITENE (Packaging, Transport and Logistics Research Centre) Valencia, Spain.

Cover design: Hai Zhang

Printed in Spain

Onion illustration: Ryo Takemasa 
Learn to fail, or fail to learn 



\section{Contents}

1 GENERAL INTRODUCTION.............................................................

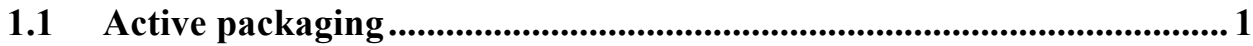

1.2 Antimicrobial packaging and shelf life extension .................................. 4

1.3 Essential oil encapsulated by cyclodextrin: a controlled release system 6

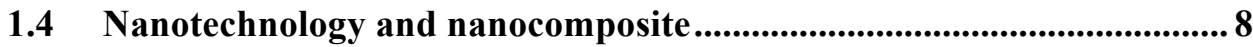

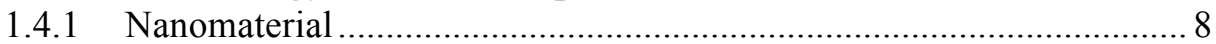

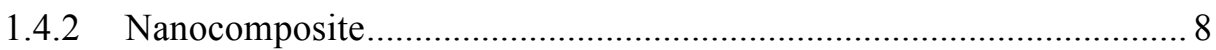

1.4.3 How the clay-polymer system works ................................................ 9

1.4.4 Clay structure and organic modification ............................................ 9

1.4.5 Clay exfoliation and barrier reinforcement ....................................... 11

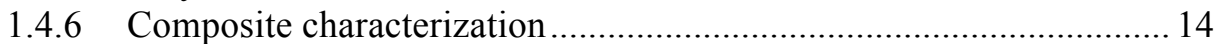

1.4.7 Improvement in other properties ...................................................... 16

1.4.8 Summary and market prospect....................................................... 19

1.5 Metallic nanoparticles for active packaging application ....................... 20

1.5.1 Introduction to metallic Nanoparticles.............................................. 20

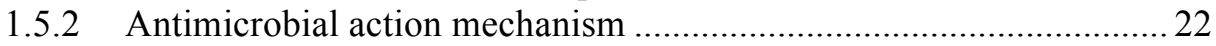

1.5.3 Hybrid metallic nanoparticles and synergistic effect.........................22

1.5.4 Methods to incorporate nanoparticles in the host materials ................22

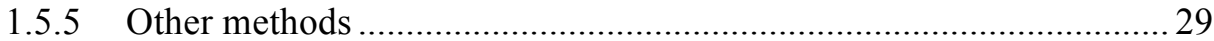

1.6 End-of-life of nanocomposite as packaging material ............................29

1.6.1 Effect of nano-reinforcement on biopolymer's biodegradability........29

1.6.2 Fate of nanomaterials in the waste stream ......................................... 30

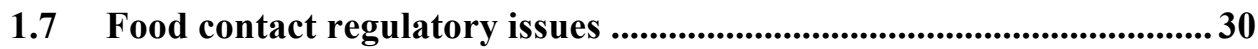

1.8 Consumer perception ....................................................................................31

1.9 Sustainability in packaging sector ....................................................32

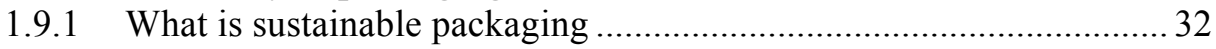

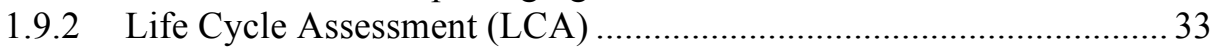

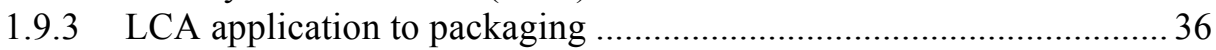

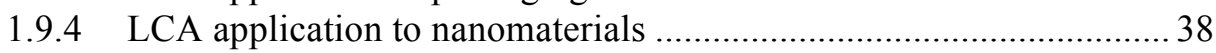

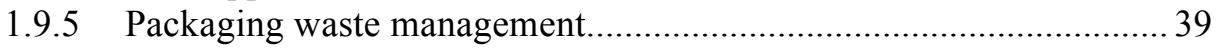

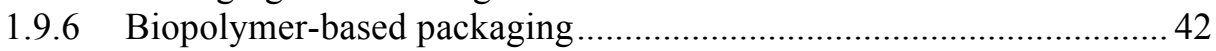

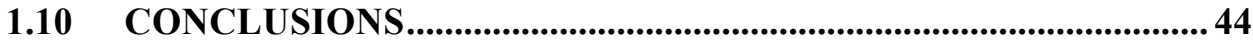

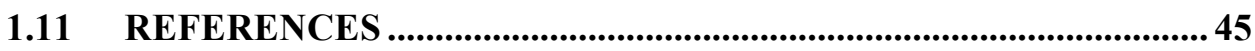

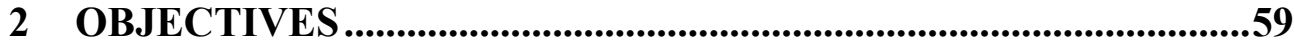

3 Paper I. ZnO-PLA nanocomposite coated paper for antimicrobial packaging application ..............................................................................................63 


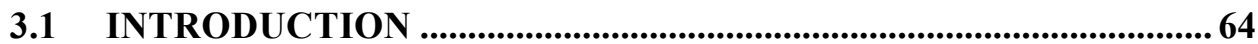

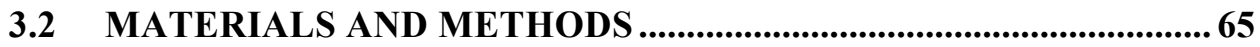

3.2.1 Coating recipe and coating on paper substrate..................................... 65

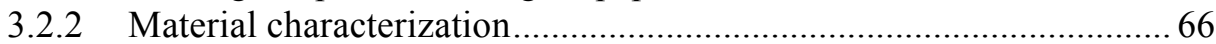

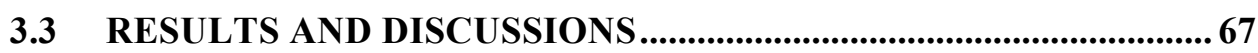

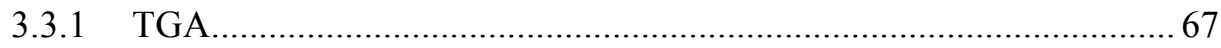

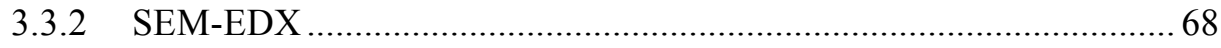

3.3.3 Antimicrobial activity ...................................................................... 71

3.3.4 Antimicrobial action mechanism and the effect of testing methods ... 73

3.3.5 Regulatory issues and market prospect ……...................................... 79

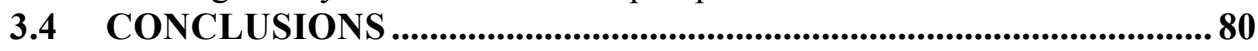

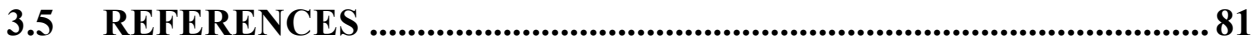

4 Paper II. PLA coated paper containing active inorganic nanoparticles: material characterization and fate of nanoparticles in the paper recycling process .......................................................................................85

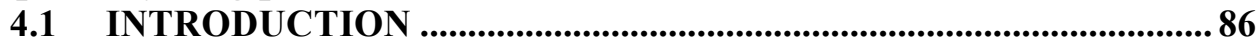

4.2 MATERIALS AND METHODS ….............................................................. 87

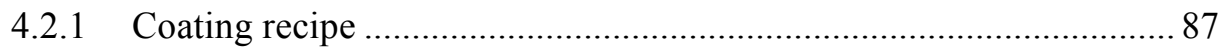

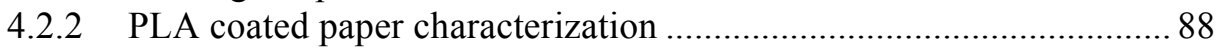

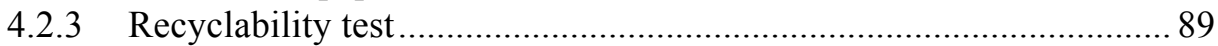

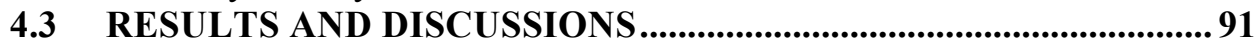

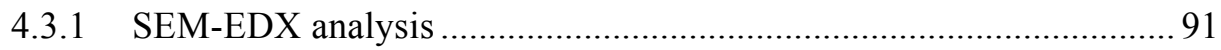

4.3.2 Surface properties of PLA coated paper ............................................. 93

4.3.3 Effect ZnO NPs on optical properties ............................................... 93

4.3.4 Mass balance in paper recycling test................................................94

4.3.5 Fate of $\mathrm{ZnO} \mathrm{NPs}$ in paper recycling test ...........................................96

4.3.6 Tensile strength of handsheets ...........................................................99

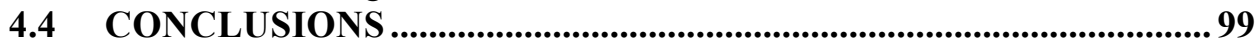

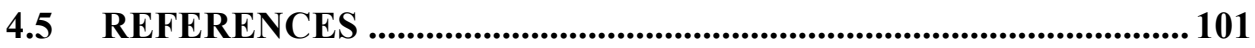

5 Paper III. The effect of active packaging on minimising food losses: Life Cycle Assessment (LCA) of essential oil component enabled packaging for fresh beef .......................................................................................105

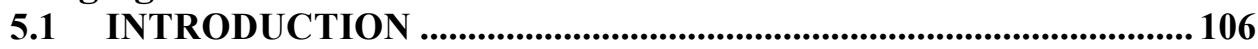

5.2 MATERIALS AND METHODS .........................................................110

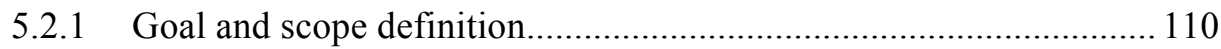

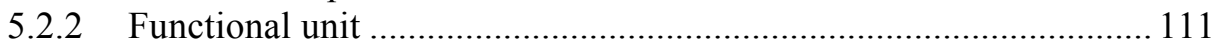

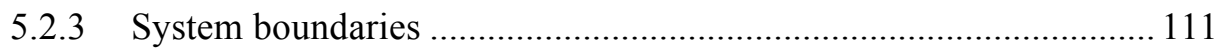

5.2.4 Life cycle inventory (LCI) .......................................................... 113

5.2.5 Selection of impact assessment categories....................................... 115

5.2.6 System performance and scenarios ................................................ 116 


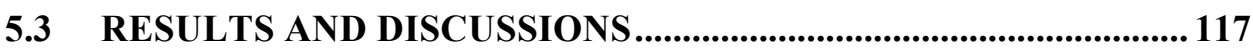

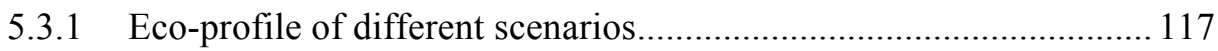

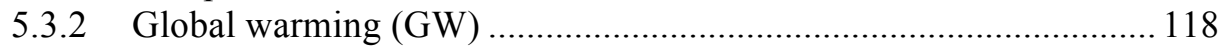

5.3.3 Cumulative energy demand (non-renewable, fossil) ....................... 120

5.3.4 Acidification Potential (AP) and Eutrophication Potential (EP)....... 122

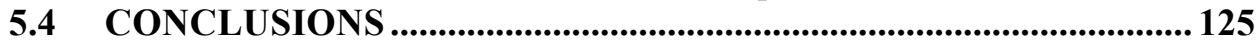

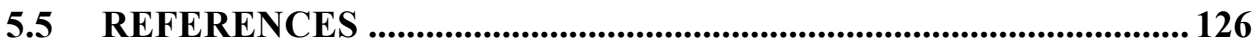

6 Paper IV. Selection of nanomaterial-based active agents for packaging applications: using Life Cycle Assessment (LCA) as a tool 131

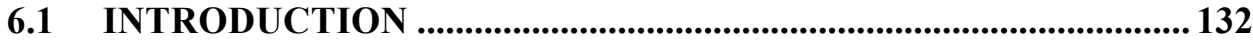

6.2 MATERIALS AND METHODS .........................................................133

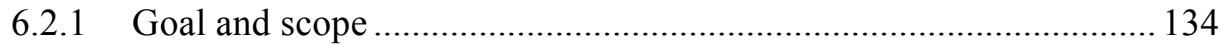

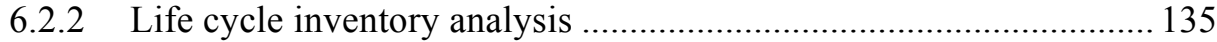

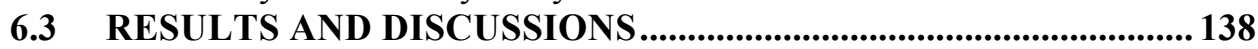

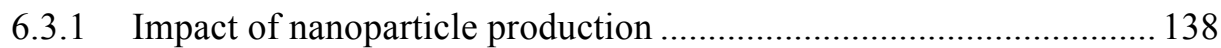

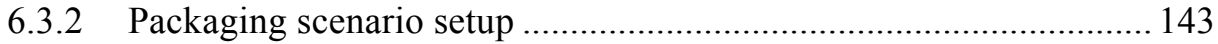

6.3.3 Impact of different packaging materials ........................................ 145

6.3.4 Nanomaterial for food contact application....................................... 148

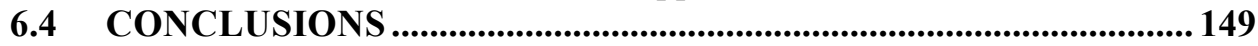

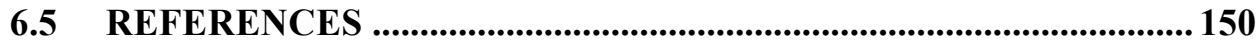

7 FINAL REMARKS AND OUTLOOK FOR FUTURE RESEARCH 155

ACKNOWLEDGEMENT 157 


\section{ABSTRACT (English)}

Packaging plays an important role in ensuring food safety and quality. The development antimicrobial packaging enables actively inhibiting/killing the spoilage microorganisms, and thus extending food product's shelf life. Generally, $50 \%$ shelf life extension is possible. The interest for using metallic nanoparticles in active packaging derives from its superior antimicrobial efficacy and no negative impact on the food sensory properties.

In this thesis, the packaging material of concern is a PLA (Polylactic Acid) coated paper incorporating zinc oxide nanoparticles ( $\mathrm{ZnO} \mathrm{NPs}$ ) in the coating layer. The material was characterized and its antimicrobial activity was evaluated. The SEM images show that the nanoparticles were homogenously distributed across the surface thanks to its surface modification. Antimicrobial assay indicates that the active material was effective in inactivating $E$. coli and $S$. aureus. Furthermore, $E$. coli was found to be more susceptible to this type of agent, showing $3.14 \mathrm{log}$ reduction for $0.5 \mathrm{wt} \%$ agent loading in the PLA coating layer. This result was compared across the publications using the same agent for treating both Grampositive and Gram-negative microorganisms. The discrepancy between the results can be explained by the fact that $\mathrm{ZnO}$ nanoparticles have multiple action mechanisms, and different antimicrobial testing methods may activate part of the action mechanisms.

On the other hand, recyclability is regarded as an important attribute for paperbased packaging material, as it enables to conserve the resources and reduce the environmental impacts. Accordingly, when it comes to the nano-enabled paper packaging material, recyclability should be maintained. In this case, a recyclability test was carried out in a lab-scale paper recycling line. The protocol was based on a method adapted from the ATICELCA MC501-13, which enabled to recover over $99 \%$ of the solids material. The mass balance result indicates that $86 \%-91 \%$ zinc oxide nanoparticles ended up in the rejected material stream, mostly embedded within the polymer coating; whereas 7\%-16\% nanoparticles ended up in the accepted material stream. Besides, the tensile strength of the recycled handsheets suggests that the nano-enabled coating had no negative impacts on the recovered fibre quality.

Active packaging plays a positive role in reducing food losses. If food and packaging are considered as a whole system, its overall environmental impact can be justified by incorporating the food loss reduction due to the application of active packaging. The LCA calculation shows that a breakeven point can be easily achieved for the case of red meat products of high environmental impact. 


\section{RESUMEN (Castellano)}

El envase juega un papel importante asegurando la seguridad y calidad de los alimentos. El desarrollo de envases activos, especialmente envase antimicrobiano, permite inhibir o matar los microorganismos causantes del deterioro de los alimentos, alargando por tanto su vida útil. De forma general es posible extender la vida útil de los alimentos en un 50\%. El interés por el uso de nanopartículas metálicas en el envasado activo se deriva de su gran efectividad antimicrobiana sin causar un efecto negativo en sus propiedades sensoriales.

En la presente tesis, se ha desarrollado un papel recubierto de PLA (ácido poliláctico) con nanopartículas de óxido de zinc (ZnO NPs) incorporadas en la capa de recubrimiento. Se ha caracterizado el material y se ha evaluado su capacidad antimicrobiana. Las imágenes obtenidas mediante SEM muestran que las nanopartículas fueron distribuidas a lo largo de la superficie gracias a su modificación. Los ensayos de efectividad antimicrobiana indicaron una actividad del material frente a $E$. coli y a $S$. aureus. Además, E. coli resultó ser más susceptible a este agente activo incorporado al $0.5 \%$ en peso en el recubrimiento de PLA, mostrando una reducción de $3.14 \mathrm{log}$. Este resultado fue comparado con publicaciones donde se emplearon los mismos agentes activos para frente a microorganismos Gram-positivos y Gram-negativos. Las discrepancias encontradas entre los resultados pueden deberse a que las nanopartículas de $\mathrm{ZnO}$ tienen múltiples mecanismos de acción, y los diferentes métodos de ensayo poder estimular parte de estos mecanismos.

Por otra parte, el reciclado juega un importante papel en la conservación de los recursos y en la reducción de los impactos medioambientales. Por tanto, cuando se trata de un material de envase de papel con sustancias de tamaño nano, el reciclado debe tratarse adecuadamente. El ensayo de reciclabilidad fue llevado a cabo a escala laboratorio en una línea de reciclado de papel. El protocolo de ensayo se basó en el método adaptado de ATICELCA MC501-13, permitiendo una recuperación del 99\% de material sólidos. Los resultados del balance de materia indicaron que el 86\%-91\% de las nanopartículas de óxido de zinc llegaron al flujo de material de rechazo, principalmente mezclado en el recubrimiento polimérico. Además, los resultados de tracción de las láminas recicladas sugieren que el recubrimiento con partículas nano no tiene un efecto negativo sobre la calidad de la fibra recuperada.

El envase activo juega un papel positivo en la reducción de los residuos alimentarios. Como resultado del uso del envase activo, considerando el envase y el alimento como un todo, el impacto ambiental sobre este sistema completo puede ser compensado por la reducción de pérdidas de alimentos. El cálculo LCA muestra 
que el punto de equilibrio se puede conseguir fácilmente en el caso de productos de carne roja de elevado impacto ambiental. 


\section{RESUM (Valenciano)}

L'envàs té un paper prou important en la seguretat i la qualitat del aliments. El desenvolupament dels envasos actius, especialment l'envàs antimicrobià, el qual permeteix l'inhibició o mort dels microorganismes que produeixen el deteriorament dels aliments i, per tant, allargant la seua vida útil. De manera general, es possible l'allargament de la vida útil dels aliments en un 50\%. L'interès per la utilització de nanopartícules metàl-liques en l'envasat actiu es deriva de la seua gran efectivitat antimicrobiana sense produir un efecte negatiu en les seus propietats sensorials.

En aquesta present tesis, s'ha desenvolupat un paper recobert de PLA (àcid polilàctic) amb nanopartícules d'òxid de zinc (ZnO NPs) incorporades a la capa de recobriment. S'ha caracteritzat el material i s'ha avaluat la seua capacitat antimicrobiana. Les imatges obtingudes per mitjà del SEM mostren que les nanopartícules foren distribuïdes en tota la superfície gràcies a la seua modificació. Els assajos d'efectivitat antimicrobiana varen indicar una activitat del material front a E.coli i a $S$. aureus. A més, E. coli va resultar ser més susceptible a aquest agent actiu incorporat al $0.5 \%$ en pes en el recobriment de PLA, mostrant una reducció de $3.14 \log$. Aquest resultat va ser comparat amb publicacions on es van emprar els mateixos agents actius front a microorganismes Gram-positiu i Gram-negatiu. Les discrepàncies trobades entre els resultats poden deure's a que les nanopartícules de $\mathrm{ZnO}$ tenen diversos mecanismes d'acció, i els diferents mètodes d'assaig poder estimular part d'aquestes mecanismes.

Per altra banda, el reciclatge també té un paper important en la conservació dels recursos i en la reducció dels impactes mediambientals. Per tant, quan es tracta d'un material d'envàs de paper amb substàncies de la grandària 'nano', el reciclatge ha de tractar-se adequadament. El assaig de reciclabilitat va ser dut a terme a escala de laboratori en una línia de reciclatge de paper. El protocol de l'assaig es va basar en el mètode adaptat d'ATICELCA MC501-13, permetent una recuperació del 99\% del material sòlid. Els resultats del balanç de matèria van indicar que el 86-91\% de les nanopartícules d'òxid de zinc varen arribar al fluix material de rebuig, principalment mesclat en el recobriment polimèric. A més, els resultats de tracció de les làmines reciclades suggereixen que el recobriment amb nanopartícules nano no tenen un efecte negatiu sobre la qualitat de la fibra recuperada.

L'envàs actiu juga un paper positiu en la reducció dels residus alimentaris. Com a resultat de l'ús de l'envàs actiu, considerant l'envàs i l'aliment com un tot conjunt, l'impacte ambiental sobre aquest sistema complet pot ser compensat per la reducció de pèrdues d'aliments. El càlcul LCA mostra que el punt d'equilibri es pot aconseguir fàcilment en el cas de productes de carn roja d'elevat impacte ambiental. 


\section{ABBREVIATIONS}

AP: Acidification Potential

CD: Cyclodextrin

CEC: Cation Exchange Capacity

CFU: Colony Forming Unit

EFSA: European Food Safety Authority

EP: Eutrophication Potential

FDA: US Food and Drug Administration

FU: Functional Unit

GWP: Global Warming Potential

ICP-MS: Inductively Coupled Plasma-Mass Spectrometer

LCA: Life Cycle Assessment

LCI: Life Cycle Inventory analysis

LCIA: Life Cycle Impact Assessment

MMT: Montmorillonite

NFC: Nanofibrillated Cellulose

NP: Nanoparticle

PCL: Polycaprolactone

LDPE: Low-Density Polyethylene

PHA: Polyhydroxyalkanoates

PLA: Polylactic Acid

PP: Polypropylene

RH: Relative Humidity

ROS: Reactive Oxygen Species

SEM: Scanning Electron Microscopy

SML: Specific Migration Limit

TEM: Transmission Electron Microscopy

TGA: Thermogravimetric Analysis

TSA: Tryptone Soy Agar

WWTP: Wastewater Treatment Plant

XRD: X-Ray Diffraction 


\section{GENERAL INTRODUCTION}

\subsection{Active packaging}

The latest trend of food consumption shows that minimally processed food and food containing less synthetic preservatives and additives are gaining popularity. This will pose more pressure to the food distribution. On the other hand, food producers and distributors already suffer significant food losses, and reducing food waste has become a strong voice in our society. In recent years, active packaging has attracted significant research efforts for being an effective solution for the abovementioned problems.

The official definition of active packaging is given in the regulation EC No. 450/2009 [1]: active materials and articles means materials and articles that are intended to extend the shelf-life or to maintain or improve the condition of packaged food; they are designed to deliberately incorporate components that would release or absorb substances into or from the packaged food or the environment surround the food.

A typical structure of active packaging is illustrated in Figure 1. The outer layer next to the environment functions as a barrier against microorganisms, chemicals, light, moisture, oxygen, etc.; while the internal layer containing active agents can actively interact with the foodstuff for the intended purposes.

\section{Environment}

\section{Barrier layer}

Against microorganisms, chemicals, light, moisture, oxygen, etc.

\section{Active layer}

- Release or absorb substances

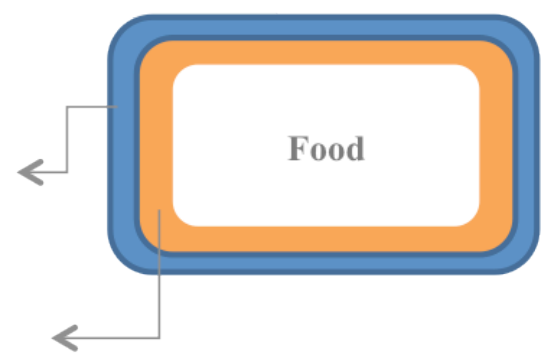

- Shelf life extension

- Other improved properties

Figure 1. The concept of active packaging. 
In a packaging system, several mass transport mechanisms co-exist (see Figure 2):

1) Gas molecules, moisture, small aroma molecules from the environment could permeate through the polymer packaging material to reach the food; the transport can also occur in the reverse direction, from the food to the environment, depending on the concentration equilibrium at the phase interfaces.

2) The residues and additives (including active agents) contained within the polymer packaging material could migrate to the other phases, the environment and the headspace of the packaging/food. The kinetics of mass transport is governed by the Fick's diffusion law and this will be discussed in details in Section 1.4.5.

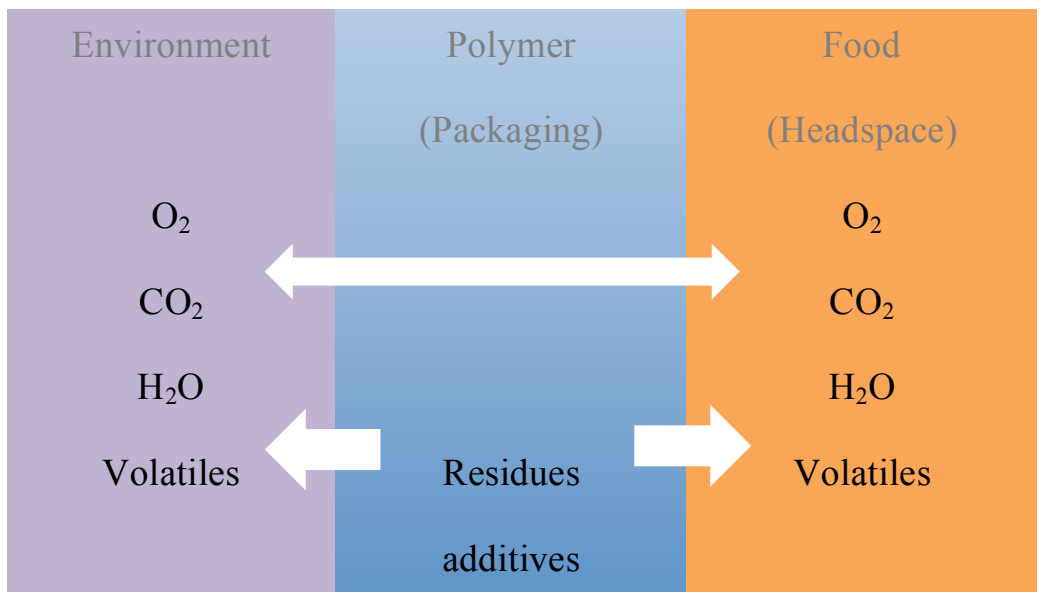

Figure 2. Mass transport in a packaging system.

The first generation of active packaging is based on the concept of "sachet"-the active agents are contained within a permeable bag. However, this solution has some obvious drawbacks. For example, it has poor consumer perception (many consumers show rejection to a sachet printed with words like "DO NOT EAT" next to their food). There is also a risk of consumer exposure to high concentration of active agents, which is especially dangerous to children. Besides, this solution requires additional operations at food producer's site. To overcome these drawbacks, active packaging evolves to the second generation, in which the agents are incorporated in the polymer matrix, i.e. being part of the packaging material [2] (see Figure 1).

Over the past decade various types of active packaging have emerged to the market. Some typical active packaging applications are summarized in Table 1. (It should 
be noted that active packaging is mainly used for food but not limited to food; other applications are possible, e.g. cosmetics and pharmaceuticals.)

Active packaging needs to be tailor made for a specific food. This is because a successful design requires identifying the spoilage mechanisms and choosing the corresponding active agent to suppress the spoilage. For example, ground coffee is a lipid-rich food product, and the lipid substances can be quickly oxidized after exposure to oxygen and result in deterioration of taste (e.g. rancidity). In this case, oxygen-scavenging packaging could effectively reduce the rancidity, and hence extending the product's shelf life.

As claimed by a UK food retailer, use of ethylene-absorbing packaging has cut the waste of berries by $4 \%[3]$. US army has showed great interest to use nano-enabled antimicrobial packaging for ready-to-eat food for their soldiers [4]. Furthermore, antimicrobial packaging can be used as a measure to control the microbiological risks in food distribution [5-7].

Table 1. Different types of active packaging and their applications. Reproduced from [8].

\begin{tabular}{|l|l|}
\hline Active packaging types & Target food \\
\hline Oxygen scavenging & $\begin{array}{l}\text { Fresh and pre-cooked pasta, catering, meat } \\
\text { products (e.g. smoked ham and salami), bakery } \\
\text { products (e.g. bread, pizza crust, pastries, cookies, } \\
\text { cakes), cheese, coffee, nuts and potato chips }\end{array}$ \\
\hline $\begin{array}{l}\text { Carbon dioxide } \\
\text { absorbing/emitting }\end{array}$ & $\begin{array}{l}\text { The } \mathrm{O}_{2} \text { absorbers/ } \mathrm{CO}_{2} \text { generators are mainly used } \\
\text { in products where package volume and package } \\
\text { appearance are critical e.g. peanuts or potato } \\
\text { crisps }\end{array}$ \\
\hline Moisture absorbing & $\begin{array}{l}\text { Cheeses, meats, chips, nuts, popcorn, candies, } \\
\text { gums and spices }\end{array}$ \\
\hline Ethylene scavenging & Fresh fruits and vegetables \\
\hline Ethanol emitting & Fruits \\
\hline $\begin{array}{l}\text { Antimicrobial } \\
\text { releasing/contact active }\end{array}$ & Meat, fish, poultry, bread, cheese, fruits \\
\hline
\end{tabular}




\begin{tabular}{|l|l|}
\hline Antioxidant releasing & Meat, cereals \\
\hline Flavour absorbing & Juice, fish \\
\hline Flavour releasing & Ice cream \\
\hline
\end{tabular}

Among these applications, antimicrobial packaging has attracted more research effort than the others for its ability to reduce food losses[9, 10]. These advantages will be explored in details in the following sections.

\subsection{Antimicrobial packaging and shelf life extension}

Shelf life is an important characteristic of food products. It is subjected to the relevant regulations. Basically, anyone who packages and sells food that is required to be labeled "use by" or "best before" date is legally responsible for calculating how long their products can be reasonably expected to keep under what storage conditions without any appreciable change in quality $[11,12]$. In most of the cases, it is the responsibility of the food producers, but it is also applicable to other players in food distribution, e.g. the re-packers, secondary processors, and food retailers (e.g. supermarket).

Two factors influence the food product's shelf life:

- Microbial spoilage

This means spoilage/pathogenic organism growth and amount of microorganisms present. It is usually regulated by the relevant industry standards.

- Non-microbial spoilage

This means sensory or biochemical deterioration, e.g. colour, texture, flavours, etc.

Active packaging extends the shelf life by counteracting either of the spoilage mechanisms: to inhibit the microorganism growth (e.g. the antimicrobial type), or to enhance or maintain the sensory qualities (to control the internal atmosphere, e.g. oxygen, moisture, humidity, $\mathrm{CO}_{2}$, ethanol, ethylene, etc.). Accordingly, in a shelf life study $[13,14]$, a set of criteria will be considered, including the sensory change, microbiological change and physiochemical change due to spoilage (microbe's metabolism). The effect of active packaging on shelf life extension is significant. As observed in many works (see Table 2), generally, $50 \%$ of shelf life extension is possible. 
Table 2. Examples of shelf life extension as a result of using active packaging.

\begin{tabular}{|c|c|c|c|c|}
\hline $\begin{array}{l}\text { Food } \\
\text { products }\end{array}$ & $\begin{array}{l}\text { Shelf life in } \\
\text { control } \\
\text { packaging } \\
\text { [day] }\end{array}$ & $\begin{array}{l}\text { Shelf life in } \\
\text { active } \\
\text { packaging } \\
\text { [day] }\end{array}$ & $\begin{array}{l}\text { Active packaging } \\
\text { description }\end{array}$ & References \\
\hline $\begin{array}{l}\text { Ground } \\
\text { beef }\end{array}$ & 5 & 9 & $\begin{array}{l}\text { Coating layer } \\
\text { containing } \\
\text { nisin/lacticin }\end{array}$ & $\begin{array}{l}\text { Kim et al., } 2002 \\
{[15]}\end{array}$ \\
\hline Beef steak & 14 & 23 & $\begin{array}{l}\text { PP film coated with } \\
\text { oregano extract }\end{array}$ & $\begin{array}{l}\text { Camo et al., } 2011 \\
{[16]}\end{array}$ \\
\hline Beef steak & 12 & 14 & $\begin{array}{l}\text { PP film co-extruded } \\
\text { with natural } \\
\text { antioxidants }\end{array}$ & $\begin{array}{l}\text { Nerín et al., } 2006 \\
{[17]}\end{array}$ \\
\hline $\begin{array}{l}\text { Fresh lamb } \\
\text { steaks }\end{array}$ & 8 & 13 & $\begin{array}{l}\text { Active film } \\
\text { containing extracts of } \\
\text { rosemary/oregano }\end{array}$ & $\begin{array}{l}\text { Camo et al., } 2008 \\
{[18]}\end{array}$ \\
\hline $\begin{array}{l}\text { Raw } \\
\text { skinless } \\
\text { sausages }\end{array}$ & 7 & 15 & Chitosan treatment & $\begin{array}{l}\text { Sagoo et al., } 2002 \\
{[19]}\end{array}$ \\
\hline $\begin{array}{l}\text { Grilled } \\
\text { pork }\end{array}$ & 14 & 28 & $\begin{array}{l}\text { Chitosan treatment } \\
\text { (on sample surface) }\end{array}$ & $\begin{array}{l}\text { Yingyuad et al., } \\
2006[20]\end{array}$ \\
\hline $\begin{array}{l}\text { Fresh-cut } \\
\text { fruit }\end{array}$ & $1-2$ & $5-7$ & $\begin{array}{l}\text { Polymer extrusion } \\
\text { incorporating } \\
\text { essential oil } \\
\text { component }\end{array}$ & www.easyfruit.eu \\
\hline $\begin{array}{l}\text { Mozzarella } \\
\text { cheese }\end{array}$ & $5-7$ & $10-14$ & $\begin{array}{l}\text { Packaging } \\
\text { incorporating lemon } \\
\text { extract }\end{array}$ & $\begin{array}{l}\text { Conte et al., } 2007 \\
{[21]}\end{array}$ \\
\hline $\begin{array}{l}\text { Peeled } \\
\text { shrimps }\end{array}$ & 5 & 14 & $\begin{array}{l}\text { MAP in combination } \\
\text { with thymol-enabled } \\
\text { coating }\end{array}$ & $\begin{array}{l}\text { Mastromatteo et } \\
\text { al., } 2010 \text { [22] }\end{array}$ \\
\hline
\end{tabular}




\subsection{Essential oil encapsulated by cyclodextrin: a controlled release system}

Depending on the design, active packaging may function as a release system or as a contact active system. A release system means the agents could migrate to the packaging's headspace or to the food surface in a controlled manner [23]; while for a contact active system, the agents are immobilized in the packaging material, and it functions by direct contacting with the food surface. Cyclodextrin (CD) encapsulated essential oil component is a good example of release system.

It is well known that some essential oils (extracted from herbs and plants) contain intrinsic antimicrobial properties, e.g. carvacrol in thyme and oregano [22, 24], eugenol in clove [25], and cinnamic acid in cinnamon [26].

Cyclodextrin (CD) is a derivative product of starch. It is often used as a complexing agent to entrap some guest molecules. The complexation/encapsulation is an equilibrium process (see Figure 3). The disassociation of a complex is driven by water molecule concentration gradient in the surrounding environment, i.e. the $\mathrm{RH}$ (Relative Humidity) [27], which can be seen as a triggering mechanism for the design of a release system.

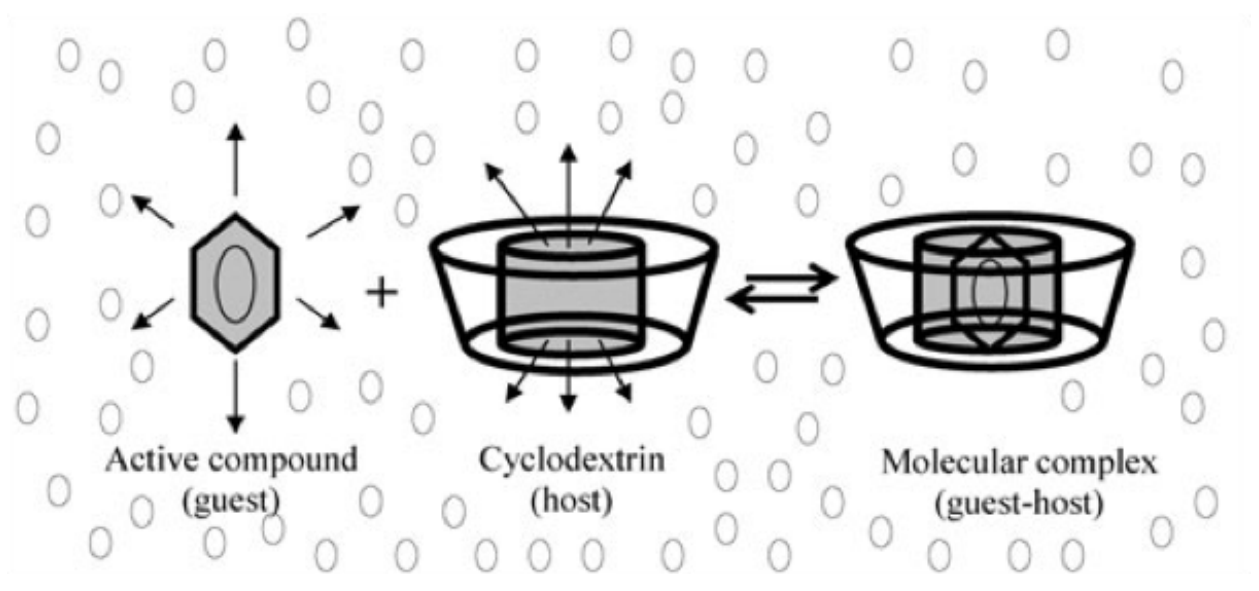

Figure 3. Illustration of active compound and CD complexation equilibrium in water environment. Reproduced from [27].

Ayala-Zavala et al. proposed a release system for packaging fresh-cut fruits (See Figure 4) [27]. As the fruit respired, the RH within packaging started to increase. When the RH reached a threshold point (33\% in this case, as shown in Figure 5), the release of the active compounds (eugenol) was triggered. 


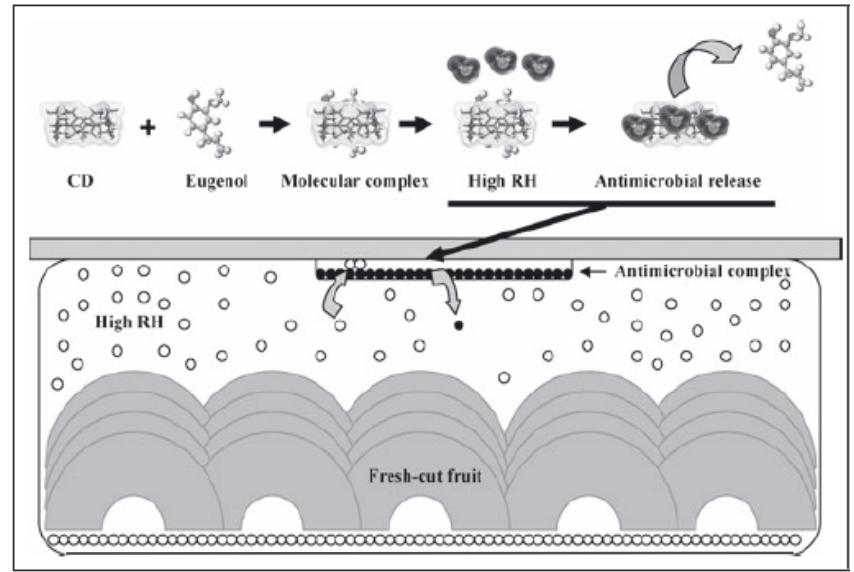

Figure 4. An active packaging system using eugenol as antimicrobial agents for fresh-cut fruits.

The release of eugenol is triggered by the RH within the packaging. Reproduced from [27].

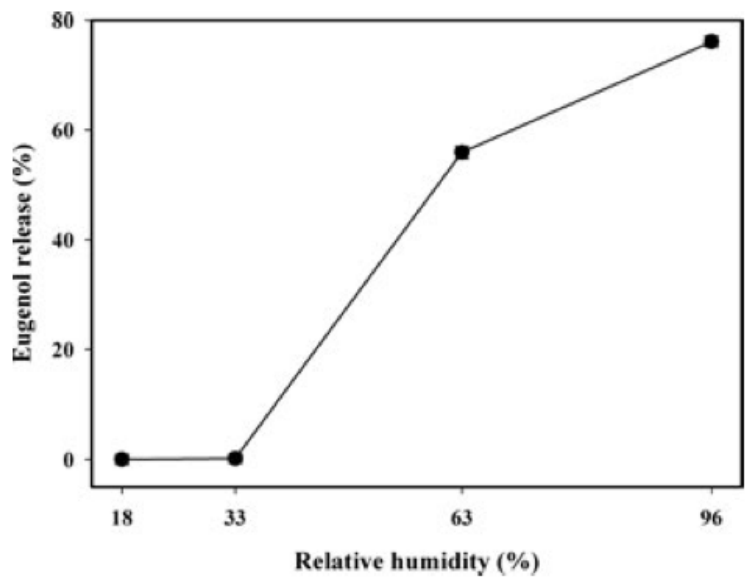

Figure 5. Controlled release of eugenol from $\beta$-Cd complex as a function of the RH (Relative Humidity). Reproduced from [27]. 


\subsection{Nanotechnology and nanocomposite}

\subsubsection{Nanomaterial}

Nanomaterial means solids substance with at least one dimension less than $100 \mathrm{~nm}$ (nanometre) $[28,29]$. In contrast to the bulk material of the identical composition, when a material's physical dimension is reduced to nano-scale, its physical and chemical properties are governed by the Quantum mechanics, which leads to the enhanced reactivity, catalysis, mechanical strength, electrical conductivity, etc.

Another important attribute of nanomaterial is its exceptional large surface-tovolume ratio. This can be demonstrated with an example (see Figure 6): for a cube of $1 \times 1 \times 1 \mathrm{~cm}$, the total surface area is $6 \mathrm{~cm}^{2}$; when the cube is broken into smaller cubes, $1 \times 1 \times 1 \mathrm{~mm}$, the total surface area will be 10 times larger; if further broken into nano cubes, $1 \times 1 \times 1 \mathrm{~nm}$, the total surface area will be $10^{6}$ times larger. When such large surface area exposed to the surrounding environment, it will influence the interactions occurring at the interface and hence the behaviour of nanomaterials, e.g. transport, deposit and uptake mechanisms [30-32].

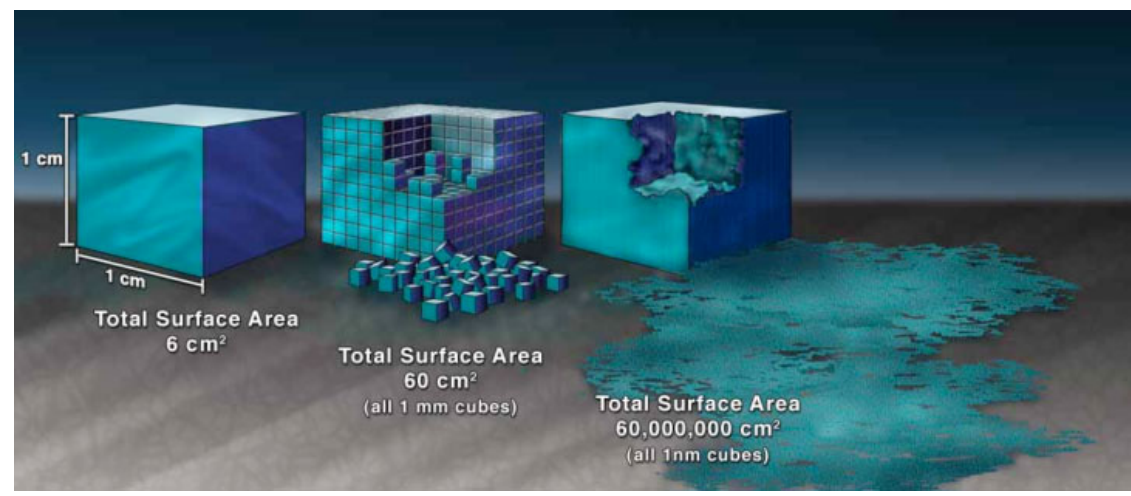

Figure 6. Nanomaterial: surface to volume ratio. Reproduced from [33].

\subsubsection{Nanocomposite}

The clay-polymer system is a typical example of nanocomposite. The relevant research work began in the 1980s, and it was found that by introducing a small amount of nanoclay into the polymer matrix, a range of properties could be improved. In particular, the enhancement in barrier properties and flame retardant property has attracted more research interest. Food packaging is seen as one of its potential applications. The recent research work shows that the best reinforcement 
effect is attained when the silicate layers are in a exfoliated state, i.e. exposing its nano-structure $[34,35]$. This will be discussed in details in the following sections.

\subsubsection{How the clay-polymer system works}

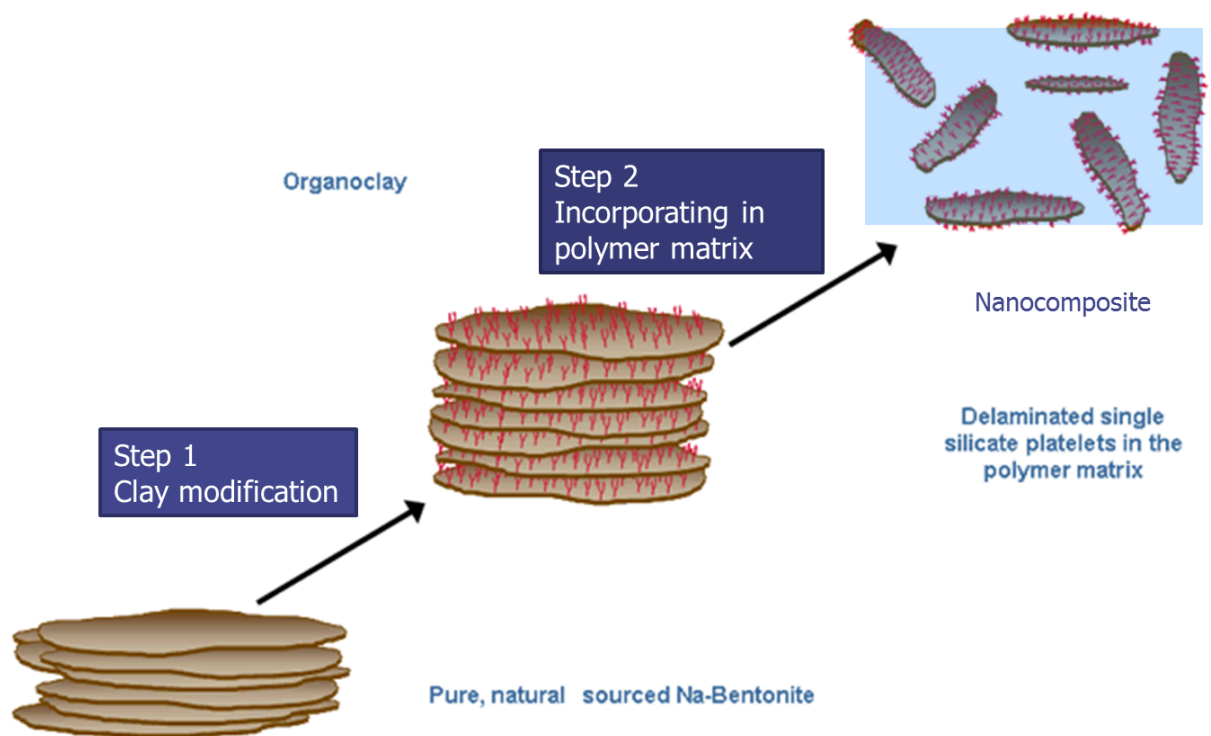

Figure 7. The process to produce a clay-polymer nanocomposite. Adapted from [36]

As illustrated in Figure 7, a typical clay-polymer nanocomposite contains three fundamental components: the nanoclay, modifier, and polymer matrix. To fabricate the nanocomposite, pure clay needs to be modified first. The aim of the modification treatment is to render the hydrophilic clay surface to be hydrophobic, and this will ensure better compatibility with the polymer matrix. After that, the organically modified clay (also called "organoclay") is incorporated into the polymer as additives/fillers, usually at a loading less than $5 \mathrm{wt} \%$. Melt-extrusion is the most readily accepted method by the industry for it would not cause significant changes to the existing polymer processing.

\subsubsection{Clay structure and organic modification}

Nanoclay (Montmorillonite, MMT for short) is a material with naturally occurring nano-structure. As illustrated in Figure 8, a clay particle is actually composed of numerous silicate layers (also called "platelets"). Typically, one single platelet is about $1 \mathrm{~nm}$ in thickness and the lateral dimension can be as large as $10 \mu \mathrm{m}[4,35]$. If described in aspect ratio, the value can range from 10 to 1000 . These silicate 
layers are stacked together by van der Waals' forces and/or weak ionic interactions, and can be separated with engineering methods.

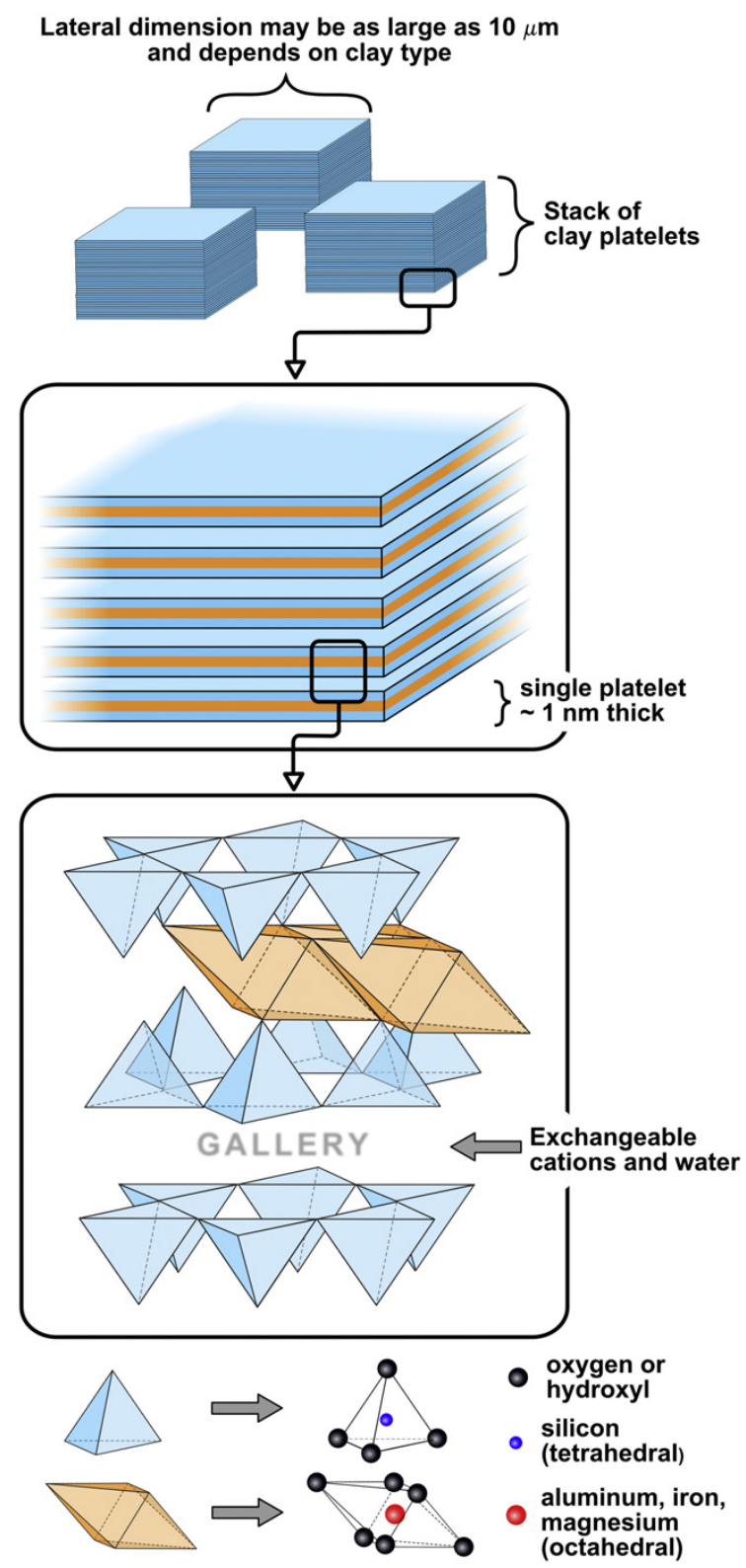

Figure 8. The structure of nanoclay on different scale levels. Reproduced from [4]. 
Nanoclay has a typical 2:1 structure: 2 tetrahedral sheets (opposing 6-unit-rings with a silicon atom in the centre) sandwiching an octahedral sheet (the unit has a aluminium/iron/magnesium atom in the centre). The sheets are connected by sharing the apical oxygen or hydroxyl.

Interestingly, between the "sandwiches", there is an interlayer (called "gallery") consisting of water and interlayer cations (e.g. $\mathrm{Na}^{+}, \mathrm{Ca}^{2+}$, and $\mathrm{Mg}^{2+}$ ), which can be exchanged with other cations, e.g. organo-surfactant [37]. The reaction readily takes place in aqueous media. Usually, a portion of ethanol and heat are used to enhance the reaction.

Cation Exchange Capacity (CEC) is an indicator to describe the number of sites available for the ion exchange. It is measured by reacting the nanoclay with $\mathrm{Cu}(\text { trien })^{2+}$ [38]. MMT has a typical value of CEC $80-150$ meq/100g clay.

\subsubsection{Clay exfoliation and barrier reinforcement}

The enhanced barrier properties have important meanings for packaging application. This mechanism of the reinforcement is illustrated in Figure 9. When a nanocomposite is properly produced, the silicate layers are homogenously dispersed within the polymer matrix, and thus building up a tortuous pathway for the permeating molecules. The clay platelet is well crystallized, it is impermeable to the small molecules, e.g. $\mathrm{O}_{2}$ and $\mathrm{H}_{2} \mathrm{O}$ [39]. As a result of this, the molecules need to travel a more tortuous route $d$ ' instead of a more direct route $d$, which corresponds to the case when no clay is used. For the case of travelling the route $d$ ', in accordance with the Fick's diffusion law (see Equation 1 and 2), the material's apparent diffusivity of is reduced. 


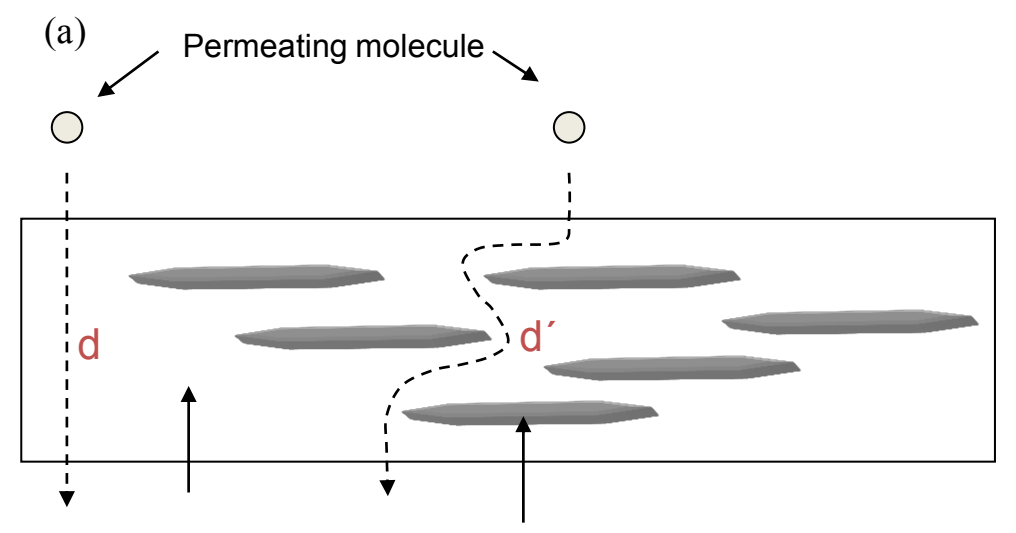

Polymer matrix

Clay platelets

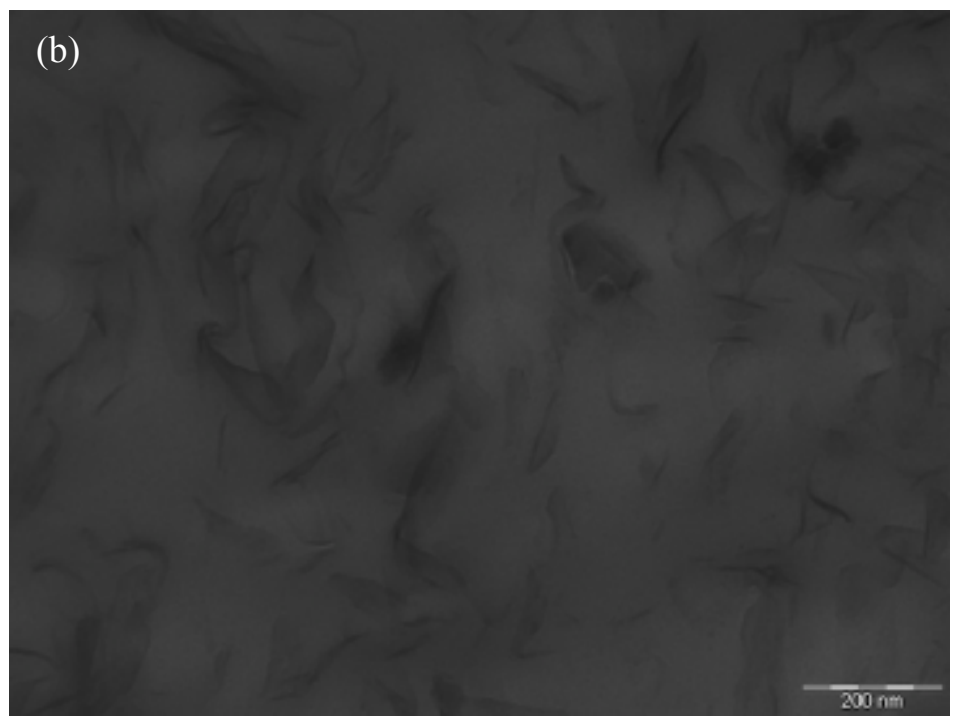

Figure 9. Image (a): the mechanism of barrier enhancement in the clay-polymer system. Image (b): a TEM image showing the exfoliated silicate layers distributed within the PLA matrix.

Fick's first law of diffusion is described in Equation 1 [40]:

$$
J=-D \frac{\partial c}{\partial x}
$$

where 
$J$ is the diffusion flux, with a unit of $\frac{\mathrm{mol}}{\mathrm{m}^{2} \mathrm{~s}}$. It measures amount of substance flowing through a unit area per unit time.

$D$ is the diffusivity (also called diffusion coefficient), with a unit of $\mathrm{m}^{2} / \mathrm{s}$.

$c$ is the concentration of the substance of interest, with a unit of $\mathrm{mol} / \mathrm{m}^{3}$.

$x$ is the position in the spatial dimension considered.

Fick's second law of diffusion describes how the concentration profile evolves with respect to time (see Equation 2) [40]:

$$
\frac{\partial c}{\partial t}=D \frac{\partial^{2} c}{\partial x^{2}}
$$

The reinforcement in barrier properties depends on how well the clay is dispersed in the polymer matrix. The desired state of dispersing is called exfoliation, in which the individual palates are separated by the polymer phase [35].

Clay modification is essential to achieve the exfoliation. Surfactant containing QAG groups (Quaternary Ammonium Group) is often used to do this job. After modification, the clay becomes "organoclay", and the interlayer distance (d-spacing) increases. In fact, from clay modification to clay incorporation (melt-intercalating), it can be seen as a process of progressively expanding the silicate layers.

As an example, the relevant data are extracted from a comparative study [39] (see Table 3). The same polymer is reinforced with different organoclays (based on the same clay but modified with different modifiers; the number of octadecyl carbon chain connecting to the nitrogen atom increases from 1 to 4). The data indicates that the d-spacing of the organoclay increases as a function of the number of alky chains. While on the nanocomposite level, a greater d-spacing of the organoclay (c.a. $2 \mathrm{~nm}$ increasing) enables $27 \%$ decreasing in the composite's oxygen permeability. This relationship is illustrated in Figure 10. 
Table 3. The effect of modifier on the composite's oxygen permeability. Data source [39].

\begin{tabular}{|l|l|l|l|l|}
\hline & $\mathbf{C 1 8}$ & $\mathbf{2 C 1 8}$ & $\mathbf{3 C 1 8}$ & $\mathbf{4 C 1 8}$ \\
\hline $\begin{array}{l}\text { The d-spacing of the } \\
\text { organoclay [nm] }\end{array}$ & 1.85 & 2.66 & 3.58 & 3.94 \\
\hline $\begin{array}{l}\text { The } \mathbf{O}_{\mathbf{2}} \text { permeability of the } \\
\text { composite } \\
{\left[\mathbf{c m}^{\mathbf{3}} \mathbf{\mu m} / \mathbf{m} \mathbf{2} \cdot \text { day } \mathbf{m m H g} \text { m }\right.}\end{array}$ & 44 & 33 & 34 & 32 \\
\hline
\end{tabular}

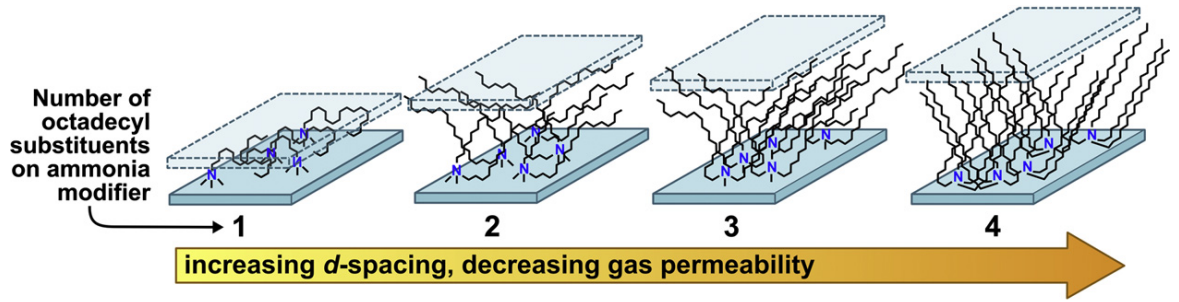

Figure 10. The effect modifier type on the d-spacing of the organoclay and the gas permeability of the composite material using this organoclay. Reproduced from [4].

Research shows that when clay is modified with two modifiers, at least one polar and one non-polar, preferably having different chain lengths, the organic modification result is better than a single modifier system [41, 42]. In a twomodifier system, it is assumed that on a platelet surface there might be some regions consisting of a single organic modifier type, and other regions consisting of another single organic modifier type. And the platelet surface got "roughening" or "texturing". Thus, such modification will greatly enhance the interactions between the platelet and the polymer matrix.

\subsubsection{Composite characterization}

The composite material's performance (i.e. the effect of nano-reinforcement) greatly depends on how well the clay is dispersed within the polymer matrix. This can be explained from a physical point of view: as the stacked clay platelets becomes delaminated and separated by the polymer phase (exfoliated), more nano- 
scale solids surface area become exposed, which allows for more interactions between the surface and polymer chains.

XRD (X-Ray Diffraction) and TEM (Transmission Electron Microscopy) are often used to characterize clay-polymer nanocomposite. They are useful tools to evaluate the clay dispersing state within the composite. As an example, Figure 11 shows different clay dispersing states that can be achieved within a composite: intercalated, intercalated-flocculated, and exfoliated. However, it should be noted that in a composite the state of clay dispersing can be complex and various states may coexist. Generally, XRD provides a more averaged picture about the test piece, while the TEM image gives direct information about the clay's spatial distribution in a specific observation spot.
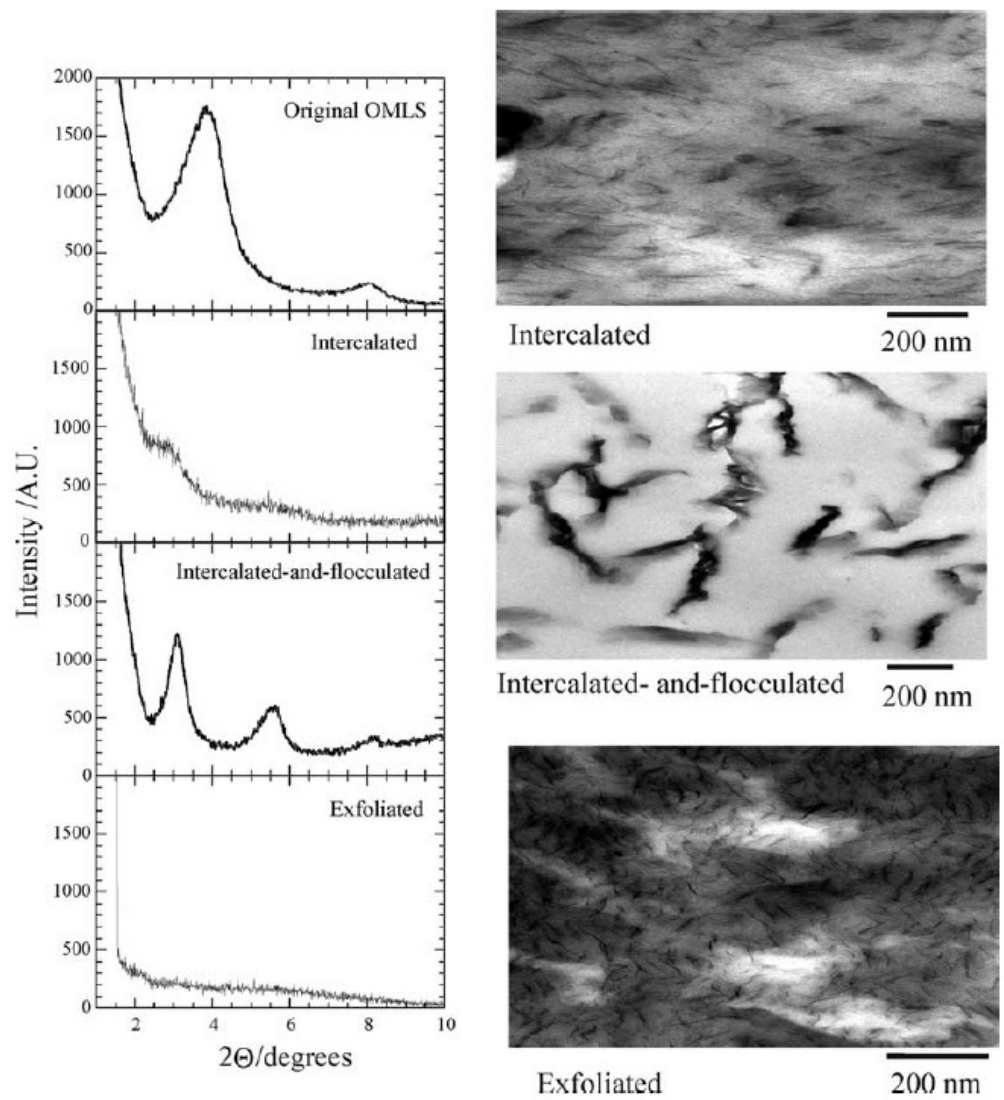

Figure 11. Different clay dispersing states within a composite as examined by XRD and TEM. Reproduced from [35]. 


\subsubsection{Improvement in other properties}

For the clay-polymer system, besides the gas barrier properties, the enhancement is also observed in other properties such as the mechanical properties, flame retardant property, thermostability and antimicrobial properties $[35,43,44]$.

In terms of mechanical properties, the effect of reinforcement is significant. For example, in a study shows that the incorporation of organoclay improved the material's yield strength by $44.6 \%$ [45]. The reinforcement effect can be explained by the adhesion created between the polymer matrix and clay platelets which restricts the segmental motion of polymer chains [45].

However, this reinforcement in is not yet comparable with the conventional glass fibre. A comparison was made for the best possible reinforcement that can be achieved with the two filler systems (see Figure 12). In this study, Nylon-6 was reinforced with $4 \mathrm{wt} \%$ nanoclay and $48 \mathrm{wt} \%$ glass fibre, respectively. Clearly, in both tensile strength and Young's modulus the fibre-reinforced composite has outperformed the clay system with a great margin [34]. 

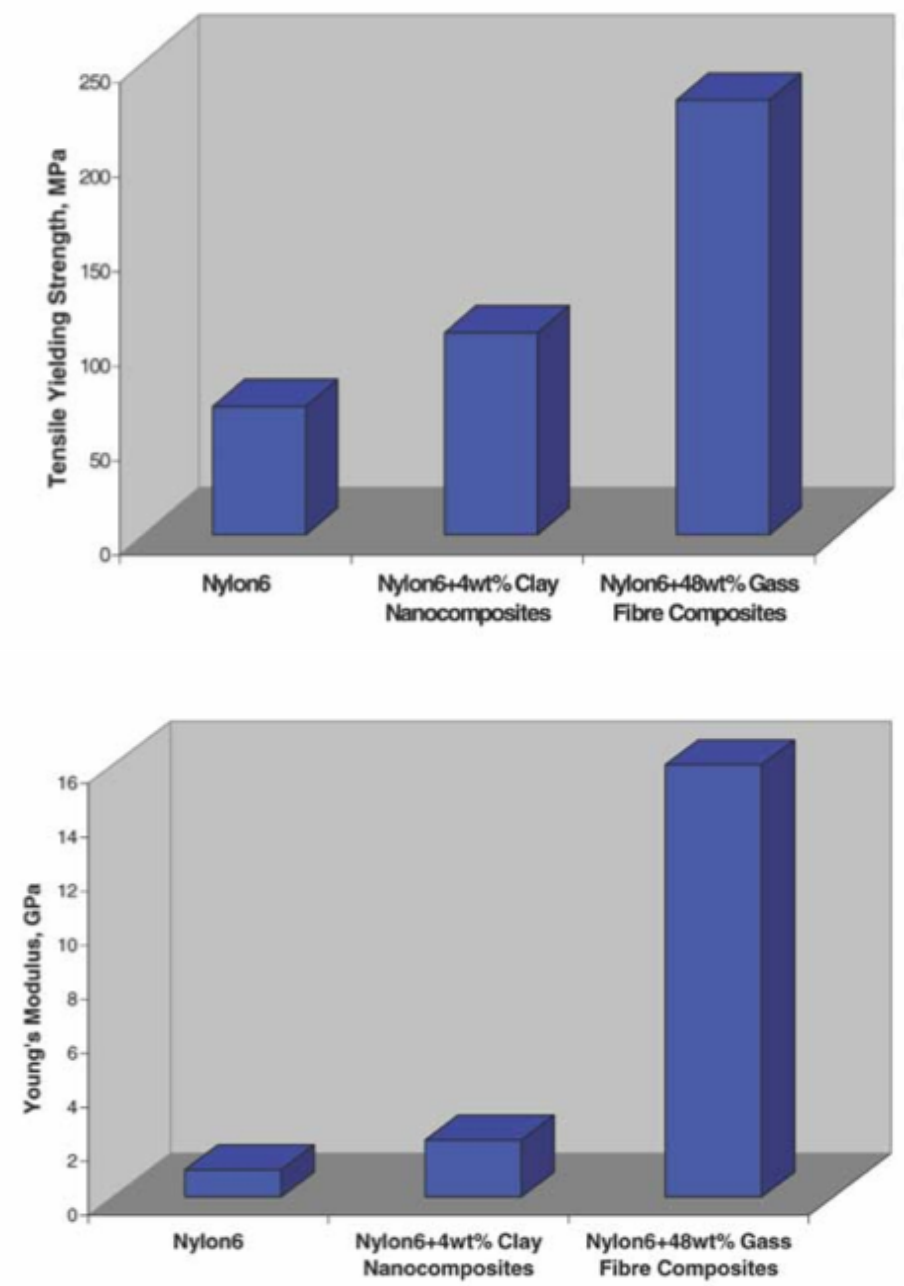

Figure 12. The reinforcement in mechanical properties of Nylon6 (tensile strength and Young's modulus) by using two different filler systems: $4 \mathrm{wt} \%$ nanoclay and $48 \mathrm{wt} \%$ glass fibre. Reproduced from [34].

The clay-polymer nanocomposite also contains good flame retardant property [46, 47]. This is because a special char forms (silicate based) during the material burning, and the char functions as an insulation layer to retard the mass and heat transport (e.g. the ingression of oxygen and the diffusion of compostable products). The nanofiller has already been commercialized as flame retardant additive for thermal plastics, e.g. the CLOISITE from BYK [36], the Maxxam ${ }^{\circledR}$ from PolyOne 
and a similar additive from Eupen [48]. They are often used in the cable jacket material to meet the flammability regulations (e.g. UL94 V-0).

As claimed in the relevant patent information [42], nanoclay also improves the material's thermostability. This reinforcement is especially useful for some biopolymers (e.g. PLA) that are susceptible to high temperature applications, e.g. as beverage packaging for hot filling. A study shows that the clay-PLA nanocomposite bottles maintained their shapes after conditioning in the oven of $60{ }^{\circ} \mathrm{C}$, while the pristine PLA bottle got deformed (see Figure 13) [49].

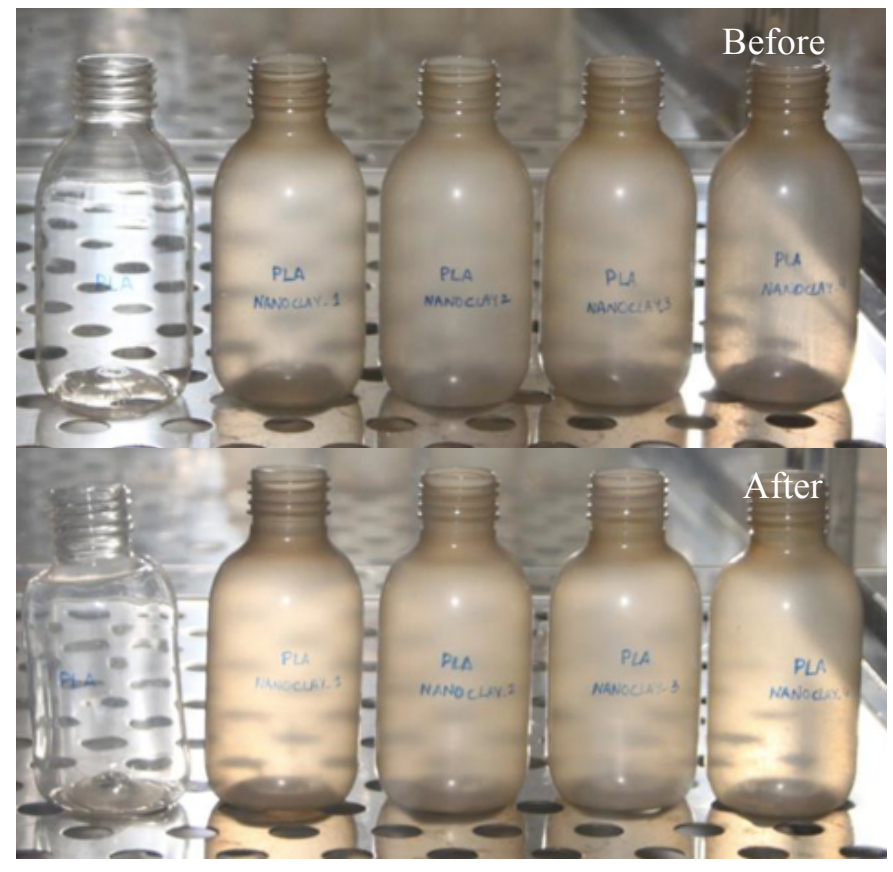

Figure 13. Thermostability test of clay-PLA nanocomposite bottles. Before and after conditioning in the oven of $60^{\circ} \mathrm{C}$. Adapted from [49].

Due to the enhancement in barrier property, one concern about using nanoclay in biopolymer is that it may compromise the material's intrinsic biodegradability.

Some biopolymers such as PLA, their biodegradation depends on the mechanism of hydrolysis. Thus, the penetration of moisture plays an important role in this process. On the other hand, a concern is that using nanoclay to enhance PLA's barrier property may compromise the material's biodegradability. By contrast, based on the results from various studies, it is found that the biodegradation of the composite is accelerated rather than being retarded. For example (see Figure 14), in a 
comparative study [50, 51], when the clay-PLA composite reached $90 \%$ of biodegradation degree, the pristine PLA only reached $60 \%$ (image a). This result is consistent with the evolution of the molecular weight of the test pieces (image b). As concluded in the work, this behaviour is attributed to the hydroxyl groups presented on the clay platelets, which may trigger the heterogeneous hydrolysis of the PLA matrix.
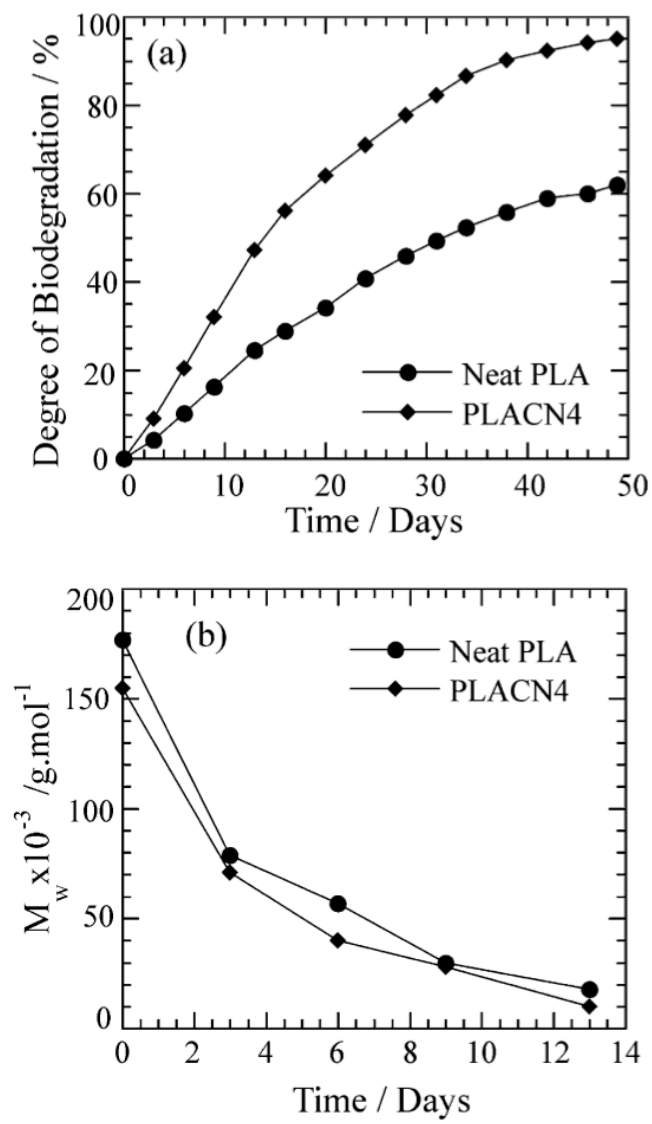

Figure 14. A comparative biodegradation test: the biodegradation degree $\left(\mathrm{CO}_{2}\right.$ evolution, image a) and the evolution of the test piece' molecular weight (image b). PLACN4 means PLA contains $4 \mathrm{wt} \%$ of nanoclay filler. Reproduced from [50].

\subsubsection{Summary and market prospect}


Nanoclay holds a great potential in the application of lightweight packaging. That is, to achieve the same barrier property, adding nanoclay will reduce the material's thickness. The cost of nanoclay is low, which is favoured by the packaging industry.

Besides, the nanoclay is a good filler for biopolymers such PLA. It enables to reinforce the material's thermostability and biodegradability. And this will make the composite material more competitive for the packaging application.

Lastly, it is anticipated that nanoclay will be approved by the authority (EFSA) for food contact application in the near future.

\subsection{Metallic nanoparticles for active packaging application}

\subsubsection{Introduction to metallic Nanoparticles}

Metallic particles could possibly mean several chemical forms [52, 53], including the metal particles (e.g. Ag), the metal oxides $\left(\mathrm{TiO}_{2}\right)$, as well as the hybrid particles with layers of different metals (e.g. $\mathrm{Ag}-\mathrm{TiO}_{2}$ ).

It is well known and widely accepted that metallic particles have antimicrobial properties $[52,54]$. Compared with the bulk form of these particles, the nano-size form (metallic nanoparticles) has enhanced antimicrobial activity [55]. In general, the smaller the particle size the greater the antimicrobial activity [54], which makes them promising antimicrobial agent for packaging application [52, 56]. Some representative research works are summarized in Table 4 . The focus is placed on three $\mathrm{NPs}, \mathrm{ZnO}, \mathrm{TiO}_{2}$ and $\mathrm{Ag}$, as they are the top three candidates for antimicrobial packaging application. 


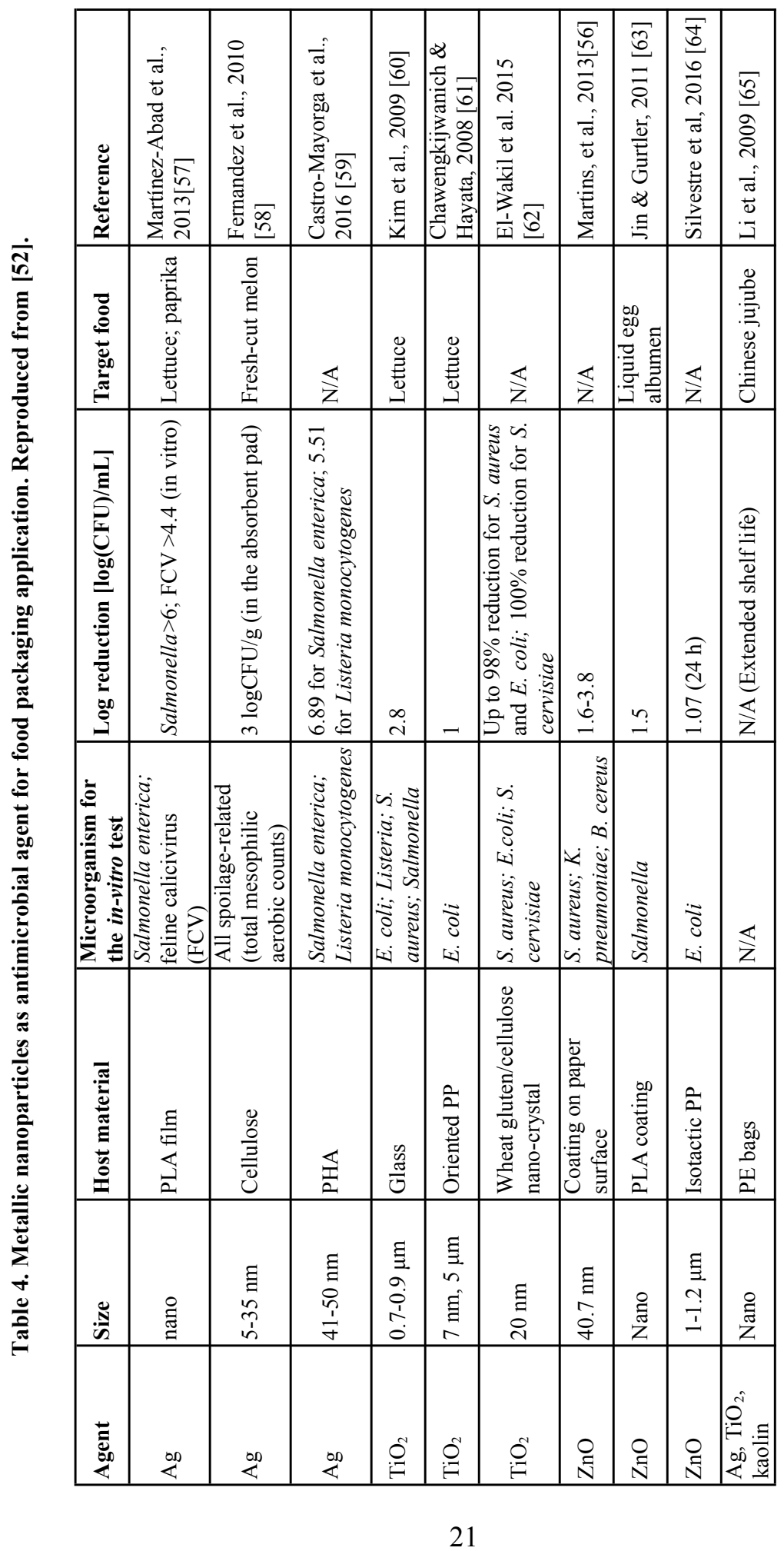


In the following discussion, two aspects will addressed:

1) the action of mechanism of the NPs,

2) and the method to incorporate the NPs into the host material.

\subsubsection{Antimicrobial action mechanism}

\subsubsection{Zinc oxide nanoparticles}

As reported in the work of Liu, et al. [66], zinc oxide nanoparticles (ZnO NPs) of particle size $70 \pm 15 \mathrm{~nm}$ in various concentrations were "immobilized" by a TSA agar (Tryptone Soy Agar) to prevent the particle precipitation. And then the challenge culture was inoculated and then incubated for $12 \mathrm{~h}$. The assay indicates that the antimicrobial effect was evident and in line with the NP concentration. The bacterial strain (E. coli O157:H7) was completely inhibited by the NPs at concentration of $12 \mathrm{mmol} / \mathrm{L}$.

In the same study, SEM (Scanning Electron Microscopy) was used to investigate the NP's action mechanism (see Figure 15). It was found that the ZnO NPs had a tendency to interact with the cell membrane without causing significant changes to the cell's morphology (size, shape, appearance, etc.). However, the change underlying the morphology was observed with TEM (see Figure 16) on a thin slice of microbe cell. It can be seen that the cell's membrane was perforated and the leakage of intracellular contents such as nucleic acids were detected. The attacking action was also supported by the Raman spectra-the products from destruction/denaturalization of lipid and protein were detected, which gives evidence to the cell membrane damage. 


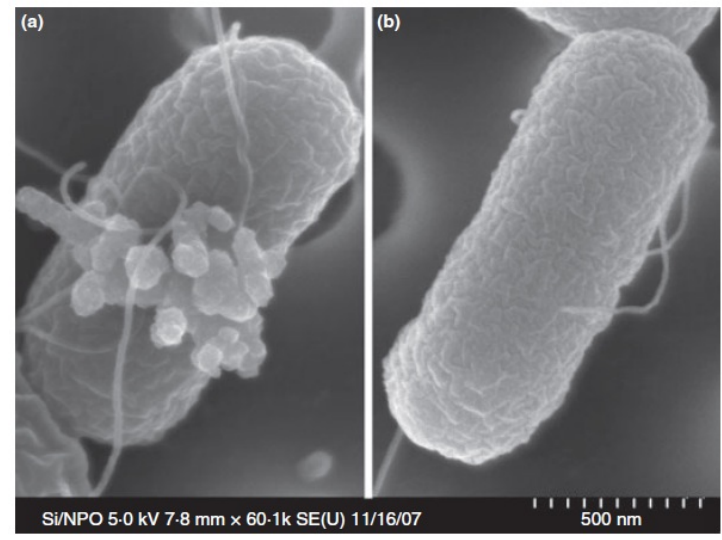

Figure 15. SEM images showing $E$. coli $\mathrm{O} 157: \mathrm{H} 7$ cells with (image a) and without (image b) the ZnO NPs treatment. Reproduced from [66].

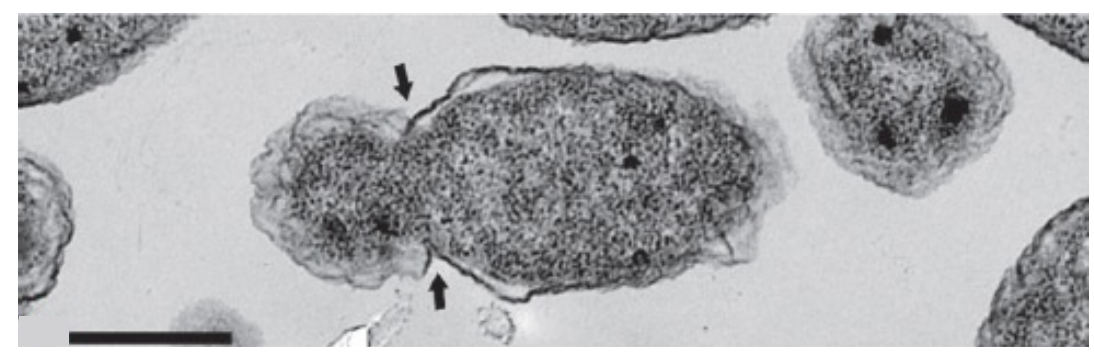

Figure 16. TEM image showing the $E$. coli $\mathrm{O} 157: \mathrm{H} 7$ cell membrane is damaged after treating with ZnO NPs. Reproduced from [66].

After the attacking action, the well-dispersed NPs became agglomerated and partly entrapped by the leaked contents, as seen from the image (a) in Figure 15. This may provide evidence to the interaction between the NPs and the denatured protein. This hypothesis is also supported by the experimental results from another work [67], in which Ag NPs were used to inactivate E. coli. It was found that the NPs coagulated/chelated with the leaked intracellular contents. As a result of this, some antimicrobial agents became isolated from the system.

Activity and toxicity are closely related to each other. In a study [68], the toxicity of $\mathrm{ZnO}$ NPs was investigated using fish egg hatching rate. It was found that the $\mathrm{ZnO}$ NPs had a greater toxicity than the zinc salt solution of the same concentration (see Figure 17). This suggests that the dissolved $\mathrm{Zn}^{2+}$ is not solely responsible for the ZnO NP's toxicity. 


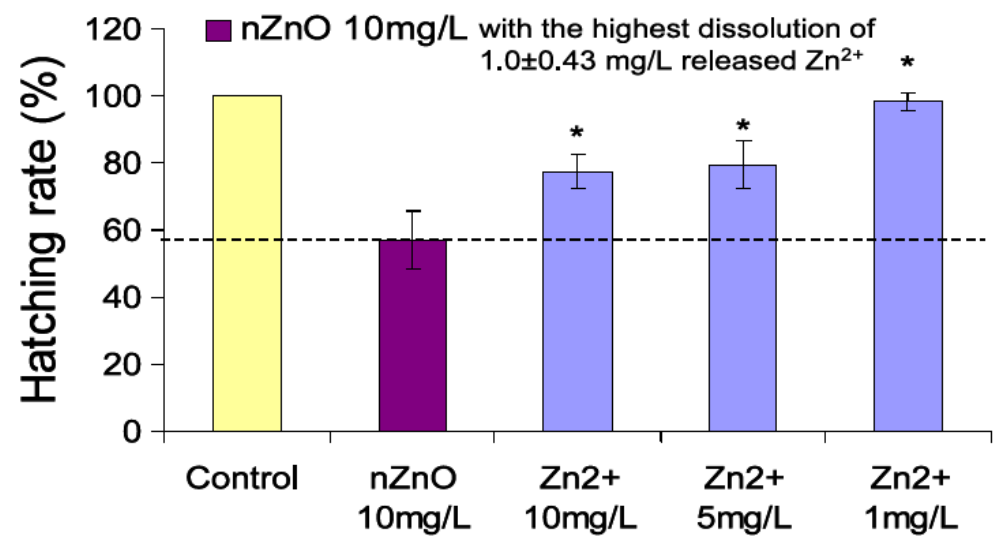

Figure 17. Fish egg hatching rate as a function of different treatments. nZnO means $\mathrm{ZnO}$ NPs dispersion. $\mathrm{Zn}^{2+}$ means zinc salt solution. Reproduced from [68].

As concluded in various sources, $\mathrm{ZnO}$ NP has multiple action mechanisms $[56,66$, $68,69]$. They are

1) leaching of metallic ions (i.e. $\mathrm{Zn}^{2+}$ ),

2) direct contact with the microorganism's cell membrane,

3) and the ROS (Reactive Oxygen Species) due to the photocatalytic property of $\mathrm{ZnO}$.

Very often, these mechanisms work together to create an enhanced activity, which is termed as the "synergistic effect" $[63,69,70]$.

\subsubsection{Titanium dioxide nanoparticles}

The antimicrobial activity of titanium dioxide nanoparticles $\left(\mathrm{TiO}_{2} \mathrm{NPs}\right)$ can be attributed to the semiconductor nature of this material $[60,71,72]$. ROS can be generated though a series of photocatalysis reactions (Equations 3-7). The ROS include the superoxide radicals $\left(\mathrm{O}_{2}^{--}\right)$in Equation 4, the hydroxyl radicals $(\mathrm{HOO} \cdot)$ in Equation 6, and the hydrogen peroxide $\left(\mathrm{H}_{2} \mathrm{O}_{2}\right)$ in Equation 7. It is the oxidative stress of these ROS that causes damages to the microbe's cell membrane, altering its permeability and integrity, and inactivating the microbes.

$$
\begin{gathered}
\mathrm{TiO}_{2}+h v \rightarrow e_{C B}^{-}+h_{V B}^{+} \\
\mathrm{O}_{2}+e^{-} \rightarrow \mathrm{O}_{2}^{--}
\end{gathered}
$$




$$
\begin{gathered}
\mathrm{H}_{2} \mathrm{O} \rightarrow \mathrm{OH}^{-}+\mathrm{H}^{+} \\
\mathrm{O}_{2}^{--}+\mathrm{H}^{+} \rightarrow \mathrm{HOO} \cdot \\
\mathrm{HOO} \cdot+\mathrm{H}^{+} \rightarrow \mathrm{H}_{2} \mathrm{O}_{2}
\end{gathered}
$$

where

$h v$ is photo energy of light irradiation

$e^{-}$is electron

$h^{+}$is hole

N.B. subscript of $\mathrm{CB}$ and $\mathrm{VB}$ in Equation 3 indicate different energy bands.

One noticeable property of $\mathrm{TiO}_{2}$ is that, if given sufficient reaction time, the dead cell (debris) can be completely degraded to $\mathrm{CO}_{2}$ and $\mathrm{H}_{2} \mathrm{O}$. This process is illustrated in Figure 18: first, the ROS attack on the outer membrane, and then on the inner membrane, and finally degrade the entire cell membrane.

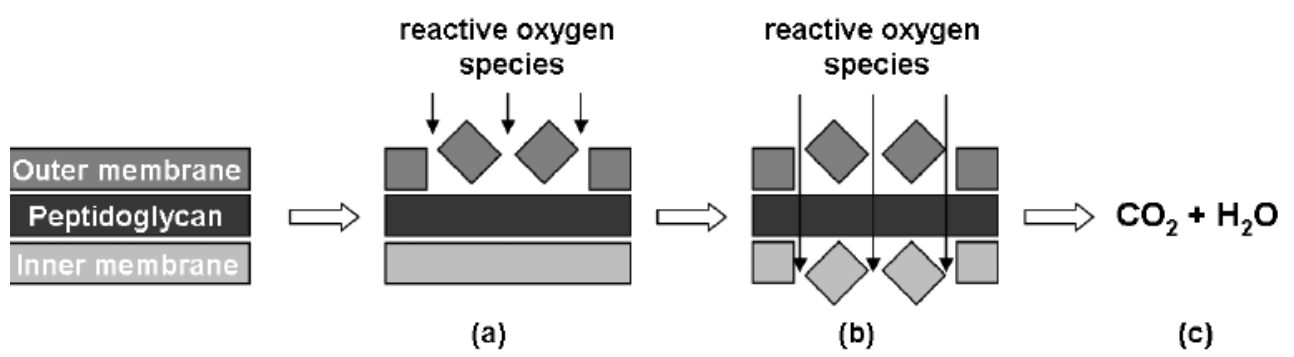

Figure 18. The action mechanism of $\mathrm{TiO}_{2} \mathrm{NPs}$. Reproduced from [72].

\subsubsection{Silver nanoparticles}

Similar to the case of ZnO NP, Ag NP has multiple action mechanisms. Ag NPs have a strong tendency to interact with the cell membrane (see Figure 19). Thus, direct contact is regarded as an important action mechanism for this agent. As reported in one study [67], the E. coli suspension was treated with Ag NPs, and the change of morphology was captured by SEM (see Figure 20). It can be seen that the cell membrane was perforated. In another study [73], it was found that the Ag NPs dispersion contained stronger activity than the silver salt solution $\left(\mathrm{AgNO}_{3}\right)$ at the same concentration. 


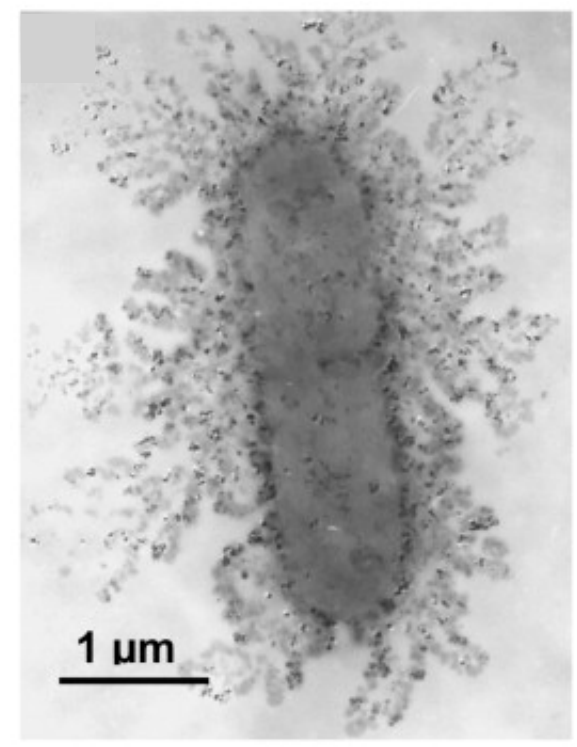

Figure 19. TEM image showing Ag NPs attacking on an E. coli cell. Reproduced from [67].

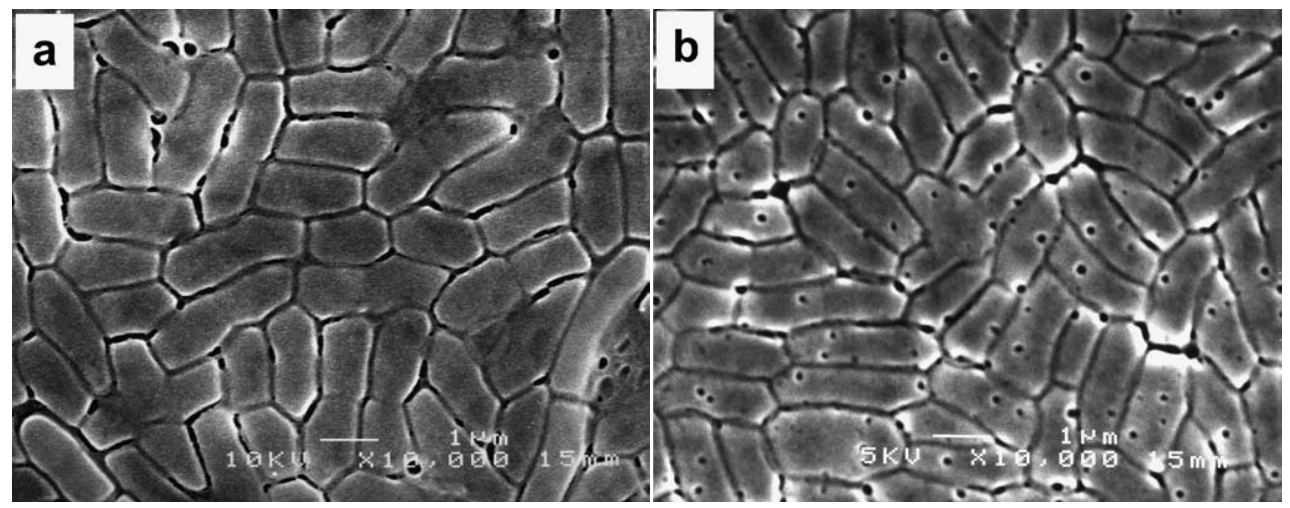

Figure 20. E. coli cells before (image a) and after (image b) treating with Ag NPs. Reproduced from [67].

The Ag NP's morphology also plays a role in its activity $[4,74,75]$. In accordance with the study of Pal et al. [76], Ag NPs in triangle shape enjoyed greater activity than the circle and rod shapes (see Figure 21).

Besides, some external conditions such as the electric field, photo-excitation can also affect the NP's activity [4]. 


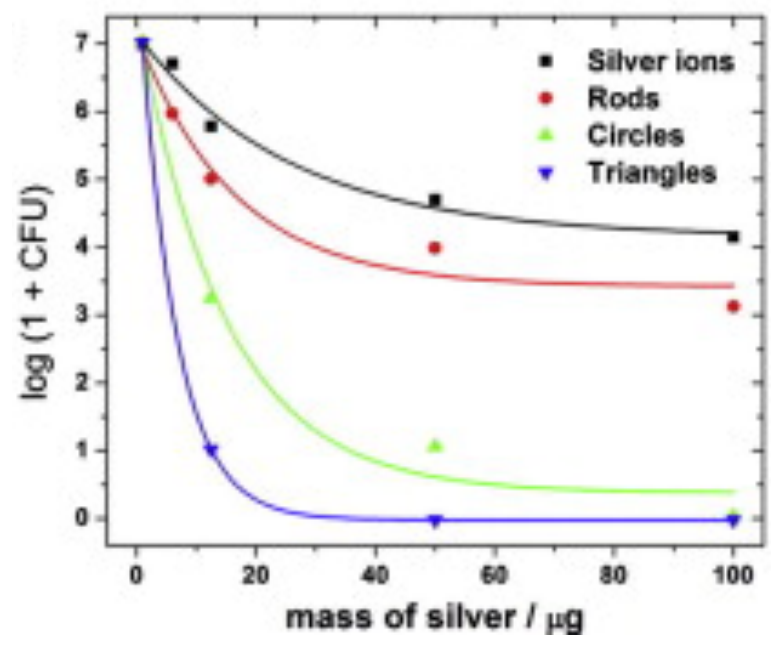

Figure 21. The effect of Ag NP's morphology on its activity. Reproduced from [76].

In summary, Ag NP has multiple action mechanisms [4, 52]. They are:

1) direct contact with the cell membrane,

2) oxidative stress from the generated ROS,

3) and the disruption effect on the cell DNA replication.

\subsubsection{Hybrid metallic nanoparticles and synergistic effect}

The synergistic effect has been identified when using different antimicrobial agents in a system. For example, the $\mathrm{TiO}_{2}-\mathrm{Ag}$ hybrid NPs are being frequently reported $[77,78]$. The hybrid NPs are synthesized by reducing sliver nitrate $\left(\mathrm{AgNO}_{3}\right)$ in the presence of the $\mathrm{TiO}_{2}$ NPs. Or simply mix two or more NPs will also give a enhanced activity [65].

Besides, metallic NPs can be used in combination with other organic antimicrobial agents. For example, Ag NPs in combination with lysozyme demonstrated good inhibitory effect against two silver-resistant strains (Proteus mirabili and a pMG101 type E. coli) [79]; ZnO NPs in combination with allyl isothiocyanate and nisin showed higher efficacy than the single agent system in inhibiting Salmonella [63].

\subsubsection{Methods to incorporate nanoparticles in the host materials}


For packaging application, these metallic NPs are incorporated into the polymer material with two methods: 1) in coating formulation 2) as nanofillers for polymer processing.

\subsubsection{Coating formulation}

This method has been found in many studies. For example, ZnO NPs were formulated in a NFC-based coating color to produce antimicrobial paper [56, 80]. Similarly, Ag NPs were introduced into a starch-based coating to produce antimicrobial paper [81]. $\mathrm{TiO}_{2} \mathrm{NPs}$ were dispersed in a PCL-based coating colour [71], and Ag NPs were incorporated in a PLA-based coating colour [57].

\subsubsection{Nanocomposite}

In this method, the NPs are used as nanofiller for polymer processing, e.g. for film extrusion $[65,82,83]$. Usually, the NPs are surface modified in order to achieve a good dispersing within the polymer matrix.

\subsubsection{Embedded in a inorganic carrier}

It is possible to embed metallic NPs into inorganic carriers (e.g. nanoclay, zeolite, halloysite, cloisite, kaolinite, zironium phosphate, etc.) [52]. The aim is to achieve a controlled release system.

- Silver-loaded clay

In this method, silver nitrate solution $\left(\mathrm{AgNO}_{3}\right)$ is added to a clay suspension for ion-exchange, and after that $\mathrm{Ag}^{+}$is reduced to $\mathrm{Ag} \mathrm{NP}$ by adding a reducing agent (e.g. NaBH4, formaldehyde and ascorbic acid) [52]. In this way, Ag NPs become intercalated in the clay gallery [84]. This type of agent is commercially available (e.g. from Nanobiomatters).

- Silver-loaded zeolite

In a similar way, Ag NPs can be loaded in zeolite $[52,85,86]$. This type of agent is also commercially available (e.g. from Agion-Tech).

The release of $\mathrm{Ag}^{+}$from the carrier follows the first order kinetics, which can be described with Equation 8 and 9 [85]. 


$$
\begin{gathered}
\ln \left(\frac{\left[\mathrm{Ag}^{+}\right]_{t}}{[\mathrm{Ag}]_{0}}\right)=-k t \\
T_{1 / 2}=\frac{\ln 2}{k}
\end{gathered}
$$

Where $k$ is the decay constant;

$\ln \left[\mathrm{Ag}^{+}\right]_{0}$ and $\ln \left[\mathrm{Ag}^{+}\right]_{t}$ are the concentrations at initial exposure time $(t=0)$ and at time $t$ (after each exposure and after retrieval/reuse);

$\mathrm{T}_{1 / 2}$ is the half life of the decay.

\subsubsection{Other methods}

There are other methods to deposit a nano-scale coating on a solid surface, e.g. chemical vapour deposition and physical vapour deposition [87].

\subsection{End-of-life of nanocomposite as packaging material}

\subsubsection{Effect of nano-reinforcement on biopolymer's biodegradability}

As the consumer's environmental awareness increases, materials of biodegradability (e.g. cellulose, PLA, PHA, PCL) are being used for packaging applications [86, 88-90]. The biodegradation of these polymers strongly depends on the microbe flora contained in the compost. Thus, one concern is that if an antimicrobial agent is incorporated in these polymers, will they still retain the biodegradability? And to what extent will the biodegradation be retarded?

This issue has been investigated in a comparative study [91], in which a cotton fabric was incorporated with three different silver-based agents, $\mathrm{Ag} \mathrm{NPs}, \mathrm{AgCl}$ (silver salt) and Ag NPs in a stabilized colloidal state. The effect of antimicrobial agent on the fabric's biodegradation was investigated with a soil burial test. It was found that the degradation rate and degree was in an order of $\mathrm{Ag} \mathrm{NPs}, \mathrm{AgCl}$ (silver salt), and colloidal silver, in an inverse proportion with the agent's antimicrobial potency. When exposed to the soil compost, the Ag NPs got agglomerated and therefore lost its nano-specific activity. The fabric coated with $\mathrm{AgCl}$ retained its activity by leaching silver ions $\left(\mathrm{Ag}^{+}\right)$. While the colloidal $\mathrm{Ag}$ NPs were stabilized to maintain its nano-form, so the system showed the highest activity. 
Balaguer et al. [92] carried out a compostability test on the PLA-based composites reinforced with three different nanofillers, organoclay, $\mathrm{CaCO}_{3}$, and $\mathrm{SiO}_{2}$. The biodegradability test shows that the incorporation of organoclay and $\mathrm{CaCO}_{3}$ accelerated the biodegradation slightly. As PLA degrades with hydrolysis, it is estimated that these nanofillers have some effect on this mechanism[50]. In terms of eco-toxicity, no significant differences were observed between the composites and the control (pristine PLA). However, the degradation of the ZnO-PLA composite in phosphate buffer solution was remarkably retarded [93].

\subsubsection{Fate of nanomaterials in the waste stream}

For nano-enabled application, a big concern is the issue of waste management [32, 94-96]. For example, when nano-enabled packaging enters the municipal waste stream, will they be properly processed the existing waste processing equipment? Are there any nano-specific risks? Besides, when NPs release to the environment, they will interact with the eco-system (e.g. soli, water, and air). And this will further affect the their transport, transformation and persistence in the environment [97].

The issue becomes clearer as the number of research work increases. There are a few positive feedbacks. In accordance with a risk assessment study [98], nanoenabled applications have low risk and limited impact to environment and human health. In biological WWTPs (Wastewater Treatment Plants), bacteria are employed to degrade the organic matters, and they may be susceptible to the accumulation of NPs. Wang et al. investigated this issue [32], and they found that within the environmentally-relevant NP loading and biomass concentration, the NPs in question $\left(\mathrm{Ag}, \mathrm{TiO}_{2}\right.$ and $\left.\mathrm{C}_{60}\right)$ had negligible effects on the system. Another study indicates that the NP's toxicity can be mitigated when exposed to the natural sediment (consisting of sand, silt-clay mixture, alpha cellulose, humic acid, and dolomite) [68].

NPs have a strong tendency of agglomeration/aggregation [99, 100]. The agglomeration even starts when the NPs are in dry powder form. Therefore, in some applications, the NPs are surface modified to achieve a stabilized dispersion system [101]. And these surface modified NPs may pose higher risks to the biological and environmental system. Therefore, further research is needed to clarify this issue.

\subsection{Food contact regulatory issues}

Active food contact material shall comply with the EU regulation (EC) No. $450 / 2009$, which gives particular attention to the nanomaterials, stating that a case- 
by-case approach shall be used [102]. To ensure consumer safety, one important issue is the agent migration. Especially the migration of NPs has raised significant concern regarding its food contact application[103-106].

In 2005, EFSA issued a positive opinion on silver loaded zeolite for food contact application, with a SML (Specific Migration Limit) of $50 \mu \mathrm{g} \mathrm{Ag} / \mathrm{kg}$ food [107]. More specifically, the agent loading in the polymer (silver zeolite A, containing $\leq$ $5 \%$ silver) should not exceed 10\% (w/w). In 2009, FDA (the US Food and Drug Administration) approved silver as antimicrobial agent for bottled water with a $\mathrm{SML}$ of $17 \mu \mathrm{g} \mathrm{Ag} / \mathrm{kg}$ water [52]. However, the migration in nano-form of is not clear in these early cases.

In a more recent publication, Echegoyen and Nerín investigated the nano-form migration from commercially available food containers containing Ag NPs [108]. The samples included two rigid PP lunch boxes and one LDPE resealable bag. The Migration test was carried out in accordance with the EU food contact regulation. It was found that acetic acid 3\% (w/v) as food simulant promoted the highest amount of Ag leaching $\left(31.46 \mathrm{ng} / \mathrm{cm}^{2}\right)$, which is attributed to the dissolved silver ions. This value is still far below the SML set by the EU regulation and FDA. The migration of silver in nano-form was confirmed with ICP-MS and SEM-EDX.

In accordance with the work of Reig et al. [109], to date only three nanomaterials are authorized by EFSA (the European Food Safety Authority) to be used for food contact applications. They are titanium nitride (TiN), carbon black (C) and silica $\left(\mathrm{SiO}_{2}\right)$, and all of them are to be used as polymer production aids (no active properties).

For active packaging application, the some nano agents are currently under reviewing. In 2015, EFSA carried out a specific migration test with a composite (LDPE film containing ZnO NPs). In their report, the panel expresses their worries on the zinc migration for high concentration of $\mathrm{Zn}^{2+}$ was detected in a food simulant, acetic acid 3\% (w/v) [110].

Agent migration (both ionic-form and nano-form) from the composite could be affected by many factors, such as the host polymer's property [4, 89, 111], processing parameters (by affecting the polymer's crystallinity) [86], particle size, particle support (e.g. zeolite or kaolinite), ionic strength of immersion solution [53], coating methods and surface roughness [112]. Thus, further studies are needed to clarify this issue.

\subsection{Consumer perception}


Besides regulator, other players along the packaging value chain, e.g. the food producer, brand owner, packaging producer, and consumers, their perception to the nano-enabled packaging also matters $[113,114]$. A survey conducted with Swiss consumers suggests that nano-enabled packaging is positively welcomed for its advantages in food preservation [113]. On the other hand, German consumers held a more conservative attitude towards the application of nanotechnology to food and food packaging [115].

\subsection{Sustainability in packaging sector}

In recent years, as the consumer's environmental awareness increases, and the society development advocates low carbon economy, the packaging's sustainability has drawn significant attention. Packaging not only plays an important role in product protection and distribution, but also serves as a direct medium where the food producers can inform their commitment to sustainability, which is often reflected on the packaging's attributes, e.g. the material selection, design, format, carrying eco label/mark, easy to empty for minimizing product losses, use of biodegradable materials, etc. Improvement on these attributes could greatly enhance the consumer's user experience and is valued by the consumer of high environmental awareness. And this will strongly influence their buying decisions. A study suggests that sustainable packaging solution can potentially lift the sales by of $2-4 \%[116]$.

\subsubsection{What is sustainable packaging}

When it comes to the definition of "sustainable packaging", things become fuzzy as it covers so many aspects. For example, Allione and Petruccelli proposed a sustainability indicator matrix in their work [117], which covers the aspects of environment, function and communication In fact, it is very likely that each economic operator in the packaging value chain has their own understanding and interpretation of sustainability. On a regional level, the packaging associations have reached agreement. This includes:

SPA (the Sustainable Packaging Alliance of Australia) in 2010 issued their definition about sustainable packaging [118]. A sustainable packaging comprises four key attributes:

1) effective (fit for purpose)

2) efficient (minimal use of materials, energy, water)

3) cyclic (generates minimal waste)

4) safe (non-polluting and non-toxic) 
In 2009, EUROPEN (the European Organization for Packaging and the Environment) and ECR Europe jointly published a report "Packaging in the sustainability agenda: a guide for corporate decision makers" [119]. The report stressed the packaging's role in promoting the sustainability rather than the packaging itself. In accordance with this report, a sustainable packaging should:

- be designed holistically with the product in order to optimize overall environmental performance;

- be made from responsibly sourced materials;

- be designed to be effective and safe throughout its life cycle;

- meet market criteria for performance and cost;

- meet consumer choice and expectations;

- and be recovered efficiently after use.

SPC (the Sustainable Packaging Coalition of the US) also presented their definition of sustainable packaging in 2009 [120]. So, a sustainable packaging

1) is beneficial, safe and healthy for individuals and communities throughout its life cycle;

2) meets market criteria for performance and cost;

3) is sourced, manufactured, transported and recycled using renewable energy;

4) optimizes the use of renewable or recycled source materials;

5) is manufactured using clean production technologies and best practices;

6) is made from materials healthy in all probable end-of-life scenarios;

7) is physically designed to optimize materials and energy;

8 ) is effectively recovered and utilized in biological and/or industrial closed loop cycles.

\subsubsection{Life Cycle Assessment (LCA)}

In sustainability assessment, the "three pillar model" is often employed. It considers the impacts of environmental, economic and social aspects [121]. Particularly, in recent years the environmental impacts has gained more attention.

Life cycle assessment (LCA) is the most recognized tool for evaluating the impacts caused to the environment due to the use of product or service. It enables a holistic view by evaluating a product's life cycle. As shown in Figure 22, LCA takes into account all the inputs (e.g. raw materials, chemicals, energy, etc.) and outputs (e.g. emissions, waste, co-products, etc.) associated with the life cycle of product (raw material extraction, manufacturing, use/reuse/maintenance, and the end-of-life). If a full life cycle is considered, it is termed as "cradle-to-grave" approach [121]. 
Therefore, LCA helps to avoid shifting the potential environmental burdens from one stage to another, or from one stakeholder to another.

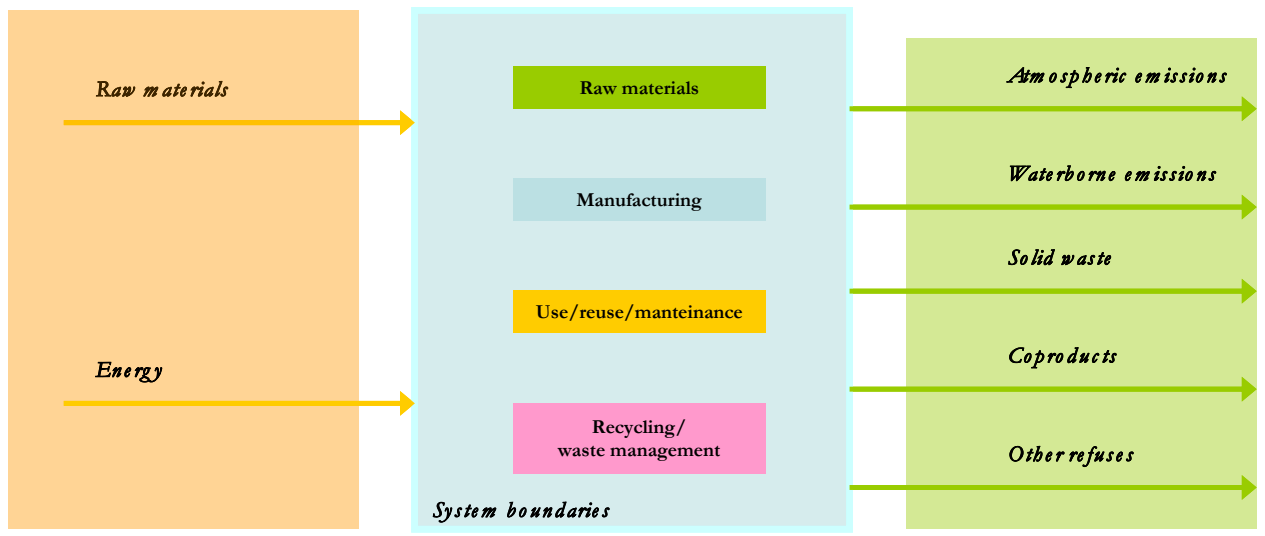

Figure 22. Principles of LCA. Reproduced from [122].

LCA is conducted with respect to the international standard framework (ISO 14040 and ISO 14044) [123-125]. Generally, a full LCA consists of four stages (see Figure 23).

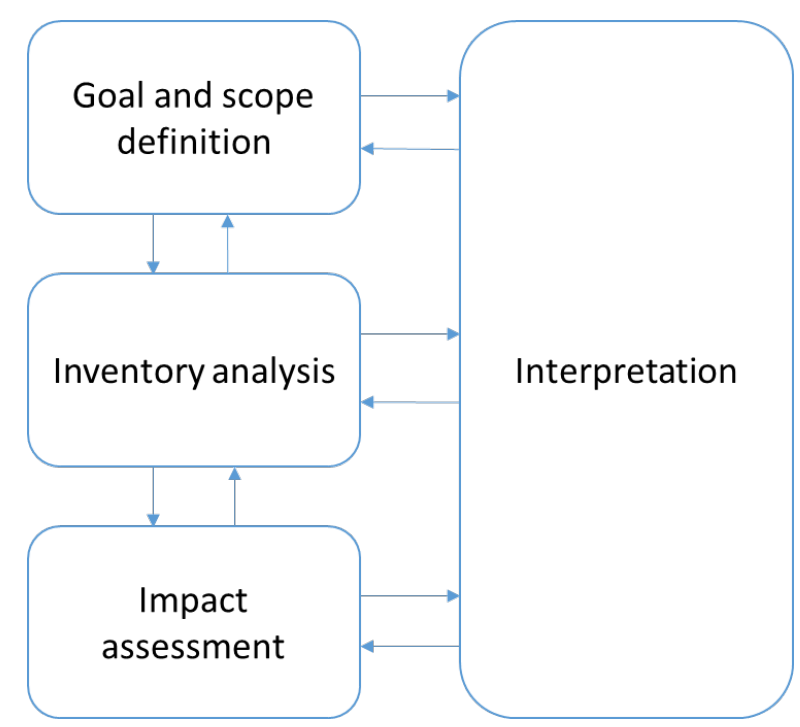

Figure 23. The key steps in carrying out a LCA study. Adapted from [131, 132].

1) Goal and scope definition 
In this stage, the aim or the intended use of LCA is defined. It concerns about defining two important parameters, the "system boundaries" and "FU (Functional Unit)". The system boundaries define the scope of the study, i.e. what life cycle stages are included or excluded. The FU provides a common basis for comparing the LCA results between the systems. For example, Cordella et al. carried out a LCA study to compare the environmental impacts of two different beer packaging systems, a $20 \mathrm{~L}$ returnable steel $\mathrm{keg}$ and a $33 \mathrm{cl}$ single use disposal glass bottle [126]. The system boundaries were set as "cradle-to-grave", including the raw material production (agricultural processes of barley and hop), malt and beer production, manufacturing of packaging and other auxiliary materials, transportation to consuming point, and end-of-life of packaging. The FU was defined as $1 \mathrm{~L}$ beer served to the consumer.

2) Life Cycle Inventory analysis (LCI)

LCI is a step for collecting the data and summarizing the inputs (raw material and energy) and outputs (emissions, wastes, co-products and refuses) from each life cycle stage defined in the system boundaries. The data should match the industry level as close as possible, and reflect the average technology and practice in the geographical area considered.

3) Life Cycle Impact assessment (LCIA)

In this step, the inventory data are translated into different impact indicators to quantify the impacts on the environment, human health, or depletion of natural resources. The conversion process can be described with Equation 10.

Inventory Data $\mathrm{x}$ Characterization Factors $=$ Impact Indicators

An example is given in Figure 24. For the impact of acidification (measured in $\mathrm{SO}_{2}$ equivalents), all the contributing emissions $\left(\mathrm{NH}_{3}, \mathrm{NOx}\right.$ and $\mathrm{SO}_{2}$ ) are multiplied with a specific conversion factor, which derives from the experimental studies $(1.88,0.7$, and 1$)$. It should be noted that one substance can contribute to more than one impact indicators, e.g. NOx contributes to both acidification and eutrophication. 


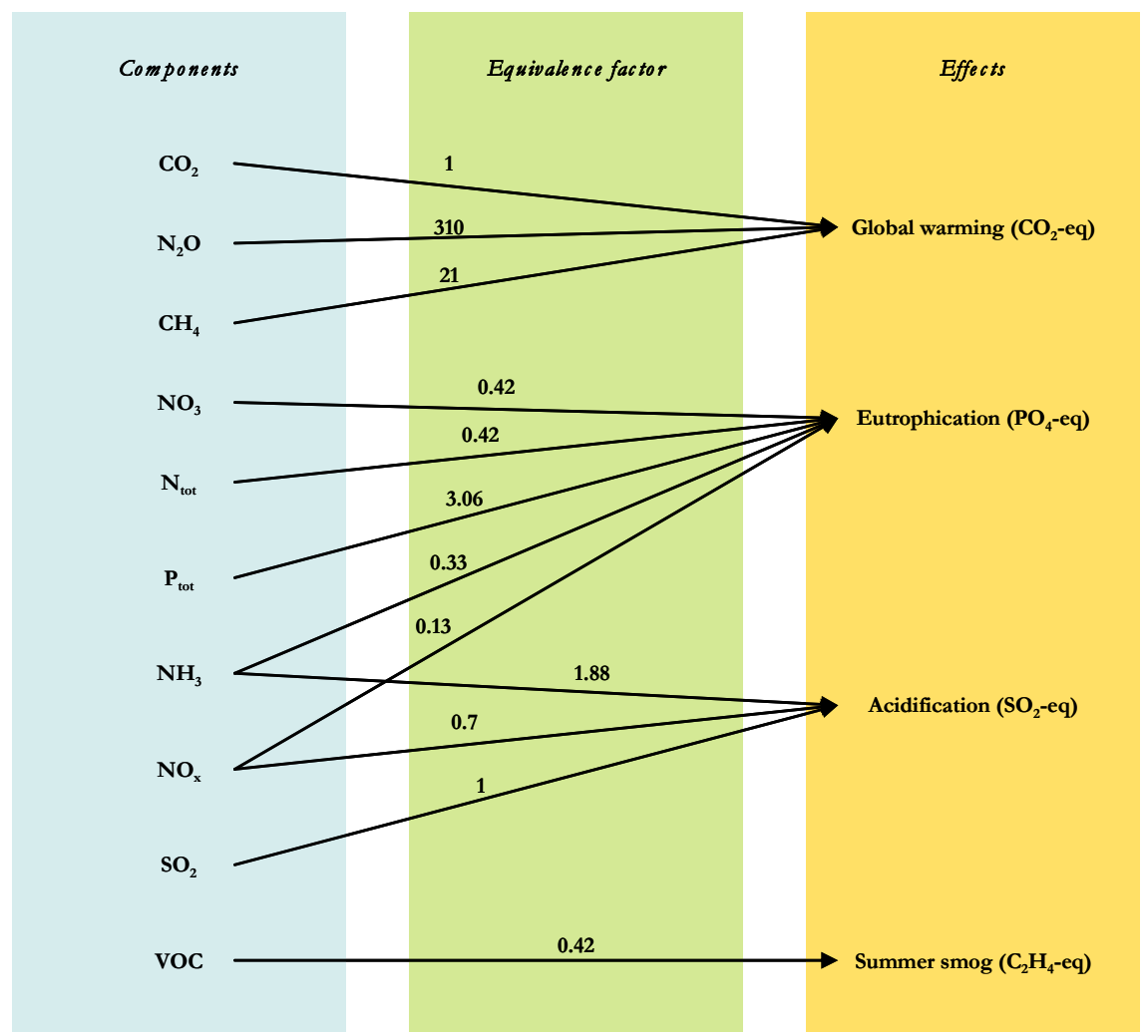

Figure 24. Illustration of impact indicator calculation. Reproduced from [131, 132].

\section{4) Interpretation}

In this step, the following tasks can be performed:

- the environmental scores for each alternative system in comparison (scenario) can be ranked;

- the key impacts can be identified;

- and the methods for reducing of impacts can be proposed by evaluating the alternative systems.

Besides, uncertainty analysis is usually performed in order to draw a robust conclusion.

\subsubsection{LCA application to packaging}


LCA has been widely used to evaluate the environmental impacts of packaging [126-130]. As depicted in Figure 25, a typical packaging life cycle is closely related to the life cycle of the product it packages. For example, for food packaging, packaging's role on food waste reduction should be taken into account [131]. As already discussed in Section 1.2, active packaging enables shelf life extension, which further contributes to the minimizing of food waste. To demonstrate this relationship, a study developed a model to describe the potential environmental gains as a result of using a more advanced packaging system [132, 133]. It was found that for the same fraction of food loss reduction, the food of high impact e.g. cheese and beef enjoyed a greater freedom in packaging design (without increasing the system's environmental impact) than the food of low impact e.g. bread and ketchup.

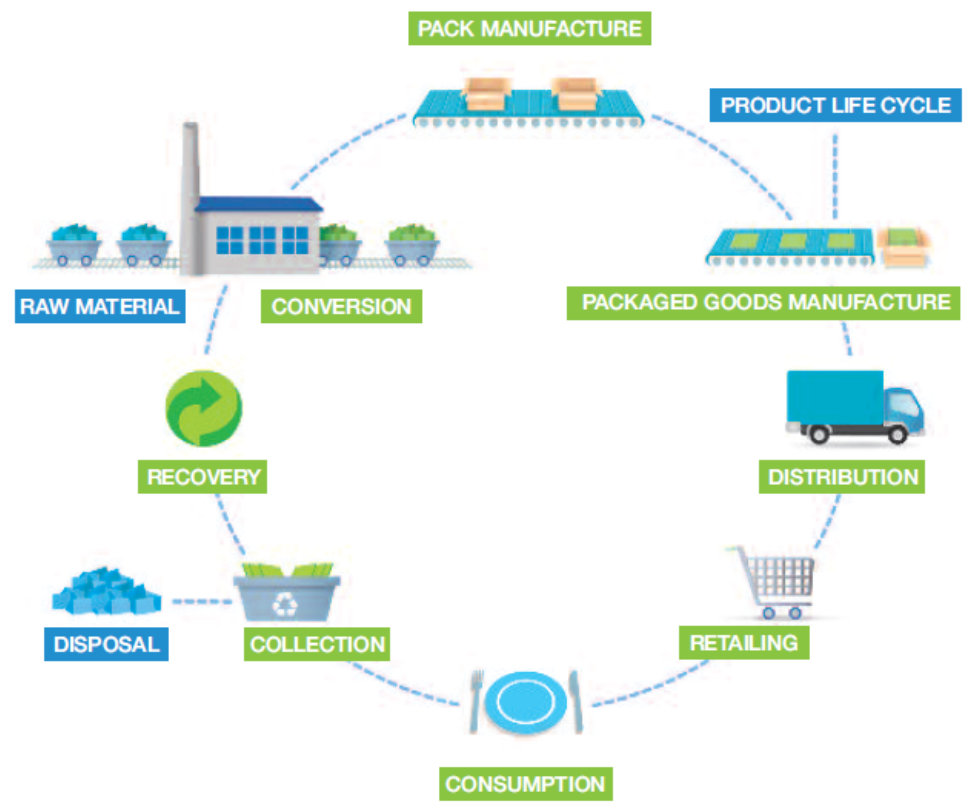

Figure 25. The life cycle of food packaging. Reproduced from [134].

To carry out a LCA for packaging, various commercial tools are available [135]. Tools such as "SimaPro" and "GaBi" are designed for the professional LCA practitioners. They contain comprehensive and updated databases and are used to evaluate the generic product.

Additionally, there are streamlined LCA tools that only target a specific sector or product. Tools such as COMPASS, PIQET, PackageSmart, and Pack-in are tailor- 
made for packaging. They are designed for the "non-LCA" users. So, they usually come with user-friendly interface for an easy modelling experience, packagingspecific impact indicators, and quick calculation (e.g. less than $30 \mathrm{~min}$ ). The results are reported in a bar chart or radar chart for easy interpretation.

\subsubsection{LCA application to nanomaterials}

As concluded within the LCA research community $[29,136,137]$ the existing ISObased LCA framework (ISO14040 and ISO14044) is fully applicable to nanomaterials/nanomaterial-enabled products despite the barriers/gaps for performing a comprehensive LCA. The early attempt of using LCA for nanomaterial evaluation can be found in a publication in 2001 [138], in which Greijer et al. investigated a nanocrystalline dye (made of $\mathrm{TiO}_{2} \mathrm{NPs}$ and carbon powder) following a cradle-to-grave approach. In 2003, Lloyd and Lave carried out a hybrid LCA on a nanoclay-reinforced composite [139]. After that, the number of publications on such topic has increased drastically, and in the meanwhile the research interest has expanded to more types of nanomaterials and application fields, e.g. carbon nanotube [140], nanosilver [55] nano silica [141]. By going through these publications, some common issues with regard to applying LCA for nanomaterials can be extracted:

- scarcity of inventory data (in particular the comprehensiveness on the emission side),

- lack of appropriate characterization factors to address nano-specific toxicity in the LCIA (Life Cycle Impact Assessment),

- and uncertainty/ambiguity concerned with the fate of nanomaterials, which strongly depends on the nanomaterial's colloidal behaviour.

One major concern about using nanomaterials is its toxicity posed to the environment and human health [28]. At current stage the USEtox ${ }^{\mathrm{TM}}$ model is the best existing characterization model to quantify the toxicity impact to human and freshwater $[142,143]$. However, it is not applicable to evaluate nano-toxicity [142, 144]. In accordance with [145], to date only two publications pioneered in quantifying the nano-specific toxicity of freshwater using LCIA. One concerns about titanium dioxide nanoparticles [146] and the other about carbon nanotube [147].

Hischier and Walser in their work proposed some useful strategies to overcome the existing gaps for applying LCA to nanomaterials [144]. First of all, the data of the most important nanomaterials should be improved. The release of nanomaterial during their product life cycle should be tracked. The fate and transport parameters should be investigated to support the characterization of nano-toxicity [147]. 


\subsubsection{Packaging waste management}

\subsubsection{EU strategies in packaging waste management}

In 1994 the European parliament adapted the "Packaging and Packaging Waste Directive" (94/62/EC). The aim is to harmonize the national measures, and to prevent and minimize the environmental impacts caused by packaging and packaging waste. The directive uses a hierarchy strategy (see Figure 26). In the hierarchy, the resources efficiency decreases from top to bottom, which is in agreement with the packaging waste valorisation. The approaches are explained in details in the following discussions.

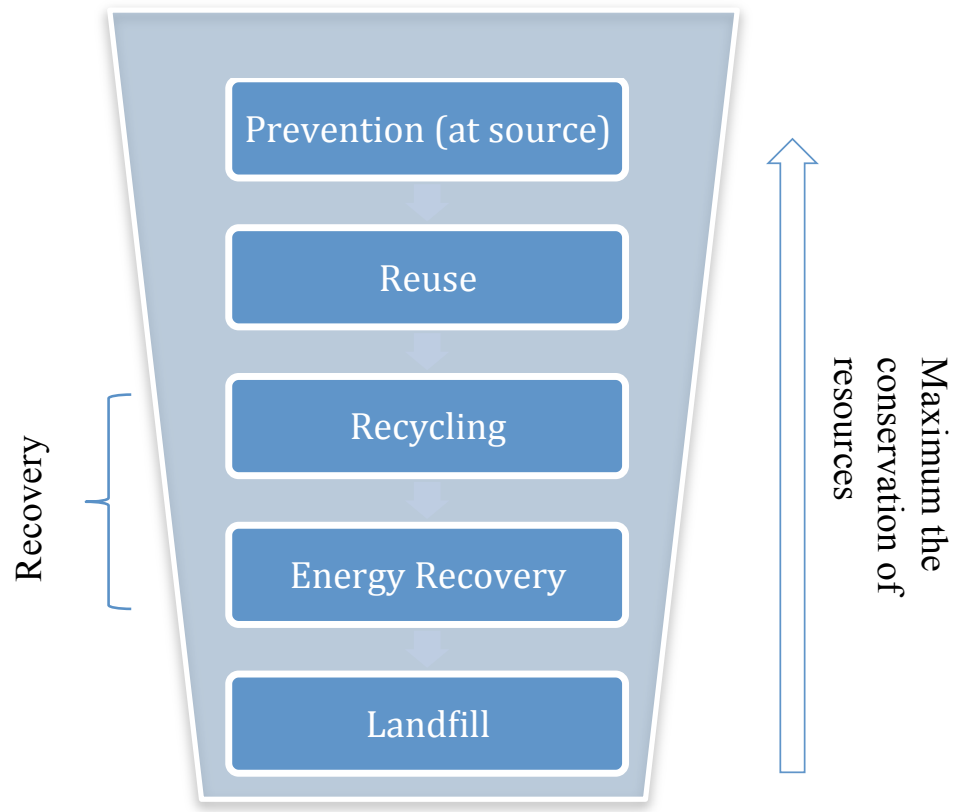

Figure 26. The packaging waste management hierarchy described in the directive of 94/62/EC.

\section{Prevention (at source)}

Prevention means use less packaging material, e.g. use lightweight material, only use the necessary amount, and generate less waste from the producer, converter, and user. It focuses on the waste source:

- materials and substances contained in the packaging (quantity/mass),

- and packaging waste generated in the course of production, distribution, utilization and elimination. 
For example, in a case study of packaging waste generated by a fast food company (has 87 stores in Finland), it was found that packaging material harmonization was an effective measure in reducing the packaging waste [148]. This includes increasing the use of lightweight and less bulky material, reducing the types of materials, and simplifying the waste sorting process (better sorting means less contamination). It was estimated that these measures would cut the company's annual packaging waste by $16 \%$.

\section{Reuse}

Reuse means that packaging can be reused for the same purpose or for other purposes.

\section{Recycling}

Recycling covers two aspects (see Figure 27,), material recycling (e.g. PET bottles are recycled to make new PET bottles or carpet) and organic recycling (e.g. use biodegradable materials to produce compost). Furthermore, under the scope of organic recycling, there are aerobic and anaerobic processes. N.B. landfill shall not be considered as a form of organic recycling.

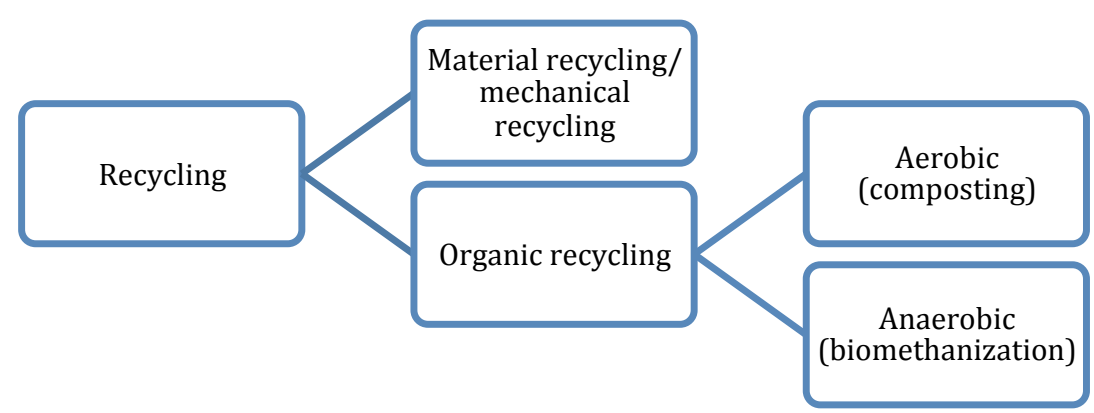

Figure 27. The concept of recycling in packaging waste management.

\section{Recovery}

The "Waste Directive" (75/442/EEC) defines a number of recovery operations. With regard to packaging waste, it covers material recycling and energy recovery. 
Energy recovery means direct incinerating the material for energy. In addition, recovery involves collecting, sorting and transportation.

\subsubsection{Packaging waste recycling and recovery in the $E U$}

The EU packaging waste directive contains specific measures and targets addressing the rate of recovery and recycling to be achieved by the member states. The target is revised every 5 years. Figure 28 and Figure 29 depict the rate of recovery and rate of recycling of packaging waste respectively for the time period of 2005-2012 in the EU-27.

As reported by Eurostat [153], the rate of recovery is defined in Equation 11 (unit in weight):

Rate of recovery $=($ recycled + incinerated $) /$ total waste generated

\section{Rate of recovery of packaging waste in the EU-27}

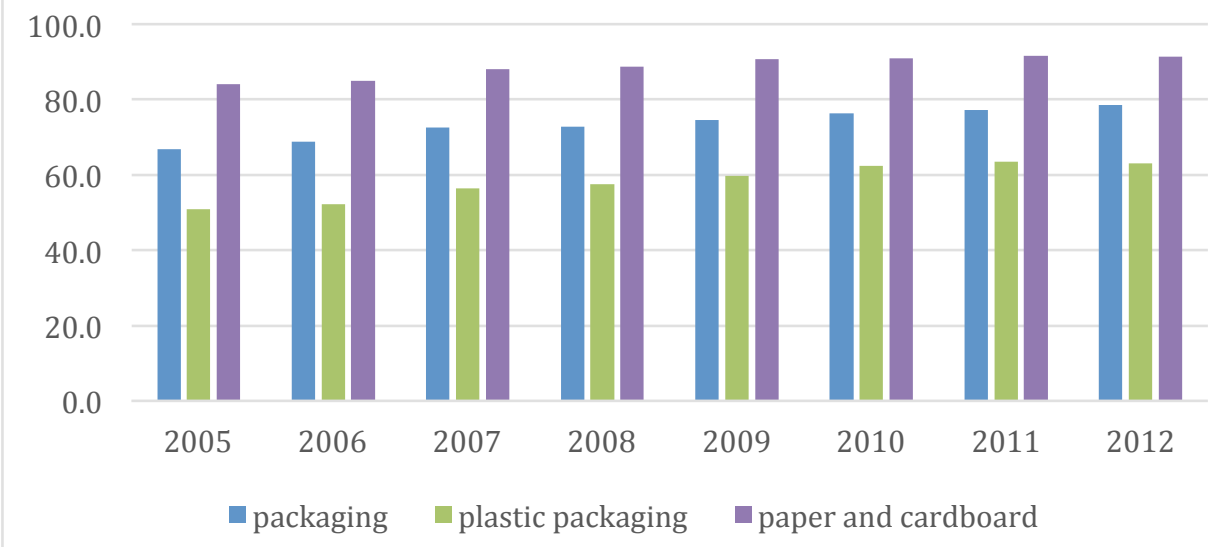

Figure 28. The rate of recovery of packaging waste in the EU-27 (2005-2012). Data source: Eurostat [149] 


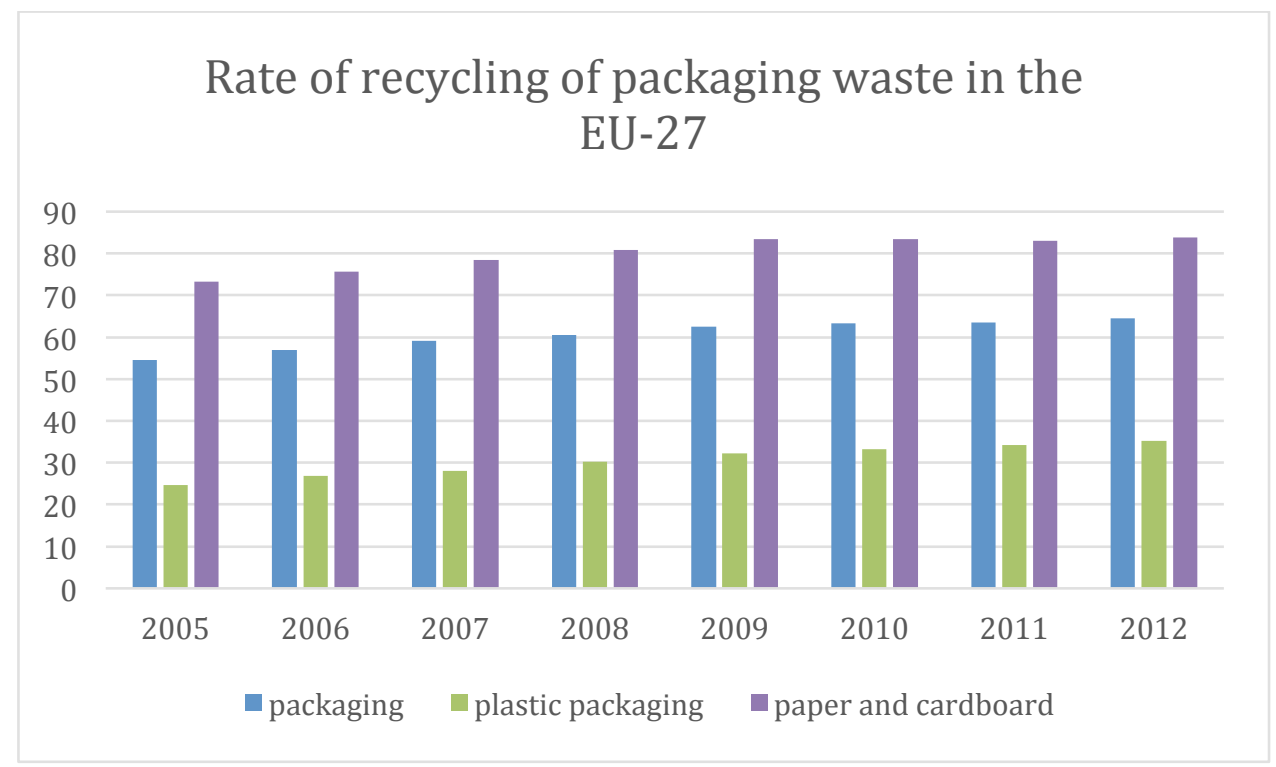

Figure 29. The rate of recycling of packaging waste in the EU-27 (2005-2012). Data source: Eurostat [150].

In an overview, it can be seen that there is a steady increasing in both the recycling and recovery rate on a yearly basis (2005-2012). Especially the category of paper and cardboard enjoyed the highest rate of recovery and recycling among the packaging waste, being $83.8 \%$ and $91.3 \%$ respectively in 2012 . On the other hand, the recycling rate of plastic packaging was only $35.3 \%$ in 2012, far lagging behind the paper and cardboard. As pointed out in a report [151], this situation is attributed to several factors:

- a large number of different polymers are in use (50 different family groups and under which there are hundreds of varieties);

- the difficulty in collection and sorting, which accounts for $2 / 3$ of financial cost spent in plastic recycling;

- the problems of transporting a large amount of bulky and flammable material;

- products made from different polymers containing different additives (e.g. composites), which adds difficulty to the separation;

- post-consumer contamination (e.g. food packaging).

\subsubsection{Biopolymer-based packaging}


Biopolymer/biodegradable polymer has experienced a fast growing demand for its environmental benefits, e.g. its biodegradability and a shorter carbon cycle [152]. As a successful example, PLA has already reached a global production capacity of 240,000 tons [153]. And PLA-based packaging applications are available on the market, e.g. yogurt cups, cold drink cups, trays, beverage bottles (still beverages), packaging films, etc.

In general, biopolymer/biodegradable polymer can be classified in three categories $[90,154]$ :

1) polymer directly extracted from the biomass, e.g. polysaccharides (starch, cellulose, chitosan), proteins, polypeptides, polynucleotides;

2) polymer produced by classical chemical synthesis using renewable biobased monomers, e.g. PLA, or mixed sources of biomass and petroleum, e.g. PCL, PVA, PGA;

3) polymer produced by microorganisms or genetically modified bacteria, e.g. polyhydroxybutyrate (PHAs), bacterial cellulose, xanthan, curdlan, pullan.

Davis and Song in their work [151] concluded that the biodegradable material is highly suitable for single use disposable packaging (e.g. shopping bag and yogurt cup), where the post-consumer packaging can be locally composted. A typical industrial composting facility (anaerobic process) enables the PLA degradation up to $85 \mathrm{wt} \% .95 \mathrm{wt} \%$ of the biogenic gas (mainly methane) can be recovered. After collection and purification, it can be fed to the industrial furnace to generate electricity [155]. On the other hand, several LCA studies pointed out that for the end-of-life of PLA-based packaging a close-loop recycling was the best option, having less impacts of GWP (Global Warming Potential) and CED (Cumulative Energy Demand) $[127,155]$.

More importantly, the biopolymer-based packaging enables to divert the organic waste from landfilling to composting. As is often the case post-consumer packaging is often highly contaminated [148], especially when they used to package some sticky and viscos foods. Therefore, packaging like this is no longer feasible for material recycling. By introducing the biopolymer-based packaging, this part of waste stream can be better valorised for composting instead of landfilling (see Figure 26). Besides, food and its packaging can be disposed in one go, which will greatly ease the waste sorting. Survey results show that the households are willing to sort and collect organic waste (kitchen waste, garden waste, etc.) when biodegradable bags are available [152]. 


\subsection{CONCLUSIONS}

From the literature review, we learn that active packaging holds a great potential in prolonging the food shelf life, and generally $50 \%$ of extension is possible. This is very appealing for food producers and all the other players along the food value chain, including the consumers. Especially, the concept proposed in one study where the cyclodextrin $(\mathrm{CD})$ encapsulated eugenol can be triggered by the relative humidity within the packaging [27]. This enables packaging designer to finely control the release of the active agent.

However, from a life cycle point of view, there is one issue that requires our attention. As the packaging system gets more advanced, accordingly its environmental profile increases, which results from the manufacturing of the active agent and the processing to incorporate it into the packaging material, either by coating or by extrusion. In the meanwhile, such active packaging enables food loss saving, which may offset the additional aforementioned input and emissions. So, it becomes interesting to investigate where exactly the threshold point locates. This can be done with LCA by considering food and its packaging as whole system.

As compared with the organic agents (e.g. organic acid, essential oil component, nisin, etc.), using metallic nanoparticles (NPs) as antimicrobial agent offers a number of advantages, such as superior antimicrobial efficacy, no negative impacts on the food sensory properties, and compatibility with harsh polymer processing conditions. This type of agent can be simply used as additives in polymer processing without any further modifications or investment in the equipment. We can see that currently there are lots of research works going on in this field. They focus on the material's antimicrobial efficacy, food contact regulatory issues, migration of NPs, potential toxic effects to human and ecosystem, etc.

Considering the antimicrobial material developed in our project, some issues require further investigation. For example, there is limited information available for the following two points:

1) When several metallic nanoparticles are available to be used as active agent, which solution gives the lowest environmental impacts.

2) Since the active agent will be coated on a paper substrate, the material needs to be characterized and its recyclability need to be checked. Especially, the fate of NPs in paper recycling process should be tracked to avoid any harmful effects at an early stage. 


\subsection{REFERENCES}

1. Restuccia D, Spizzirri UG, Parisi OI, Cirillo G, Curcio M, Iemma F, Puoci F, Vinci G, Picci N. New EU regulation aspects and global market of active and intelligent packaging for food industry applications. Food Control 2010; 21(11), pp. 1425-1435.

2. Suppakul P, Miltz J, Sonneveld K, Bigger SW. Active packaging technologies with an emphasis on antimicrobial packaging and its applications. Journal of Food Science 2003; 68(2), pp. 408-420.

3. $\quad$ Smithers R. Marks \& Spencer breaks mould with packaging for 'longerliving' fruit. 2012 [cited 26-06-2014]; Available from:

http://www.theguardian.com/environment/2012/jan/06/marks-and-spencerpackaging-fruit?guni=Article:in body link.

4. Duncan TV. Applications of nanotechnology in food packaging and food safety: Barrier materials, antimicrobials and sensors. Journal of colloid and interface science 2011; 363(1), pp. 1-24.

5. Muriel-Galet V, López-Carballo G, Gavara R, Hernández-Muñoz P. Antimicrobial food packaging film based on the release of LAE from EVOH. International journal of food microbiology 2012; 157(2), pp. 239244.

6. Solomakos N, Govaris A, Koidis P, Botsoglou N. The antimicrobial effect of thyme essential oil, nisin and their combination against Escherichia coli O157: H7 in minced beef during refrigerated storage. Meat science 2008; 80(2), pp. 159-166.

7. Li X, Xing Y, Jiang Y, Ding Y, Li W. Antimicrobial activities of $\mathrm{ZnO}$ powder-coated PVC film to inactivate food pathogens. International journal of food science \& technology 2009; 44(11), pp. 2161-2168.

8. Vermeiren L, Devlieghere F, Van Beest M, De Kruijf N, Debevere J. Developments in the active packaging of foods. Trends in Food Science \& Technology 1999; 10(3), pp. 77-86.

9. Muriel-Galet V, Cerisuelo JP, López-Carballo G, Aucejo S, Gavara R, Hernández-Muñoz P. Evaluation of EVOH-coated PP films with oregano essential oil and citral to improve the shelf-life of packaged salad. Food Control 2013; 30(1), pp. 137-143.

10. López-de-Dicastillo C, Gómez-Estaca J, Catalá R, Gavara R, HernándezMuñoz P. Active antioxidant packaging films: development and effect on lipid stability of brined sardines. Food Chemistry 2012; 131(4), pp. 13761384.

11. NSW Food Authority, Shelf life testing-"use-by" dates for food safety, N.F. Authority, Editor, NSW Food Authority: NSW. p. 10.

12. Food Standards Agency. Food Standards Agency guidance on the safety and shelf-life of vacuum and modified atmosphere packed chilled foods 
with respect to non-proteolytic Clostridium botulinum. 2008 [cited 15-042014]; Available from:

http://food.gov.uk/multimedia/pdfs/publication/vacpacguide.pdf.

13. Skandamis PN, Nychas G-JE. Preservation of fresh meat with active and modified atmosphere packaging conditions. International Journal of Food Microbiology 2002; 79(1), pp. 35-45.

14. Chouliara E, Karatapanis A, Savvaidis I, Kontominas M. Combined effect of oregano essential oil and modified atmosphere packaging on shelf-life extension of fresh chicken breast meat, stored at 4 C. Food Microbiology 2007; 24(6), pp. 607-617.

15. Kim YM, Paik HD, Lee DS. Shelf-life characteristics of fresh oysters and ground beef as affected by bacteriocin-coated plastic packaging film. Journal of the Science of Food and Agriculture 2002; 82(9), pp. 998-1002.

16. Camo J, Lorés A, Djenane D, Beltrán JA, Roncalés P. Display life of beef packaged with an antioxidant active film as a function of the concentration of oregano extract. Meat science 2011; 88(1), pp. 174-178.

17. Nerín C, Tovar L, Djenane D, Camo J, Salafranca J, Beltrán JA, Roncalés P. Stabilization of beef meat by a new active packaging containing natural antioxidants. Journal of Agricultural and Food Chemistry 2006; 54(20), pp. 7840-7846.

18. Camo J, Beltrán JA, Roncalés P. Extension of the display life of lamb with an antioxidant active packaging. Meat Science 2008; 80(4), pp. 1086-1091.

19. Sagoo S, Board R, Roller S. Chitosan inhibits growth of spoilage microorganisms in chilled pork products. Food Microbiology 2002; 19(2), pp. 175-182.

20. Yingyuad S, Ruamsin S, Reekprkhon D, Douglas S, Pongamphai S, Siripatrawan U. Effect of chitosan coating and vacuum packaging on the quality of refrigerated grilled pork. Packaging technology and science 2006; 19(3), pp. 149-157.

21. Conte A, Scrocco C, Sinigaglia M, Del Nobile M. Innovative active packaging systems to prolong the shelf life of mozzarella cheese. Journal of dairy science 2007; 90(5), pp. 2126-2131.

22. Mastromatteo M, Danza A, Conte A, Muratore G, Del Nobile MA. Shelf life of ready to use peeled shrimps as affected by thymol essential oil and modified atmosphere packaging. International journal of food microbiology 2010; 144(2), pp. 250-256.

23. Ammor MS, Argyri A, Nychas G-JE. Rapid monitoring of the spoilage of minced beef stored under conventionally and active packaging conditions using Fourier transform infrared spectroscopy in tandem with chemometrics. Meat science 2009; 81(3), pp. 507-514. 
24. Guarda A, Rubilar JF, Miltz J, Galotto MJ. The antimicrobial activity of microencapsulated thymol and carvacrol. International journal of food microbiology 2011; 146(2), pp. 144-150.

25. Wang J, Cao Y, Sun B, Wang C. Physicochemical and release characterisation of garlic oil- $\beta$-cyclodextrin inclusion complexes. Food Chemistry 2011; 127(4), pp. 1680-1685.

26. Ponce Cevallos PA, Buera MP, Elizalde BE. Encapsulation of cinnamon and thyme essential oils components (cinnamaldehyde and thymol) in $\beta$ cyclodextrin: Effect of interactions with water on complex stability. Journal of Food Engineering 2010; 99(1), pp. 70-75.

27. Ayala-Zavala J, Del-Toro-Sánchez L, Alvarez-Parrilla E, González-Aguilar G. High Relative Humidity In-Package of Fresh-Cut Fruits and Vegetables: Advantage or Disadvantage Considering Microbiological Problems and Antimicrobial Delivering Systems? Journal of food science 2008; 73(4), pp. R41-R47.

28. Savolainen K, Alenius H, Norppa H, Pylkkänen L, Tuomi T, Kasper G. Risk assessment of engineered nanomaterials and nanotechnologies-a review. Toxicology 2010; 269(2), pp. 92-104.

29. Som C, Berges M, Chaudhry Q, Dusinska M, Fernandes TF, Olsen SI, Nowack B. The importance of life cycle concepts for the development of safe nanoproducts. Toxicology 2010; 269(2), pp. 160-169.

30. Kunhikrishnan A, Shon HK, Bolan NS, El Saliby I, Vigneswaran S. Sources, distribution, environmental fate and ecological effects of nanomaterials in wastewater streams. Critical Reviews in Environmental Science and Technology 2015; 45(4), pp. 277-318.

31. Kaegi R, Ulrich A, Sinnet B, Vonbank R, Wichser A, Zuleeg S, Simmler $\mathrm{H}$, Brunner S, Vonmont $\mathrm{H}$, Burkhardt $\mathrm{M}$. Synthetic $\mathrm{TiO}_{2}$ nanoparticle emission from exterior facades into the aquatic environment. Environmental Pollution 2008; 156(2), pp. 233-239.

32. Wang Y, Westerhoff P, Hristovski KD. Fate and biological effects of silver, titanium dioxide, and $\mathrm{C}_{60}$ (fullerene) nanomaterials during simulated wastewater treatment processes. Journal of hazardous materials 2012; 201, pp. 16-22.

33. EPA. Nanomaterials. Available from: http://www.epa.gov.

34. Gao F. Clay/polymer composites: the story. Materials Today 2004; 7(11), pp. 50-55.

35. Sinha Ray S, Okamoto M. Polymer/layered silicate nanocomposites: a review from preparation to processing. Progress in polymer science 2003; 28(11), pp. 1539-1641.

36. BYK. 2014; Available from: http://www.byk.com/en/additives/productgroups/rheology/former-rockwood-additives/technical-brochures.html. 
37. Xie W, Gao Z, Liu K, Pan W-P, Vaia R, Hunter D, Singh A. Thermal characterization of organically modified montmorillonite. Thermochimica Acta 2001; 367, pp. 339-350.

38. Osman MA. Organo-vermiculites: synthesis, structure and properties. Platelike nanoparticles with high aspect ratio. J. Mater. Chem. 2006; 16(29), pp. 3007-3013.

39. Osman MA, Rupp JE, Suter UW. Gas permeation properties of polyethylene-layered silicate nanocomposites. Journal of Materials Chemistry 2005; 15(12), pp. 1298-1304.

40. Bird RB, Stewart WE, Lightfoot EN. Transport phenomena. 2002. JohnWiley \& Sons, New York.

41. Martin D, Edwards G, Polymer composites having particles with mixed organic modifications, 2014, Google Patents.

42. Romero SA, Beneyto MJ, Soriano JMA, Blanca MG, Saldaña JMB, Ramos $\mathrm{MH}$, Polymer nanocomposite comprising polylactic acid reinforced with the modified phyllosilicate, 2011, Google Patents.

43. Rhim J-W, Hong S-I, Ha C-S. Tensile, water vapor barrier and antimicrobial properties of PLA/nanoclay composite films. LWT-Food Science and Technology 2009; 42(2), pp. 612-617.

44. Nigmatullin R, Gao F, Konovalova V. Polymer-layered silicate nanocomposites in the design of antimicrobial materials. Journal of Materials Science 2008; 43(17), pp. 5728-5733.

45. Nigmatullin R, Gao F, Konovalova V. Permanent, Non-Leaching Antimicrobial Polyamide Nanocomposites Based on Organoclays Modified with a Cationic Polymer. Macromolecular Materials and Engineering 2009; 294(11), pp. 795-805.

46. Gao F, Beyer G, Yuan Q. A mechanistic study of fire retardancy of carbon nanotube/ethylene vinyl acetate copolymers and their clay composites. Polymer degradation and stability 2005; 89(3), pp. 559-564.

47. Liu A, Walther A, Ikkala O, Belova L, Berglund LA. Clay nanopaper with tough cellulose nanofiber matrix for fire retardancy and gas barrier functions. Biomacromolecules 2011; 12(3), pp. 633-641.

48. Morgan AB, Gilman J. Polymer-clay nanocomposites: Design and application of multi-functional materials. Mater. Matters 2007; 2, pp. 20 25.

49. Jorda-Beneyto M, Ortuño N, Devis A, Aucejo S, Puerto M, GutiérrezPraena D, Houtman J, Pichardo S, Maisanaba S, Jos A. Use of nanoclay platelets in food packaging materials: technical and cytotoxicity approach. Food Additives \& Contaminants: Part A 2014; 31(3), pp. 354-363.

50. Sinha Ray S, Yamada K, Okamoto M, Ueda K. New polylactide-layered silicate nanocomposites. 2. Concurrent improvements of material 
properties, biodegradability and melt rheology. Polymer 2003; 44(3), pp. 857-866.

51. Rhim J-W, Park H-M, Ha C-S. Bio-nanocomposites for food packaging applications. Progress in Polymer Science 2013; 38(10), pp. 1629-1652.

52. Llorens A, Lloret E, Picouet PA, Trbojevich R, Fernandez A. Metallicbased micro and nanocomposites in food contact materials and active food packaging. Trends in Food Science \& Technology 2012; 24(1), pp. 19-29.

53. Besinis A, De Peralta T, Handy RD. The antibacterial effects of silver, titanium dioxide and silica dioxide nanoparticles compared to the dental disinfectant chlorhexidine on Streptococcus mutans using a suite of bioassays. Nanotoxicology 2014; 8(1), pp. 1-16.

54. Yamamoto O. Influence of particle size on the antibacterial activity of zinc oxide. International Journal of Inorganic Materials 2001; 3(7), pp. 643646.

55. Walser T, Demou E, Lang DJ, Hellweg S. Prospective environmental life cycle assessment of nanosilver T-shirts. Environmental science \& technology 2011; 45(10), pp. 4570-4578.

56. Martins NC, Freire CS, Neto CP, Silvestre AJ, Causio J, Baldi G, Sadocco $\mathrm{P}$, Trindade T. Antibacterial paper based on composite coatings of nanofibrillated cellulose and $\mathrm{ZnO}$. Colloids and Surfaces A: Physicochemical and Engineering Aspects 2013; 417, pp. 111-119.

57. Martínez-Abad A, Ocio M, Lagarón J, Sánchez G. Evaluation of silverinfused polylactide films for inactivation of Salmonella and feline calicivirus in vitro and on fresh-cut vegetables. International journal of food microbiology 2013; 162(1), pp. 89-94.

58. Fernández A, Picouet $\mathrm{P}$, Lloret E. Cellulose-silver nanoparticle hybrid materials to control spoilage-related microflora in absorbent pads located in trays of fresh-cut melon. International Journal of Food Microbiology 2010; 142(1), pp. 222-228.

59. Castro-Mayorga J, Fabra M, Lagaron J. Stabilized nanosilver based antimicrobial poly (3-hydroxybutyrate-co-3-hydroxyvalerate) nanocomposites of interest in active food packaging. Innovative Food Science \& Emerging Technologies 2016; 33, pp. 524-533.

60. Kim Y, Choi Y, Kim S, Park J, Chung M, Song KB, Hwang I, Kwon K, Park J. Disinfection of Iceberg Lettuce by Titanium Dioxide-UV Photocatalytic Reaction. Journal of Food Protection ${ }^{\circledR}$ 2009; 72(9), pp. 1916-1922.

61. Chawengkijwanich $\mathrm{C}$, Hayata Y. Development of $\mathrm{TiO} 2$ powder-coated food packaging film and its ability to inactivate Escherichia coli in vitro and in actual tests. International journal of food microbiology 2008; 123(3), pp. 288-292. 
62. El-Wakil NA, Hassan EA, Abou-Zeid RE, Dufresne A. Development of wheat gluten/nanocellulose/titanium dioxide nanocomposites for active food packaging. Carbohydrate polymers 2015; 124, pp. 337-346.

63. Jin T, Gurtler J. Inactivation of Salmonella in liquid egg albumen by antimicrobial bottle coatings infused with allyl isothiocyanate, nisin and zinc oxide nanoparticles. Journal of applied microbiology 2011; 110(3), pp. 704-712.

64. Silvestre C, Duraccio D, Marra A, Strongone V, Cimmino S. Development of Antibacterial Composite Films Based on Isotactic Polypropylene and Coated $\mathrm{ZnO}$ Particles for Active Food Packaging. Coatings 2016; 6(1), pp. 4.

65. Li H, Li F, Wang L, Sheng J, Xin Z, Zhao L, Xiao H, Zheng Y, Hu Q. Effect of nano-packing on preservation quality of Chinese jujube (Ziziphus jujuba Mill. var. inermis (Bunge) Rehd). Food chemistry 2009; 114(2), pp. 547-552.

66. Liu Y, He L, Mustapha A, Li H, Hu Z, Lin M. Antibacterial activities of zinc oxide nanoparticles against Escherichia coli O157: H7. Journal of applied microbiology 2009; 107(4), pp. 1193-1201.

67. Sondi I, Salopek-Sondi B. Silver nanoparticles as antimicrobial agent: a case study on E. coli as a model for Gram-negative bacteria. Journal of colloid and interface science 2004; 275(1), pp. 177-182.

68. Zhu X, Wang J, Zhang X, Chang Y, Chen Y. The impact of ZnO nanoparticle aggregates on the embryonic development of zebrafish (Danio rerio). Nanotechnology 2009; 20(19), pp. 195103.

69. Espitia PJP, Soares NdFF, dos Reis Coimbra JS, de Andrade NJ, Cruz RS, Medeiros EAA. Zinc oxide nanoparticles: synthesis, antimicrobial activity and food packaging applications. Food and Bioprocess Technology 2012; 5(5), pp. 1447-1464.

70. Chen S, Guo Y, Zhong H, Chen S, Li J, Ge Z, Tang J. Synergistic antibacterial mechanism and coating application of copper/titanium dioxide nanoparticles. Chemical Engineering Journal 2014; 256, pp. 238-246.

71. Sökmen M, Tatlıdil İ, Breen C, Clegg F, Buruk CK, Sivlim T, Akkan Ş. A new nano- $\mathrm{TiO}_{2}$ immobilized biodegradable polymer with self-cleaning properties. Journal of hazardous materials 2011; 187(1), pp. 199-205.

72. Visai L, De Nardo L, Punta C, Melone L, Cigada A, Imbriani M, Arciola CR. Titanium oxide antibacterial surfaces in biomedical devices. International Journal of Artificial Organs 2011; 34(9), pp. 929-946.

73. Navarro E, Piccapietra F, Wagner B, Marconi F, Kaegi R, Odzak N, Sigg L, Behra R. Toxicity of silver nanoparticles to Chlamydomonas reinhardtii. Environmental Science \& Technology 2008; 42(23), pp. 8959-8964.

74. Esmailzadeh H, Sangpour P, Shahraz F, Hejazi J, Khaksar R. Effect of nanocomposite packaging containing $\mathrm{ZnO}$ on growth of Bacillus subtilis 
and Enterobacter aerogenes. Materials Science and Engineering: $C$ 2016; 58, pp. 1058-1063.

75. Stanković A, Dimitrijević S, Uskoković D. Influence of size scale and morphology on antibacterial properties of $\mathrm{ZnO}$ powders hydrothemally synthesized using different surface stabilizing agents. Colloids and Surfaces B: Biointerfaces 2013; 102, pp. 21-28.

76. Pal S, Tak YK, Song JM. Does the antibacterial activity of silver nanoparticles depend on the shape of the nanoparticle? A study of the gram-negative bacterium Escherichia coli. Applied and environmental microbiology 2007; 73(6), pp. 1712-1720.

77. Pratt AS, Smith PR, Antimicrobial compositions consisting of metallic silver combined with titanium oxide or tantalum oxide, 1989, Google Patents.

78. Montazer M, Pakdel E, Behzadnia A. Novel feature of nano-titanium dioxide on textiles: Antifelting and antibacterial wool. Journal of Applied Polymer Science 2011; 121(6), pp. 3407-3413.

79. Eby DM, Schaeublin NM, Farrington KE, Hussain SM, Johnson GR. Lysozyme catalyzes the formation of antimicrobial silver nanoparticles. ACS nano 2009; 3(4), pp. 984-994.

80. Martins NC, Freire CS, Pinto RJ, Fernandes SC, Neto CP, Silvestre AJ, Causio J, Baldi G, Sadocco P, Trindade T. Electrostatic assembly of Ag nanoparticles onto nanofibrillated cellulose for antibacterial paper products. Cellulose 2012; 19(4), pp. 1425-1436.

81. Sharma VK, Yngard RA, Lin Y. Silver nanoparticles: green synthesis and their antimicrobial activities. Advances in colloid and interface science 2009; 145(1), pp. 83-96.

82. Murariu M, Doumbia A, Bonnaud L, Dechief AL, Paint Y, Ferreira M, Campagne C, Devaux E, Dubois P. High-performance polylactide/ZnO nanocomposites designed for films and fibers with special end-use properties. Biomacromolecules 2011; 12(5), pp. 1762-1771.

83. Pantani R, Gorrasi G, Vigliotta G, Murariu M, Dubois P. PLA-ZnO nanocomposite films: Water vapor barrier properties and specific end-use characteristics. European Polymer Journal 2013; 49(11), pp. 3471-3482.

84. Praus $\mathrm{P}$, Turicová $\mathrm{M}$, Machovič V, Študentová S, Klementová M. Characterization of silver nanoparticles deposited on montmorillonite. Applied Clay Science 2010; 49(3), pp. 341-345.

85. Kwakye-Awuah B, Williams C, Kenward M, Radecka I. Antimicrobial action and efficiency of silver-loaded zeolite X. Journal of applied microbiology 2008; 104(5), pp. 1516-1524. 
86. Fernández A, Soriano E, Hernández-Muñoz P, Gavara R. Migration of antimicrobial silver from composites of polylactide with silver zeolites. Journal of food science 2010; 75(3), pp. E186-E193.

87. Song D-H, Uhm S-H, Lee S-B, Han J-G, Kim K-N. Antimicrobial silvercontaining titanium oxide nanocomposite coatings by a reactive magnetron sputtering. Thin Solid Films 2011; 519(20), pp. 7079-7085.

88. Del Nobile M, Conte A, Buonocore G, Incoronato A, Massaro A, Panza O. Active packaging by extrusion processing of recyclable and biodegradable polymers. Journal of Food Engineering 2009; 93(1), pp. 1-6.

89. Shameli K, Ahmad MB, Yunus WMZW, Ibrahim NA, Rahman RA, Jokar M, Darroudi M. Silver/poly (lactic acid) nanocomposites: preparation, characterization, and antibacterial activity. International journal of nanomedicine 2010; 5, pp. 573.

90. Sorrentino A, Gorrasi G, Vittoria V. Potential perspectives of bionanocomposites for food packaging applications. Trends in Food Science \& Technology 2007; 18(2), pp. 84-95.

91. Klemenčič D, Simončič B, Tomšič B, Orel B. Biodegradation of silver functionalised cellulose fibres. Carbohydrate polymers 2010; 80(2), pp. 426-435.

92. Balaguer M, Aliaga C, Fito C, Hortal M. Compostability assessment of nano-reinforced poly (lactic acid) films. Waste Management 2016; 48, pp. 143-155.

93. Benali S, Aouadi S, Dechief A-L, Murariu M, Dubois P. Key factors for tuning hydrolytic degradation of polylactide/zinc oxide nanocomposites. Nanocomposites 2015.

94. Kim B, Park C-S, Murayama M, Hochella Jr MF. Discovery and characterization of silver sulfide nanoparticles in final sewage sludge products. Environmental science \& technology 2010; 44(19), pp. 75097514.

95. Lombi E, Donner E, Tavakkoli E, Turney TW, Naidu R, Miller BW, Scheckel KG. Fate of zinc oxide nanoparticles during anaerobic digestion of wastewater and post-treatment processing of sewage sludge. Environmental science \& technology 2012; 46(16), pp. 9089-9096.

96. Skoglund S, Lowe TA, Hedberg J, Blomberg E, Wallinder IO, Wold S, Lundin M. Effect of laundry surfactants on surface charge and colloidal stability of silver nanoparticles. Langmuir 2013; 29(28), pp. 8882-8891.

97. Lowry G, Casman E, Nanomaterial transport, transformation, and fate in the environment, in Nanomaterials: risks and benefits. 2009, Springer. p. 125-137.

98. Boxall AB, Tiede K, Chaudhry Q. Engineered nanomaterials in soils and water: how do they behave and could they pose a risk to human health? 2007. 
99. Vasiliev AN, Gulliver EA, Khinast JG, Riman RE. Highly dispersible polymer-coated silver nanoparticles. Surface and Coatings Technology 2009; 203(19), pp. 2841-2844.

100. Zhang Y, Chen Y, Westerhoff P, Hristovski K, Crittenden JC. Stability of commercial metal oxide nanoparticles in water. Water research 2008; 42(8), pp. 2204-2212.

101. Sperling R, Parak W. Surface modification, functionalization and bioconjugation of colloidal inorganic nanoparticles. Philosophical Transactions of the Royal Society A: Mathematical, Physical and Engineering Sciences 2010; 368(1915), pp. 1333-1383.

102. Rossi M, Cubadda F, Dini L, Terranova M, Aureli F, Sorbo A, Passeri D. Scientific basis of nanotechnology, implications for the food sector and future trends. Trends in Food Science \& Technology 2014; 40(2), pp. 127148.

103. Mackevica A, Olsson ME, Hansen SF. Silver nanoparticle release from commercially available plastic food containers into food simulants. Journal of Nanoparticle Research 2016; 18(1), pp. 1-11.

104. Hannon JC, Kerry JP, Cruz-Romero M, Azlin-Hasim S, Morris M, Cummins E. Assessment of the migration potential of nanosilver from nanoparticle-coated low-density polyethylene food packaging into food simulants. Food Additives \& Contaminants: Part A 2016; 33(1), pp. 167178.

105. Kuorwel KK, Cran MJ, Orbell JD, Buddhadasa S, Bigger SW. Review of mechanical properties, migration, and potential applications in active food packaging systems containing nanoclays and nanosilver. Comprehensive Reviews in Food Science and Food Safety 2015; 14(4), pp. 411-430.

106. Ramos K, Gómez-Gómez M, Cámara C, Ramos L. Silver Speciation and characterization of nanoparticles released from plastic food containers by single particle ICPMS. Talanta 2016.

107. EFSA. Opinion of the Scientific Panel on food additives, flavourings, processing aids and materials in contact with food (AFC) related to a 7th list of substances for food contact materials. EFSA Journal 2005(201), pp. $1-28$.

108. Echegoyen Y, Nerín C. Nanoparticle release from nano-silver antimicrobial food containers. Food and Chemical Toxicology 2013; 62, pp. 16-22.

109. Reig CS, Lopez AD, Ramos MH, Ballester VAC. Nanomaterials: a map for their selection in food packaging applications. Packaging Technology and Science 2014; 27(11), pp. 839-866.

110. EFSA CEF Panel on Food Contact Materials E, Flavourings and Processing Aids. Scientific Opinion on the safety evaluation of the substance zinc oxide, nanoparticles, uncoated and coated with [3-(methacryloxy)propyl] 
trimethoxysilane, for use in food contact materials. EFSA Journal 2015; 13(4), pp. 4063-4072, DOI: doi:10.2903/j.efsa.2015.4063.

111. Kumar R, Münstedt $H$. Silver ion release from antimicrobial polyamide/silver composites. Biomaterials 2005; 26(14), pp. 2081-2088.

112. Sánchez-Valdes S, Ortega-Ortiz H, Ramos-de Valle L, Medellín-Rodríguez F, Guedea-Miranda R. Mechanical and antimicrobial properties of multilayer films with a polyethylene/silver nanocomposite layer. Journal of applied polymer science 2009; 111(2), pp. 953-962.

113. Siegrist M, Stampfli N, Kastenholz H, Keller C. Perceived risks and perceived benefits of different nanotechnology foods and nanotechnology food packaging. Appetite 2008; 51(2), pp. 283-290.

114. Bieberstein A, Roosen J, Marette S, Blanchemanche S, Vandermoere F. Consumer choices for nano-food and nano-packaging in France and Germany. European review of agricultural economics 2013; 40(1), pp. 7394.

115. The Federal Institue for Risk Assessment of Germany (BfR). The majority of consumers view the development of nanotechnology favourably. 2007 [cited 04-05-2015]; Available from:

http://www.bfr.bund.de/en/press information/2007/23/the majority of co nsumers view the development of nanotechnology favourably10563.html.

116. Stora Enso Packaging Solutions. Press release. 2015 [cited 21-06-2015]; Available from: http://renewablepackaging.storaenso.com/news/improvenet-sales-and-ebit-with-sustainable-packaging.

117. Allione C, Petruccelli L, A multicriteria method for assessing the ecoperformances of food packaging, 2012, 2nd World Sustainability Forum.

118. Sustainable Packaging Alliance, PRINCIPLES, STRATEGIES \& KPIS FOR PACKAGING SUSTAINABILITY, 2010, Sustainable Packaging Alliance.

119. ECR \& Europe, EUROPEN, Packaging in the Sustainability Agenda: A Guide for Corporate Decision Makers, 2009, ECR Europe \& EUROPEN.

120. Sustainable Packaging Coalition, Sustainable Packaging Indicators and Metrics Framework (V. 1.0), 2009, Sustainable Packaging Coalition.

121. Kloepffer W. Life cycle sustainability assessment of products. The International Journal of Life Cycle Assessment 2008; 13(2), pp. 89-95.

122. EPA, Life cycle assessment: principles and practice, N.r.m.r.l.o.o.r.a. development, Editor 2006, U.S. environmental protection agency (EPA)

123. Finkbeiner M, Inaba A, Tan R, Christiansen K, Klüppel H-J. The new international standards for life cycle assessment: ISO 14040 and ISO 14044. The international journal of life cycle assessment 2006; 11(2), pp. $80-85$. 
124. ISO I. 14044: environmental management-life cycle assessmentrequirements and guidelines. International Organization for Standardization 2006.

125. ISO I. 14040. Environmental management-life cycle assessmentprinciples and framework 2006.

126. Cordella M, Tugnoli A, Spadoni G, Santarelli F, Zangrando T. LCA of an Italian lager beer. The International Journal of Life Cycle Assessment 2008; 13(2), pp. 133-139.

127. Madival S, Auras R, Singh SP, Narayan R. Assessment of the environmental profile of PLA, PET and PS clamshell containers using LCA methodology. Journal of Cleaner Production 2009; 17(13), pp. 11831194.

128. Wikström F, Williams H, Verghese K, Clune S. The influence of packaging attributes on consumer behaviour in food-packaging life cycle assessment studies-a neglected topic. Journal of Cleaner Production 2014; 73, pp. 100-108.

129. Manfredi M, Fantin V, Vignali G, Gavara R. Environmental assessment of antimicrobial coatings for packaged fresh milk. Journal of Cleaner Production 2015; 95, pp. 291-300.

130. Humbert S, Rossi V, Margni M, Jolliet O, Loerincik Y. Life cycle assessment of two baby food packaging alternatives: glass jars vs. plastic pots. The International Journal of Life Cycle Assessment 2009; 14(2), pp. 95-106.

131. Vignali G, Life-Cycle Assessment of Food-Packaging Systems, in Environmental Footprints of Packaging. 2016, Springer. p. 1-22.

132. Williams H, Wikström F. Environmental impact of packaging and food losses in a life cycle perspective: a comparative analysis of five food items. Journal of Cleaner Production 2011; 19(1), pp. 43-48.

133. Wikström F, Williams H. Potential environmental gains from reducing food losses through development of new packaging-a life-cycle model. Packaging Technology and Science 2010; 23(7), pp. 403-411.

134. EUROPEN. Packaging - Delivering Resource Efficiency. 2013 [cited 1410-2014]; Available from: http://www.europen-packaging.eu/library/allpublications.html.

135. Verghese K, Lockrey S, Selecting and applying tools, in Packaging for sustainability. 2012, Springer. p. 251-283.

136. Klöpffer W, Curran MA, Frankl P, Heijungs R, Köhler A, Olsen SI, Nanotechnology and Life Cycle Assessment. A systems approach to Nanotechnology and the environment: Synthesis of Results Obtained at a Workshop Washington, DC 2-3 October 2006, 2007, European Commission, DG Research, jointly with the Woodrow Wilson International Center for Scholars. 
137. Eckelman MJ, Zimmerman JB, Anastas PT. Toward green nano. Journal of Industrial Ecology 2008; 12(3), pp. 316-328.

138. Greijer H, Karlson L, Lindquist S-E, Hagfeldt A. Environmental aspects of electricity generation from a nanocrystalline dye sensitized solar cell system. Renewable Energy 2001; 23(1), pp. 27-39.

139. Lloyd SM, Lave LB. Life cycle economic and environmental implications of using nanocomposites in automobiles. Environmental Science \& Technology 2003; 37(15), pp. 3458-3466.

140. Bauer C, Buchgeister J, Hischier R, Poganietz W, Schebek L, Warsen J. Environmental prospects in products-a framework for life cycle thinking on nano scales. J Clean Prod 2008; 16(8-9), pp. 910-926.

141. Roes A, Marsili E, Nieuwlaar E, Patel M. Environmental and cost assessment of a polypropylene nanocomposite. Journal of Polymers and the Environment 2007; 15(3), pp. 212-226.

142. Hauschild MZ, Goedkoop M, Guinée J, Heijungs R, Huijbregts M, Jolliet O, Margni M, De Schryver A, Humbert S, Laurent A. Identifying best existing practice for characterization modeling in life cycle impact assessment. The International Journal of Life Cycle Assessment 2013; 18(3), pp. 683-697.

143. Rosenbaum RK, Bachmann TM, Gold LS, Huijbregts MA, Jolliet O, Juraske R, Koehler A, Larsen HF, MacLeod M, Margni M. USEtox-the UNEP-SETAC toxicity model: recommended characterisation factors for human toxicity and freshwater ecotoxicity in life cycle impact assessment. The International Journal of Life Cycle Assessment 2008; 13(7), pp. 532546.

144. Hischier R, Walser T. Life cycle assessment of engineered nanomaterials: State of the art and strategies to overcome existing gaps. Science of The Total Environment 2012;425, pp.271-282.

145. Barberio G, Scalbi S, Buttol P, Masoni P, Righi S. Combining life cycle assessment and qualitative risk assessment: The case study of alumina nanofluid production. Science of The Total Environment 2014; 496, pp. 122-131.

146. Salieri B, Righi S, Pasteris A, Olsen SI. Freshwater ecotoxicity characterisation factor for metal oxide nanoparticles: A case study on titanium dioxide nanoparticle. Science of The Total Environment 2015; 505, pp. 494-502.

147. Eckelman MJ, Mauter MS, Isaacs JA, Elimelech M. New perspectives on nanomaterial aquatic ecotoxicity: production impacts exceed direct exposure impacts for carbon nanotoubes. Environmental science \& technology 2012; 46(5), pp. 2902-2910. 
148. Aarnio T, Hämäläinen A. Challenges in packaging waste management in the fast food industry. Resources, Conservation and Recycling 2008; 52(4), pp. 612-621.

149. Eurostat. Recovery rates for packaging waste. 2014 [cited 07-01-2015]; Available from:

http://ec.europa.eu/eurostat/en/web/main/data/database?node code=ten000 62.

150. Eurostat. Recycling rates for packaging waste. 2014 [cited 07-01-2015]; Available from:

http://ec.europa.eu/eurostat $/ \operatorname{tgm} /$ table.do?tab $=$ table $\&$ init $=1 \&$ language $=$ en $\&$ pcode $=$ ten $00063 \&$ plugin $=1$.

151. Davis G, Song J. Biodegradable packaging based on raw materials from crops and their impact on waste management. Industrial crops and products 2006; 23(2), pp. 147-161.

152. European Bioplastics. Publications Bioplastics facts and figures. 2014 [cited 09-01-2015]; Available from: http://en.europeanbioplastics.org/multimedia/.

153. European Bioplastics. Fact sheet, better packaging with bioplastics. 2016 [cited 09-02-2016]; Available from: http://docs.europeanbioplastics.org/2016/publications/fs/EUBP fs packaging.pdf

154. Siracusa V, Rocculi P, Romani S, Rosa MD. Biodegradable polymers for food packaging: a review. Trends in Food Science \& Technology 2008; 19(12), pp. 634-643.

155. Piemonte V. Bioplastic wastes: the best final disposition for energy saving. Journal of Polymers and the Environment 2011; 19(4), pp. 988-994. 


\section{OBJECTIVES}

This thesis is part of the "NewGenPak" project (7th Framework Program of the EU, grant agreement No. 290098), which aims to develop the next generation cellulosebased packaging material. In order to compete with the oil-derived polymer, cellulose-based material will be imparted with novel properties e.g. enhanced barrier properties by using nanoclay, antimicrobial properties by incorporating organic/inorganic agents, in addition to the material's biodegradability and renewability. While introducing these novel properties, the material's overall sustainability should be maintained (the general objectives).

The objective of this thesis is to ensure the sustainability of the active materials developed in the project. It is a collection of manuscripts (either published or unpublished, a list is attached on the following page). The relationship between the general objectives and the specific objectives of each paper is illustrated in Figure 30 .

First of all, an active material incorporating metallic nanoparticles (NPs) will be produced and characterized. The material's antimicrobial activity will be assessed in accordance with the relevant standards and its action of mechanisms will be analysed. As the material is intended for food contact application, the migration of nanoparticles will be taken into account (the objective of Paper I).

The end-of-life of such packaging material will be investigated. As the NPcontaining coating will be applied on a paper substrate, it is expected that such material will entre the paper recycling process after disposal. Therefore, it becomes important to know the fate of NPs in paper recycling process in order to avoid any harmful effects (Objective of Paper II).

Furthermore, under the "NewGenPak" project, there are two students working with the organic agents (cinnamaldehyde, penicillin, nisin, phenyl isothiocyanate). From an environmental point view, there is a need to justify the trade-off relationship between the food loss saving and the additional input and emissions involved in use such type of active packaging. This will be demonstrated with a case study: essential oil component enabled active MAP (Modified Atmosphere Packaging) for fresh beef (the objective Paper III).

There are another two students working with the inorganic agents $\left(\mathrm{TiO}_{2}\right.$ and $\mathrm{ZnO}$ NPs). Several metallic NPs have been shown to contain antimicrobial properties and they are suitable to be incorporated into the coating formulation, and the choice of which can be assisted by considering their environmental profiles. While the 
challenge is the scarcity of the inventory data of these NPs despite the current ISObased LCA framework is applicable to nanomaterials (the objective of Paper IV).

\section{General objectives:}

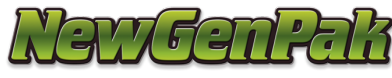

- Material's sustainability (environmental impacts, renewability, biodegradability, etc.

- Technical performance (antimicrobial and barrier properties)

\begin{tabular}{|c|c|c|c|}
\hline $\begin{array}{l}\text { Material preparation } \\
\text { and characterisation } \\
\text { (Objective of Paper I) }\end{array}$ & $\begin{array}{l}\text { End-of-life of } \\
\text { material (Objective } \\
\text { of Paper II) }\end{array}$ & $\begin{array}{l}\text { Reducing food waste } \\
\text { (Objective of Paper } \\
\text { III) }\end{array}$ & $\begin{array}{l}\text { Selection of active } \\
\text { agents (Objective of } \\
\text { paper IV) }\end{array}$ \\
\hline $\begin{array}{l}\text { - NP dispersing } \\
\text { - Coating recipe } \\
\text { - Surface morphology } \\
\text { by SEM } \\
\text { - AM test and the } \\
\text { effect of testing } \\
\text { methods }\end{array}$ & $\begin{array}{l}\text { - Fate of } \\
\text { nanomaterial in } \\
\text { fibre based } \\
\text { packaging recycling } \\
\text { steam }\end{array}$ & $\begin{array}{l}\text {-LCA: essential oil } \\
\text { component enabled } \\
\text { MAP* for fresh beef } \\
\text {-Trade-off } \\
\text { relationship } \\
\text { between active } \\
\text { packaging and food } \\
\text { loss saving }\end{array}$ & $\begin{array}{l}\text {-LCA: selection of } \\
\text { nanomaterial based } \\
\text { antimicrobial agent }\end{array}$ \\
\hline
\end{tabular}

${ }^{*} \mathrm{MAP}$, modified atmosphere packaging

Figure 30. The relationship between the general objectives and the specific objectives of each paper. 


\section{LIST OF PUBLICATIONS:}

- PAPER I. ZnO-PLA nanocomposite coated paper for antimicrobial packaging application. Hai Zhang, Mercedes Hortal, Maria Jordá-Beneyto, Estela Rosa, Marta Lara-Lledo, Inmaculada Lorente. Submitted to the LWT-Food Science and Technology.

- PAPER II. PLA coated paper containing active inorganic nanoparticles: Material characterization and fate of nanoparticles in the paper recycling process. Hai Zhang, Daniele Bussini, Mercedes Hortal, Graziano Elegir, Joana Mendes, Maria Jordá-Beneyto. Published in the Waste Management, 2016, 52: 339-345.

- PAPER III. The effect of active packaging on minimising food losses: Life Cycle Assessment (LCA) of essential oil component enabled packaging for fresh beef. Hai Zhang, Mercedes Hortal, Antonio Dobon, Jose M. Bermudez and Marta Lara-Lledo. Published in the Packaging Technology and Science, 2015, 28 (9): 761-774.

- PAPER IV. Selection of nanomaterial-based active agents for packaging applications: Using Life Cycle Assessment (LCA) as a tool. Hai Zhang, Mercedes Hortal, Antonio Dobon, Maria Jorda-Beneyto, and Jose M. Bermudez. Accepted manuscript for the Packaging Technology and Science, 2016. 
3 Paper I. ZnO-PLA nanocomposite coated paper for antimicrobial packaging application 


\subsection{INTRODUCTION}

Choosing appropriate active agent is key to the development of antimicrobial packaging system. Compared with the organic agents (e.g. organic acid, essential oil component, nisin, etc.), metallic-based nanoparticles (NPs) as antimicrobial agent offers a few advantages, such as superior antimicrobial efficacy, no negative impacts on the food sensory properties, and compatibility with the harsh polymer processing conditions [1-4]. As a result of NP' strong antimicrobial activity, it holds potential application not only in food spoilage control [5-7], but also in food safety control by inactivating the food-borne pathogens. The latter aspect has been explored in a number of research works, for example, impressive inhibitory effect was observed in treating E. coli $\mathrm{O} 157: \mathrm{H} 7$ with ZnO NPs [4]; PLA coating containing $\mathrm{ZnO}$ NPs was found to be effective in inactivating Salmonella inoculated in liquid egg albumen [8]; in the test with ready-to-eat chicken, $2 \log$ reduction in the inoculated bacteria (S. aureus and S. typhimurium) was observed after $24 \mathrm{~h}$ applying the $\mathrm{ZnO} \mathrm{NP}$-containing active packaging, and complete inhibition after 6-8 days [9].

Survey of literature shows that the relevant research has mainly concentrated on four nanoparticles: silver $(\mathrm{Ag})$, titanium dioxide $\left(\mathrm{TiO}_{2}\right)$, zinc oxide $(\mathrm{ZnO})$ and copper $(\mathrm{Cu})$ [2]. Among them, there is an increasing interest to use ZnO NPs for food contact application, which derives from the following merits:

1) The non-nano form of $\mathrm{ZnO}$ is already authorized by EFSA (European Food Safety Authority) as an additive for plastic materials and articles, with a SML (Specific Migration Limit) of $25 \mathrm{mg} / \mathrm{kg}$ food [10].

2) $\mathrm{ZnO}$ NPs exhibit low toxicity to the biological systems [11]. Furthermore, zinc is an essential element for human's physiological activity, c.a. 10 $\mathrm{mg} /$ person/day needed [10]. Toxicity studies recommend an upper limit of $25 \mathrm{mg} / \mathrm{person} /$ day [10].

3) In food packaging, transparency remains a determining factor for choosing the packaging material. On the other hand, some foods are susceptible to UV light. To solve this problem, UV-blocking agent is used in polymer processing. Studies showed that $\mathrm{ZnO}$ NP loading as low as $1 \mathrm{wt} \%$ enabled good UV-blocking performance without impairing the host polymer's transparency [12-14].

In this study, we proposed a paper-based packaging material, which is coated with ZnO-PLA nanocomposite. The application can be paper wrap for deli foods since there is a relatively high risk of microbiological contamination in suchlike cold processed foods. The focus is placed on the assessment of the antimicrobial activity. 


\subsection{MATERIALS AND METHODS}

\subsubsection{Coating recipe and coating on paper substrate}

ZnO NPs (Zano ${ }^{\circledR} 20$ Plus-3) were kindly supplied by Umicore, Belgium. The NPs are surface coated with organosilane ([3-(methacryloxy)propyl] trimethoxysilane) for improved dispersibility in polymer processing. The NPs have an average particle size of $30 \mathrm{~nm}$ [13]. As the NPs were supplied in powder form, first they were dispersed in the solvent: adding a proper amount of NPs $(0.075 \mathrm{~g}, 0.15 \mathrm{~g}$, and $0.45 \mathrm{~g}$ in respective beakers) into $100 \mathrm{~mL}$ ethyl acetate, stirring vigorously for 10 min, and then applying 5 min ultrasonic treatment (Sonics, microtip CV 334, $750 \mathrm{w}$ $20 \mathrm{kHz}$ ) to break up the agglomerates/aggregates. Afterwards, $15 \mathrm{~g}$ PLA pellets (Polylactic Acid, 4060D, Natureworks) were added into each NPs dispersion under vigorous stirring at room temperature until full dissolving. In this way, three coating solutions were prepared, in concentrations of $0.5 \mathrm{wt} \%, 1 \mathrm{wt} \%$ and $3 \mathrm{wt} \%$ (NP over PLA in dry solids weight).

A white bleached kraft paper (basis weight $106 \mathrm{~g} / \mathrm{m}^{2}$, ash content $7.7 \%$, top side sized) was used as substrate for coating. The coating was done on the sized side.

Coating was carried out on a lab film applicator (Elcometer 4340) using a smooth bar for depositing 50 micron wet film onto the substrate. After coating, the samples were allowed to dry overnight at room temperature. The structure of the final packaging material is illustrated in Figure 31. Sample identification and description is summarised in Table 5 .

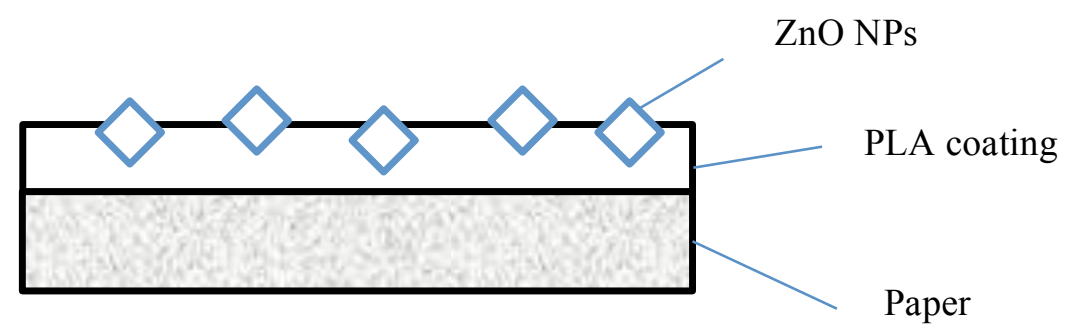

Figure 31. The packaging material's structure. 
Table 5. Sample identification and sample description.

\begin{tabular}{|l|l|}
\hline Sample identification & Sample description \\
\hline Control/Substrate & Base paper coated with pristine PLA \\
\hline $0.5 \%-\mathrm{NP}$ & Substrate coated with $0.5 \mathrm{wt} \% \mathrm{ZnO}-\mathrm{PLA}$ composite \\
\hline $1 \%-\mathrm{NP}$ & Substrate coated with $1 \mathrm{wt} \% \mathrm{ZnO-PLA} \mathrm{composite}$ \\
\hline $3 \%-\mathrm{NP}$ & Substrate coated with $3 \mathrm{wt} \%$ ZnO-PLA composite \\
\hline
\end{tabular}

\subsubsection{Material characterization}

\subsubsection{Nanoparticle analysis by TGA}

The NPs are surface coated with organosilane that serves as coupling/dispersing agent to improve the agent dispersibility. The amount of surface coating was determined with TGA (Thermogravimetric Analysis, measurement carried out with TGA Q5000, TA). $7.36 \mathrm{mg} \mathrm{ZnO}$ NPs were loaded in a platinum sample holder. The temperature program was set as following: hold the temperature at $80{ }^{\circ} \mathrm{C}$ for 10 min, then increase it to $600{ }^{\circ} \mathrm{C}$ at a rate of $20{ }^{\circ} \mathrm{C} / \mathrm{min}$, and after that, hold it at 600 ${ }^{\circ} \mathrm{C}$ for $10 \mathrm{~min}$. Nitrogen gas of flow rate $25 \mathrm{~mL} / \mathrm{min}$ was used to purge the sample atmosphere.

\subsubsection{SEM of coating surface}

The morphology of the coated material and the NP distribution were examined with SEM (Scanning Electron Microscopy). Prior to analysis, the samples were coated with a thin layer of carbon, $15 \mathrm{~nm}$ in thickness (sputter coating carried out with Q150T ES, Quorum). The images were captured with a SEM system (Quanta 650, FEI) equipped with detectors of secondary electrons and backscattered electrons. The presence and distribution of ZnO NPs were further confirmed with EDX (Energy Dispersive X-ray spectroscopy, supplied by X-MAX, Oxford Instrument, coupled with the SEM).

\subsubsection{Antimicrobial assay}

The sample's antimicrobial activity was assessed with JIS Z 2801, which is widely used for evaluating the antimicrobial activity of non-porous surfaces or materials, 
e.g. plastic. In brief, the treated and control samples were cut into squares $5 \times 5 \mathrm{~cm}$, the coated side was inoculated with $0.4 \mathrm{~mL}$ inoculum (S. aureus $1.1 \mathrm{E} 6 \mathrm{CFU} / \mathrm{mL}$, E.coli 8.4E5 CFU/mL), covered with a piece of clear film $4 \times 4 \mathrm{~cm}$ (cleaned with ethanol before use), and placed in a covered petri dish. The samples were incubated at $35^{\circ} \mathrm{C}$ and $\mathrm{RH} \geq 90 \%$ for $24 \mathrm{~h}$. Afterwards, the samples were washed with $50 \mathrm{~mL}$ neutralizing solution (recipe: $34 \mathrm{~g}$ neutralizing broth base in $1 \mathrm{~L}$ distilled water with $5 \mathrm{~mL}$ Polysorbate 80, boil and autoclaved) with a stomacher (BagMixer, Interscience). The serial dilutions of the rinse liquid were plated on agar plate using an automatic plater (easySpiral, Interscience) to enumerate the viable cells in CFU (Colony Forming Unit). Controls at $0 \mathrm{~h}$ and $24 \mathrm{~h}$ of inoculation were used and denoted as $\mathrm{C} 0$ and $\mathrm{C} 24$, respectively.

Each sample was tested in triplicate (two CFU readings per assay). Data were presented as mean \pm standard deviation. The differences between the samples (the effect of NP presence and NP loading) were evaluated with one-way analysis of variance (ANOVA, StatPlus:mac). The difference was considered statistically significant when $p$ value $<0.05$.

Log Reduction (also called activity value) is an indicator to describe a material's antimicrobial activity. As shown in Equation 12, it is calculated as the difference between the number of viable cells in the control $\left(\log C F U_{\text {control24h }}\right)$ and in the treated sample ( $\left.\log \mathrm{CFU}_{\text {treated } 24 \mathrm{~h}}\right)$ after $24 \mathrm{~h}$ inoculation.

$$
\log \text { Reduction }=\log \mathrm{CFU}_{\text {control } 24 \mathrm{~h}}-\log \mathrm{CFU}_{\text {treated 24h }}
$$

\subsection{RESULTS AND DISCUSSIONS}

Good dispersion of NPs in the polymer matrix influences the final material's antimicrobial performance. NPs have a strong tendency to agglomerate, so it is essential to apply the de-agglomeration treatment. The de-agglomeration protocol used in this study is established by testing with different treatment methods (e.g. ultrasonic tip and high speed rotor-stator dispersion tool) and treatment times. The improvement on particle size distribution is monitored with a laser diffraction device. This part of result is not reported in this article. Besides, as the PLA pellets dissolve in the solvent, the solution viscosity increases, which helps to retard the NPs' re-agglomeration.

\subsubsection{TGA}

The weight loss behaviour of the NPs is shown in Figure 32. The isothermal segment at $80{ }^{\circ} \mathrm{C}$ for $10 \mathrm{~min}$ is to dry the NPs' moisture. After that, with the 
temperature increasing, in total $1.24 \%$ weight loss was observed (the green curve), which corresponds to the thermal degradation of the organosilane coating.

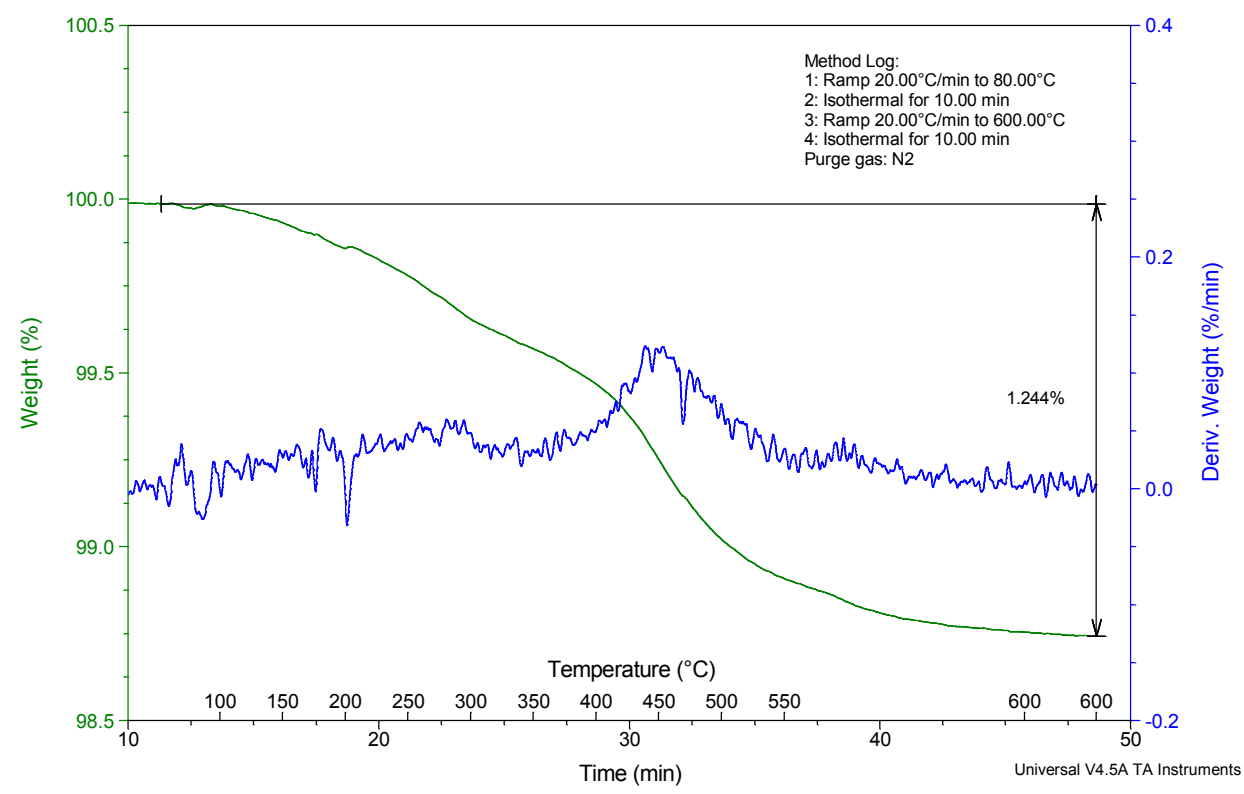

Figure 32. Weight loss (green) and derivative weight loss (blue) of $\mathrm{ZnO}$ nanoparticles.

The peak at the derivative curve (the blue curve) centres at $450{ }^{\circ} \mathrm{C}$, and covers a broad temperature range from 200 to $550{ }^{\circ} \mathrm{C}$. In practical industrial production, extrusion coating is widely used. This suggests that the organosilane coated on NPs is able to sustain the PLA melt-extrusion temperature, which is around $200{ }^{\circ} \mathrm{C}$ [15]. However, in this study we used solvent casting method for coating. The material produced with this method is suitable to study the material's antimicrobial property.

\subsubsection{SEM-EDX}

Representative SEM images were taken from each sample (see Figure 33). Note that the images are presented in pairs as they were captured at the same view spot but generated with different detectors: secondary electrons gives more information about the sample's morphology (e.g. image a), while backscattered electrons contrast the material's composition (e.g. images a'). 

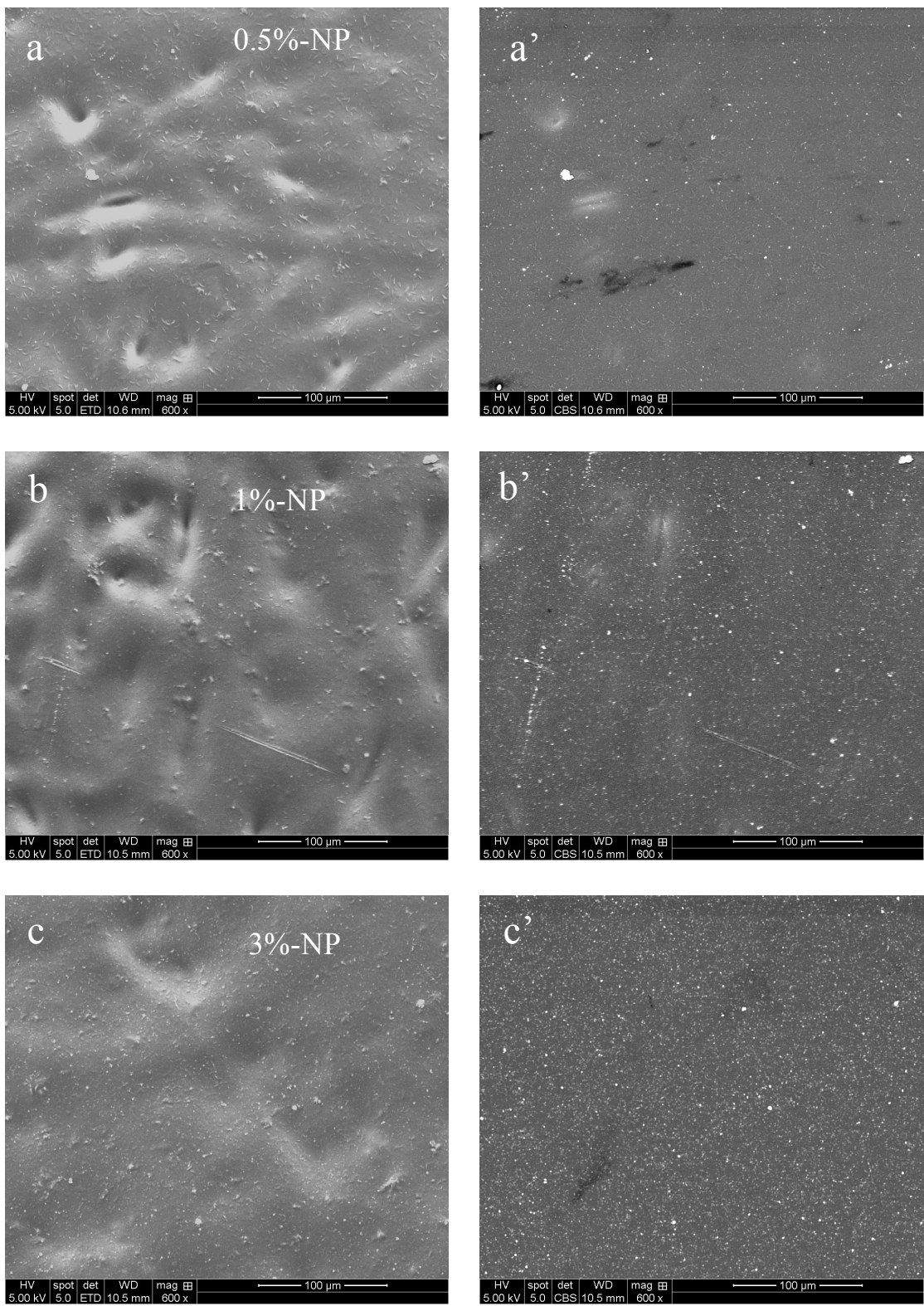

Figure 33. SEM images of the coated samples: images are put in pairs (e.g. a and a') for they were probed at the same spot but generated by different detectors: secondary electrons ( $a, b$ and c) and backscattered electrons (a', b' and c'). 
In an overview, the paper surface was well covered by the coating, showing good smoothness and absence of surface pores. This is important for the following antimicrobial test with the standard JIS Z 2801. Moreover, the NPs were homogenously distributed, which is more evident in the backscattered images (small white dots); on the other hand, few NP aggregates persisted in the coating (bigger white dots). Clearly, as the NP loading increases, more NPs became present on the surface, and thus stronger antimicrobial activity from the material can be expected.

EDX was carried out with the sample $1 \%-\mathrm{NP}$, and the element distribution is depicted in a 2D map (see Figure 34). It shows that zinc is homogenously distributed over the sample surface, which provides additional support to the observation in Figure 33 b'. The presence of the elements is confirmed with a spectrum by summing the signal from the probed area. The spike of zinc is identified. Besides, as the coating is PLA-based and the sample is carbon coated, there are spikes of carbon and oxygen. 

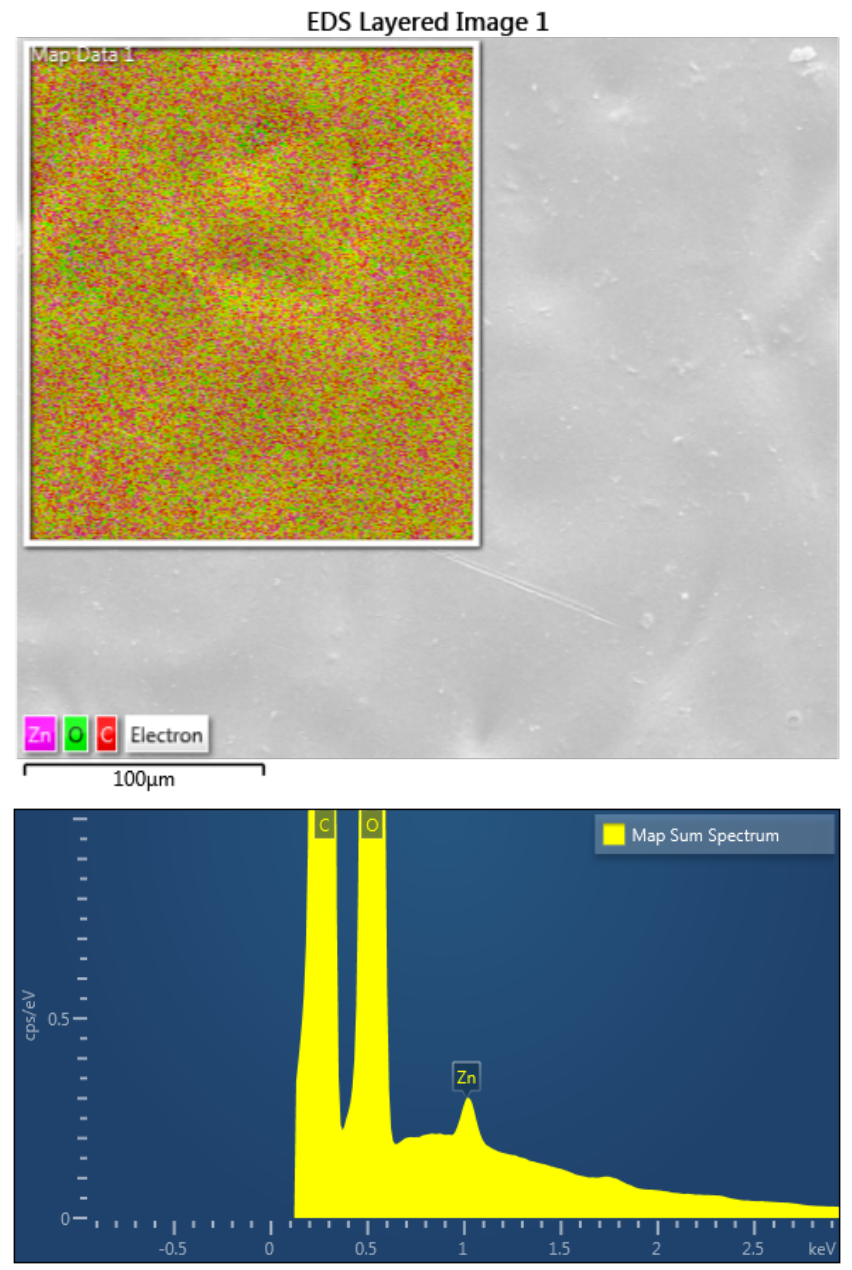

Figure 34. EDX analysis for identifying the elements and their 2D distribution over the surface of sample $1 \%$-NP.

\subsubsection{Antimicrobial activity}

The susceptibility assay of $S$. aureus (Gram-positive) with respect to the active materials is shown in Figure 35. For the convenience of comparison, the bacterial concentration of the control at $0 \mathrm{~h}$ is used as baseline. As expected, the susceptibility of $S$. aureus follows the NP concentration - higher concentration gives a stronger antimicrobial effect. If translated into $\log$ reduction, this corresponds to $1.17,1.68$, and 5.17 . A log reduction greater than 2 suggests the killing efficacy is greater than $99 \%$, and accordingly the material can be described 
as "antimicrobial" $[13,16]$. Thus, in this sense, only the sample 3\%-NP can be said antimicrobial against $S$. aureus.

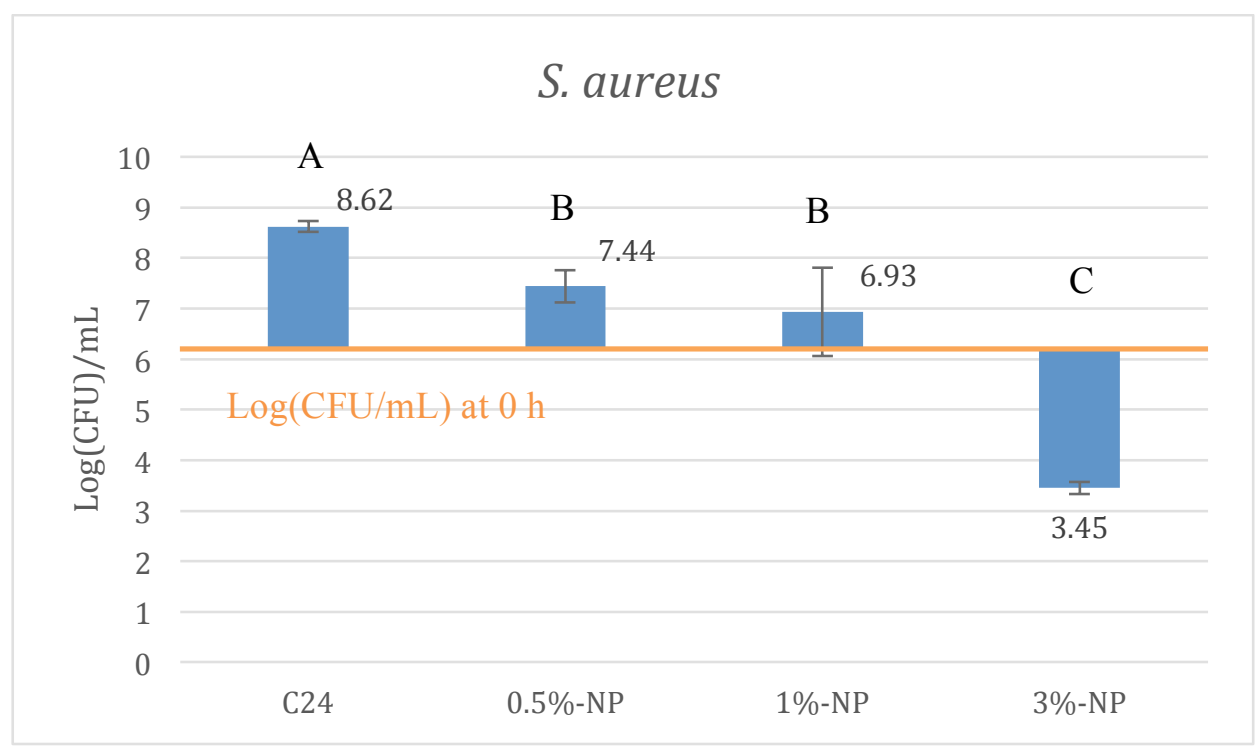

Figure 35. Antimicrobial assay against $S$. aureus. The number of viable cells after $24 \mathrm{~h}$ inoculation is reported in CFU (Colony Forming Unit). The bacterial concentration at $0 \mathrm{~h}$ is used as baseline (the horizontal line). Error bar represents the standard deviation from three replicates. Different letters over the bar end $(A, B$, and $C)$ indicate significant differences between the samples. $3.4 \log (\mathrm{CFU} / \mathrm{mL})$ is the detection limit of the agar plating method used. Refer to Table 5 for sample identification description.

This result is comparable with those reported in previous publications: for example in the study of Martins, et al. [1], starch based coating containing $1.37 \mathrm{wt} \% \mathrm{ZnO}$ NPs induced $1.6 \log$ reduction against S. aureus; in a similar study [13], $3 \mathrm{wt} \% \mathrm{NP}$ loading achieved $4.3 \mathrm{log}$ reduction against the same bacterial strain; whereas in the work of Pantani et al. [16], it took longer time (7 days instead of $24 \mathrm{~h}$ ) to reach a satisfactory log reduction.

The discrepancy between the results from different sources can be attributed to several factors. The NP grade is one of them, which concerns about NP attributes such as size/particle size distribution, shape/morphology, with or without surface modification, etc. [3]. As reported in the relevant research, $\mathrm{ZnO} \mathrm{NP}$ in certain morphology has stronger activity than the others [17]. Additionally, the smaller the particle size the stronger the antimicrobial efficacy [18]. As a result of this, issues such as the de-agglomeration treatment before incorporating NPs into the host 
material and how well the NPs are dispersed within the host polymer all have impacts on the final material's antimicrobial performance.

As shown in Figure 36, stronger inhibitory effect was observed with all the NPenabled samples against E. coli (Gram-negative), which induced 3.14, 3.55 and $4.29 \log$ reduction, respectively, in proportion with their NP loadings. Note that the detection limit of the agar plating method used is $3.4 \log (\mathrm{CFU} / \mathrm{mL})$. Clearly, this assay provides evidence that $E$. coli (Gram-negative) is more susceptible to $\mathrm{ZnO}$ NPs than $S$. aureus (Gram-positive).

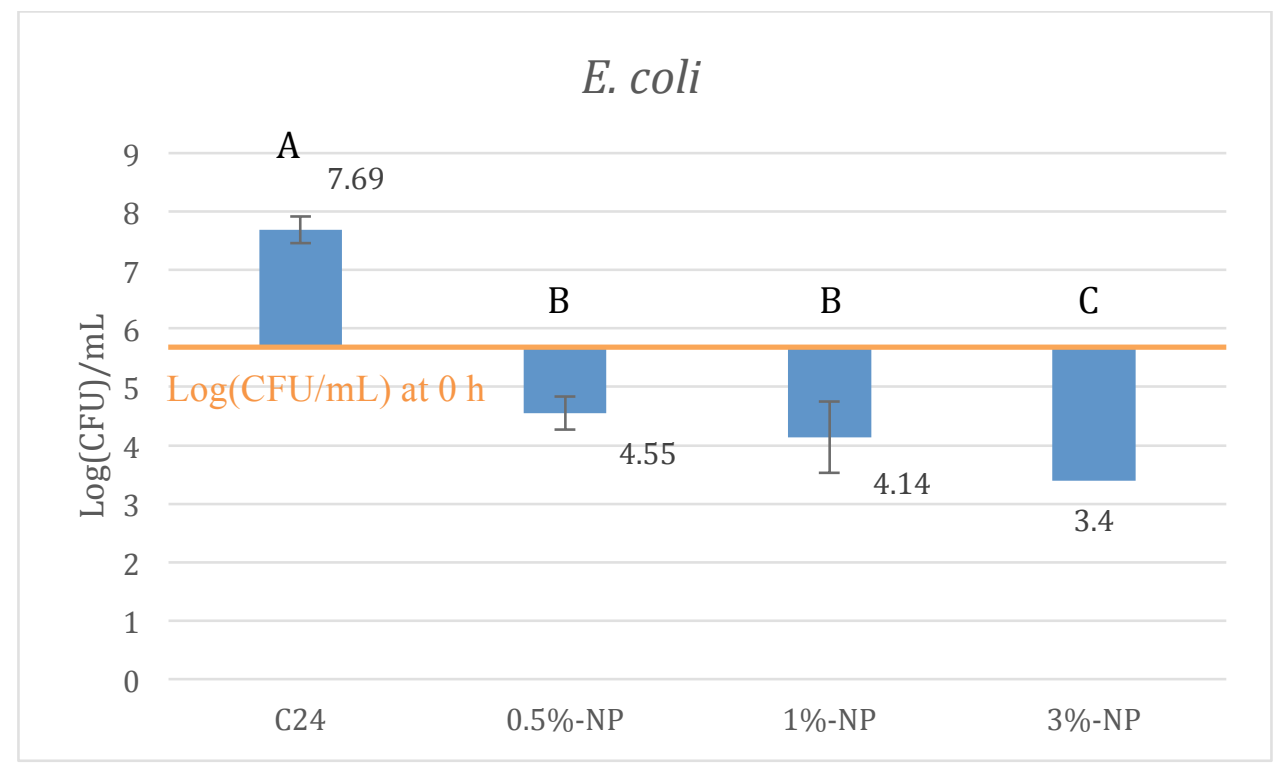

Figure 36. Antimicrobial assay against $E$. coli. The number of viable cells after $24 \mathrm{~h}$ inoculation is reported in CFU (Colony Forming Unit). The bacterial concentration at $\mathrm{O} h$ is used as baseline (the horizontal line). Error bar represents the standard deviation from three replicates.

Different letters over the bar end (A, B, and C) indicate significant differences between the samples. $3.4 \log (\mathrm{CFU} / \mathrm{mL})$ is the detection limit of the agar plating method used. Refer to Table 5 for sample identification description.

\subsubsection{Antimicrobial action mechanism and the effect of testing methods}

Our test indicates that E. coli (Gram-negative) was less resistant to ZnO NPs than $S$. aureus (Gram-positive). However, it is generally accepted that the Gram-negative species are more resistant to this agent than the Gram-positive one for the following reasons [19]: 
1) The Gram-negative bacteria have an additional outer membrane as compared to the Gram-positive one.

2) The membrane of $S$. aureus is less negatively charged than that of E. coli. As a result of this, $S$. aureus has stronger interactions with the negatively charged ROS (Reactive Oxygen Species), which is associated with one of the action mechanisms of $\mathrm{ZnO}$ NPs.

On the other hand, the antimicrobial activity of ZnO NPs has been assessed in different studies, and the results seem to lack consistency. For the convenience of comparison, a table is compiled (see Table 6). Key information includes the agent characteristics, testing method and target bacteria used in each test (Gram-positive and Gram-negative). Particular interest is placed on the susceptibility of the microorganisms to $\mathrm{ZnO}$ NPs. 


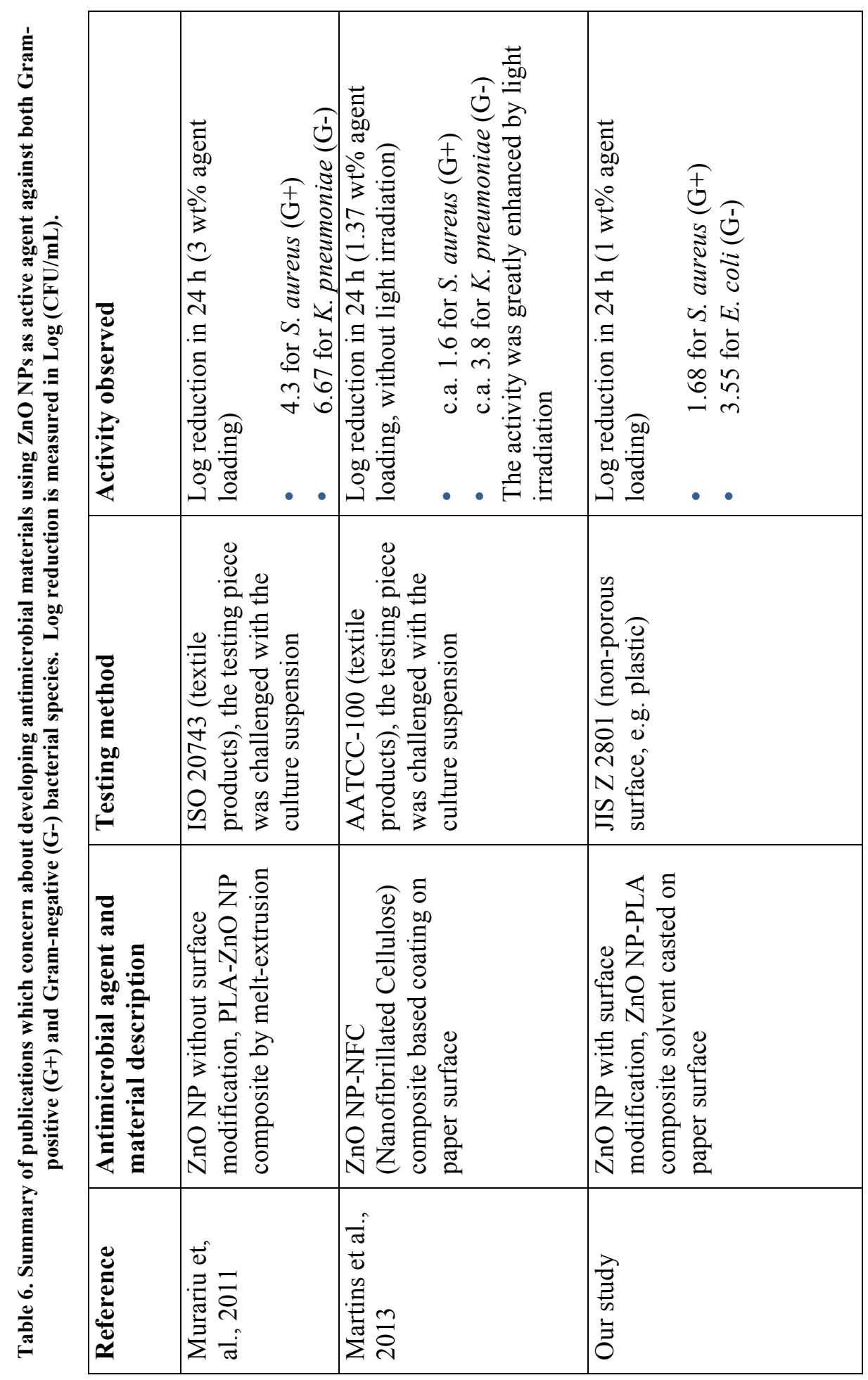




\begin{tabular}{|c|c|c|c|c|}
\hline 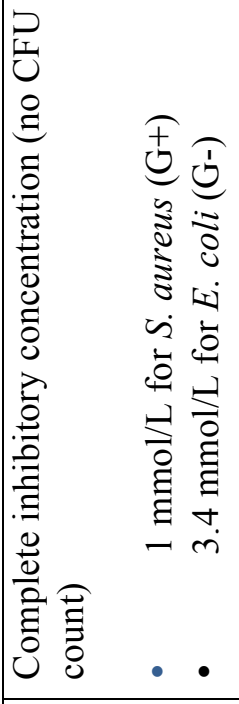 & 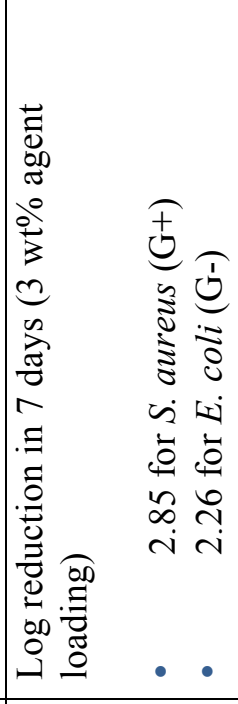 & 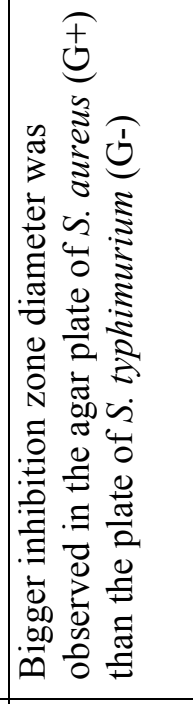 & 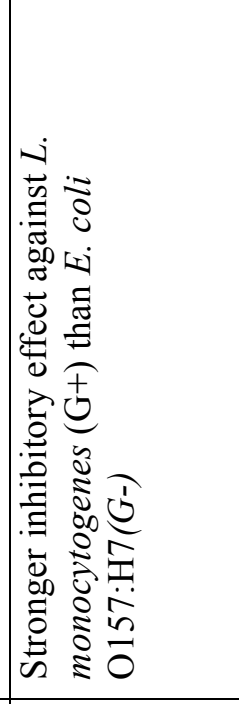 & 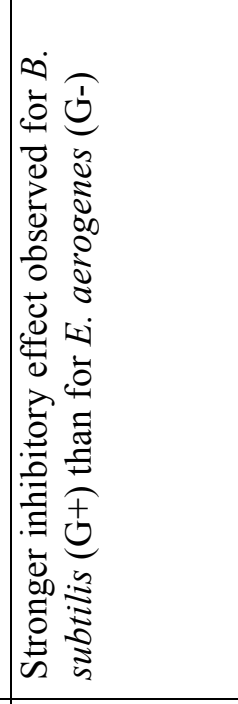 \\
\hline 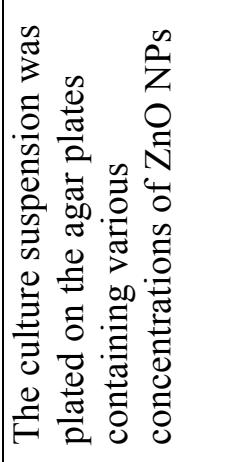 & 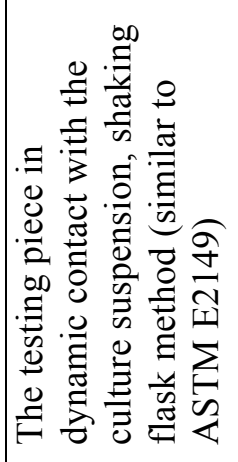 & 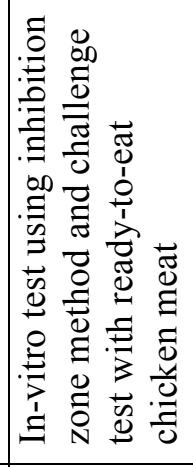 & 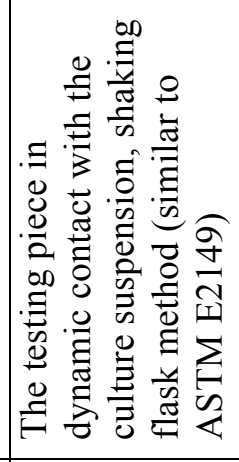 & 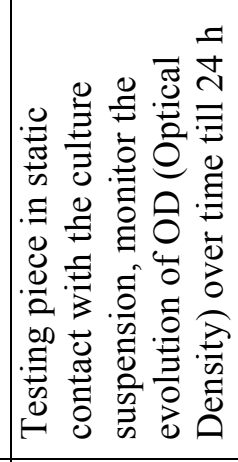 \\
\hline 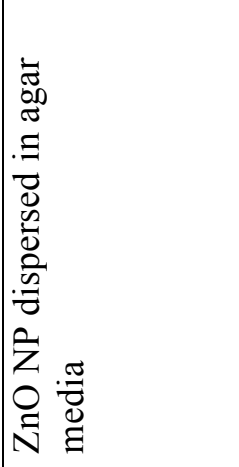 & 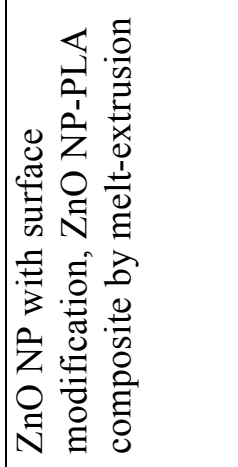 & 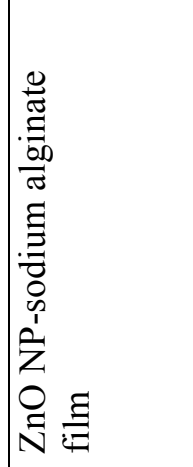 & 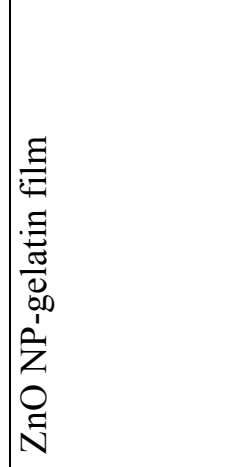 & 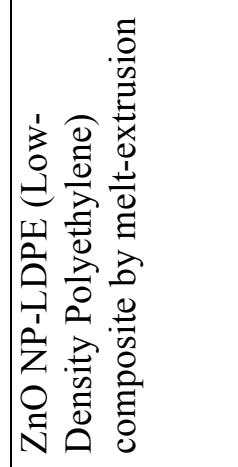 \\
\hline 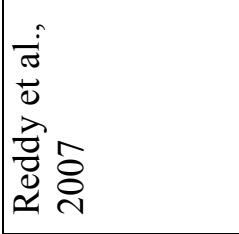 & 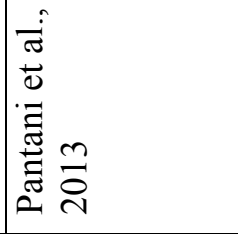 & 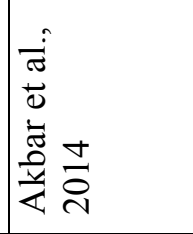 & 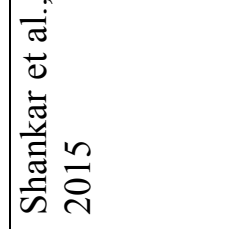 & 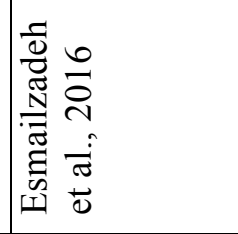 \\
\hline
\end{tabular}


As reported in these works $[1,13], \mathrm{ZnO}$ NPs showed a stronger inhibiting effect against K. pneumoniae (Gram-negative) than S. aureus (Gram-positive), which is in good agreement with our results. On the other hand, opposite results are reported: the $\log$ reduction for $S$. aureus was found to be slightly greater than $E$. coli [16]. Stronger inhibitory effect was observed against L. monocytogenes $\left(\mathrm{G}^{+}\right)$than E. coli O157:H7 (G-) [20]; In another study [17], the evolution of OD (Optical Density) versus time suggests that Bacillus subtilis (Gram-positive) was more susceptible to the $\mathrm{ZnO}$ NP-enabled material than Enterobacter aerogenes (Gram-negative). Similarly, the complete inhibitory concentration (no CFU count in the agar plate) was found to be $3.4 \mathrm{mmol} / \mathrm{L}$ for $E$. coli, which was 3 times of that for $S$. aureus [11].

To explain the inconsistency of the results, one needs to look at the action mechanisms of ZnO NP. Basically, ZnO NP is more complex than other types of agents since it has multiple action mechanisms. As concluded in various publications, $[1,4,9,19-21]$, these action mechanisms include

a) leaching of metallic ions (i.e. $\mathrm{Zn}^{2+}$ ions),

b) direct contact between the NP surface and the microorganism's cell membrane,

c) and photocatalytic production of ROS (Reactive Oxygen Species) with the aid of external conditions.

Very often, a stronger activity can be achieved when several different action mechanisms work together, which is termed as synergistic effect $[8,19,22]$. Nonetheless, for the case of $\mathrm{ZnO} \mathrm{NP}$ it is not known which mechanism plays a greater role than the others [20]. Besides, it is necessary to provide suitable conditions to activate these mechanisms. In this sense, a proper leaching medium, direct contact between the agent and the microorganism, and proper external conditions such as moisture and light irradiation are essential for activating the respective mechanisms.

Antimicrobial surfaces incorporating ZnO NPs appear in various research fields, e.g. textile products, biomedical devices, and food packaging. Therefore, various testing methods are used to meet the requirement from different industries. However, some testing methods may only activate part of the action mechanisms of the agent, and this may lead to the inconsistency in the results.

\section{Light irradiation}

It is known that the material's antimicrobial activity can be greatly enhanced by exposing to light irradiation [1], which is attributed to the ROS (Reactive Oxygen 
Species) generated in the photocatalytic reactions with the aid of $\mathrm{ZnO}$ NPs. Therefore, as shown in the study of Pantani, et al. [16] and Esmailzadeh, et al. [17], this action mechanism is activated and the generated ROS would favour the interactions with $S$. aureus than $E$. coli due to the cell membrane polarity [19]. If this mechanism dominates in the assay, it will lead to the conclusion that $S$. aureus is more susceptible to this agent. While for other testing methods, e.g. JIS Z2801, ISO 20743 and AATCC-100, the factor of light irradiation is not particularly stressed and the assay is often carried out in a dark incubator, and accordingly the action mechanism of ROS may be depressed. In this case, a different conclusion may be drawn.

\section{Leaching media}

In our study, before testing with the standard JIS Z 2801, the same material was tested with ASTM E2180, a method that allows full contact of bacterial cultures with the test surfaces with the aid of agar slurry (recipe: $0.85 \mathrm{~g} \mathrm{NaCl}$ and $0.3 \mathrm{~g}$ agar-agar in $100 \mathrm{~mL}$ deionised water). However, after $24 \mathrm{~h}$ contact time no antimicrobial effect was observed. The possible reason is that as the bacterial culture is retained within the slurry (gel like under the incubation condition), which is not a proper medium to facilitate the leaching of $\mathrm{Zn}^{2+}$ ions. Moreover, the gel structure lacks fluid movement, restricting the access to the NPs.

The inhibition zone method has been used in some studies to assess the material's activity $[9,23]$. Inhibition zone is a good indicator of the leaching of $\mathrm{Zn}^{2+}$ ions/the diffusion of ROS, which is sensitive to the moisture content within the surrounding environment. However, it overlooks the mechanisms of NPs in direct contact with the microorganisms. And therefore, in some cases, it may lead to a wrong conclusion.

\section{Food types and packaging forms}

Furthermore, the discussion of action mechanisms could provide useful tips for the selection of food and packaging forms for the application of such active packaging materials. As shown in the example of Akbar, et al., [9] satisfactory inhibitory effect is achieved when the active material is allowed to be in tight contact with the food, used as sausage wrap. The same can be seen from the example of agent in direct contact with a liquid food [8]. On the contrary, in another example [6], the packaging setup prevents the agent from direct contact with the melon, and the action mechanism only functions by leaching of silver ion into the melon juice imbibed into the absorbent pad, which gives weak activity (less than $1 \log$ reduction in mesophilic and psychrotrophic counts). 


\subsubsection{Regulatory issues and market prospect}

Under the current EU regulation framework, active packaging material shall comply with the general requirements for food contact materials (EC 1935/2004) as well as the specific requirements on the use of active and intelligent materials (EC 450/2009), including nanomaterials [24]. In accordance with the work of Reig, et al. [25], to date only three nanomaterials are authorised by EFSA to be used for food contact applications. They are titanium nitride (TiN), carbon black (C) and silica $\left(\mathrm{SiO}_{2}\right)$, and all of them are to be used as polymer production aids (no active properties). The only metallic-based nanoparticles, TiN, according to the EFSA scientific opinion [26], is only to be used in PET (Polyethylene Terephthalate) up to $20 \mathrm{mg} / \mathrm{kg}$ (i.e. loading $20 \mathrm{ppm}$ ), and within the PET matrix, both primary particles $(20 \mathrm{~nm})$ and agglomerates $(100-500 \mathrm{~nm})$ coexist. The scientific panel concluded that there is no safety concern for consumers under intended use conditions (for all types of foodstuffs and up to hot filling temperature) [26].

From this case, one can infer the authority's attitude towards nanomaterials. Firstly, a case-by-case approach. This means if this application is aimed for PET, all the tests will concentrate on PET, and once approved, it is regulated only to be used in PET below a specific loading, which has been verified by the test. Secondly, the authority is very cautious with nanomaterials. Apart from the experimental studies using food simulants, they also carried out theoretical analysis based on diffusion models [27].

In our case, the ZnO-PLA composite coating was shown to be effective in inactivating the selected bacterial strains. However, for successful food contact application, another important issue is migration. In regard to this point, EFSA carried out specific migration test on a similar composite material (the same agent but incorporated in LDPE film) and the panel expressed their worries on zinc migration for high concentration of $\mathrm{Zn}^{2+}$ was detected in the food simulant $\mathrm{B}$, acetic acid 3\% (w/v) [10]. This is attributed to the enhanced solubility of the NP when the particle size is reduced to nano-range. Thus, in order to get this agent authorised, the key lies in suppressing the dissolution of NPs in acid media and at the same time maintaining other desired properties, e.g. antimicrobial activity and UVblocking property. This implies challenges for future research.

Moreover, in accordance with the regulation of EFSA, the organosilane coated on the NP surface should also respect the SML (Specific Migration Limit) [10]. For the case of [3-(methacryloxy)propyl] trimethoxysilane, the SML is $0.05 \mathrm{mg} / \mathrm{kg}$.

Besides the regulator and policy maker, other actors along the value chain, e.g. food producer, brand owner, packaging producer, and consumers, their perception and 
acceptance to this material/technology also matters [28, 29]. If one examines the TiN case closely, it can be noticed that the agent loading is far below the commonly accepted range for nanomaterials, shifting from pph (part per hundred) to ppm (part per million), but in the meanwhile such low loading enables over $10{ }^{\circ} \mathrm{C}$ reheat temperature improvement in PET blow moulding production [30], which means significant saving of energy and cost for the packaging producers.

\subsection{CONCLUSIONS}

In this study, $\mathrm{ZnO}$ NPs were incorporated in PLA coating for antimicrobial packaging application. The NPs were surface coated with $1.24 \mathrm{wt} \%$ organosilane, which is thermally stable in the PLA extrusion temperature range as suggested by the TGA analysis. The packaging material was characterised with SEM and the NPs were found to be homogenously distributed across the surface thanks to the surface modification, despite some aggregated persisted. Antimicrobial assay indicates that the incorporation of $\mathrm{ZnO} \mathrm{NPs}$ rendered the material surface antimicrobial against $S$. aureus and E. coli. In addition, the agent was found to be more potent against $E$. coli, giving $3.14 \mathrm{log}$ reduction for $0.5 \mathrm{wt} \%$ agent loading. Comparison was made between the results reported from different sources, and the lack of consistency is attributed to the different testing methods used. $\mathrm{ZnO} \mathrm{NP}$ has multiple action mechanisms of $\mathrm{ZnO} \mathrm{NP}$ and different testing methods may only activate part of the action mechanisms.

To introduce a novel packaging material to market, besides the technical performance, other important factors should be considered, for example the regulatory issues regarding nanomaterials for food contact application. The regulator (EFSA) is adapting a case-by-case approach towards nanomaterials. To get the agent authorised, there are still some challenges lying ahead, e.g. control the zinc migration both in nano-form and in ionic-form.

There are constraints in this study. For future research, the following improvements can be considered. Firstly, the material can be produced with extrusion coating, which is more close to the industrial application. Secondly, apart from the in vitro test, the material's antimicrobial performance should be validated by testing with real food. 


\subsection{REFERENCES}

1. Martins NC, Freire CS, Neto CP, Silvestre AJ, Causio J, Baldi G, Sadocco $\mathrm{P}$, Trindade T. Antibacterial paper based on composite coatings of nanofibrillated cellulose and $\mathrm{ZnO}$. Colloids and Surfaces A: Physicochemical and Engineering Aspects 2013; 417, pp. 111-119.

2. Llorens A, Lloret E, Picouet PA, Trbojevich R, Fernandez A. Metallicbased micro and nanocomposites in food contact materials and active food packaging. Trends in Food Science \& Technology 2012; 24(1), pp. 19-29.

3. Duncan TV. Applications of nanotechnology in food packaging and food safety: Barrier materials, antimicrobials and sensors. Journal of colloid and interface science 2011; 363(1), pp. 1-24.

4. Liu Y, He L, Mustapha A, Li H, Hu Z, Lin M. Antibacterial activities of zinc oxide nanoparticles against Escherichia coli O157: H7. Journal of applied microbiology 2009; 107(4), pp. 1193-1201.

5. Maneerat $\mathrm{C}$, Hayata $\mathrm{Y}$. Antifungal activity of $\mathrm{TiO}_{2}$ photocatalysis against Penicillium expansum in vitro and in fruit tests. International journal of food microbiology 2006; 107(2), pp. 99-103.

6. Fernández A, Picouet P, Lloret E. Cellulose-silver nanoparticle hybrid materials to control spoilage-related microflora in absorbent pads located in trays of fresh-cut melon. International Journal of Food Microbiology 2010; 142(1), pp. 222-228.

7. Li X, Xing Y, Jiang Y, Ding Y, Li W. Antimicrobial activities of ZnO powdererals to control spoilage-related microflora. International journal of food science \& technology 2009; 44(11), pp. 2161-2168.

8. Jin T, Gurtler J. Inactivation of Salmonella in liquid egg albumen by antimicrobial bottle coatings infused with allyl isothiocyanate, nisin and zinc oxide nanoparticles. Journal of applied microbiology 2011; 110(3), pp. 704-712.

9. Akbar A, Anal AK. Zinc oxide nanoparticles loaded active packaging, a challenge study against Salmonella typhimurium and Staphylococcus aureus in ready-to-eat poultry meat. Food Control 2014; 38, pp. 88-95.

10. EFSA CEF Panel on Food Contact Materials E, Flavourings and Processing Aids. Scientific Opinion on the safety evaluation of the substance zinc oxide, nanoparticles, uncoated and coated with [3-(methacryloxy)propyl] trimethoxysilane, for use in food contact materials. EFSA Journal 2015; 13(4), pp. 4063-4072, DOI: doi:10.2903/j.efsa.2015.4063.

11. Reddy KM, Feris K, Bell J, Wingett DG, Hanley C, Punnoose A. Selective toxicity of zinc oxide nanoparticles to prokaryotic and eukaryotic systems. Applied physics letters 2007; 90(21), pp. 213902. 
12. Therias S, Larché J-F, Bussière P-O, Gardette J-L, Murariu M, Dubois P. Photochemical behavior of polylactide $/ \mathrm{ZnO}$ nanocomposite films. Biomacromolecules 2012; 13(10), pp. 3283-3291.

13. Murariu M, Doumbia A, Bonnaud L, Dechief AL, Paint Y, Ferreira M, Campagne C, Devaux E, Dubois P. High-performance polylactide/ZnO nanocomposites designed for films and fibers with special end-use properties. Biomacromolecules 2011; 12(5), pp. 1762-1771.

14. El-Feky OM, Hassan EA, Fadel SM, Hassan ML. Use of $\mathrm{ZnO}$ nanoparticles for protecting oil paintings on paper support against dirt, fungal attack, and UV aging. Journal of Cultural Heritage 2014; 15(2), pp. 165-172.

15. Jordá-Beneyto M, Alonso J, Salas J, Gallur M, Aucejo S, Clegg F, Breen C. Processed biopolymer films filled with modified montmorillonite for food packaging applications. in Proc. of the Polymer Processing Society 24th Annual Meeting-PPS-24. 2008.

16. Pantani R, Gorrasi G, Vigliotta G, Murariu M, Dubois P. PLA-ZnO nanocomposite films: Water vapor barrier properties and specific end-use characteristics. European Polymer Journal 2013; 49(11), pp. 3471-3482.

17. Esmailzadeh H, Sangpour P, Shahraz F, Hejazi J, Khaksar R. Effect of nanocomposite packaging containing $\mathrm{ZnO}$ on growth of Bacillus subtilis and Enterobacter aerogenes. Materials Science and Engineering: $C$ 2016; 58, pp. 1058-1063.

18. Yamamoto O. Influence of particle size on the antibacterial activity of zinc oxide. International Journal of Inorganic Materials 2001; 3(7), pp. 643646.

19. Espitia PJP, Soares NdFF, dos Reis Coimbra JS, de Andrade NJ, Cruz RS, Medeiros EAA. Zinc oxide nanoparticles: synthesis, antimicrobial activity and food packaging applications. Food and Bioprocess Technology 2012; 5(5), pp. 1447-1464.

20. Shankar S, Teng X, Li G, Rhim J-W. Preparation, characterization, and antimicrobial activity of gelatin/ $\mathrm{ZnO}$ nanocomposite films. Food Hydrocolloids 2015; 45, pp. 264-271.

21. Zhu X, Wang J, Zhang X, Chang Y, Chen Y. The impact of $\mathrm{ZnO}$ nanoparticle aggregates on the embryonic development of zebrafish (Danio rerio). Nanotechnology 2009; 20(19), pp. 195103.

22. Chen S, Guo Y, Zhong H, Chen S, Li J, Ge Z, Tang J. Synergistic antibacterial mechanism and coating application of copper/titanium dioxide nanoparticles. Chemical Engineering Journal 2014; 256, pp. 238-246.

23. Lian Z, Zhang Y, Zhao Y. Nano-TiO 2 particles and high hydrostatic pressure treatment for improving functionality of polyvinyl alcohol and chitosan composite films and nano-TiO 2 migration from film matrix in food simulants. Innovative Food Science \& Emerging Technologies 2015. 
24. Rossi M, Cubadda F, Dini L, Terranova M, Aureli F, Sorbo A, Passeri D. Scientific basis of nanotechnology, implications for the food sector and future trends. Trends in Food Science \& Technology 2014; 40(2), pp. 127148.

25. Reig CS, Lopez AD, Ramos MH, Ballester VAC. Nanomaterials: a map for their selection in food packaging applications. Packaging Technology and Science 2014; 27(11), pp. 839-866.

26. EFSA CEF Panel on Food Contact Materials E, Flavourings and Processing Aids. Scientific Opinion on the safety evaluation of the substance, titanium nitride, nanoparticles, for use in food contact materials. EFSA Journal 2012; 10(3), pp. 2641-2649, DOI: 10.2903/j.efsa.2012.2641.

27. EFSA CEF Panel on food contact materials e, flavourings and processing aids. 21st list of substances for food contact materials. EFSA Journal 2008, pp. 888-890.

28. Siegrist M, Stampfli N, Kastenholz H, Keller C. Perceived risks and perceived benefits of different nanotechnology foods and nanotechnology food packaging. Appetite 2008; 51(2), pp. 283-290.

29. Bieberstein A, Roosen J, Marette S, Blanchemanche S, Vandermoere F. Consumer choices for nano-food and nano-packaging in France and Germany. European review of agricultural economics 2013; 40(1), pp. 7394.

30. Xia Z, Stafford SL, Sims S, Colhoun FL, Polyester polymer and copolymer compositions containing titanium nitride particles, 2008, Patent US7368523 B2. 
4 Paper II. PLA coated paper containing active inorganic nanoparticles: material characterization and fate of nanoparticles in the paper recycling process 


\subsection{INTRODUCTION}

Incorporating Nanoparticles (denoted as NPs) in paper products has recently become a strong innovating point and therefore has attracted many research efforts, including several EU-funded projects. For example, silver nanoparticles (Ag NPs) [1] and zinc oxide nanoparticles ( $\mathrm{ZnO} \mathrm{NPs}$ ) [2] were used as antimicrobial agents in paper coating, which holds potential application in active packaging; in a similar fashion, Ag NP-enabled cellulose absorbent pad was used in the packaging of fresh cut fruit [3]; Manda et al. [4] proposed a sandwich-like structure for producing printing paper using $\mathrm{TiO}_{2}$ NP-based coating layers to shield the unbleached kraft pulp in between, which enables to omit the pulp bleaching stage, and hence reducing the associated consumption of energy and chemicals as well as emissions; in the work of Steward et al. [5], the authors explored the innovation opportunities in using NPs to enhance paper's printability and deinkability.

In the case of paper and paperboard packaging material, recycling is regarded as one of the most favourable options in terms of waste management [6] for its important role in minimising the packaging's environmental impacts [7]. Therefore, when it comes to the nano-enabled paper packaging material, its recyclability shall be retained and not be compromised. However, only very few studies have addressed this issue: for example, a relevant research found that using NFC (Nano Fibrillated Cellulose) to replace part of the synthetic latex in paperboard coating would not cause negative impacts on paper recycling [8]. As reported in a recent publication [9], Ag NP-based ink had some noticeable impacts on the optical properties of the recovered fibres.

Nanomaterial as a new class of material, its safe and sustainable use has raised considerable attention. One major concern is the nanomaterial's toxicity (ecosystem and human health). As the dimension of solid material is reduced below 100 $\mathrm{nm}$, it tends to exhibit enhanced reactivity/activity/toxicity, which is associated with nano-specific physico-chemical properties, such as particle size distribution, particle shape, solubility, surface charge, surface functionalization, etc. [10]. Furthermore, when nanomaterials release to the environment or expose to human, their fate and nano-toxicity strongly depends on the NPs' colloidal behaviour, e.g. the kinetics of transformation, aggregation and degradation, which is a complex mechanism and not yet fully understood [11, 12]. In a relevant study [13] the researchers tracked the emission of the NPs from a building's exterior facades that are coated with NP-containing paint. And they found that $30 \%$ of Ag NPs released after one-year exposure, and these released NPs were in binder attached colloidal form. 
The objective of this study is to track the fate of nanomaterials in the paper recycling process. It will help to identify the critical stages where control measures should be implemented for the safe use of nanomaterials. The packaging material of concern is a PLA (Polylactic Acid) coated paper incorporating ZnO NPs in the coating layer. It is to be used as sandwich wrap or deli wrap to control the microbiological risk.

In the case of antimicrobial packaging application, the material shall comply with the EU regulation EC No 450/2009. The authority is taking a case-by-case approach towards the nano-agent/nano-additive [14]. Agent migration in both nanoform and ionic form is a key issue in successful authorisation [15].

\subsection{MATERIALS AND METHODS}

A white bleached kraft paper (basis weight $106 \mathrm{~g} / \mathrm{m}^{2}$, ash content $7.7 \%$, top side sized) was used as substrate for coating.

\subsubsection{Coating recipe}

PLA pellets (4060D, Natureworks) were dissolved in ethyl acetate under vigorous stirring at room temperature. The final solution had a concentration of $15 \mathrm{wt} . \%$.

$\mathrm{ZnO}$ nanoparticles (Zano® 20 Plus-3) were kindly supplied by Umicore, Belgium. In accordance with the producer's information, the NPs are silane coated (ester functional group) for enhanced dispersibility in polymer. The NPs have an average particle size of $30 \mathrm{~nm}$ [16]. As the NPs were supplied in powder form, first they were dispersed in the solvent: adding $2 \mathrm{~g}$ NPs into $100 \mathrm{~mL}$ ethyl acetate, stirring vigorously for $10 \mathrm{~min}$, and then applying ultrasonic treatment for $5 \mathrm{~min}$ (Sonics, microtip CV 334, $750 \mathrm{w} 20 \mathrm{kHz}$ ) to break up the agglomerates/aggregates. Afterwards, the NPs dispersion was mixed with the PLA solution at the designated loadings, $0.5 \%, 1 \%$ and $3 \%$, NPs over PLA in dry solids weight. The mixtures were subjected to 20 min vigorous stirring before coating.

Coating was carried out on a lab film applicator (Elcometer 4340) using a smooth bar which allows to deposit 50 micron wet film onto the substrate. Coating was applied on the sized side of the paper in order to control the polymer solution penetration. After coating, the samples were dried overnight at room temperature.

The structure of the packaging material is illustrated in Figure 37. 


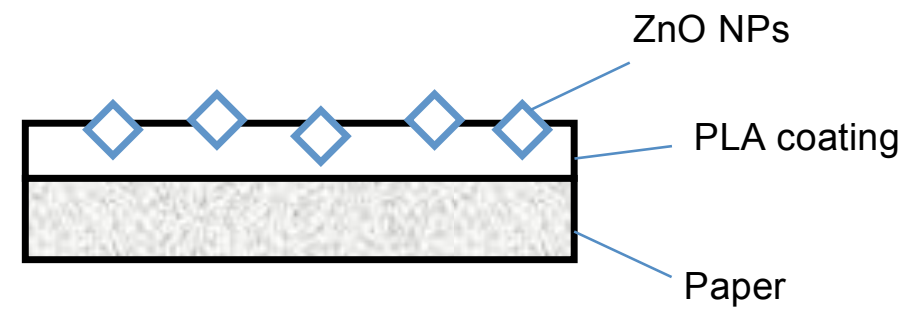

Figure 37. Schematic illustration of the paper packaging material produced.

In total, three different coated samples were produced. Base paper without coating was used as control. Sample identification and description are listed in Table 7.

Table 7. Sample identification and description.

\begin{tabular}{|l|l|}
\hline $\begin{array}{l}\text { Sample } \\
\text { identification }\end{array}$ & Description \\
\hline Blank & Base paper, no coating applied \\
\hline Coat-0.5 & PLA coating containing $0.5 \mathrm{wt} . \% \mathrm{ZnO}$ NPs on base paper \\
\hline Coat-1 & PLA coating containing $1 \mathrm{wt} . \% \mathrm{ZnO} \mathrm{NPs} \mathrm{on} \mathrm{base} \mathrm{paper}$ \\
\hline Coat-3 & PLA coating containing $3 \mathrm{wt} . \% \mathrm{ZnO} \mathrm{NPs} \mathrm{on} \mathrm{base} \mathrm{paper}$ \\
\hline
\end{tabular}

\subsubsection{PLA coated paper characterization}

Before testing, all the samples were conditioned at $23{ }^{\circ} \mathrm{C}, 50 \% \mathrm{RH}$.

Basis weight was determined with an analytical balance (Sartorius, CPA 225D). The measurement was done in triplicate. Data were presented as mean \pm standard deviation.

Sample Coat-3 was selected for the SEM-EDX measurement (Scanning Electron Microscope and Energy Dispersive X-ray spectroscopy). The SEM images were acquired from the gold coated specimen (carried out with Cressington 108 auto), using a field emission scanning electron microscope (MIRA3, Tescan) operating at $15 \mathrm{kV}$ accelerating voltage. The elemental analysis was carried out with an energy 
dispersive X-ray spectroscopy (Quantax EDS, detector Xflash 6/10, Bruker), which is coupled with the SEM instrument.

In order to assess the coating quality, the following tests were carried out according to their respective standards. N.B. for sample Blank, all the measurements were conducted on the sized side.

- Smoothness was measured with a Bendtsen smoothness tester following ISO 8791-2:2013. 10 measurements were made for each sample. Data were presented as mean \pm standard deviation.

- Water absorptiveness was determined with Cobb-60 method (apparatus Acquati Giuseppe). The measurement was done in triplicate following ISO 535:2014.

- Contact angle was measured with an optical instrument (OCA 15EC, DataPhysics) using water as the probe liquid. The images were recorded within 1 min time span, and the measurement was done in duplicate.

- Brightness was measured with a spectrophotometer (UltraScan PRO, HunterLab). 10 measurements were made for each sample.

\subsubsection{Recyclability test}

\subsubsection{Testing protocol}

The testing protocol was based on the Italian method of recyclability of paper-based packaging (ATICELCA MC501-13, Testing of recyclability of paper based packaging. <www.aticelca.it $>$ ). To accommodate our interest in tracking the fate of NPs in paper recycling line, the method was partly modified and the procedure is illustrated in Figure 38. In brief, $25 \mathrm{~g}$ samples were cut into squares, approximately $2 \times 2 \mathrm{~cm}$, fed in a laboratory wet disintegrator (Enrico Toniolo, Italy), pulped with $1.5 \mathrm{~L} 40{ }^{\circ} \mathrm{C}$ tap water for $20 \mathrm{~min}$, following ISO 5263:2004. After that, the pulp suspension was subjected to 7 min Somerville screening (L\&W, Sweden, slits width 150 micron), following a modified procedure deriving from Standard TAPPI T 275 sp-12. All the "rejects" (material separated by the screen) and the "accepts" (fibrous material passing through the screen and possible coating fragments and filler particles) were collected, filtered and oven dried overnight at $105^{\circ} \mathrm{C}$ to obtain the solids weight. 

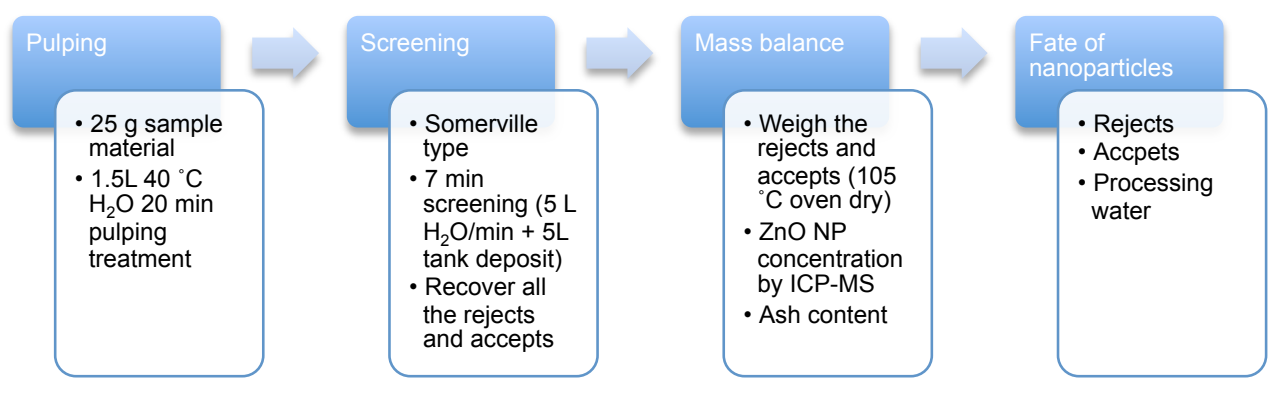

Figure 38. The protocol for the recyclability test: tracking the fate of nanoparticles.

\subsubsection{Materials from the paper recycling test}

For the materials involved in the recycling test, the following tests were carried out:

- ICP-MS (Inductively Coupled Plasma-Mass Spectrometer)

Zinc concentration was determined with an ICP-MS instrument equipped with a double pass spray chamber (Sciex Elan 9000, Perkin Elmer). In sample preparation, a proper amount of sample was dissolved in a mixture of $\mathrm{HNO}_{3}, \mathrm{H}_{2} \mathrm{O}_{2}$, and $\mathrm{HF}$ (volume ratio 16:8:1), with the aid of a microwave reactor (Multiwave 3000, Anto Paar). The corresponding ICP calibration curve was carried out with multi-elements standard solution XVI, $100 \mathrm{mg} / \mathrm{l}$ (Merck). After dilution the concentration used for $\mathrm{ZnO}$ were 50-100-200-1000 ug/l.

The measurement was done in duplicate. Data were presented as mean \pm standard deviation.

- Ash content

Ash content was determined on ignition of the samples at $525{ }^{\circ} \mathrm{C}$ in a furnace (Bicasa B.E.43), following ISO 1762:2001. The measurement was done in duplicate.

- Tensile strength of recycled paper handsheets

In order to assess the effect of PLA coating/NPs on the quality of the recovered fibres, laboratory handsheets were made with a Rapid-Köthen type sheet former (Estanit, Germany) following ISO 5269-2:2004. The protocol is similar to the one described in Figure 38. $25 \mathrm{~g}$ sample was pulped and screened, but only the accepts coming out in the first minute were collected and used to make the handsheets. The 
handsheets were about $1.8 \mathrm{~g}$ and $20 \mathrm{~cm}$ in diameter, which is equivalent to basis weight $60 \mathrm{~g} / \mathrm{m}^{2}$.

The handsheets were tested on a universal tensile testing machine (M350-20CT) following ISO 1924-3:2005. In brief, the preconditioned strips were subjected to a constant rate of elongation $(100 \mathrm{~mm} / \mathrm{min})$ from a pair of clamps with a span of 100 mm. 10 measurements were made for each sample.

\subsection{RESULTS AND DISCUSSIONS}

\subsubsection{SEM-EDX analysis}

SEM-EDX analysis was performed on sample Coat-3 to learn the surface morphology of the coating (in a 2D perspective). The SEM images (see Figure 39) show that the coating provided a certain degree of coverage over the paper surface, but still left some surface pores unshielded (image a), which can inevitably cause uncertainties and poor values in the material characterization, e.g. contact angle and Cobb-60 test. Secondly, as shown in a greater magnification (image b), the distribution of $\mathrm{ZnO}$ NPs was fairly homogenous, which is mainly attributed to the NP surface modification. The presence of ZnO NPs (the white dots in the images) is confirmed with the EDX spectrum (shown in Figure 39 c), in which the peaks of $\mathrm{Zn}$ are dominant (area under the peaks); while Au (gold) and Pd (palladium) came from the test piece preparation. 

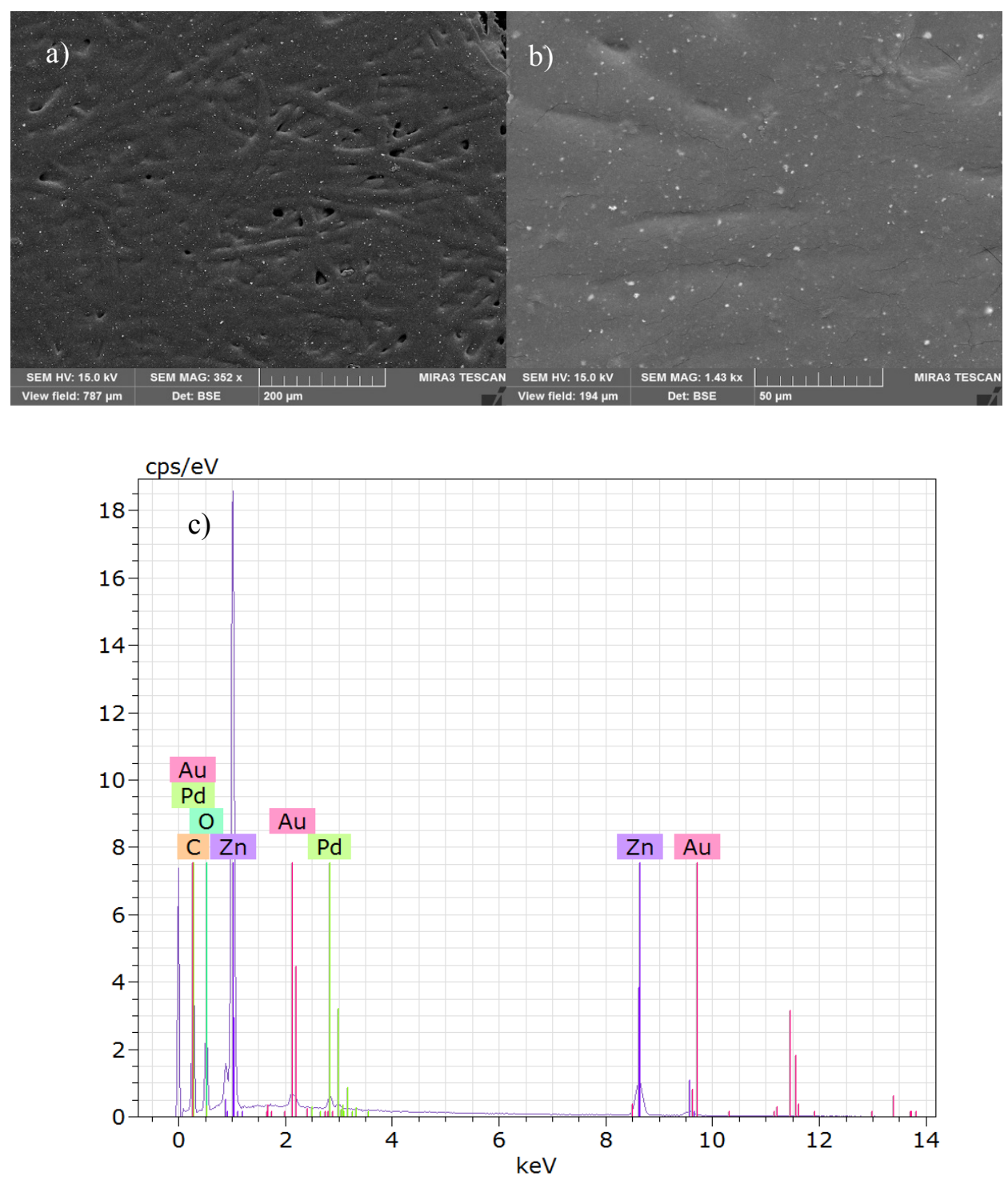

Figure 39. SEM images (a and b) and EDX spectrum (c) for sample Coat-3 (refer to Table 7 for sample description). Two magnifications were used: 353 times in image a and 1430 times in image $b$.

On the other hand, some NP aggregates/agglomerates persisted in the coating. This is partly because the magnetic stir used for preparing the coating solution has a rather low agitation torque, especially for treating a highly viscous polymer 
solution. It is therefore anticipated that the NP dispersing could be further improved by using a better tool, e.g. Turrax.

\subsubsection{Surface properties of PLA coated paper}

As indicated in the measurement, the paper substrate had a basis weight of $106.1 \pm 1.5 \mathrm{~g} / \mathrm{m}^{2}$, and c.a. $9.4 \pm 2.1 \mathrm{~g} / \mathrm{m}^{2}$ coat weight was achieved for the coated samples.

Table 8 summaries the results of Bendtsen smoothness, Cobb-60 and contact angle. In regard to smoothness, generally all the values showed large variations, which implies the irregularities of the contour of the samples. In addition, it suggests that the PLA coating does not improve the surface smoothness as expected. This may originate from the constraint of the solvent casting method used (not enough coating material deposited over the paper surface, i.e. not good coverage). Another possible cause could be the NP aggregates/agglomerates presented on the surface. For the results of Cobb-60 and contact angle, the coated samples distinguished themselves from the control sample: water absorption decreased significantly and contact angle dropped to 70 degree from 96 degree (sized paper surface). However, a relationship between the loading of NP and its effect on Cobb-60/contact angle is difficult to establish, since at this coating weight the surface morphology is complex, which can be observed from the SEM images (see Figure 39).

Table 8. Surface characterization: the control and PLA coated samples.

\begin{tabular}{|l|l|l|l|}
\hline Sample ID & $\begin{array}{l}\text { Smoothness } \\
{[\mathrm{mL} / \mathrm{min}]}\end{array}$ & $\begin{array}{l}\text { Cobb-60 } \\
{\left[\mathrm{g} / \mathrm{m}^{2}\right]}\end{array}$ & $\begin{array}{l}\text { Contact angle } \\
{[\text { degree }]}\end{array}$ \\
\hline Blank & $709 \pm 252$ & 24.2 & 96.1 \\
\hline Coat-0.5 & $662 \pm 188$ & 1.8 & 72.9 \\
\hline Coat-1 & $743 \pm 186$ & 2.8 & 76.1 \\
\hline Coat-3 & $565 \pm 240$ & 3.4 & 71.2 \\
\hline
\end{tabular}

\subsubsection{Effect ZnO NPs on optical properties}

As indicated in Figure 40, the samples' brightness value dropped as a function of NP loading in the coating. It is well known that ZnO NPs have good UV (Ultraviolet) blocking property, and the relevant research [16] suggests that PLA 
film incorporating $\mathrm{ZnO}$ NPs as low as $0.5 \mathrm{wt} \%$ can effectively reduce the light transmittance at the UV range $(<400 \mathrm{~nm})$ while can only cause slight changes to the visible range $(400-700 \mathrm{~nm})$. Particularly, the effect is more noticeable at the low wavelength end, i.e. close to the $400 \mathrm{~nm}$ end. As brightness measures the spectral reflectance at $457 \mathrm{~nm}$ (blue/violet light), the incorporation of $\mathrm{ZnO}$ NPs will reduce the reflectance at this wavelength, and hence a lower brightness value can be expected.

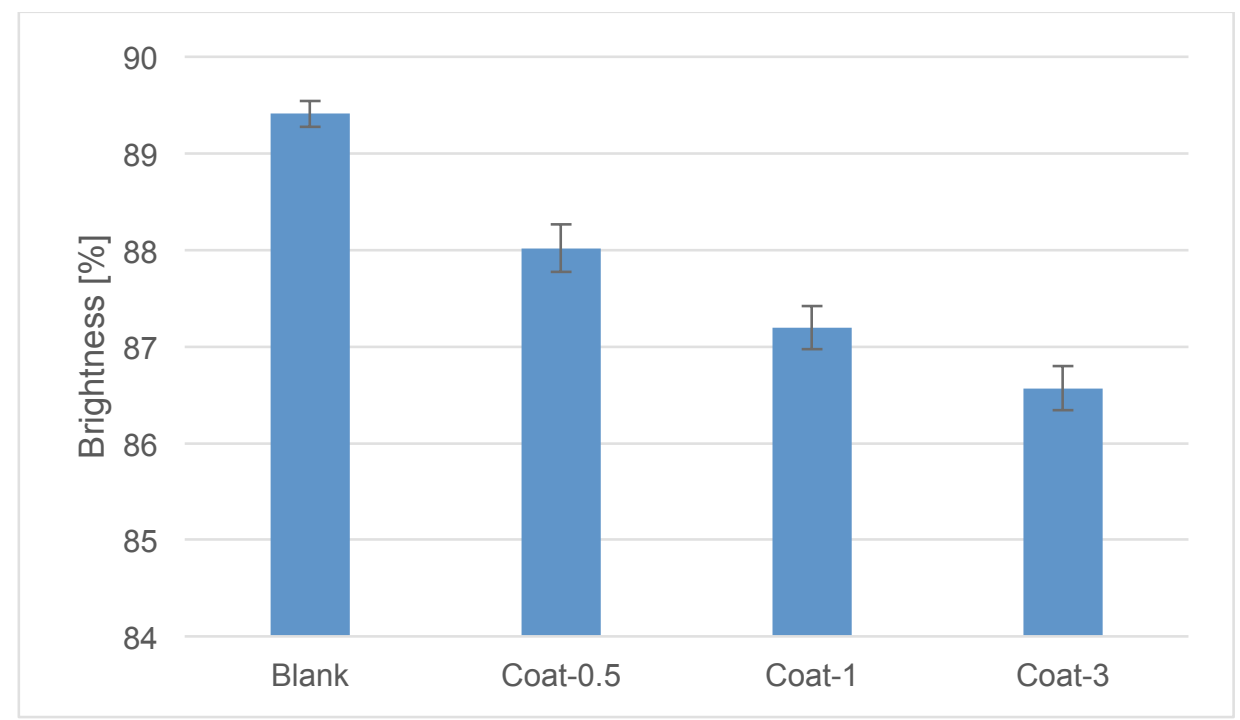

Figure 40. Brightness of the samples. Error bar represents $95 \%$ confidence interval from 10 measurements. Refer to Table 7 for the sample description.

\subsubsection{Mass balance in paper recycling test}

The mass balance of the materials in the recycling test is presented in Table 9. In an overview, the protocol enabled to recover the most of the solids material in the system $(>99 \%)$, including the fines such as mineral fillers (confirmed by the ash content measurement, results presented in Table 11), fibre fines, and maybe tiny fragments of the PLA coating. 
Table 9. Material mass balance in the paper recycling test.

\begin{tabular}{|l|l|l|}
\hline & Coat-1 & Coat-3 \\
\hline Coated sample [g] & 24.82 & 24.79 \\
\hline Rejects [g] & 5.29 & 5.31 \\
\hline Accepts [g] & 19.32 & 19.38 \\
\hline Total recovered [g] & 24.61 & 24.69 \\
\hline Process Loss [g] & 0.21 & 0.10 \\
\hline
\end{tabular}

The process waste (i.e. the rejects separated by the screen) was very high, being $21 \%$ (see Figure 41). Theoretically if the polymer coating and fibres were completely separated, it would give a maximum value corresponding to $8 \%$ process waste. According to the evaluation criteria of the method ATICELCA MC501-13, such high percentage of waste shall be rated as "level C", which means that the sample is recyclable only upon specific sorting arranged during the municipality collection in order to separate this kind of material for dedicated recycling in specialized plants. Apart from the process waste, the material had an acceptable disintegration behaviour, absence of adhesion in the recycled handsheets and low level of optical inhomogeneity.

We assume that such high process waste is mainly attributed to the solvent casting method used to produce the samples. As the PLA coating solution can penetrate deep into the fibre network, after solvent evaporation the polymer will bind significant amount of fibres that are subsequently rejected by the screen. This also reflects the dilemma in formulating a suitable polymer coating solution for paper substrate: if the concentration is too high, it will cause problems in dispersing the NPs (low agitation torque of the magnetic stir), as well as runnability issues on the lab coater; if it is too low, large amount of coating will be imbibed by the paper substrate, which will increase the process waste as seen in this example. However, it is anticipated that such problem could be avoided in the industrial production where extrusion coating is used. 


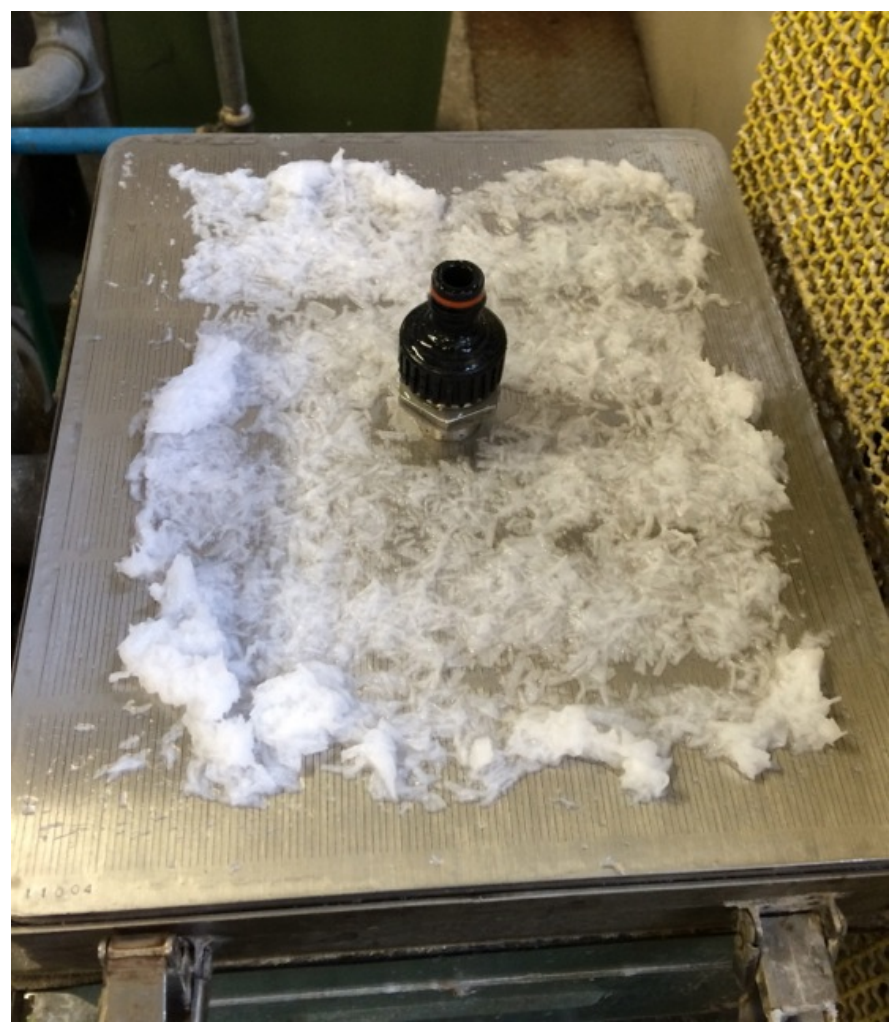

Figure 41. Rejects after Somerville screening.

\subsubsection{Fate of ZnO NPs in paper recycling test}

The main objective of this study is to track the fate of $\mathrm{ZnO}$ NPs in paper recycling line. The test involves different material flows and the possible NP exposure routes include the rejects, the accepts, and the processing water during screening (see Figure 38), it is therefore necessary to track the ZnO NP concentration in each of them. However, as the processing water had a large volume (c.a. $40 \mathrm{~L}$ ) and low NP concentration, direct measurement is difficult. But, instead, it can be roughly estimated on the basis of mass balance calculation.

First of all, it is important to clarify that the value measured with ICP-MS can represent the NPs contained in the different material streams. Many of such nanoenabled materials are intended for food contact applications, and therefore the issue of NP migration has been addressed in a number of studies [17-19]. A recent report published by European Food Safety Authority [15] concluded that in the case of LDPE (Low-Density Polyethylene) film using ZnO NPs as nanofillers (both surface 
coated and uncoated), zinc does not migrate in nano-form, i.e. immobilised by the polymer matrix, but migrates in ionic form $\left(\mathrm{Zn}^{2+}\right)$ due to the NP solubilisation. $\mathrm{ZnO}$ NP is practically insoluble in aqueous media, below $50 \mathrm{mg} / \mathrm{L} \mathrm{[20],} \mathrm{but} \mathrm{more}$ susceptible to acidic media [15].

As compared with the migration test, a paper recycling process commonly involves intensive mechanical impacts in a neutral or weak alkaline media over a shorter period of time. By considering these aspects, it is reasonable to assume that NP solubilisation will not occur during the paper recycling test. Thus, the mass balance of $\mathrm{ZnO}$ NPs can be calculated on the basis of the zinc concentration determined from the ICP-MS measurement.

For future investigation, zinc in different forms, i.e. the nano-form and ionic form, can be distinguished with the ICP-MS following the method described in the relevant publications [21, 22]: skip the acid dissolving step in the sample preparation, and set the ICP-MS instrument to work in spectrum mode for single particle detection.

The mass balance calculation of ZnO NPs are given in Table 10, where Re-1 and Ac-1 mean the corresponding rejects and accepts coming from the recycling trial of sample Coat- 1 . The same applies to sample Coat-3. In an overview, $86 \%-91 \%$ of $\mathrm{ZnO}$ NPs ended up in the rejects, and very likely most of the NPs were embedded within the PLA matrix. On the other hand, about $7-16 \% \mathrm{ZnO}$ NPs ended up in the accepts, which is exceptionally high. Several factors may contribute to this result. Firstly, when the coating penetrates into the fibre network, it may attach to the surface of individual fibres, and therefore it is small enough to pass the screen slit and consequently ends up in the accepts as tiny coating fragments. Another possibility is that part of the PLA coating gets fragmented and even dissolved during the recycling process. According to the producer's information [23], PLA coating is readily repulpable for its greater water susceptibility and lower impact strength compared with the petroleum-derived polymer coating. Under some harsh pulping conditions (e.g. $\mathrm{pH}$, temperature and aid of chemicals), a small amount of coating may degrade and get dissolved in water. In our test, after pulping, the suspension was measured as $\mathrm{pH} 8.81$ and temperature $32.6{ }^{\circ} \mathrm{C}$. So there is a possibility that a small amount of $\mathrm{ZnO}$ NPs leach into the pulp suspension due to PLA degradation, and become associated with the recovered fibres.

The deviation of NPs balance from $100 \%$ may be attributed to the statistical sample size (mean value from two measurements) and the potential NP leaching to the processing water. Therefore, more measurement points are recommended for future study in order to get close to the true mean value. 
Table 10. Mass balance of ZnO NPs in the paper recycling test. Coat-1 means PLA coating containing 1 wt.\% of ZnO NPs on base paper; Re-1 and Ac-1 mean the corresponding rejects and accepts coming from the recycling trial of Coat-1. The same applies to sample Coat-3.

\begin{tabular}{|l|l|l|l|l|}
\hline & $\begin{array}{l}\text { Zn concentration } \\
{[\mathrm{mg} / \mathrm{g}]}\end{array}$ & $\begin{array}{l}\text { Material } \\
\text { balance }[\mathrm{g}]\end{array}$ & $\begin{array}{l}\text { ZnO NPs } \\
\text { balance } \\
{[\mathrm{mg} / \mathrm{g}]}\end{array}$ & $\begin{array}{l}\text { ZnO NPs } \\
\text { balance in } \\
\%\end{array}$ \\
\hline Coat-1 & $0.687 \pm 0.240$ & 24.82 & 21.23150 & \\
\hline Re-1 & $2.775 \pm 0.130$ & 5.29 & 18.27851 & $86 \%$ \\
\hline Ac-1 & $0.0595 \pm 0.0049$ & 19.32 & 1.43135 & $7 \%$ \\
\hline Coat-3 & $1.6625 \pm 0.1266$ & 24.79 & 51.31689 & \\
\hline Re-3 & $7.0285 \pm 0.1577$ & 5.31 & 46.47071 & $91 \%$ \\
\hline Ac-3 & $0.3395 \pm 0.0078$ & 19.38 & 8.19249 & $16 \%$ \\
\hline
\end{tabular}

Due to presence of mineral fillers, the interpretation of the ash content results becomes difficult (see Table 11). However, some information can be extracted: if assume Re-3 only contains NPs, (i.e. all the mineral fillers end up in Ac-3), the ash content value can be interpreted as $\mathrm{ZnO}$ NPs concentration, $43.40 \mathrm{mg} / \mathrm{g}$, which is close to the value obtained from the ICP-MS measurement, $46.47 \mathrm{mg} / \mathrm{g}$. This consistency suggests good NP dispersing in the coating.

Table 11. Ash content. Coat-3 means PLA coating containing 3 wt. $\%$ of ZnO NPs on base paper, Re-3 and Ac-3 mean the corresponding rejects and accepts coming from the recycling trial of

Coat-3.

\begin{tabular}{|l|l|}
\hline Sample ID & Ash content [\%] \\
\hline Blank & 7.75 \\
\hline Coat-3 & 7.43 \\
\hline Ac-3 & 8.16 \\
\hline Re-3 & 4.34 \\
\hline
\end{tabular}




\subsubsection{Tensile strength of handsheets}

As known from the aforementioned discussion, a large proportion of ZnO NPs ended up in the accepts. These NPs may associate with the fibres with some interactions or they may be embedded in the fragments of the PLA coating. And both cases may cause negative effects on the recycled paper. To clarify this issue, handsheets were made from the accepts and the tensile strength was tested. The results are given in Figure 42. It can be seen that sample HS-Coat-1 (handsheet made from the accepts of Coat-1 trial) had a higher value than the other two samples, including the control; whereas sample HS-Coat-3 (handsheet made from the accepts of Coat-3 trial) was not statistically significant different than the control HS-Blank. Thus, the NP-enabled PLA coating has no negative impacts in the tensile strength of the handsheet. Besides, the result may suggest that the coating fragments/NPs are not strongly associated with the fibre and thus can be drained away in handsheet-making. And if this is the case, the water drained during sheet preparation should be analysed in future investigation.

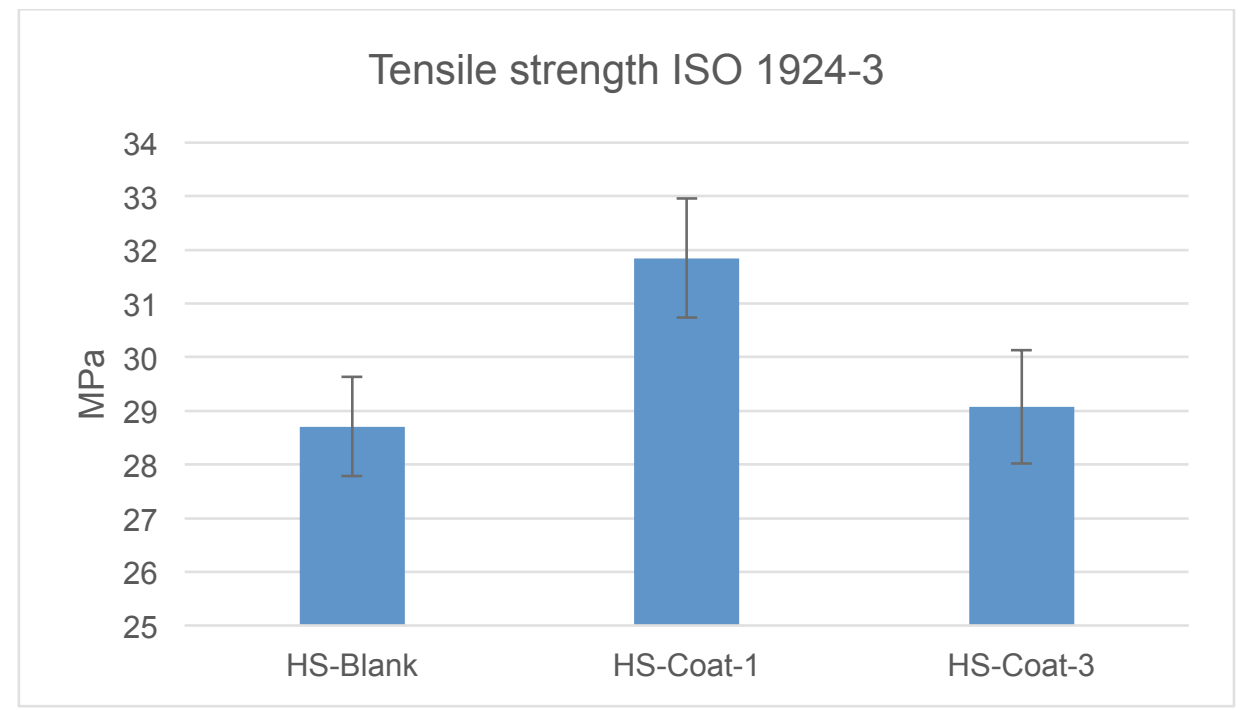

Figure 42. Tensile strength of the handsheets. HS-Coat-1 means handsheet made from the accepts of Coat-1 trial. The same applies to HS-Coat-3. Error bar represents $95 \%$ confidence interval from 10 measurements.

\subsection{CONCLUSIONS}

In this study, a paper-based packaging material containing ZnO NPs was produced and characterized, and particular attention was paid to the fate of nanomaterials in the paper recycling process. The SEM-EDX analysis suggests that the coating (coat 
weight $9.4 \mathrm{~g} / \mathrm{m}^{2}$ ) provided some degree of coverage over the paper surface but left some surface pores unshielded, which affected the material's performance in water absorptiveness (Cobb-60) and wetting properties (contact angle). The NPs were homogenously distributed in the polymer matrix thanks to the NP surface modification, and the presence of aggregates can be further minimised by using a better mixing tool.

The recyclability of such packaging material was assessed with a method adapted from ATICELCA MC501-13, which enabled to recover over 99\% of the solids material. The $\mathrm{ZnO}$ NPs mass balance indicates that $86 \%-91 \%$ NPs ended up in the rejected material stream, mostly embedded within the coating; whereas 7\%-16\% NPs were found in the accepted fibre material stream. However, since NPs were not directly measured in the process water, their presence cannot be completely ruled out. As a matter of fact, tiny coating fragments/residues loosely attached to the recovered fibres might still migrate into the water system in handsheets' formation. In a broader view, this means that some NPs may accumulate in the white water system of paper machine, and therefore proper measures should be taken for the safe use of nanomaterials. The tensile strength of the handsheets suggested that the $\mathrm{ZnO} \mathrm{NP}-$-enabled coating has no negative impacts on the recycled paper quality.

For future research, it is interesting to apply the same testing method to samples produced with extrusion coating. The concentration of the NPs in the processing water shall be assessed in order to obtain a more complete picture about the fate of NPs in the paper recycling process. Besides, the physical state of these NPs in the different process streams should be further investigated with suitable techniques (e.g. TEM), as it influences the nano-toxicity. 


\subsection{REFERENCES}

1. Martins NC, Freire CS, Pinto RJ, Fernandes SC, Neto CP, Silvestre AJ, Causio J, Baldi G, Sadocco P, Trindade T. Electrostatic assembly of Ag nanoparticles onto nanofibrillated cellulose for antibacterial paper products. Cellulose 2012; 19(4), pp. 1425-1436.

2. Martins NC, Freire CS, Neto CP, Silvestre AJ, Causio J, Baldi G, Sadocco P, Trindade T. Antibacterial paper based on composite coatings of nanofibrillated cellulose and ZnO. Colloids and Surfaces A: Physicochemical and Engineering Aspects 2013; 417, pp. 111-119.

3. Fernández A, Picouet P, Lloret E. Cellulose-silver nanoparticle hybrid materials to control spoilage-related microflora in absorbent pads located in trays of fresh-cut melon. International Journal of Food Microbiology 2010; 142(1), pp. 222-228.

4. Manda B, Blok K, Patel MK. Innovations in papermaking: An LCA of printing and writing paper from conventional and high yield pulp. Science of the Total Environment 2012; 439, pp. 307-320.

5. Steward F, Tsoi JC, Coles A-M. Innovation and sustainability in printon-paper: a comparison of nanoparticle and deinking niches as emergent sociotechnical networks. Journal of cleaner production 2008; 16(8), pp. 957-966.

6. Directive 94/62/EC, European Parliament and Council Directive 94/62/EC of 20 December 1994 on packaging and packaging waste 1994.

7. Merrild H, Damgaard A, Christensen TH. Life cycle assessment of waste paper management: the importance of technology data and system boundaries in assessing recycling and incineration. Resources, Conservation and Recycling 2008; 52(12), pp. 1391-1398.

8. Hohenthal C, Ovaskainen M, Bussini D, Sadocco P, Pajula T, Lehtinen H, Kautto J, Salmenkivi K, Final Assessment of Nano Enhanced New Products, in Scaleup nanoparticles in modern papermaking-report SUNPAP2012.

$<$ http://sunpap.vtt.fi/pdf/SUNPAP_WP2_DEL2_5_\%2020121031_VTT.pd $\mathrm{f}>$ (retrived 15.10.15)

9. Aliaga C, Zhang H, Dobon A, Hortal M, Beneventi D. The influence of printed electronics on the recyclability of paper: A case study for smart envelopes in courier and postal services. Waste Management 2015; 38, pp. 41-48.

10. Duncan TV. Applications of nanotechnology in food packaging and food safety: Barrier materials, antimicrobials and sensors. Journal of colloid and interface science 2011; 363(1), pp. 1-24. 
11. Powell MC, Kanarek MS. Nanomaterial health effects-part 2: uncertainties and recommendations for the future. Wisconsin Medical Journal 2006; 105(3), pp. 18-23.

12. Kunhikrishnan A, Shon HK, Bolan NS, El Saliby I, Vigneswaran S. Sources, distribution, environmental fate and ecological effects of nanomaterials in wastewater streams. Critical Reviews in Environmental Science and Technology 2015; 45(4), pp. 277-318.

13. Kaegi R, Sinnet B, Zuleeg S, Hagendorfer H, Mueller E, Vonbank R, Boller M, Burkhardt M. Release of silver nanoparticles from outdoor facades. Environmental pollution 2010; 158(9), pp. 2900-2905.

14. Rossi M, Cubadda F, Dini L, Terranova M, Aureli F, Sorbo A, Passeri D. Scientific basis of nanotechnology, implications for the food sector and future trends. Trends in Food Science \& Technology 2014; 40(2), pp. 127-148.

15. EFSA CEF Panel on Food Contact Materials E, Flavourings and Processing Aids. Scientific Opinion on the safety evaluation of the substance zinc oxide, nanoparticles, uncoated and coated with [3(methacryloxy)propyl] trimethoxysilane, for use in food contact materials. EFSA Journal 2015; 13(4), pp. 4063-4072, DOI: doi:10.2903/j.efsa.2015.4063.

16. Murariu M, Doumbia A, Bonnaud L, Dechief AL, Paint Y, Ferreira M, Campagne C, Devaux E, Dubois P. High-performance polylactide/ZnO nanocomposites designed for films and fibers with special end-use properties. Biomacromolecules 2011; 12(5), pp. 1762-1771.

17. Llorens A, Lloret E, Picouet PA, Trbojevich R, Fernandez A. Metallicbased micro and nanocomposites in food contact materials and active food packaging. Trends in Food Science \& Technology 2012; 24(1), pp. 19-29.

18. Echegoyen Y, Nano-developments for Food Packaging and Labeling Applications, in Nanotechnologies in Food and Agriculture, M. Rai, et al., Editors. 2015, Springer International Publishing: Cham. p. 141-166.

19. Bumbudsanpharoke N, Ko S. Nano-Food Packaging: An Overview of Market, Migration Research, and Safety Regulations. Journal of Food Science 2015; 80(5), pp. R910-R923.

20. Scientific Committee on Consumer Safety (SCCS), OPINION on Zinc oxide (nano form), 2012, European Union. $<\mathrm{http} / / /$ ec.europa.eu/health/scientific_committees/consumer_safety/docs/sc cs_o_103.pdf> (retrieved 20.10.15)

21. Laborda F, Jiménez-Lamana J, Bolea E, Castillo JR. Selective identification, characterization and determination of dissolved silver (I) and silver nanoparticles based on single particle detection by 
inductively coupled plasma mass spectrometry. Journal of Analytical Atomic Spectrometry 2011; 26(7), pp. 1362-1371.

22. Echegoyen Y, Nerín C. Nanoparticle release from nano-silver antimicrobial food containers. Food and Chemical Toxicology 2013; 62, pp. 16-22.

23. Nangeroni J, Hartmann MH, Iwen ML, Ryan CM, Kolstad JJ, McCarthy $\mathrm{KT}$, Coating grade polylactide and coated paper, preparation and uses thereof, and articles prepared therefrom (US6183814 B1), U.S.P.a.T. Office., Editor 2001, Cargill, Incorporated. 
5 Paper III. The effect of active packaging on minimising food losses: Life Cycle Assessment (LCA) of essential oil component enabled packaging for fresh beef 


\subsection{INTRODUCTION}

The statistics for food losses is staggering: a rough estimation for avoidable losses in EU (European Union) is $280 \mathrm{~kg}$ per capita per year, of which $13 \%$ arising from the agricultural production, $31 \%$ from the product processing, and $45 \%$ from the household [1]. In particular, the household is subject to criticism for generating such high percentage of food waste; for example, a survey conducted by Williams, et al. in 2012 revealed that food waste was $1.7 \mathrm{~kg}$ per week per household in a local community in Sweden [2]. This situation may be attributed to various reasons: purchased too much, leftover after cooking, leftover after eating, misunderstanding of "use before"(inedible after due date) and "best before" (safe to taste and judge by the consumers) [2], mismatch between the packaging size and a smaller family unit as the society develops, which is very often associated with the failure of protection once the packaging is opened, packaging difficult to empty, e.g. yoghurt and ketchup.

To minimise food losses, a number of practical measures have been proposed to consumers [1]; for example, pre-shopping planning, avoiding the temptation of special offer coming with large quantity packs, decreasing the cooking/warming proportions in one's diet, etc. However, when looking at the issue from a bigger picture, i.e. the whole food chain, packaging plays a key role in reducing food losses. This is because foods serving to our tables are subject to various risks, including physical damage, physicochemical deterioration, microbial spoilage, etc., and particularly, contamination/cross-contamination of pathogens could cause severe threat to human health [3]. Packaging provides an effective barrier against these risks, and the development of active packaging, especially the antimicrobial packaging enables actively inhibiting/eliminating the food spoilage mechanisms, e.g. bacteria, fungi and virus [4-6], and hence leading to longer shelf life and safer food.

In accordance with Commission Regulation EC No. 450/2009 from the European Union [7], the official definition of active packaging is given as: "active materials and articles means materials and articles that are intended to extend the shelf-life or to maintain or improve the condition of packaged food; they are designed to deliberately incorporate components that would release or absorb substances into or from the packaged food or the environment surround the food." Depending on the intended applications, there are different types of active packagings on the market [8], including the antimicrobial/antioxidant type, the internal atmosphere control type (e.g. oxygen scavenging, moisture control, $\mathrm{CO}_{2}$ generating, ethylene absorbing, etc.), and odour/aroma removing/enhancing type [9-12]. 
One of the most attractive benefits of using active packaging is to extend the shelf life of the packaged food $[13,14]$. Generally, two main factors influence food's shelf life [15]:

- Microbial spoilage: contamination caused by spoilage/pathogenic microorganisms and the amount of microorganisms present. It is usually regulated by relevant industry standards/laws [16].

- Non-microbial spoilage: sensory or biochemical deterioration, e.g. colour, texture, flavours, etc.

The active agents to be incorporated in the packaging material may function by combating either of the spoilage mechanisms, or sometimes both. However, one thing should be noted is that in the literature research very often shelf life extension is not clearly identified: depending on the authors research interest, in some studies the active material was just tested with the challenging culture (agar/liquid media) [17-19], and therefore the effect on real food is not known; while in other studies, test of sensory properties is missing (e.g. food was used as a medium for culturing or the author only focused on a specific spoilage mechanism of interest) $[10,20$, 21]. However, shelf life is an averaged indicator consisting of considerations in microbiological limit and sensory properties (e.g. physicochemical attributes, colour, taste, texture, odour, decay rate, etc.). And the latter usually involves panel test and unbiased evaluation remains challenging [22], despite the increasing application of electronic nose/electronic tongue [23].

Table 12 summaries the life extension reported from different sources, focusing on the application of active packaging on red meat products. The data of shelf life extension were extracted by considering the following factors: in some cases, the data may be subject to specific test conditions, for example both the control and the sample using active packaging were evaluated at the refrigeration temperature; in some works the authors have clearly indicated the achieved/anticipated shelf life extension, while in other works this information has been merged in each indicator tested, and thus, estimation has been made. It can be seen that almost $50 \%$ shelf life extension can be attained, which is a remarkable effect. 
Table 12. Active packaging application for red meat products and its effect on shelf life extension.

\begin{tabular}{|l|l|l|l|l|}
\hline $\begin{array}{l}\text { Red meat } \\
\text { products }\end{array}$ & $\begin{array}{l}\text { Shelf life } \\
\text { in control } \\
\text { packaging }\end{array}$ & $\begin{array}{l}\text { Shelf life in } \\
\text { active } \\
\text { packaging }\end{array}$ & $\begin{array}{l}\text { Active packaging } \\
\text { description }\end{array}$ & References \\
\hline Ground beef & 5 days & 9 days & $\begin{array}{l}\text { Coating layer } \\
\text { containing } \\
\text { nisin/lacticin }\end{array}$ & $\begin{array}{l}\text { Kim et al., } \\
2002[24]\end{array}$ \\
\hline Ground beef & 12 days & 16 days & $\begin{array}{l}\text { Oregano essential oil } \\
\text { releasing from a } \\
\text { paper disc }\end{array}$ & $\begin{array}{l}\text { Ammor et al., } \\
2009[25]\end{array}$ \\
\hline Beef steak & 10 days & 20 days & $\begin{array}{l}\text { Spray on beef surface } \\
\text { Rosemary extract \& } \\
\text { vitamin C) }\end{array}$ & $\begin{array}{l}\text { Djenane et al., } \\
2003[26]\end{array}$ \\
\hline Beef steak & 14 days & 23 days & $\begin{array}{l}\text { PP film coated with } \\
\text { oregano extract }\end{array}$ & $\begin{array}{l}\text { Camo et al., } \\
2011[27]\end{array}$ \\
\hline Beef steak & 12 days ${ }^{\dagger}$ & 14 days & $\begin{array}{l}\text { PP film co-extruded } \\
\text { with natural } \\
\text { antioxidants }\end{array}$ & $\begin{array}{l}\text { Nerin et al., } \\
2006[28]\end{array}$ \\
\hline $\begin{array}{l}\text { Fresh lamb } \\
\text { steaks }\end{array}$ & 8 days & 13 days & $\begin{array}{l}\text { Active film } \\
\text { containing extracts of } \\
\text { rosemary/oregano }\end{array}$ & $\begin{array}{l}\text { Camo et al., } \\
2008[29]\end{array}$ \\
\hline $\begin{array}{l}\text { Raw skinless } \\
\text { sausages }\end{array}$ & 7 days & 15 days & $\begin{array}{l}\text { Chitosan treatment } \\
\text { (on sample surface) }\end{array}$ & $\begin{array}{l}\text { Sagoo et al., } \\
2002[30] \\
\text { al., 2006 [31] }\end{array}$ \\
\hline Grilled pork & 14 days & 28 days & $\begin{array}{l}\text { Chitosan treatment } \\
\text { (anguad et }\end{array}$ \\
\hline
\end{tabular}

${ }^{\dagger}$ Shelf life only based on sensory panel evaluation. 
Obviously, all the stakeholders involved in the food chain would welcome products of longer shelf life, not only for the economic reasons, but also for issues such as the pressure imposed on logistics, food waste management, and sustainability concerns. Interestingly, from an environmental perspective, when adapting a more sophisticated packaging system for food, on the one hand, it will induce additional resources input and emissions; on the other hand, it will enable to lower a product's environmental impact by minimising food losses. So, some questions would naturally arise: will the additional input be offset by the saved food losses? What is the desired product shelf life in order to achieve a positive/improved sustainability profile? To answer these questions, it is helpful to assess the environmental performance of the food and its packaging as a whole system incorporating the effect of food loss reduction by means of Life Cycle Assessment (LCA). As concluded by McMillin in the his work [32], "from a life cycle perspective, any assessment of the environmental impact of food packaging must take into account the positive benefits of reduced food losses in the value chain".

Although there have been extensive studies addressing the eco-profile of food packaging using LCA, most of them focused on issues such as using of biopolymers, increasing the share of renewable energy in the system input, as well as the end-of-life impacts of packaging materials [33-35]. On the other hand, the capability of active packaging in reducing food losses has already been widely recognised by the packaging and food industry. Wikstrom and Williams in their works $[36,37]$ proposed a model that describes the potential environmental gains from reducing food losses by using new packaging. This is an important issue simply because not all active packaging will lead to an improved eco-profile of the system. First of all, the food type matters. As shown in their study [36], for the same fraction of food loss reduction, the high impact foods e.g. cheese and beef enjoy a greater freedom in new packaging design (without increasing the system's environmental impact) than the low impact foods e.g. bread and ketchup. In other words, the high impact food and its packaging give good response to food loss reduction. Additionally, for example, when using metal nanoparticles (e.g. Ag, $\left.\mathrm{TiO}_{2}, \mathrm{ZnO}\right)$ as antimicrobial agents $[38,39]$, and very likely, it tends to rise the system's environmental burden, due to the high energy input in nanoparticle manufacturing [40], dispersing and incorporation in host material [41], and its ecotoxicity, i.e. the fate when these engineered nanoparticles releasing to the environment [42].

The objective of this study is to provide a link between food loss saving and foodpackaging system's overall environmental performance. Therefore, LCA methodology has been applied to contrast the situations of food using conventional packaging (current state) and food using novel active packaging (containing active coating). This was demonstrated with a case study, focusing on the application of 
essential oil component enabled active packaging for fresh beef. Additionally, a sensitivity analysis has been integrated, with the aim to identify the breakeven point of the balance. (A breakeven point means the threshold where the environmental impact becomes equal to the control case.) It is expected that the obtained results would serve as guidelines for active packaging development, which strives for a positive sustainability profile of the food-packaging system.

\subsection{MATERIALS AND METHODS}

SimaPro 7.3.3 (PRé Consultants, Netherlands) was used for the LCA modelling and the corresponding life cycle impact assessment (LCIA) calculation. It is a software specifically designed for the purpose of LCA, considering inputs and outputs from the defined system boundaries with respect to the framework defined by the standards (ISO14040 and 14044).

\subsubsection{Goal and scope definition}

The purpose of this LCA study is to assess the eco-profile of the food and its packaging as a whole system, i.e. a product-packaging system [35], and the interest is placed on the effect of active packaging on food loss reduction, which further leads to reduced environmental impact. This relationship was demonstrated with a specific case study: fresh beef packaged in essential oil component enabled active packaging.

The conventional packaging concerned is the modified atmosphere packaging (MAP), which is the industrial standard solution for distributing fresh beef. As shown in Figure 43, for using MAP, a designed gas mixture is flushed into the tray to replace air, and then the tray is sealed with a lid film. In order to provide a good gas barrier, usually the packaging is made from multilayer structure material, e.g. co-extruded PP and EVOH. The active packaging of interest only differs from the "conventional MAP" in an additional active coating layer coated on the lid film. The active coating is formulated with $\mathrm{EVOH}$ polymer and thymol/carvacrol as antimicrobial agent. In the following discussion, this system will be denoted as "active MAP". 


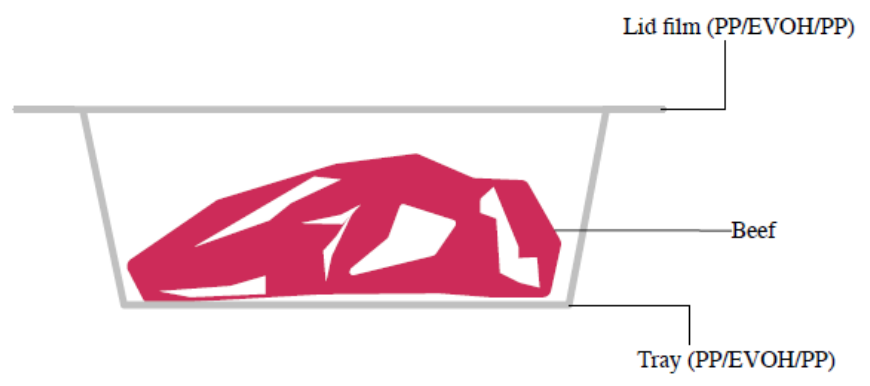

Figure 43. Schematic illustration of the packaging system concerned.

As the active MAP is still under development, specific issues such as choice and validation of active agent, methods to incorporate in packaging material are to be determined. Detailed LCA modelling is therefore restricted by data availability. However, this kind of situation will become more and more common with the industry's increasing acceptance and application of eco-design concept [43]. To address such problem, for example, Kunnari, et al. in their publication [44] proposed a stepwise LCA procedure, which was about a continuous iterative process as the data quality improves in parallel with the development of the product. Following this concept, a preliminary LCA modelling was set up and the model will be updated once more data become available.

\subsubsection{Functional unit}

The Functional unit (FU) is defined as to deliver $1 \mathrm{~kg}$ fresh beef to the retail gate and display until the end of shelf life.

\subsubsection{System boundaries}

The system boundaries are illustrated in Figure 44. The LCA was performed in a cradle-to-gate perspective, i.e. from raw material extraction to the retail gate (supermarket). 


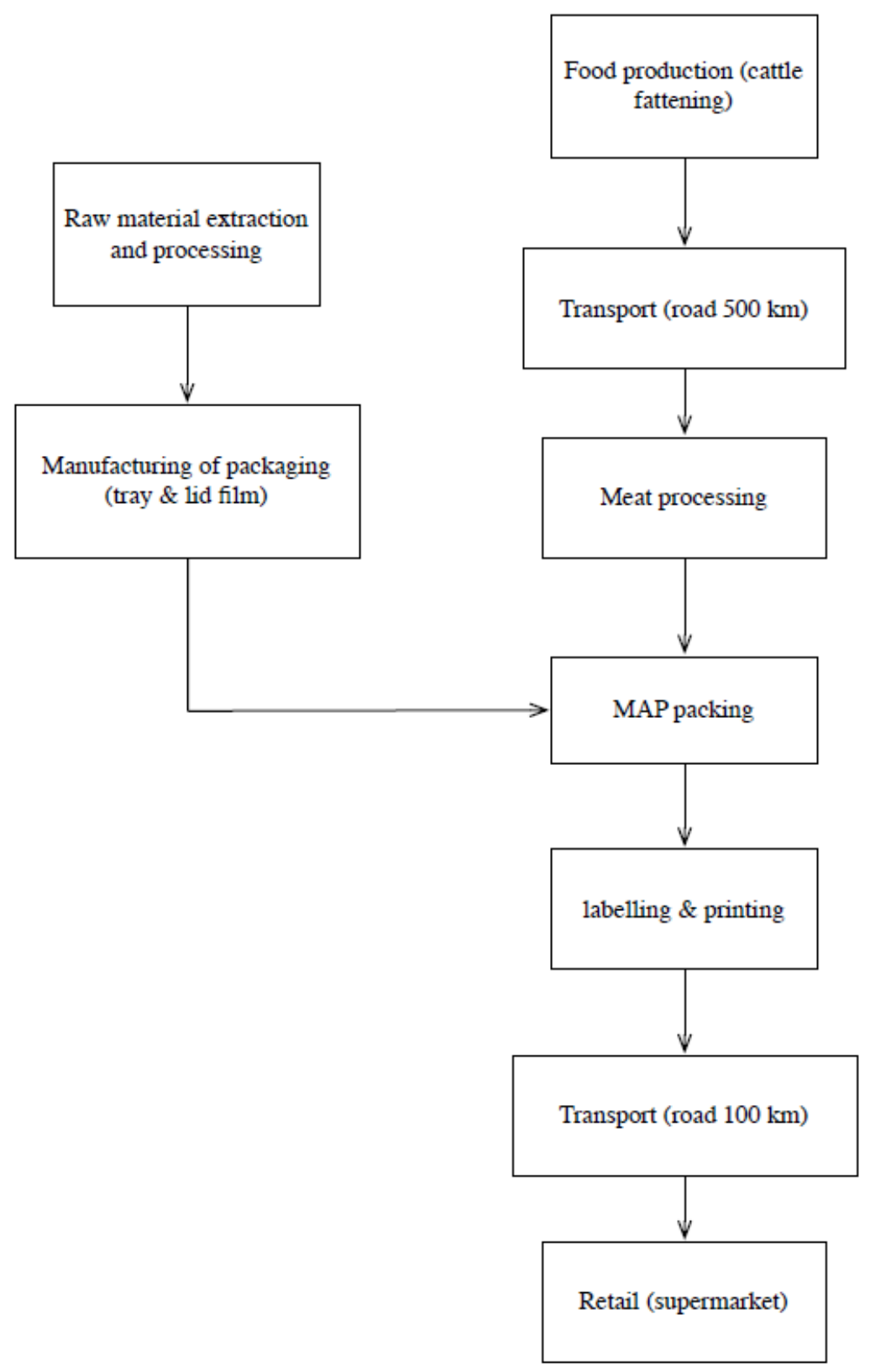

Figure 44. System boundary and key life cycle stages considered. 
Food consumption at household level was deliberately excluded from the system boundaries. One of the reasons is that before the consumption stage the food flow is generally managed by few major players/stakeholders (e.g. farmers, food packers, brand holders, wholesalers and supermarkets), so data collection is relatively easy [1]. However, as the flow reaching the consumption stage, this situation drastically changes due to the diversity of consumer behaviour. And as a result, the food loss data collection becomes challenging and inevitably involves large amount of variations.

More importantly, in the modelling we are especially looking for food waste data attributed to the expiry of shelf life, which concerns about the issues of food waste classification, definition and methods used in the data source. For example, Lebersorger \& Schneider in their work [45] proposed a methodology for household food waste classification and practised it with a case study by focusing on a district in the northwest of Austria (consisting of 58500 inhabitants). By analysing the waste composition, it was found that $6 \%$ (in mass) food waste was in originally packaged \& whole unused, and $15 \%$ in opened package and partly consumed. However, the exact reason behind these waste is still missing: it may be because no longer wanted, or due of shelf life.

End-of-life of packaging was also excluded, assuming both the conventional and the active packaging would be subject to the identical disposal scenario (e.g. municipal incineration). Additionally, the active coating layer containing essential oil component accounts for a small weight share over the entire packaging, and it is therefore reasonable to assume that the associated impact is negligible.

The geographical boundary was set that all activities happened in the EU.

\subsubsection{Life cycle inventory (LCI)}

Data sources and their references used in this study are summarised in Table 13. Data from SimaPro databases, especially Ecoinvent unit data were preferably used when available. For chemicals/substances/processing not available in SimaPro databases, the inventory was established by referring to the relevant publications, scientific papers, datasheet of equipment, on site visit, and consulting experts in the relevant fields. 
Table 13. Summary of data sources (life cycle inventory).

\begin{tabular}{|c|c|c|}
\hline Life cycle stages/processes & $\begin{array}{l}\text { Data } \\
\text { source }\end{array}$ & Notes and references \\
\hline $\begin{array}{l}\text { Food production (cattle } \\
\text { fattening) }\end{array}$ & $\begin{array}{l}\text { Nguyen et } \\
\text { al. [47] }\end{array}$ & $\begin{array}{l}\text { Data for suckler cow-calf system was } \\
\text { used }\end{array}$ \\
\hline Slaughtering house & $\begin{array}{l}\text { SimaPro, } \\
\text { literatures }\end{array}$ & A study regarding LCA on meat [48] \\
\hline $\begin{array}{l}\text { Packaging raw material } \\
\text { extraction (pellets } \\
\text { production) }\end{array}$ & $\begin{array}{l}\text { SimaPro } \\
\text { (Ecoinvent } \\
\text { ) }\end{array}$ & $\begin{array}{l}\text { EVOH substituted by its precursor } \\
\text { ethylene vinyl acetate copolymer } \\
\text { (EVA) }[49,50]\end{array}$ \\
\hline Co-extrusion & $\begin{array}{l}\text { SimaPro } \\
\text { (Ecoinvent } \\
\text { ) }\end{array}$ & Waste stream $0.024 \mathrm{~kg} / \mathrm{kg}$ \\
\hline Thermoforming & $\begin{array}{l}\text { SimaPro } \\
\text { (Ecoinvent } \\
\text { ) }\end{array}$ & Waste stream $0.023 \mathrm{~kg} / \mathrm{kg}$ \\
\hline $\begin{array}{l}\text { Corona treatment and other } \\
\text { converting processes }\end{array}$ & & Cut off \\
\hline $\begin{array}{l}\text { Components for coating } \\
\text { formulation }\end{array}$ & $\begin{array}{l}\text { SimaPro, } \\
\text { literatures }\end{array}$ & $\begin{array}{l}\text { Active agent loading } 5 \text { wt. } \%[51,52] \text {, } \\
\text { coat weight assumed to be } 5 \mathrm{~g} / \mathrm{m} 2\end{array}$ \\
\hline Coating and drying & & $\begin{array}{l}\text { Own calculation and assumption based } \\
\text { on industrial coating process [53] }\end{array}$ \\
\hline $\begin{array}{l}\text { MAP (modified } \\
\text { atmosphere packaging) } \\
\text { packing }\end{array}$ & $\begin{array}{l}\text { Site } \\
\text { specific }\end{array}$ & $\begin{array}{l}\text { Machine model: ULMA SMART } 300 \text {, } \\
\text { power } 5 \mathrm{~kW} \text {, sealing } 2 \text { trays per min }\end{array}$ \\
\hline $\begin{array}{l}\text { Gas mixture }(80 \% \\
\left.\mathrm{O}_{2} \& 20 \% \mathrm{CO}_{2}\right) \text { for MAP }\end{array}$ & & Cut off \\
\hline
\end{tabular}




\begin{tabular}{|c|c|c|}
\hline Supermarket shelf display & $\begin{array}{l}\text { Site } \\
\text { specific }\end{array}$ & $\begin{array}{l}\text { Machine model: ZERO ZONE } \\
\text { RVMC30, 5.61 kWh/meter/day, } 12 \\
\text { days shelf display [54] }\end{array}$ \\
\hline Transport & $\begin{array}{l}\text { SimaPro, } \\
\text { literatures } \\
\text { assumptio } \\
\text { ns }\end{array}$ & $\begin{array}{l}\text { Road transport, lorry }>32 \mathrm{t} \text {, Euro } 5 \text {. } \\
\text { Refrigerated road transport used for the } \\
\text { section from slaughtering house to } \\
\text { supermarket, which causes additional } \\
\text { diesel consumption, low-sulphur, } 5 \\
\text { L/100 km [46] }\end{array}$ \\
\hline $\begin{array}{l}\text { Electricity (allocated to } 1 \\
\mathrm{~kg} \text { fresh beef) }\end{array}$ & $\begin{array}{l}\text { SimaPro, } \\
\text { literatures }\end{array}$ & $\begin{array}{ll}\text { slaughtering house } & 0.079 \mathrm{kWh} \\
\text { coating on lid film } & 39.359 \mathrm{~kJ} \\
\text { packing machine } & 0.149 \mathrm{kWh} \\
& \\
\text { supermarket shelf display } \\
\text { (refrigeration) } & 0.687 \mathrm{kWh}\end{array}$ \\
\hline
\end{tabular}

Electricity is the major form of energy input for production processes, so the origin of electricity has a strong influence on the environmental impact calculation. In this study, UCTE electricity mix (data supplied by Union for the Co-ordination of the Transmission of Electricity, including most of European countries) was used as default to reflect the EU average level in electricity generation, transmission, and consumption. For the industrial users, e.g. on-farm production, packaging production plant, medium voltage electricity was chosen; while for the end users, e.g. supermarket, low voltage electricity was chosen.

Road transport (lorry $>32$ t, Euro 5) and the distances connecting the life stages were assumed. In particular, the refrigerated transport was considered (lorry 16-32 t, Euro 5) for the section from slaughtering house to supermarket [46].

More details are available in the Supporting Information.

\subsubsection{Selection of impact assessment categories}

Following the common practice of LCA of agricultural products $[36,47,55]$, four impact categories were selected, and the method for assessment employed in SimaPro is indicated in the bracket behind each impact category: 
- Global warming (IPCC in 2007 under a 100-year perspective)

Emission of greenhouse gases is considered to be the main reason for such global warming trend development, especially, livestock production involves considerable amount of methane $\left(\mathrm{CH}_{4}\right)$ derived from enteric fermentation and manure management, nitrous oxide $\left(\mathrm{N}_{2} \mathrm{O}\right)$ coming from manure management and pasture, and applied fertilizers and crop residues, and carbon dioxide $\left(\mathrm{CO}_{2}\right)$ due to crop cultivation, land use conversion, etc. [56].

- Non-renewable fossil energy consumption (Cumulative Energy Demand, non-renewable)

This impact indicator provides information about energy generated from fossil fuels, such as coal, oil, natural gas etc., which are considered non-renewable.

- Acidification potential (CML 2 baseline 2000)

This indicator is associated with the combustion of fossil fuel (emission of $\mathrm{SO}_{\mathrm{x}}$ and $\mathrm{NO}_{\mathrm{x}}$ ), and livestock production $\left(\mathrm{NH}_{3}\right)$. Increase of acidification could cause damages to woodlands, lakes, rivers and other eco-systems in the form of acid rain or dry deposition.

- Eutrophication potential (CML 2 baseline 2000)

Using fertilizer could lead to nutrient enrichment to an aquatic system and cause damages to the eco-system.

\subsubsection{System performance and scenarios}

The objective of this study is to highlight the role of active packaging in minimising food losses, and therefore, a sensitivity study considering active packaging with different food loss saving abilities was incorporated.

The food loss data was extracted from the study of Beretta, et al. [1], who reported primary data about beef loss occurring at the retail in Swiss market, being $0.1 \%$, $0.5 \%$ and $1.2 \%$, and all of which were attributed to "too long on the retail shelves". Accordingly, four scenarios were set up to address the food-packaging systems with different food loss saving abilities (see Table 14): conventional MAP, without active coating layer, which serves as the control; Solution 1, 2, and 3 enjoy an increasing saving abilities in a cumulative manner. The unsaved losses are equivalent to produce more in the beginning of the food production flow in order to fulfil the functional unit. To model such relationship, the corresponding reference flows were scaled with a factor, which is also indicated in the table. 
Table 14. Scenarios and their corresponding food loss saving percentages and reference flow scaling factors.

\begin{tabular}{|l|l|l|l|}
\hline Scenario identification & Food loss saving & $\begin{array}{l}\text { Reference flow } \\
\text { scaling factor }\end{array}$ & Comment \\
\hline Conventional MAP & None & 1.018 & $\begin{array}{l}\text { Without active } \\
\text { coating }\end{array}$ \\
\hline Solution 1 & $0.1 \%$ & 1.017 & With active coating \\
\hline Solution 2 & $0.6 \%$ & 1.012 & \\
\hline Solution 3 & $1.8 \%$ & 1 & \\
\hline
\end{tabular}

\subsection{RESULTS AND DISCUSSIONS}

According to the data source [57], beef consumption in the EU in 2010 was 8200000 ton. So in the case of active packaging used, e.g. the Solution 3 as described in the scenario setup in Table 14, potentially, the food loss can be avoided at the retail will be 147600 tons per year. This suggests that the impact of active MAP on the beef distribution can be significant.

\subsubsection{Eco-profile of different scenarios}

Life cycle impact assessment (LCIA) was calculated with respect to the functional unit (1 kg fresh beef) and summarized in Table 15. As expected, the best performance active packaging, i.e. the one used in Solution 3, has achieved an improved eco-profile across all the impact categories evaluated, with reduction percentage about $1 \%-2 \%$ compared to the control, i.e. the conventional MAP. 
Table 15. Eco-profiles of different scenarios.

\begin{tabular}{|l|l|l|l|l|}
\hline & $\begin{array}{l}\text { Global } \\
\text { warming } \\
{[\mathrm{kg} \mathrm{CO}} \\
\text { eq.] }\end{array}$ & $\begin{array}{l}\text { Cumulative } \\
\text { energy } \\
\text { demand } \\
\text { (fossil) }[\mathrm{MJ}]\end{array}$ & $\begin{array}{l}\text { Acidification } \\
\text { potential }[\mathrm{kg} \\
\mathrm{SO}_{2} \text { eq. }\end{array}$ & $\begin{array}{l}\text { Eutrophication } \\
\text { potential }[\mathrm{kg} \\
\mathrm{PO}_{4} \text { eq. }\end{array}$ \\
\hline Conventional MAP & 23.2844 & 95.2307 & 0.2808 & 0.2157 \\
\hline Solution 1 & 23.2794 & 95.5147 & 0.2806 & 0.2156 \\
\hline Solution 2 & 23.1650 & 95.0451 & 0.2793 & 0.2145 \\
\hline Solution 3 & 22.8903 & 93.9181 & 0.2759 & 0.2120 \\
\hline
\end{tabular}

\subsubsection{Global warming (GW)}

Global warming $(\mathrm{GW})$ for different scenarios is plotted in Figure 45, including the $\mathrm{GW}$ contribution from different life cycle stages. The figure is plotted as a panel chart, which shows both the global impact distribution and the impact arising from the life stages other than food production. The same applies to the rest figures. 


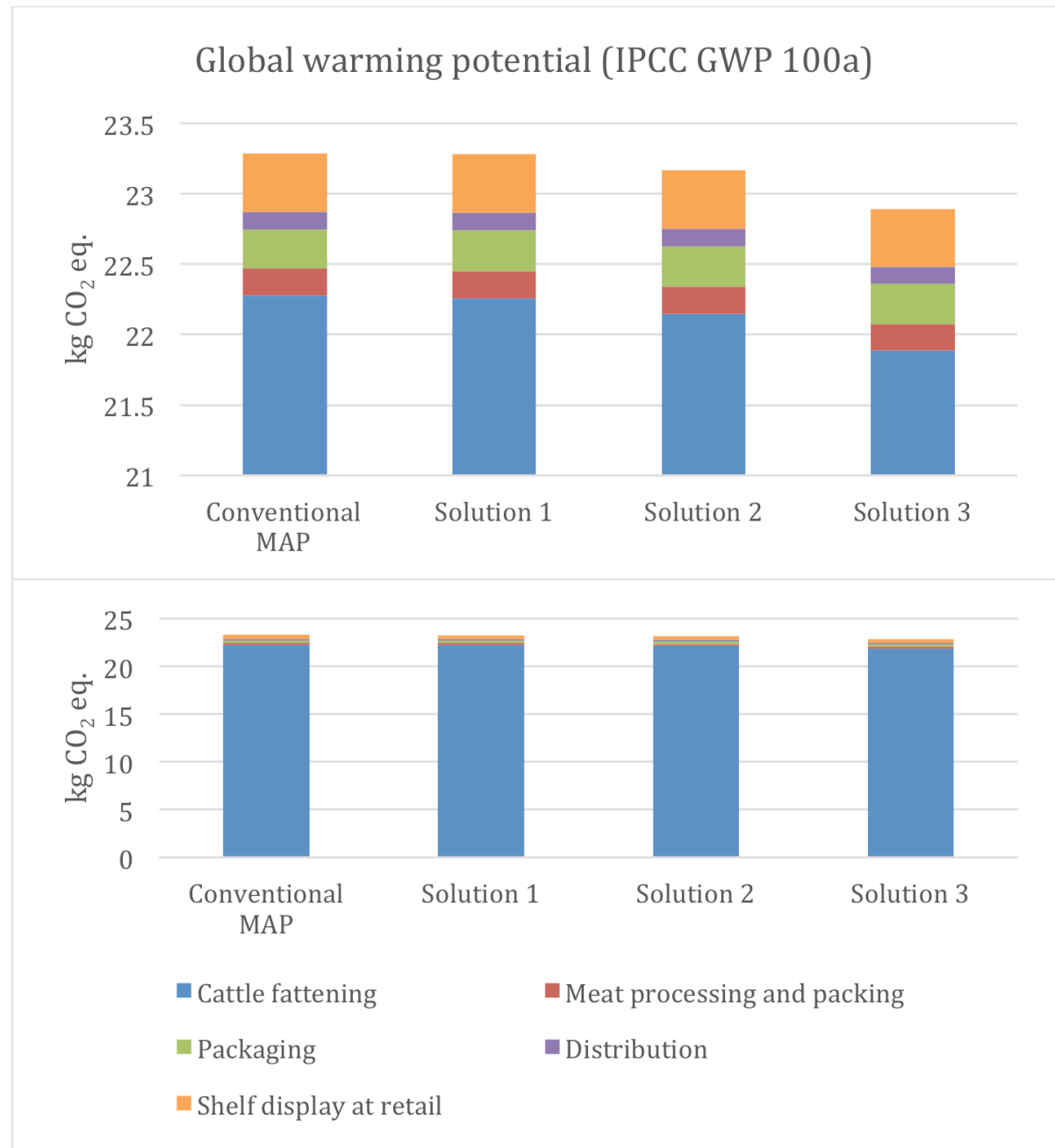

Figure 45. Global warming potential (under a 100-year perspective) for different scenarios: conventional MAP serving as reference, solution 1-3 corresponding to the application of active packagings having different food loss saving abilities $0.1 \%, 0.6 \%$ and $1.8 \%$, respectively. The figure is plotted in panel chart in order to highlight the contributions arising from the life stages other than food production.

As expected, food production (cattle fattening) contributes to the vast majority of the $\mathrm{CO}_{2}$ eq., being $96 \%$ across all the scenarios. In terms of absolute $\mathrm{GW}$, it is 21.9 $\mathrm{kg} \mathrm{CO}$ eq, which is in line with other sources: 27.3 as reported in [47] and 14-32 as reported in [55]. In this case study, food production itself overwhelmingly dominates the impact category, and the role of active packaging is to offset certain 
amount of the food losses by introducing a small amount of additional resources, and thus resulting in decreased $\mathrm{CO}_{2}$ eq. of the whole system.

It can be noticed that from conventional MAP to solution 1, their cumulative $\mathrm{CO}_{2}$ eq. are almost equal, suggesting that the eliminated food loss $(0.1 \%)$ is enough to offset the additional life cycle stages due to use of active packaging. As the food loss saving increases, the overall GW impact decreases. As seen in Solution 3, the system generates $1.7 \%$ less $\mathrm{CO}_{2}$ eq. compared to the conventional MAP.

Apart from the major contributor (cattle fattening), it is possible to locate the hotspot from other life cycle stages, although they are of minor contribution to the overall $\mathrm{GW}$ of the system. For example, shelf display at retail was responsible for $0.4 \mathrm{~kg} \mathrm{CO}$ eq., followed by packaging manufacturing $0.28 \mathrm{~kg} \mathrm{CO}$ eq., meat processing and packing $0.19 \mathrm{~kg} \mathrm{CO}_{2}$ eq., and distribution $0.12 \mathrm{~kg} \mathrm{CO}_{2}$ eq.

\subsubsection{Cumulative energy demand (non-renewable, fossil)}

Cumulative energy demand (non-renewable, fossil) for different scenarios is plotted in Figure 46, including the contributions from different life cycle stages. 


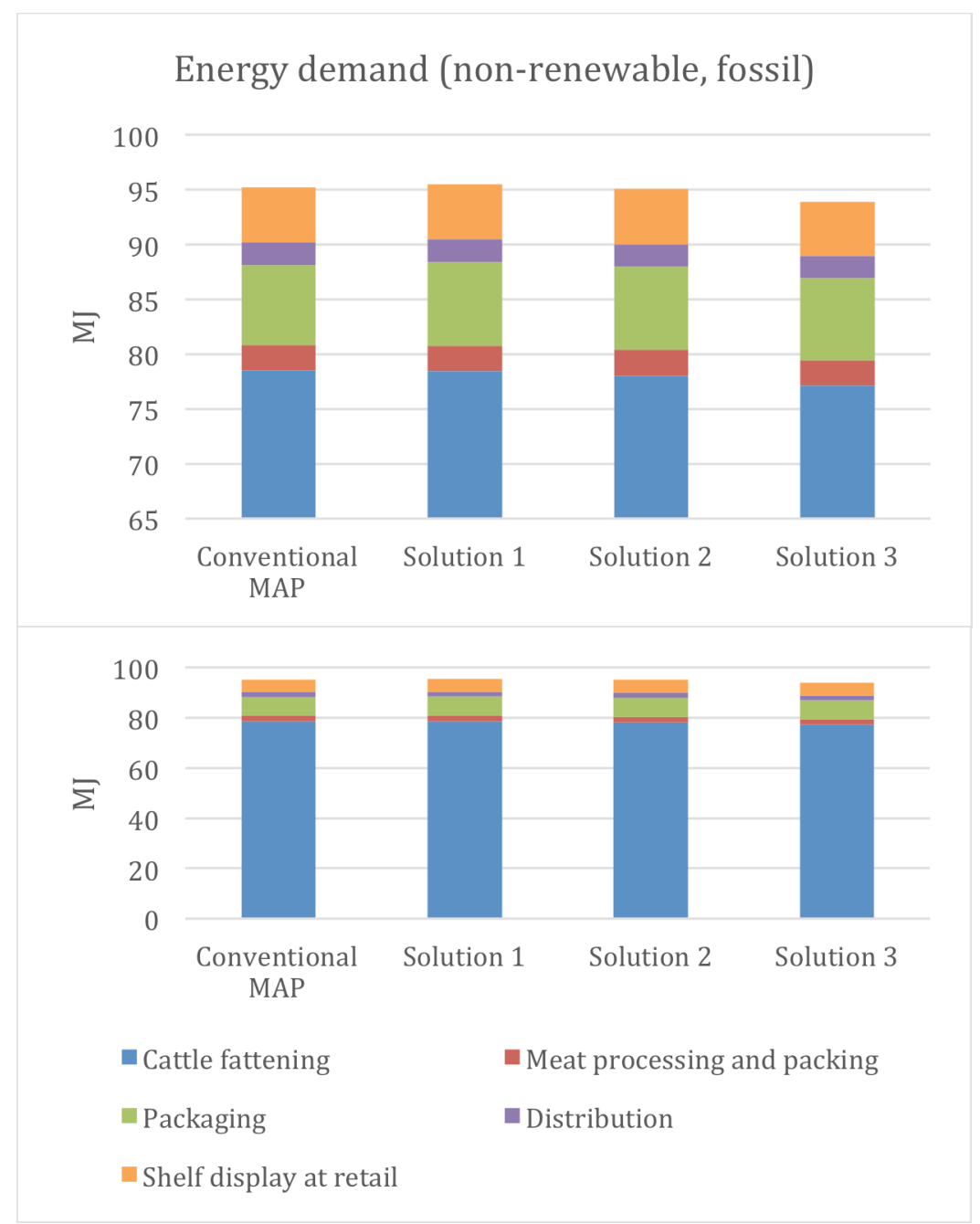

Figure 46. Cumulative energy demand (non-renewable, fossil) for different scenarios: conventional MAP serving as reference, solution 1-3 corresponding to the application of active packagings having different food loss saving abilities $0.1 \%, 0.6 \%$ and $1.8 \%$, respectively. The figure is plotted in panel chart in order to highlight the contributions arising from the life stages other than food production.

In a similar way, the food production again dominates the system's cumulative energy demand, being $82 \%$ across all the scenarios investigated. In terms of absolute value, it gives a value around $77 \mathrm{MJ}$, which is higher than that reported by other sources: for example, 59.2 MJ in [47], and 34-52 MJ in [55]. This discrepancy may be due to the impact allocation methods used in different studies $[58,59]$. In 
our calculation, we directly focus on the suckler cow-calf (SCC) system, and the impact is fully allocated to beef rather than distributing it among other products, e.g. milk, leather, etc.

Firstly, a breakeven point can only be reached after going up to Solution 2, and this is because in this impact category, the contribution from food production is slightly lower, just accounting for $82 \%$ of the system, which suggests that it requires a better performance active packaging with higher level food loss saving ability to offset the impact associated with using of active packaging.

Secondly, based on the calculation it is possible to locate the hotspots in terms of energy consumption. Among the life cycle stages, packaging manufacturing is an energy intensive component (c.a. $7.5 \mathrm{MJ}$ ), followed by shelf display at retail (c.a. 5.0 MJ), distribution and meat processing \& packing, representing c.a. 2.0 MJ and $2.3 \mathrm{MJ}$, respectively. Therefore, some improvement measures can be considered, for example, optimised packaging design, improved inventory turnover (i.e. shorter shelf display time) through refined management practices, etc.

\subsubsection{Acidification Potential (AP) and Eutrophication Potential (EP)}

Acidification potential (AP) and eutrophication potential (EP) for different scenarios are plotted in Figure 47 and Figure 48, respectively. For AP and EP, food production accounts for $98 \%$ of the overall system, which is reasonable and can be attributed to the on-farm emissions sources, including animal feeding, crop cultivation, use of fertilizer, etc. The absolute $\mathrm{SO}_{2}$ eq. and $\mathrm{PO}_{4}$ eq. locate in the reasonable range as reported in [55]. 


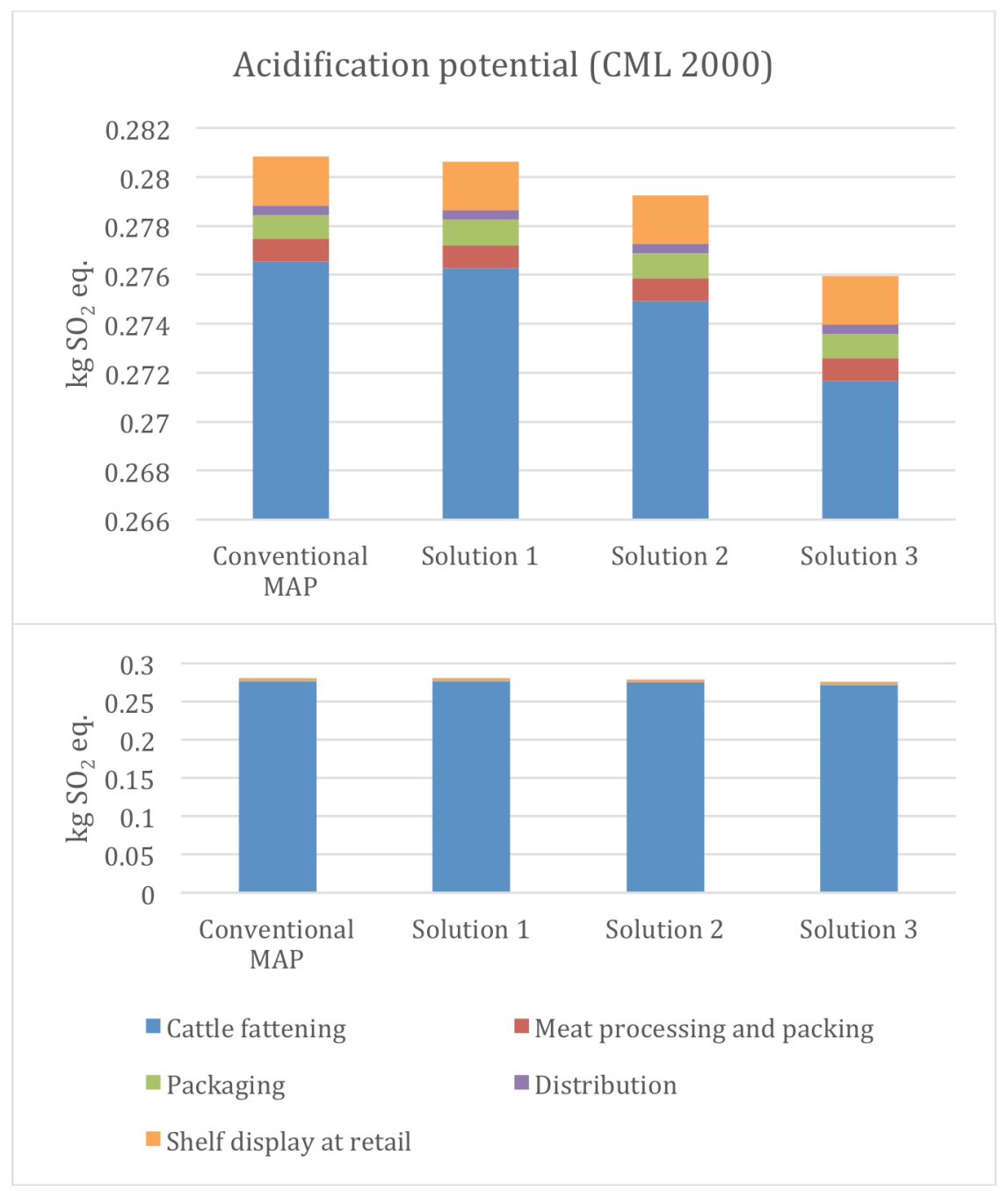

Figure 47. Acidification potential (AP) for different scenarios: conventional MAP serving as reference, solution 1-3 corresponding to the application of active packagings having different food loss saving abilities $0.1 \%, 0.6 \%$ and $1.8 \%$, respectively. The figure is plotted in panel chart in order to highlight the contributions arising from the life stages other than food production. 


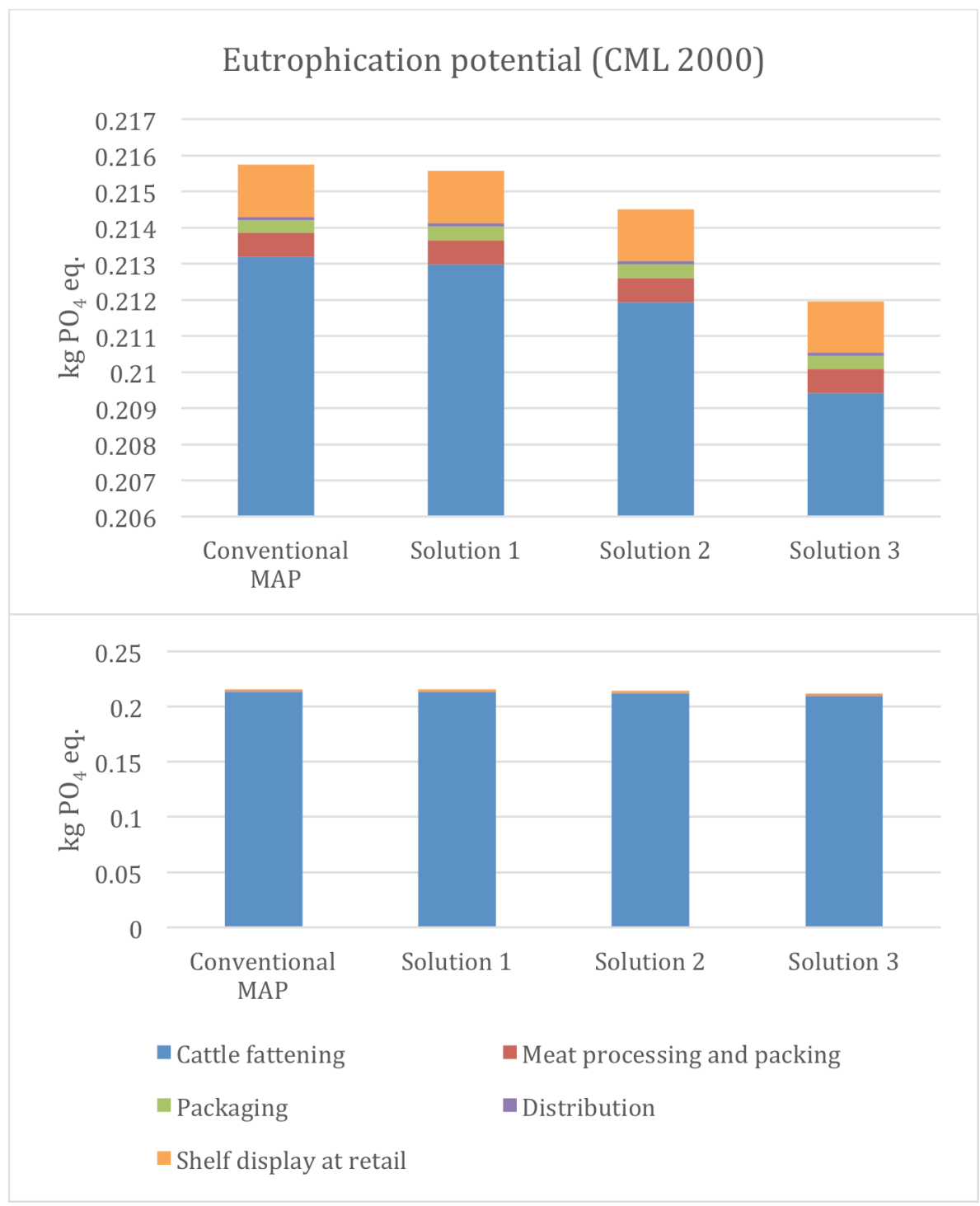

Figure 48. Eutrophication potential (EP) for different scenarios: conventional MAP serving as reference, solution 1-3 corresponding to the application of active packagings having different food loss saving abilities $0.1 \%, 0.6 \%$ and $1.8 \%$, respectively. The figure is plotted in panel chart in order to highlight the contributions arising from the life stages other than food production.

Generally, the contribution from other life cycle stages follows the use of energy, with retail and slaughterhouse taking the major shares. And the breakeven point can be achieved as early as in Solution 1 for both impact categories. 


\subsection{CONCLUSIONS}

To highlight the ability of active packaging on minimising food losses, an LCA (life cycle assessment) study was carried out by focusing on a case study, which is to use thymol/carvacrol enabled active packaging for fresh beef. From the LCIA (life cycle impact assessment) calculation, the eco-profiles of food using conventional MAP (current state) and food using novel active MAP (containing active coating) were compared.

On the basis of food loss saving ability of the active packaging concerned, a series of scenarios have been established. In the scenario using the best performance active packaging, it was shown that a breakeven point can be achieved across the four impact categories evaluated, including global warming (GW), fossil energy demand, acidification potential (AP), and eutrophication potential (EP). On the other hand, differences were observed between the impact categories; for example, for the impact of AP and EP, the breakeven point can be achieved as early as $0.1 \%$ food loss elimination, whereas in the case of cumulative energy demand (fossil), it required more efforts to reach the breakeven point, and more specifically, the active packaging performance shall be good enough to reduce food losses at least by $0.6 \%$.

As an example, using active packaging solutions could potentially reduce the beef losses at the retail of the EU market up to 147600 ton per year. Besides, if the system boundaries are extended to the consumption at household, more loss saving can be expected.

Finally, it is expected that the obtained results would serve as guidelines for active packaging development considering the reduction of food losses as a key parameter. 


\subsection{REFERENCES}

1. Beretta C, Stoessel F, Baier U, Hellweg S. Quantifying food losses and the potential for reduction in Switzerland. Waste Management 2013; 33(3), pp. 764-773, DOI: http://dx.doi.org/10.1016/j.wasman.2012.11.007.

2. Williams H, Wikström F, Otterbring T, Löfgren M, Gustafsson A. Reasons for household food waste with special attention to packaging. Journal of Cleaner Production 2012; 24, pp. 141-148.

3. Romero-Barrios P, Hempen M, Messens W, Stella P, Hugas M. Quantitative microbiological risk assessment (QMRA) of food-borne zoonoses at the European level. Food Control 2013; 29(2), pp. 343-349.

4. Benson L, Payne D. Extending shelf life with active packaging. Fleischwirtschaft international: journal for meat production and meat processing 2012(4), pp. 48.

5. Conte A, Scrocco C, Sinigaglia M, Del Nobile M. Innovative active packaging systems to prolong the shelf life of mozzarella cheese. Journal of dairy science 2007; 90(5), pp. 2126-2131.

6. Chouliara E, Karatapanis A, Savvaidis I, Kontominas M. Combined effect of oregano essential oil and modified atmosphere packaging on shelf-life extension of fresh chicken breast meat, stored at 4 C. Food Microbiology 2007; 24(6), pp. 607-617.

7. Restuccia D, Spizzirri UG, Parisi OI, Cirillo G, Curcio M, Iemma F, Puoci F, Vinci G, Picci N. New EU regulation aspects and global market of active and intelligent packaging for food industry applications. Food Control 2010; 21(11), pp. 1425-1435.

8. Brody AL, Strupinsky E, Kline LR, Active packaging for food applications. CRC press: 2001.

9. Suppakul P, Miltz J, Sonneveld K, Bigger SW. Active packaging technologies with an emphasis on antimicrobial packaging and its applications. Journal of Food Science 2003; 68(2), pp. 408-420.

10. Muriel-Galet V, López-Carballo G, Gavara R, Hernández-Muñoz P. Antimicrobial food packaging film based on the release of LAE from EVOH. International journal of food microbiology 2012; 157(2), pp. 239244.

11. Rhim J-W, Hong S-I, Ha C-S. Tensile, water vapor barrier and antimicrobial properties of PLA/nanoclay composite films. LWT-Food Science and Technology 2009; 42(2), pp. 612-617.

12. Fernández A, Soriano E, Hernández - Muñoz P, Gavara R. Migration of antimicrobial silver from composites of polylactide with silver zeolites. Journal of food science 2010; 75(3), pp. E186-E193. 
13. Kerry J, O'grady M, Hogan S. Past, current and potential utilisation of active and intelligent packaging systems for meat and muscle-based products: A review. Meat science 2006; 74(1), pp. 113-130.

14. Coma V. Bioactive packaging technologies for extended shelf life of meatbased products. Meat Science 2008; 78(1-2), pp. 90-103, DOI: http://dx.doi.org/10.1016/j.meatsci.2007.07.035.

15. Skandamis PN, Nychas G-JE. Preservation of fresh meat with active and modified atmosphere packaging conditions. International Journal of Food Microbiology 2002; 79(1), pp. 35-45.

16. Food Standards Agency. Food Standards Agency guidance on the safety and shelf-life of vacuum and modified atmosphere packed chilled foods with respect to non-proteolytic Clostridium botulinum. 2008 [cited 15-042015]; Available from: http://food.gov.uk/multimedia/pdfs/publication/vacpacguide.pdf.

17. Li X, Xing Y, Jiang Y, Ding Y, Li W. Antimicrobial activities of $\mathrm{ZnO}$ powder - coated PVC film to inactivate food pathogens. International journal of food science \& technology 2009; 44(11), pp. 2161-2168.

18. López P, Sánchez C, Batlle R, Nerín C. Development of flexible antimicrobial films using essential oils as active agents. Journal of Agricultural and Food Chemistry 2007; 55(21), pp. 8814-8824.

19. Gutierrez J, Barry-Ryan C, Bourke P. Antimicrobial activity of plant essential oils using food model media: efficacy, synergistic potential and interactions with food components. Food microbiology 2009; 26(2), pp. 142-150.

20. Jin $\mathrm{T}$, Gurtler J. Inactivation of Salmonella in liquid egg albumen by antimicrobial bottle coatings infused with allyl isothiocyanate, nisin and zinc oxide nanoparticles. Journal of applied microbiology 2011; 110(3), pp. 704-712.

21. Barbosa-Pereira L, Aurrekoetxea GP, Angulo I, Paseiro-Losada P, Cruz JM. Development of new active packaging films coated with natural phenolic compounds to improve the oxidative stability of beef. Meat science 2014; 97(2), pp. 249-254.

22. Rojas-Graü MA, Raybaudi-Massilia RM, Soliva-Fortuny RC, AvenaBustillos RJ, McHugh TH, Martín-Belloso O. Apple puree-alginate edible coating as carrier of antimicrobial agents to prolong shelf-life of fresh-cut apples. Postharvest Biology and Technology 2007; 45(2), pp. 254-264.

23. Scampicchio M, Ballabio D, Arecchi A, Cosio SM, Mannino S. Amperometric electronic tongue for food analysis. Microchimica Acta 2008; 163(1-2), pp. 11-21. 
24. Kim YM, Paik HD, Lee DS. Shelf - life characteristics of fresh oysters and ground beef as affected by bacteriocin - coated plastic packaging film. Journal of the Science of Food and Agriculture 2002; 82(9), pp. 998-1002.

25. Ammor MS, Argyri A, Nychas G-JE. Rapid monitoring of the spoilage of minced beef stored under conventionally and active packaging conditions using Fourier transform infrared spectroscopy in tandem with chemometrics. Meat science 2009; 81(3), pp. 507-514.

26. Djenane D, Sanchez-Escalante A, Beltran JA, Roncalés P. Extension of the shelf life of beef steaks packaged in a modified atmosphere by treatment with rosemary and displayed under UV-free lighting. Meat Science 2003; 64(4), pp. 417-426.

27. Camo J, Lorés A, Djenane D, Beltrán JA, Roncalés P. Display life of beef packaged with an antioxidant active film as a function of the concentration of oregano extract. Meat science 2011; 88(1), pp. 174-178.

28. Nerín C, Tovar L, Djenane D, Camo J, Salafranca J, Beltrán JA, Roncalés P. Stabilization of beef meat by a new active packaging containing natural antioxidants. Journal of Agricultural and Food Chemistry 2006; 54(20), pp. 7840-7846.

29. Camo J, Beltrán JA, Roncalés P. Extension of the display life of lamb with an antioxidant active packaging. Meat Science 2008; 80(4), pp. 1086-1091.

30. Sagoo S, Board R, Roller S. Chitosan inhibits growth of spoilage microorganisms in chilled pork products. Food Microbiology 2002; 19(2), pp. 175-182.

31. Yingyuad S, Ruamsin S, Reekprkhon D, Douglas S, Pongamphai S, Siripatrawan U. Effect of chitosan coating and vacuum packaging on the quality of refrigerated grilled pork. Packaging technology and science 2006; 19(3), pp. 149-157.

32. McMillin KW. Where is MAP going? A review and future potential of modified atmosphere packaging for meat. Meat Science 2008; 80(1), pp. 43-65.

33. Gironi F, Piemonte V. Life cycle assessment of polylactic acid and polyethylene terephthalate bottles for drinking water. Environmental Progress \& Sustainable Energy 2011; 30(3), pp. 459-468.

34. Vink ET, Rabago KR, Glassner DA, Gruber PR. Applications of life cycle assessment to NatureWorks ${ }^{\mathrm{TM}}$ polylactide (PLA) production. Polymer Degradation and stability 2003; 80(3), pp. 403-419.

35. Chiellini E, Environmentally compatible food packaging. Woodhead Publishing Limited and CRC Press LLC: 2008.

36. Williams H, Wikström F. Environmental impact of packaging and food losses in a life cycle perspective: a comparative analysis of five food items. Journal of Cleaner Production 2011; 19(1), pp. 43-48. 
37. Wikström F, Williams H. Potential environmental gains from reducing food losses through development of new packaging-a life - cycle model. Packaging Technology and Science 2010; 23(7), pp. 403-411.

38. Li H, Li F, Wang L, Sheng J, Xin Z, Zhao L, Xiao H, Zheng Y, Hu Q. Effect of nano-packing on preservation quality of Chinese jujube (Ziziphus jujuba Mill. var. inermis (Bunge) Rehd). Food chemistry 2009; 114(2), pp. 547-552.

39. Duncan TV. Applications of nanotechnology in food packaging and food safety: Barrier materials, antimicrobials and sensors. Journal of colloid and interface science 2011; 363(1), pp. 1-24.

40. Walser T, Demou E, Lang DJ, Hellweg S. Prospective environmental life cycle assessment of nanosilver T-shirts. Environmental science \& technology 2011; 45(10), pp. 4570-4578.

41. Xie L, Rielly CD, Özcan - Taşkin G. Break - Up of Nanoparticle Agglomerates by Hydrodynamically Limited Processes. Journal of Dispersion Science and Technology 2008; 29(4), pp. 573-579.

42. Lowry G, Casman E, Nanomaterial transport, transformation, and fate in the environment, in Nanomaterials: risks and benefits. 2009, Springer. p. 125-137.

43. Knight P, Jenkins JO. Adopting and applying eco-design techniques: a practitioners perspective. Journal of Cleaner Production 2009; 17(5), pp. 549-558.

44. Kunnari E, Valkama J, Keskinen M, Mansikkamäki P. Environmental evaluation of new technology: printed electronics case study. Journal of cleaner production 2009; 17(9), pp. 791-799.

45. Lebersorger S, Schneider F. Discussion on the methodology for determining food waste in household waste composition studies. Waste management 2011; 31(9), pp. 1924-1933.

46. Rizo SC. Estudio de las características ambientales y económicas de los envases de cartón ondulado con respecto a los envases reutilizables de plástico utilizados en el transporte a larga distancia de productos hortofrutícolas. Instituto Tecnológico del Embalaje, Transporte y Logística, 2005.

47. Nguyen TLT, Hermansen JE, Mogensen L. Environmental consequences of different beef production systems in the EU. Journal of Cleaner Production 2010; 18(8), pp. 756-766.

48. Roy P, Orikasa T, Thammawong M, Nakamura N, Xu Q, Shiina T. Life cycle of meats: an opportunity to abate the greenhouse gas emission from meat industry in Japan. Journal of environmental management 2012; 93(1), pp. 218-224. 
49. Humbert S, Rossi V, Margni M, Jolliet O, Loerincik Y. Life cycle assessment of two baby food packaging alternatives: glass jars vs. plastic pots. The International Journal of Life Cycle Assessment 2009; 14(2), pp. 95-106.

50. Pardo G, Zufía J. Life cycle assessment of food-preservation technologies. Journal of Cleaner Production 2012; 28, pp. 198-207.

51. Muriel-Galet V, Cerisuelo JP, López-Carballo G, Aucejo S, Gavara R, Hernández-Muñoz P. Evaluation of EVOH-coated PP films with oregano essential oil and citral to improve the shelf-life of packaged salad. Food Control 2013; 30(1), pp. 137-143.

52. Cerisuelo JP, Alonso J, Aucejo S, Gavara R, Hernández-Muñoz P. Modifications induced by the addition of a nanoclay in the functional and active properties of an EVOH film containing carvacrol for food packaging. Journal of Membrane Science 2012; 423, pp. 247-256.

53. Bates B, Eng P. State-of-the-art developments to save energy in coating drying. Proceedings of TAPPI paper conference PAPERCON 2010, Atlanta.

54. Fricke B, Becker B. Energy use of doored and open vertical refrigerated display cases. International Refrigeration and Air Conditioning Conference 2010, Purdue.

55. De Vries M, De Boer I. Comparing environmental impacts for livestock products: A review of life cycle assessments. Livestock Science 2010; 128(1), pp. 1-11.

56. Crosson P, Shalloo L, O’Brien D, Lanigan G, Foley P, Boland T, Kenny D. A review of whole farm systems models of greenhouse gas emissions from beef and dairy cattle production systems. Animal Feed Science and Technology 2011; 166, pp. 29-45.

57. Hocquette J-F, Chatellier V. Prospects for the European beef sector over the next 30 years. Animal Frontiers 2011; 1(2), pp. 20-28.

58. Cederberg C, Stadig M. System expansion and allocation in life cycle assessment of milk and beef production. The International Journal of Life Cycle Assessment 2003; 8(6), pp. 350-356.

59. Flysjö A, Cederberg C, Henriksson M, Ledgard S. How does co-product handling affect the carbon footprint of milk? Case study of milk production in New Zealand and Sweden. The International Journal of Life Cycle Assessment 2011; 16(5), pp. 420-430. 
6 Paper IV. Selection of nanomaterial-based active agents for packaging applications: using Life Cycle Assessment (LCA) as a tool 


\subsection{INTRODUCTION}

Choosing the appropriate active agent is a key to the development of antimicrobial packaging system. Compared with the organic agents (e.g. organic acid, essential oil component, nisin, etc.), metallic nanoparticles (NPs) as antimicrobial agent offers a few merits, such as superior antimicrobial efficacy, no negative impacts on the food sensory properties, and compatibility with harsh polymer processing conditions [1-4].

As the NPs contain strong antimicrobial activity, they are not only used for food spoilage control [5-7], but also used to inactivate the food-borne pathogens to ensure food safety. This attribute has been examined in a number of works: for example, PHA (Polyhydroxybutyrate) film containing silver nanoparticles (Ag NPs) induced $6.89 \log$ reduction against Salmonella enterica and $5.51 \log$ reduction against Listeria monocytogenes (log reduction greater than 2 means inactivation efficacy over 99\%) [8]; Titanium dioxide nanoparticles $\left(\mathrm{TiO}_{2} \mathrm{NPs}\right)$ embedded in wheat gluten film enabled up to $98.5 \%$ bacterial reduction after $2 \mathrm{~h}$ of light irradiation [9]; impressive inhibitory effect was observed for using zinc oxide nanoparticles ( $\mathrm{ZnO} \mathrm{NPs}$ ) to inactivate E. coli $\mathrm{O} 157: \mathrm{H} 7$ [4]; PLA coating containing $\mathrm{ZnO}$ NPs was also found to be effective in inactivating Salmonella inoculated in liquid egg albumen [10].

Survey of literature shows that the relevant research has mainly focused on four nanoparticles: silver $(\mathrm{Ag})$, titanium dioxide $\left(\mathrm{TiO}_{2}\right)$, zinc oxide $(\mathrm{ZnO})$ and copper $(\mathrm{Cu})$ [2]. So when all of them can impart good antimicrobial activity to the host material, a practical question lying ahead is how to make a selection between them. In this case, sustainability can be used as a criterion for the selection. This is because sustainability has already become an important consideration in the packaging value chain. The sustainability of packaging covers so many aspects, e.g. material selection, design, format, carrying eco label, easy to empty to minimise the product losses, and the use of biodegradable materials. Improvement on these attributes is highly valued by the group of consumers of high environmental awareness and can strongly influence their buying decisions. As claimed by a packaging producer, sustainable packaging solution can potentially lift the sales by $2-4 \%[11]$.

Life Cycle Assessment (LCA) is a tool that enables a holistic view over the impacts caused to the environment due to use of a product or a service. It takes into account all the inputs (e.g. raw materials, chemicals, energy, etc.) and outputs (e.g. emissions, waste, co-products, etc.) associated with the life stages of the product, including raw material extraction, manufacturing, use/reuse/maintenance till the end-of-life, i.e. a cradle-to-grave approach [12]. To carry out a LCA, the inventory 
data are collected and used as input for different impact characterization models such that a specific environmental impact can be measured in a quantitative manner. With regard to the packaging sector, LCA has already gained a universal recognition for being a useful tool to evaluate the environmental profile of a packaging solution. Additionally, LCA enables to avoid shifting the potential environmental burdens from one stage to another, or from one stakeholder to another.

The early attempt of using LCA for nanomaterial evaluation can be found in a publication in 2001 [13], in which the authors investigated a nanocrystalline dye (composed of $\mathrm{TiO}_{2} \mathrm{NPs}$ and carbon powder) following a cradle-to-grave approach. In 2003, Lloyd and Lave carried out a hybrid LCA on a nanoclay reinforced polymer composite [14]. After that, the number of publications on such topic has increased promptly, and in the meanwhile the research interest has expanded to more types of nanomaterials and application fields, e.g. carbon nanotube [15], nanosilver [16] and nano silica [17]. As concluded in the LCA research community the current ISO-based LCA framework (ISO14040 and ISO14044) is fully applicable to nanomaterials/nanomaterial-enabled products despite the barriers and data gaps to carry out a comprehensive LCA [18-20]. The barriers include

- scarcity of inventory data (in particular the comprehensiveness on the emission side),

- lack of appropriate characterization factors to address the nano-specific toxicity in LCIA (Life Cycle Impact Assessment),

- and uncertainty/ambiguity concerned with the fate of nanomaterials, which strongly depends on the nanomaterial's colloidal behaviour.

Hischier et al. in their work [21] proposed some strategies to overcome the existing gaps for applying LCA to nanomaterial/nanomaterial-enabled product. In this study, we incorporate these strategies to evaluate three packaging films incorporating different NPs as antimicrobial agents. The agents used are Ag NPs, $\mathrm{TiO}_{2}$ NPs, and a mixture of both since the inventory data of these two nanoparticles are available. A biodegradable polymer, PLA (Polylactic Acid), is used as the host material.

\subsection{MATERIALS AND METHODS}

This LCA study was modelled in SimaPro 7.3.3 (PRé Consultants, The Netherlands). The impact categories and the corresponding characterization models used for impact assessment are described as following:

- Climate change (IPCC 2007 GWP 100a V1.02) 
- Non-renewable energy demand, fossil (Cumulative Energy Demand V1.08)

\subsubsection{Goal and scope}

The packaging concerned is a simple polymer film made out of PLA. It is produced by blow film extrusion process incorporating the designated loadings of NPs. Three packaging films (Packaging A, B and C) were considered by considering the antimicrobial efficacy of each agent used.

The Functional Unit (FU) was defined as to produce $1 \mathrm{~kg}$ active packaging material (PLA polymer co-extruded with NPs) that provides equivalent effectiveness to ensure food safety and quality (i.e. equivalent antimicrobial efficacy). Packaging specifications, e.g. size and thickness, were not defined, as it depends on the intended applications or the user's need.

The system boundaries are depicted in Figure 49, including raw material extraction (production of PLA pellets and nanoparticles), active packaging film manufacturing (film extrusion), active film distribution and transport, use, and the end-of-life of packaging (50\% for municipal incineration and $50 \%$ for landfill), i.e. a cradle-tograve approach.

Assumption was made that the production and other life cycles took place in the EU (European Union). 


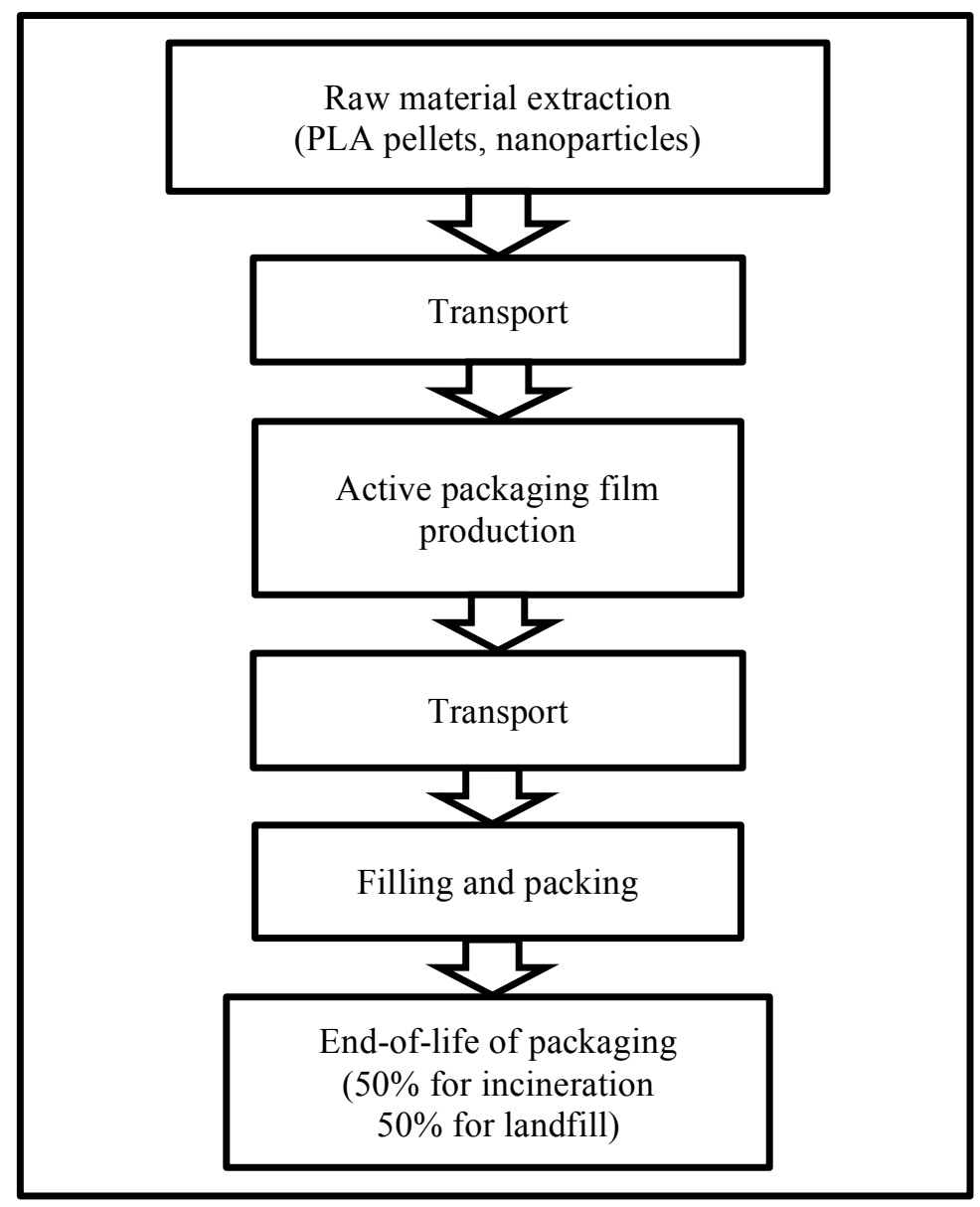

Figure 49. System boundaries. Usage by consumer is excluded.

\subsubsection{Life cycle inventory analysis}

\section{Raw material extraction and packaging manufacturing}

Data for PLA pellets production and film extrusion process were extracted from Ecoinvent database V2.2. In accordance with the description of the data source, the PLA production data was supplied by the world largest PLA plant at that time; a production yield of $97.6 \%$ was taken into account.

The inventory of Ag NP production was established according to the study of Walser et al. [16], which the data are extracted from an industrial scale FSP (Flame Spray Pyrolysis) process having a capacity of $500 \mathrm{~kg} / \mathrm{year}$. The primary data input 
is summarised in Table 16. The corresponding material and energy input was extracted from the databases of SimaPro, and the Ecoinvent process was preferably used whenever available. For the electricity use in the production, "UCTE mix" was used in order to reflect the average energy consumption in the EU.

Table 16. Resources input and emissions for producing $1 \mathrm{~kg}$ silver nanoparticles (Flame Spray Pyrolysis). Data source: [16].

\begin{tabular}{|l|l|}
\hline Input & Amount \\
\hline Oxygen $\left(\mathrm{O}_{2}\right)$ & $33.4 \mathrm{~kg}$ \\
\hline Methane $\left(\mathrm{CH}_{4}\right)$ & $1.53 \mathrm{~kg}$ \\
\hline Tap water $\left(\mathrm{H}_{2} \mathrm{O}\right)$ & $62.8 \mathrm{~kg}$ \\
\hline Silver-octanoate $\left(\mathrm{AgC}_{8} \mathrm{H}_{15} \mathrm{O}_{2}\right)$ & $2.35 \mathrm{~kg}$ \\
\hline 2-thylhexanoic acid $\left(\mathrm{C}_{8} \mathrm{H}_{16} \mathrm{O}_{2}\right)$ & $6.29 \mathrm{~kg}$ \\
\hline Xylene $\left(\mathrm{C}_{8} \mathrm{H}_{10}\right)$ & $6.29 \mathrm{~kg}$ \\
\hline Electricity, medium voltage, at grid UCTE & $25.1 \mathrm{kWh}$ \\
\hline Emissions & \\
\hline Nitric oxide & $0.387 \mathrm{~kg}$ \\
\hline Carbon dioxide, fossil & $43.9 \mathrm{~kg}$ \\
\hline Water & $16.8 \mathrm{~kg}$ \\
\hline Wastewater treatment, class 3 & $0.063 \mathrm{~m}$ \\
\hline
\end{tabular}

The inventory of $\mathrm{TiO}_{2} \mathrm{NP}$ production was extracted from the work of Grubb et al. [22]. The primary resources input is summarised in Table 17. (N.B. lack of data on the emission side). In this study, the authors reported a pilot scale production process called Hydrochloride process. No allocation was considered for the byproduct generated at pyrohydrolysis stage due to its low value. Similarly, "UCTE mix" was used as the electricity input for the production. 
Table 17. Resources input for producing $1 \mathrm{~kg}$ titanium dioxide nanoparticles (hydrochloride process). Data source: [22]

\begin{tabular}{|l|l|}
\hline Input & Amount \\
\hline Ilmenite & $2.165 \mathrm{~kg}$ \\
\hline Iron powder & $0.103 \mathrm{~kg}$ \\
\hline Hydrochloric acid $(\mathrm{HCl})$ & $0.065 \mathrm{~kg}$ \\
\hline Heat (natural gas) & $44.894 \mathrm{MJ}$ \\
\hline Steam & $14.948 \mathrm{~kg}$ \\
\hline Electricity & $5.443 \mathrm{MJ}$ \\
\hline
\end{tabular}

\section{Transport}

Assumptions were made for the transport scheme:

- the PLA pellets and the additives were shipped to the packaging plant and covered a distance of $100 \mathrm{~km}$ by lorry (16-32t, EURO 5);

- the active PLA film was shipped to other life cycle stages (packaging converter, user, and waste treatment facilities) and covered a total distance of $100 \mathrm{~km}$ by lorry $(>16 \mathrm{t})$.

\section{Filling and packing}

The active film is used for packing foods at the food plant. Operations such as filling and hot sealing were considered. No specific food is assigned to the packaging film, and food production was excluded. Usage by consumer was excluded.

\section{End-of-life of packaging}

The disposal scenario was set as 50\% going for municipal incineration [23] and the other $50 \%$ for landfill as inert material. The idea is to reflect a more realistic situation.

PLA as a biodegradable polymer offers more options in waste management. Mechanical recycling and composting are recommended [24]. But in current stage 
the facilities still lag behind and are not widely available (e.g. collecting, sorting, and recycling). In the previously published LCA studies the disposal scenarios are often based on assumptions [25], e.g. 100\% ends up in landfill [26], or $100 \%$ ends up in incineration as mixed plastics [27]. Besides, the rate of the post-consumer plastic packaging recycling is low, and a large part of it still goes for landfill [23].

PLA was treated as inert material in landfill, which is supported by the relevant study [28]. It is assumed that the incorporated nanoparticles have an inert role in the PLA composite's behaviour both in incineration and in landfill.

\subsection{RESULTS AND DISCUSSIONS}

\subsubsection{Impact of nanoparticle production}

Global Warming Potential (GWP) and Cumulative Energy Demand (CED) are the two mostly reported impacts factors as seen from the previous nanomaterialfocused LCAs [21]. Though nanomaterial is often used as additives at a low weight share $(<5 \%)$, it still makes sense to look at the energy consumption related impacts. One reason is that nanomaterial synthesis is an energy intensive process [29]. Another reason is that in recent years the global production of nanomaterials has increased rapidly. According to the report from Keller et al. [30], the global volume of nanomaterial production in 2010 was $260,000-309,000$ ton, distributing over 800-1500 consumer products [31]. In the case of $\mathrm{TiO}_{2} \mathrm{NPs}$, the total volume of production in 2010 was about 88,000 ton, with coating/paint/pigments and cosmetics being the major application fields [32]. While for Ag NPs, in the same year, the global production was 452 ton, much smaller than $\mathrm{TiO}_{2} \mathrm{NPs}$, with its application in the fields of medical (141 ton) and coating/paints/vanishes (104 ton), which together accounts for more than half of the total production volume [32].

The environmental impacts for producing $1 \mathrm{~kg}$ of NPs are summarized in Table 18 . In an overview, there is a big difference between the two NPs across the impact categories concerned. A two-order magnitude difference can be observed in GWP, and a one-order magnitude difference in the non-renewable fossil energy consumption of CED. This is mainly due to the different production methods of the NPs. Similarly, in one LCA study [22] a three-order magnitude difference was found between $\mathrm{TiO}_{2} \mathrm{NPs}$ and carbon nano fibres (CNF) in energy demand. There is also an issue of technology maturation in nanomaterial synthesis [33]. Another reason is that, as seen from the inventory (Table 16 and Table 17), the majority of material and energy input were captured for both NPs; whereas only the data source of Ag NPs [16] maintains a decent level of comprehensiveness on the emission side (air, water, and soil) [21]. In fact, as reported in the work of Hischier et al. [21], 
among the 17 nanomaterial-focused LCA studies, this data inventory has attained the best data comprehensiveness, and hence the calculated impact is closer to the true value. While for the data of $\mathrm{TiO}_{2} \mathrm{NPs}$ [22], since the emissions are omitted the calculated impacts are inevitably underestimated.

Table 18. Environmental impacts for producing $1 \mathrm{~kg}$ silver nanoparticles (Ag NPs) and titanium dioxide nanoparticles $\left(\mathrm{TiO}_{2} \mathrm{NPs}\right)$. Cradle-to-gate.

\begin{tabular}{|l|l|l|}
\hline & Ag NPs & TiO $_{2}$ NPs \\
\hline IPCC GWP 100a $\left(\mathrm{CO}_{2}\right.$ eq. $\left.\mathrm{kg}\right)$ & 291.8 & 8.24 \\
\hline Energy, non-renewable, fossil (MJ) & 3531 & 133.47 \\
\hline
\end{tabular}

The GWP impact distribution for producing $1 \mathrm{~kg}$ Ag NPs is depicted in Figure 50. It can be seen that silver octanoate (including the upstream stages, e.g. bulk silver production and mining) is the biggest contributor, accounting for $60 \%$ of the total impact, followed by the carbon dioxide fossil emission associated with the Ag NPs production (15\%) and the 2-ethylhexanoic acid (10\%). This suggests that when the emission is properly tracked, it would contribute a significant share to the overall impact. As seen in this example, $15 \%$ carbon dioxide fossil emission has been assigned to the Ag NPs production. 


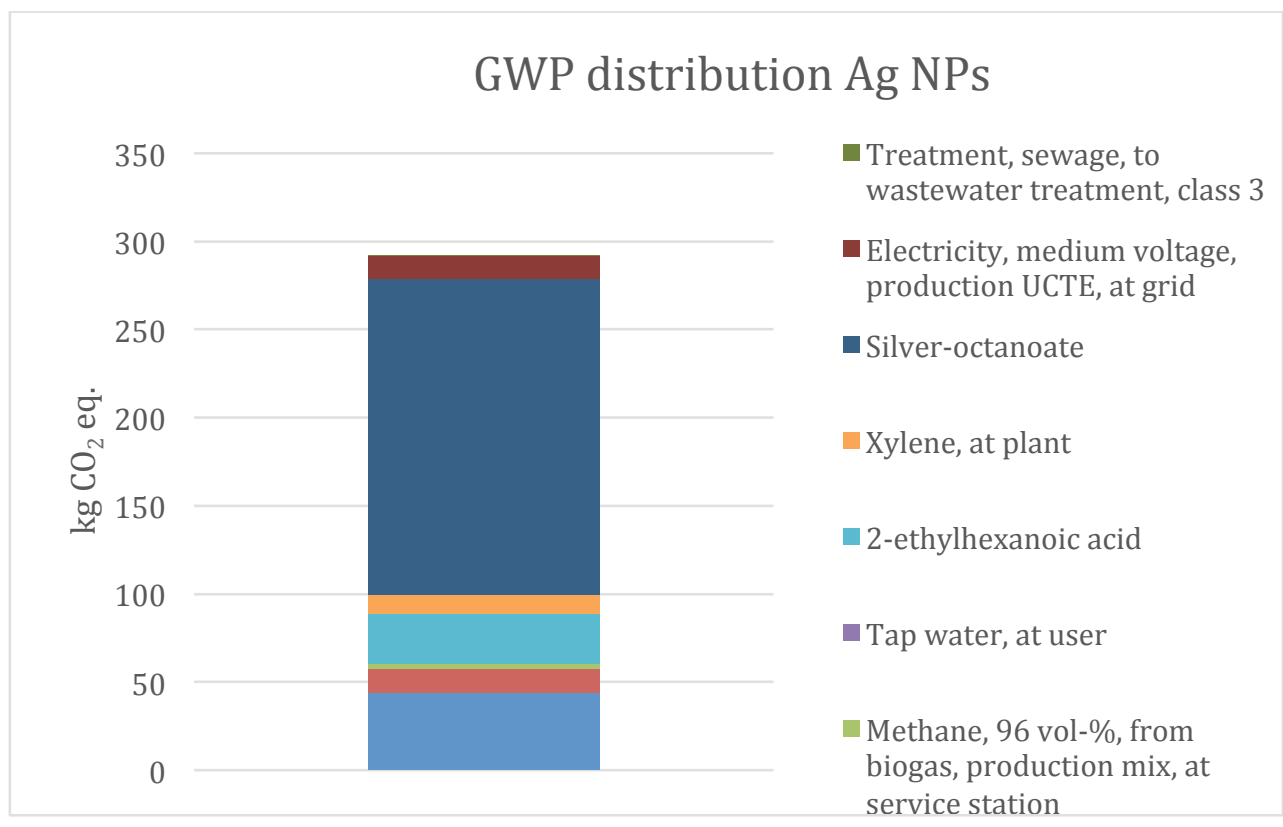

Figure 50. Global Warming Potential (GWP) for producing $1 \mathrm{~kg}$ silver nanoparticles (Ag NPs) and the contribution from each component.

The GWP impact distribution for producing $1 \mathrm{~kg} \mathrm{TiO}_{2} \mathrm{NPs}_{\text {is }}$ depicted in Figure 51. The contribution share from the mineral itself (ilmenite ore) is low, being less than $6 \%$ of the total impact; while the majority of the impact derives from using steam and burning natural gas, accounting for c.a. $42 \%$ and $39 \%$, respectively. This implies that the hydrochloride process is very energy intensive because a large amount of natural gas is burnt to dehydrate the nanoparticles, and high-pressure steam is used to drive the distillation in the parallel recycle loop of hydrochloric acid $(\mathrm{HCl})[22]$. 


\section{GWP distribution $\mathrm{TiO}_{2} \mathrm{NPs}$}

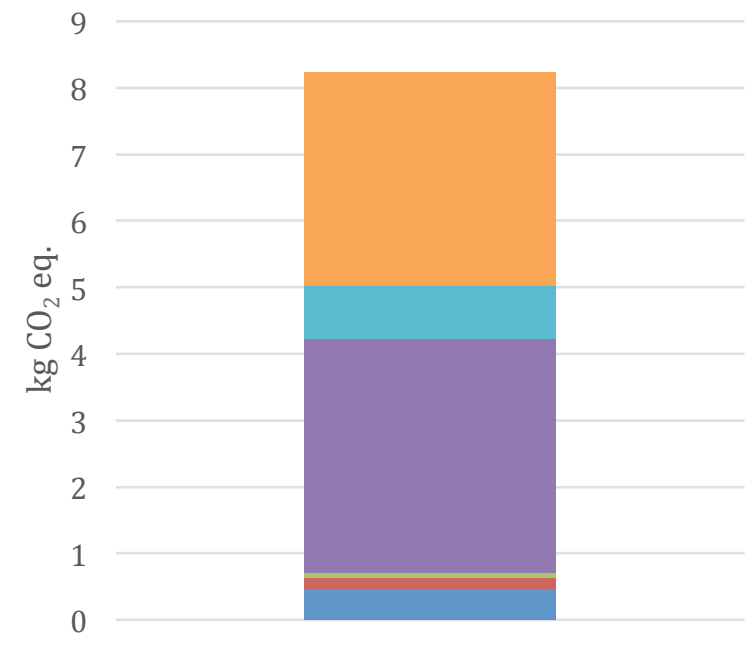

- Heat, natural gas, at industrial furnace $>100 \mathrm{~kW}$

Electricity, medium voltage, production UCTE, at grid

- Steam, for chemical processes, at plant

Hydrochloric acid, from the reaction of hydrogen with chlorine, at plant

- Cast iron, at plant

- Ilmenite, 54\% titanium dioxide, at plant

Figure 51. Global Warming Potential (GWP) for producing $1 \mathrm{~kg}$ titanium dioxide nanoparticles $\left(\mathrm{TiO}_{2} \mathrm{NPs}\right)$ and the contribution from each component.

Regarding the CED for producing $1 \mathrm{~kg} \mathrm{Ag} \mathrm{NPs,} \mathrm{in} \mathrm{particular} \mathrm{the} \mathrm{non-renewable}$ fossil energy (see Figure 52), silver octanoate (including its upstream flows) contributes over $50 \%$ of the total consumption. That is 2 GJ in absolute value. Similarly, this can be attributed to the raw material extraction and the production method. 


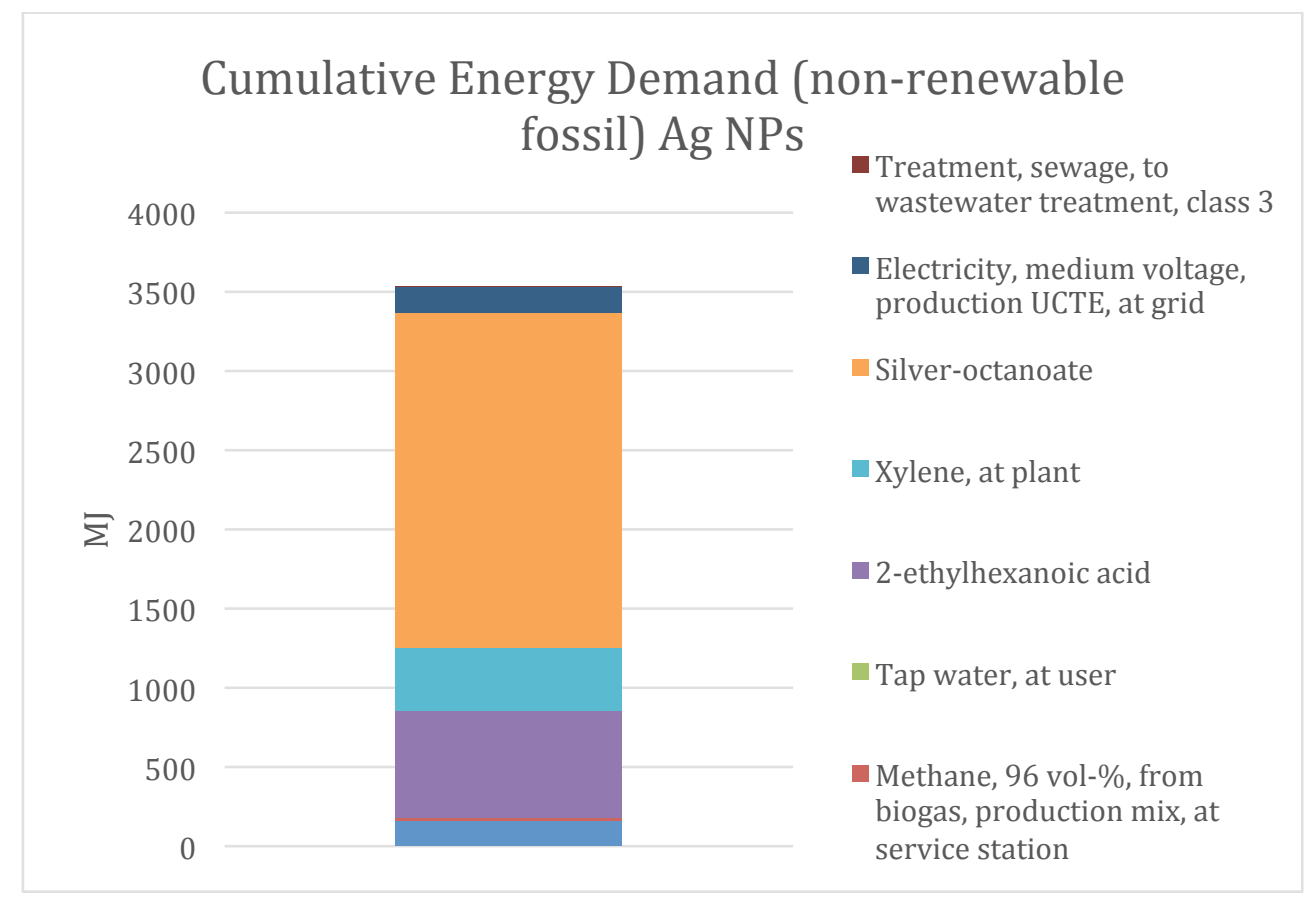

Figure 52. Cumulative Energy Demand (non-renewable fossil) for producing $1 \mathrm{~kg}$ silver nanoparticles (Ag NPs).

In contrast, for the associated energy consumption (non-renewable, fossil) for producing $1 \mathrm{~kg} \mathrm{TiO}_{2}$ NPs (see Figure 53), steam and natural gas dominate in the impact, and the two together accounts for $86 \%$ of the total consumption. That is 114.5 MJ in absolute value. This is because steam for chemical process derives from burning of natural gas and heavy fuel oil in the industrial furnace. 


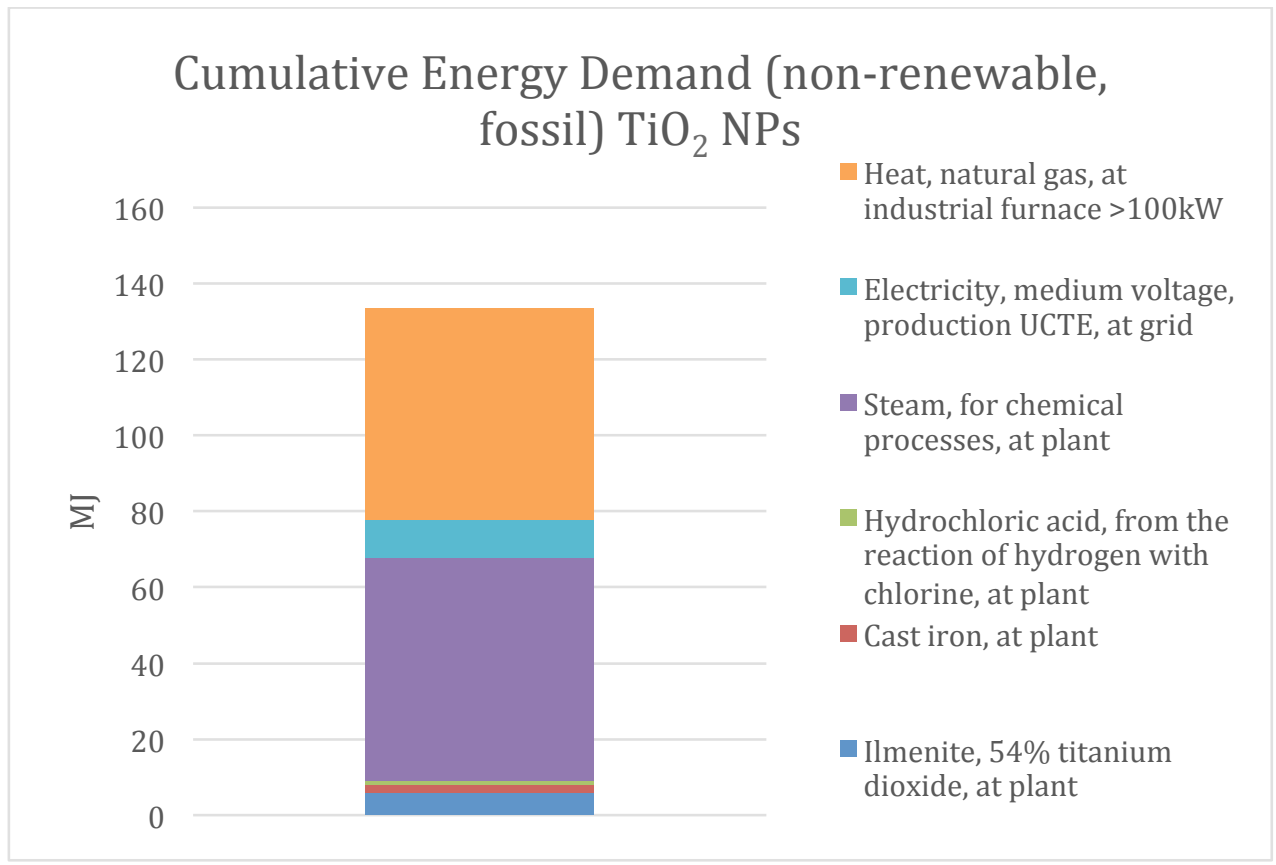

Figure 53. Cumulative Energy Demand (non-renewable, fossil) for producing $1 \mathrm{~kg}$ titanium dioxide nanoparticles $\left(\mathrm{TiO}_{2} \mathrm{NPs}\right)$ and the contribution from each component.

\subsubsection{Packaging scenario setup}

Clearly, there is a difference in the antimicrobial efficacy between the different active agents, which could leads to different loadings in the host polymer material in packaging application. Accordingly, to achieve an equivalent microbe inhibitory effect, the high efficacy agent will be added less. Thus, in order to set up a reasonable packaging scenario, the antimicrobial efficacy of Ag NPs and $\mathrm{TiO}_{2} \mathrm{NPs}$ were extracted from the relevant publications, in particular the comparative studies evaluating these two agents under the same experimental test.

Among the metallic NPs, Ag NPs are shown to have the highest antimicrobial efficacy. In the study of Besinis et al.[34] MIC (Minimum Inhibitory Concentration) of $\mathrm{Ag} \mathrm{NPs}$ and $\mathrm{TiO}_{2} \mathrm{NPs}$ were investigated against a Gram-positive bacterium (Streptococcus mutans). It was found that the MIC of the Ag NPs (mean primary particle size in water $56.8 \mathrm{~nm}$, aggregate size $164 \mathrm{~nm}$ ) was $50 \mu \mathrm{g} / \mathrm{mL}$, while the MIC of the $\mathrm{TiO}_{2} \mathrm{NPs}$ (mean primary particle size in water $22.8 \mathrm{~nm}$, aggregate size $176 \mathrm{~nm}$ ) was $100 \mu \mathrm{g} / \mathrm{mL}$. This means a 2-fold greater efficacy for the Ag NPs against the strain. As reported from the same study, the Ag NPs were found to have 8 -fold greater efficacy in the live and dead staining assay. In another study [35], the 
MIC of Ag NPs and $\mathrm{TiO}_{2}$ NPs were determined by testing against several strains and the results indicate that the Ag NPs (primary particle size 20-25 nm) had a MIC of 0.4-1.7 $\mu \mathrm{g} / \mathrm{mL}$, which is comparable to commercial antibiotics; whereas the $\mathrm{TiO}_{2}$ NPs had limited antimicrobial effect. By summarising these information, it is therefore reasonable to assume that the efficacy of $\mathrm{Ag} \mathrm{NPs}$ is 5 -fold of $\mathrm{TiO}_{2} \mathrm{NPs}$, and accordingly, in the packaging application (1 $\mathrm{kg}$ PLA polymer), $1 \mathrm{wt} \%$ of $\mathrm{Ag}$ NPs enables an equivalent antimicrobial effect as $5 \mathrm{wt} \% \mathrm{TiO}_{2} \mathrm{NPs}$. The loading of the NPs was based on the relevant studies [36, 37].

The synergistic effect from using a mixture of different NPs/hybrid NP has been verified [10, 37-39]. When different agents are used in combination, the system contains multiple action mechanisms and hence it enables stronger antimicrobial activity than the mono agent. As reported in the work of Chen et al. [38], the MIC of a hybrid NP $\left(\mathrm{Cu}-\mathrm{TiO}_{2}\right)$ against $E$. coli and $S$. aureus was about 5-fold lower than the mono NP $\left(\mathrm{Cu}\right.$ or $\left.\mathrm{TiO}_{2}\right)$, i.e. the hybrid NP contains 5-fold greater antimicrobial efficacy. Hybrid $\mathrm{Ag}-\mathrm{TiO}_{2} \mathrm{NPs}$ were found to contain stronger antimicrobial activity [40-42].

Ag NP contains several action mechanisms. This includes NPs attacking on the microbe's cell membrane by direct contact, silver ions leached from NPs, and Reactive Oxygen Species (ROS) generated on the particle surface $[2,3]$. The antimicrobial activity of $\mathrm{TiO}_{2} \mathrm{NP}$ derives from the material's photocatalytic property. Under suitable conditions ROS can be generated from the $\mathrm{TiO}_{2} \mathrm{NP}$ surface [43], e.g. superoxide radicals $\left(\mathrm{O}_{2}^{--}\right)$, hydroxyl radicals $(\mathrm{HOO} \cdot)$, and hydrogen peroxide $\left(\mathrm{H}_{2} \mathrm{O}_{2}\right)$. The ROS cause oxidative stress to the microbe's cell membrane, altering its permeability and integrity, and kill them. Thus, with regard to the packaging scenario, a reasonable assumption can be made: a mixture of $\mathrm{Ag}$ NPs and $\mathrm{TiO}_{2}$ NPs (in 1:1 ratio) at $0.2 \mathrm{wt} \%$ loading will enable an equivalent antimicrobial efficacy to $1 \mathrm{wt} \%$ loading of Ag NPs.

In summary, scenarios can be set up to address three packaging films (Packaging A, $\mathrm{B}$ and $\mathrm{C}$ ) incorporating different agents and agent loadings to fulfill the functional unit defined in this study. This is summarized in Table 19. 
Table 19. Packaging identification and description.

\begin{tabular}{|l|l|l|l|}
\hline & Packaging A & Packaging B & Packaging C \\
\hline Components & $\begin{array}{l}\text { PLA film } \\
\mathrm{Ag} \mathrm{NP}\end{array}$ & $\begin{array}{l}\mathrm{PLA} \mathrm{film} \\
\mathrm{TiO}_{2} \mathrm{NP}_{\mathrm{s}}\end{array}$ & $\begin{array}{l}\text { PLA film + Ag- } \\
\mathrm{TiO}_{2} \mathrm{NP}_{\mathrm{s}}(1: 1)\end{array}$ \\
\hline $\begin{array}{l}\text { Active agent loading with } \\
\text { respect to the polymer }\end{array}$ & $1 \mathrm{wt} \%$ & $5 \mathrm{wt} \%$ & $0.2 \mathrm{wt} \%$ \\
\hline
\end{tabular}

\subsubsection{Impact of different packaging materials}

An important benefit for applying the antimicrobial packaging is to extend the shelf life of food products, i.e. it enables food loss saving. The potential environmental gain can been clearly justified when considering packaging and food as a whole system $[44,45]$. And this is an important issue to take into account for LCA study that addresses the comparison between active packaging and non-active packaging. However, in this study, the focus is placed on the comparison between the active packaging films that are assumed to deliver the same performance, either shelf life extension or reduce the risks of food-borne illness. For this reason, the factor of food is excluded and the packaging is taken as an independent product.

The impact of GWP and CED (non-renewable fossil energy) of the active films are plotted in Figure 54 and Figure 55, respectively. N.B. the impact arising from the PLA pellets production, film extrusion, transport and end-of-life of packaging are presented in an aggregated manner, which is termed as "other life cycle stages". 


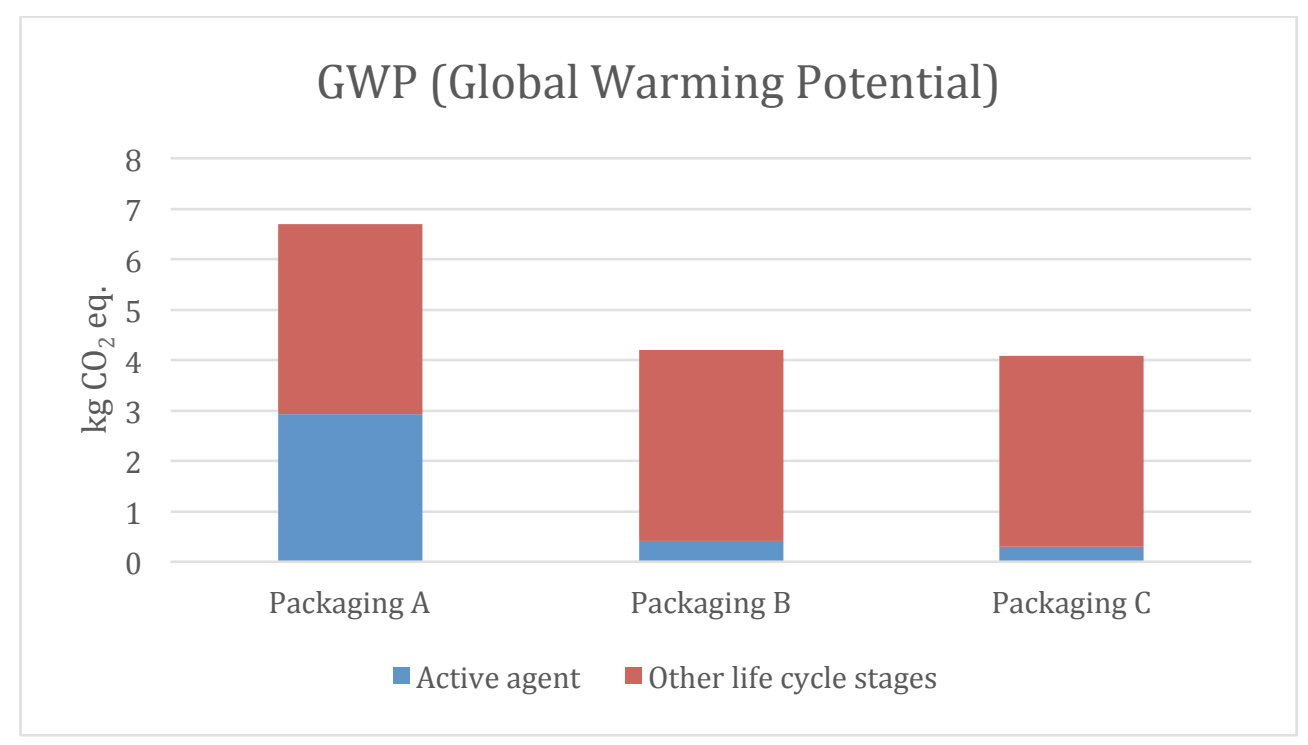

Figure 54. Global Warming Potential (GWP) of different packaging materials (cradle-to-grave). Packaging A: $1 \mathrm{wt} \%$ Ag NPs in $1 \mathrm{~kg}$ PLA packaging film; Packaging B: $5 \mathrm{wt} \% \mathrm{TiO}_{2} \mathrm{NPs}_{\text {in }} 1 \mathrm{~kg}$ PLA packaging film; Packaging C: 0.2 wt\% mixture of Ag NPs \& $\mathrm{TiO}_{2} \mathrm{NPs}^{(1: 1)}$ in $1 \mathrm{~kg}$ PLA packaging film. 


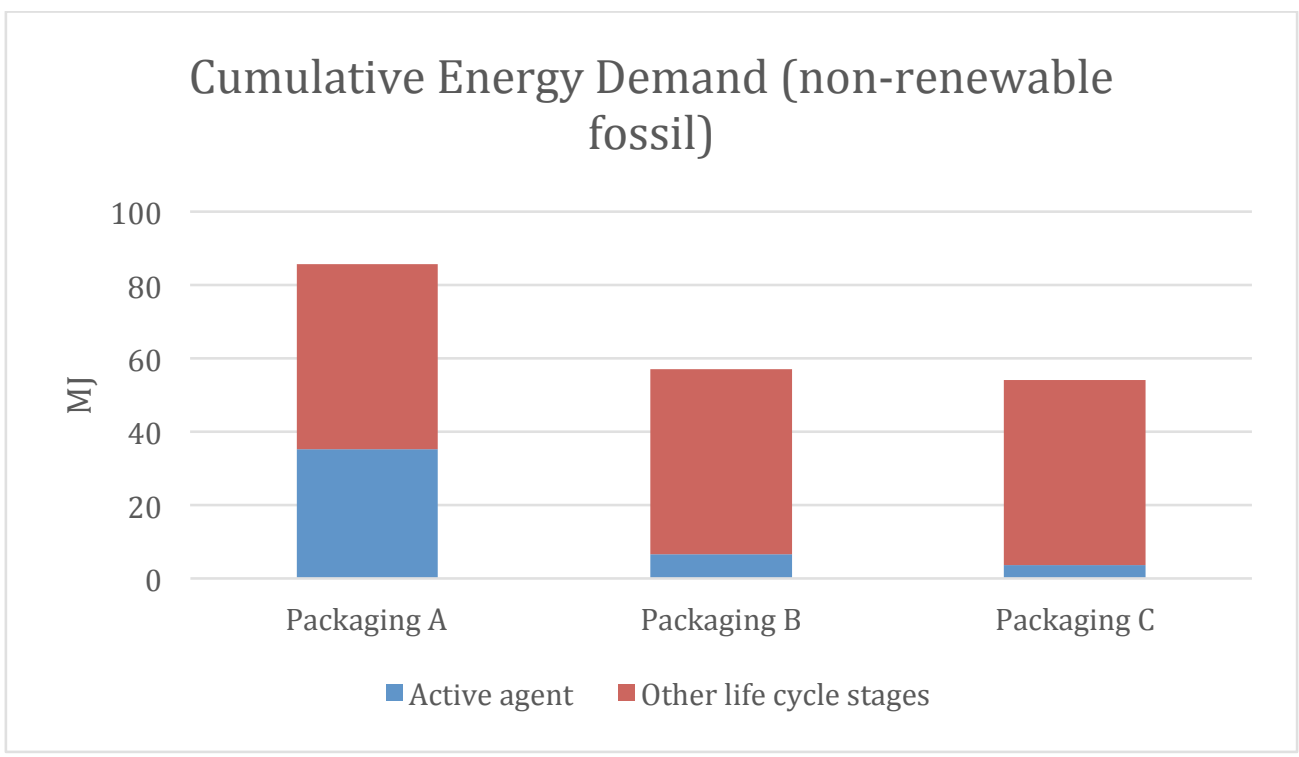

Figure 55. Cumulative Energy Demand (non-renewable fossil) of different packaging materials (cradle-to-grave). Packaging A: 1 wt\% Ag NPs in $1 \mathrm{~kg}$ PLA packaging film; Packaging B: 5 wt\% $\mathrm{TiO}_{2}$ NPs in $1 \mathrm{~kg}$ PLA packaging film; Packaging C: $0.2 \mathrm{wt} \%$ mixture of Ag NPs \& $\mathrm{TiO}_{2}$ NPs (1:1) in $1 \mathrm{~kg}$ PLA packaging film.

Generally, both impacts follow a similar trend as the packaging material shifts from A, to B and C. As seen in Packaging B, despite the weight share of the NPs is 5fold of Packaging $\mathrm{A}$, the resulting impact is still lower than its counterpart, being c.a. $63 \%$ in GWP and $67 \%$ in energy consumption (non-renewable fossil). This is due to the high impacts from producing Ag NPs. For Packaging C, both impacts are slightly lower than Packaging B. Because it has the lowest loading of NPs, it is reasonable to have the lowest environmental impacts. This result could serve as a guideline of sustainability for the nano-enabled material development.

Aside from the impacts in GWP and energy consumption, the toxicity of nanomaterial is another critical issue to look at [21]. In the framework of LCA, at current stage the USEtox ${ }^{\mathrm{TM}}$ model is the best characterization model to quantify the toxicity related impact to human and ecosystems (only in freshwater) [46, 47]. However, this model is not applicable to nano-toxicity [21, 46]. In accordance with the work of Barberio et al. [33], to date only two publications pioneer in quantifying the freshwater nano-toxicity [29, 48]. Additionally, model's satisfactory level is low, which means improvement actions are needed for this model and apply with caution [46]. Therefore, further research is needed to develop the characterization model addressing nano-toxicity. 


\subsubsection{Nanomaterial for food contact application}

Active food contact material shall comply with the EU regulation (EC No 450/2009), which gives particular attention to the nanomaterials [49]. In accordance with the work of Reig et al. [50], to date, only three nanomaterials have been authorised by EFSA (European Food Safety Authority) for food contact application. They are titanium nitride (TiN), carbon black $(\mathrm{C})$ and silica $\left(\mathrm{SiO}_{2}\right)$, and all of them are to be used as polymer production aids (ino active properties). The only metallic nanoparticles, TiN, according to the EFSA scientific opinion [51], is only to be used in PET (Polyethylene Terephthalate) up to $20 \mathrm{mg} / \mathrm{kg}$ (i.e. loading 20 ppm). Primary particles $(20 \mathrm{~nm})$ and agglomerates $(100-500 \mathrm{~nm})$ coexist within the PET matrix. The scientific panel concludes that there is no safety concern for consumers under intended use conditions (for all types of foodstuffs and up to hot filling temperature) [51].

From the TiN case, it can be noticed that the agent loading is far below the commonly accepted range for nanomaterials, shifting from pph (part per hundred) to ppm (part per million), but in the meanwhile such low loading enables good technical performance (re-heat improvement in this case) [52]. In the meanwhile, from this case one can infer the authority's attitude towards nanomaterials: a caseby-case approach. This means if this application is aimed for PET, all the tests will concentrate on PET, and once approved, it is only allowed to be used in PET below the specific loading that has been verified by the test.

Migration both in nano-form and in ionic-form is major concern for using NPs for food contact application [53, 54]. In a recent opinion issued by EFSA) [55], they evaluated the case of using ZnO NPs for food contact application. LDPE films containing the maximum use level of the $\mathrm{ZnO}$ NPs were subjected to the standard migration test, and high concentration of $\mathrm{Zn}^{2+}$ was detected in one food simulant, acetic acid 3\% (w/v). The panel expresses their concerns on such migration. Other NPs may face the same issue, because as the particle size is reduced to nano-range the NP dissolution is often enhanced.

Therefore, in order to get the NPs authorised for food contact application, the key is to suppress the dissolution of NP at the same time maintaining the desired properties, e.g. antimicrobial activity. As suggested from the LCA results of this study, using a mixture of NPs or hybrid NP can be an effective way to reduce the NP loading and minimise the associated environmental impacts. 


\subsection{CONCLUSIONS}

Nanomaterial as a new class of material, its safe and sustainable use has raised considerable concern. According to the literature, there have been some common issues agreed within the research community for applying LCA to nanomaterials: the existing ISO-based LCA framework is applicable to nanomaterial/nanomaterialenabled product; at current stage the inventory data of nanomaterial is scarce; there is lack of satisfactory characterization model to address the nano-toxicity.

Despite the barriers, we carried out a LCA by focusing on the selection of metallic NPs as active agent for food packaging application. Three packaging films were considered and their environmental impacts were calculated and compared. The functional unit was set in such a way that it directly focuses on the function that the antimicrobial packaging is supposed to deliver: to ensure food safety and quality. To this end, the antimicrobial efficacy of each agent was incorporated in the life cycle impact assessment. The result indicates that the packaging film using $\mathrm{TiO}_{2}$ NPs had lower environmental impacts in GWP and non-renewable fossil energy consumption, being c.a. $65 \%$ of the case of using Ag NPs. This is partly due to the omission of data on the emission side of $\mathrm{TiO}_{2} \mathrm{NPs}$ production. As seen in the case of using both NPs as agent, the agent loading in the film can be further reduced due to synergistic effect. Accordingly, the associated environmental impacts of this film dropped by $2-5 \%$ below the film using $\mathrm{TiO}_{2} \mathrm{NPs}$.

There are some constraints in this study, for example, we only looked at the impacts of GWP and energy consumption, and only two NPs' inventory data are available. This calls for a to-do list for future research: improve the characterization model for addressing the nano-toxicity; the producers should add more transparency in the data inventory of nanomaterials; more efforts should be made to track the nanomaterial emission and the unintentional release throughout the product's life cycle. 


\subsection{REFERENCES}

1. Martins NC, Freire CS, Neto CP, Silvestre AJ, Causio J, Baldi G, Sadocco $\mathrm{P}$, Trindade T. Antibacterial paper based on composite coatings of nanofibrillated cellulose and ZnO. Colloids and Surfaces A: Physicochemical and Engineering Aspects 2013; 417, pp. 111-119.

2. Llorens A, Lloret E, Picouet PA, Trbojevich R, Fernandez A. Metallicbased micro and nanocomposites in food contact materials and active food packaging. Trends in Food Science \& Technology 2012; 24(1), pp. 19-29.

3. Duncan TV. Applications of nanotechnology in food packaging and food safety: Barrier materials, antimicrobials and sensors. Journal of colloid and interface science 2011; 363(1), pp. 1-24.

4. Liu Y, He L, Mustapha A, Li H, Hu Z, Lin M. Antibacterial activities of zinc oxide nanoparticles against Escherichia coli 0157: H7. Journal of applied microbiology 2009; 107(4), pp. 1193-1201.

5. Maneerat C, Hayata Y. Antifungal activity of TiO2 photocatalysis against Penicillium expansum in vitro and in fruit tests. International journal of food microbiology 2006; 107(2), pp. 99-103.

6. Fernández A, Picouet P, Lloret E. Cellulose-silver nanoparticle hybrid materials to control spoilage-related microflora in absorbent pads located in trays of fresh-cut melon. International Journal of Food Microbiology 2010; 142(1), pp. 222-228.

7. Li X, Xing Y, Jiang Y, Ding Y, Li W. Antimicrobial activities of ZnO powder - coated PVC film to inactivate food pathogens. International journal of food science \& technology 2009; 44(11), pp. 2161-2168.

8. Castro-Mayorga J, Fabra M, Lagaron J. Stabilized nanosilver based antimicrobial poly (3-hydroxybutyrate-co-3-hydroxyvalerate) nanocomposites of interest in active food packaging. Innovative Food Science \& Emerging Technologies 2016; 33, pp. 524-533.

9. El-Wakil NA, Hassan EA, Abou-Zeid RE, Dufresne A. Development of wheat gluten/nanocellulose/titanium dioxide nanocomposites for active food packaging. Carbohydrate polymers 2015; 124, pp. 337-346.

10. Jin T, Gurtler J. Inactivation of Salmonella in liquid egg albumen by antimicrobial bottle coatings infused with allyl isothiocyanate, nisin and zinc oxide nanoparticles. Journal of applied microbiology 2011; 110(3), pp. 704712 .

11. Stora Enso Packaging Solutions. Press release. [cited 21-06-2015];

Available from:

http://www.storaensopack.com/sites/default/files/Millennial\%20viewpoint $\% 20$ press\%20release_EN.pdf 
12. Kloepffer W. Life cycle sustainability assessment of products. The International Journal of Life Cycle Assessment 2008; 13(2), pp. 89-95.

13. Greijer H, Karlson L, Lindquist S-E, Hagfeldt A. Environmental aspects of electricity generation from a nanocrystalline dye sensitized solar cell system. Renewable Energy 2001; 23(1), pp. 27-39.

14. Lloyd SM, Lave LB. Life cycle economic and environmental implications of using nanocomposites in automobiles. Environmental Science \& Technology 2003; 37(15), pp. 3458-3466.

15. Bauer C, Buchgeister J, Hischier R, Poganietz W, Schebek L, Warsen J. Environmental prospects in products-a framework for life cycle thinking on nano scales. J Clean Prod 2008; 16(8-9), pp. 910-926.

16. Walser T, Demou E, Lang DJ, Hellweg S. Prospective environmental life cycle assessment of nanosilver T-shirts. Environmental science \& technology 2011; 45(10), pp. 4570-4578.

17. Roes A, Marsili E, Nieuwlaar E, Patel M. Environmental and cost assessment of a polypropylene nanocomposite. Journal of Polymers and the Environment 2007; 15(3), pp. 212-226.

18. Klöpffer W, Curran MA, Frankl P, Heijungs R, Köhler A, Olsen SI, Nanotechnology and Life Cycle Assessment. A systems approach to Nanotechnology and the environment: Synthesis of Results Obtained at a Workshop Washington, DC 2-3 October 2006, 2007, European Commission, DG Research, jointly with the Woodrow Wilson International Center for Scholars.

19. Som C, Berges M, Chaudhry Q, Dusinska M, Fernandes TF, Olsen SI, Nowack B. The importance of life cycle concepts for the development of safe nanoproducts. Toxicology 2010; 269(2), pp. 160-169.

20. Eckelman MJ, Zimmerman JB, Anastas PT. Toward green nano. Journal of Industrial Ecology 2008; 12(3), pp. 316-328.

21. Hischier R, Walser T. Life cycle assessment of engineered nanomaterials: State of the art and strategies to overcome existing gaps. Science of The Total Environment 2012; 425, pp. 271-282.

22. Grubb GF, Bakshi BR. Life cycle of titanium dioxide nanoparticle production. Journal of Industrial Ecology 2011; 15(1), pp. 81-95.

23. Davis G, Song J. Biodegradable packaging based on raw materials from crops and their impact on waste management. Industrial crops and products 2006; 23(2), pp. 147-161.

24. Piemonte V. Bioplastic wastes: the best final disposition for energy saving. Journal of Polymers and the Environment 2011; 19(4), pp. 988-994.

25. Yates MR, Barlow CY. Life cycle assessments of biodegradable, commercial biopolymers-A critical review. Resources, Conservation and Recycling 2013; 78, pp. 54-66. 
26. Bohlmann GM. Biodegradable packaging life - cycle assessment. Environmental Progress 2004; 23(4), pp. 342-346.

27. Madival S, Auras R, Singh SP, Narayan R. Assessment of the environmental profile of PLA, PET and PS clamshell containers using LCA methodology. Journal of Cleaner Production 2009; 17(13), pp. 1183-1194.

28. Kolstad JJ, Vink ET, De Wilde B, Debeer L. Assessment of anaerobic degradation of Ingeo $^{\text {TM }}$ polylactides under accelerated landfill conditions. Polymer Degradation and Stability 2012; 97(7), pp. 1131-1141.

29. Eckelman MJ, Mauter MS, Isaacs JA, Elimelech M. New perspectives on nanomaterial aquatic ecotoxicity: production impacts exceed direct exposure impacts for carbon nanotoubes. Environmental science \& technology 2012; 46(5), pp. 2902-2910.

30. Keller AA, McFerran S, Lazareva A, Suh S. Global life cycle releases of engineered nanomaterials. Journal of nanoparticle research 2013; 15(6), pp. $1-17$.

31. Savolainen K, Alenius H, Norppa H, Pylkkänen L, Tuomi T, Kasper G. Risk assessment of engineered nanomaterials and nanotechnologies-a review. Toxicology 2010; 269(2), pp. 92-104.

32. Kunhikrishnan A, Shon HK, Bolan NS, El Saliby I, Vigneswaran S. Sources, distribution, environmental fate and ecological effects of nanomaterials in wastewater streams. Critical Reviews in Environmental Science and Technology 2015; 45(4), pp. 277-318.

33. Barberio G, Scalbi S, Buttol P, Masoni P, Righi S. Combining life cycle assessment and qualitative risk assessment: The case study of alumina nanofluid production. Science of The Total Environment 2014; 496, pp. 122131.

34. Besinis A, De Peralta T, Handy RD. The antibacterial effects of silver, titanium dioxide and silica dioxide nanoparticles compared to the dental disinfectant chlorhexidine on Streptococcus mutans using a suite of bioassays. Nanotoxicology 2014; 8(1), pp. 1-16.

35. Martinez-Gutierrez F, Olive PL, Banuelos A, Orrantia E, Nino N, Sanchez EM, Ruiz F, Bach H, Av-Gay Y. Synthesis, characterization, and evaluation of antimicrobial and cytotoxic effect of silver and titanium nanoparticles. Nanomedicine: Nanotechnology, Biology and Medicine 2010; 6(5), pp. 681688.

36. Nakayama N, Hayashi T. Preparation and characterization of poly (1lactic acid) $/ \mathrm{TiO}_{2}$ nanoparticle nanocomposite films with high transparency and efficient photodegradability. Polymer degradation and stability 2007; 92(7), pp. 1255-1264. 
37. Li H, Li F, Wang L, Sheng J, Xin Z, Zhao L, Xiao H, Zheng Y, Hu Q. Effect of nano-packing on preservation quality of Chinese jujube (Ziziphus jujuba Mill. var. inermis (Bunge) Rehd). Food chemistry 2009; 114(2), pp. 547-552.

38. Chen S, Guo Y, Zhong H, Chen S, Li J, Ge Z, Tang J. Synergistic antibacterial mechanism and coating application of copper/titanium dioxide nanoparticles. Chemical Engineering Journal 2014; 256, pp. 238-246.

39. Solomakos N, Govaris A, Koidis P, Botsoglou N. The antimicrobial effect of thyme essential oil, nisin and their combination against Escherichia coli 0157: H7 in minced beef during refrigerated storage. Meat science 2008; 80(2), pp. 159-166.

40. Guin D, Manorama SV, Latha JNL, Singh S. Photoreduction of silver on bare and colloidal $\mathrm{TiO}_{2}$ nanoparticles/nanotubes: synthesis, characterization, and tested for antibacterial outcome. The Journal of Physical Chemistry $C$ 2007; 111(36), pp. 13393-13397.

41. Li M, Noriega-Trevino ME, Nino-Martinez N, Marambio-Jones C, Wang J, Damoiseaux R, Ruiz F, Hoek EM. Synergistic bactericidal activity of Ag-TiO2 nanoparticles in both light and dark conditions. Environmental science \& technology 2011; 45(20), pp. 8989-8995.

42. Nino-Martinez N, Martinez-Castanon G, Aragon-Pina A, MartinezGutierrez F, Martinez-Mendoza J, Ruiz F. Characterization of silver nanoparticles synthesized on titanium dioxide fine particles. Nanotechnology 2008; 19(6), pp. 065711.

43. Visai L, De Nardo L, Punta C, Melone L, Cigada A, Imbriani M, Arciola CR. Titanium oxide antibacterial surfaces in biomedical devices. International Journal of Artificial Organs 2011; 34(9), pp. 929-946.

44. Williams H, Wikström F. Environmental impact of packaging and food losses in a life cycle perspective: a comparative analysis of five food items. Journal of Cleaner Production 2011; 19(1), pp. 43-48.

45. Zhang H, Hortal M, Dobon A, Bermudez JM, Lara - Lledo M. The Effect of Active Packaging on Minimizing Food Losses: Life Cycle Assessment (LCA) of Essential Oil Component - enabled Packaging for Fresh Beef. Packaging Technology and Science 2015; 28(9), pp. 761-774.

46. Hauschild MZ, Goedkoop M, Guinée J, Heijungs R, Huijbregts M, Jolliet O, Margni M, De Schryver A, Humbert S, Laurent A. Identifying best existing practice for characterization modeling in life cycle impact assessment. The International Journal of Life Cycle Assessment 2013; 18(3), pp. 683-697.

47. Rosenbaum RK, Bachmann TM, Gold LS, Huijbregts MA, Jolliet 0, Juraske R, Koehler A, Larsen HF, MacLeod M, Margni M. USEtox-the UNEPSETAC toxicity model: recommended characterisation factors for human toxicity and freshwater ecotoxicity in life cycle impact assessment. The International Journal of Life Cycle Assessment 2008; 13(7), pp. 532-546. 
48. Salieri B, Righi S, Pasteris A, Olsen SI. Freshwater ecotoxicity characterisation factor for metal oxide nanoparticles: A case study on titanium dioxide nanoparticle. Science of The Total Environment 2015; 505, pp. 494502.

49. Rossi M, Cubadda F, Dini L, Terranova M, Aureli F, Sorbo A, Passeri D. Scientific basis of nanotechnology, implications for the food sector and future trends. Trends in Food Science \& Technology 2014; 40(2), pp. 127-148.

50. Reig CS, Lopez AD, Ramos MH, Ballester VAC. Nanomaterials: a map for their selection in food packaging applications. Packaging Technology and Science 2014; 27(11), pp. 839-866.

51. EFSA CEF Panel on Food Contact Materials E, Flavourings and Processing Aids. Scientific Opinion on the safety evaluation of the substance, titanium nitride, nanoparticles, for use in food contact materials. EFSA Journal 2012; 10(3), pp. 2641-2649, DOI: 10.2903/j.efsa.2012.2641.

52. Xia Z, Stafford SL, Sims S, Colhoun FL, Polyester polymer and copolymer compositions containing titanium nitride particles, 2008, Patent US7368523 B2.

53. Kuorwel KK, Cran MJ, Orbell JD, Buddhadasa S, Bigger SW. Review of mechanical properties, migration, and potential applications in active food packaging systems containing nanoclays and nanosilver. Comprehensive Reviews in Food Science and Food Safety 2015; 14(4), pp. 411-430.

54. Hannon JC, Kerry JP, Cruz-Romero M, Azlin-Hasim S, Morris M, Cummins E. Assessment of the migration potential of nanosilver from nanoparticle-coated low-density polyethylene food packaging into food simulants. Food Additives \& Contaminants: Part A 2016; 33(1), pp. 167-178.

55. EFSA CEF Panel on Food Contact Materials E, Flavourings and Processing Aids. Scientific Opinion on the safety evaluation of the substance zinc oxide, nanoparticles, uncoated and coated with [3-(methacryloxy)propyl] trimethoxysilane, for use in food contact materials. EFSA Journal 2015; 13(4), pp. 4063-4072, DOI: doi:10.2903/j.efsa.2015.4063. 


\section{FINAL REMARKS AND OUTLOOK FOR FUTURE RESEARCH}

Active packaging, particularly antimicrobial packaging, can make positive contributions to reducing food losses by extending food shelf life. This benefit of applying a more advanced packaging can be clearly justified when considering packaging and food as a whole system. The breakeven point can be easily achieved for the case of high impacts foodstuff, e.g. fresh beef.

Metallic nanoparticles as antimicrobial agent offers a few advantages such as superior antimicrobial efficacy, no negative impacts on the food sensory properties, and compatibility with harsh polymer processing conditions. The strong antimicrobial activity derives from the multiple action mechanisms of the agent. The ability to inactivate food borne pathogen implies that food packaging containing metallic NPs can be an effective measure to control microbiological risks.

In this thesis, we produced a nano-enabled active packaging in the lab: PLA (Polylactic Acid) coating layer containing ZnO NPs was coated on paper surface using solvent casting method. Antimicrobial assay indicates that the active material was effective in inactivating E. coli and $S$. aureus. Furthermore, E. coli was found to be more susceptible to this type of agent, showing $3.14 \log$ reduction for $0.5 \mathrm{wt} \%$ agent loading in PLA coating layer. This result was compared across the publications using the same agent for treating both Gram-positive and Gram-native microorganisms. The discrepancy between the results can be explained by the fact that $\mathrm{ZnO}$ nanoparticles have multiple action mechanisms, and different antimicrobial testing methods may activate part of the action mechanisms.

Incorporating the life cycle thinking, the end-of-life of such packaging material was investigated. As the coating is applied on paper substrate, it is anticipated that the material will be subjected to paper recycling process after use. Therefore, the fate of nanoparticles in the paper recycling process has become an interest issue to investigate as the toxicity of the released nanoparticles has raised significant concern. The recyclability test was based on a method adapted from ATICELCA MC501-13, which enabled to recover over $99 \%$ of the solids material. The mass balance result indicates that $86 \%-91 \%$ zinc oxide nanoparticles ended up in the rejected material stream, mostly embedded within the polymer coating; whereas $7 \%-16 \%$ nanoparticles ended up in the accepted material stream. Besides, the tensile strength of the recycled handsheets suggests that the nano-enabled coating had no negative impacts on the recovered fibre quality. 
To introduce a novel packaging material to market, besides the technical performance, other important factors should be considered, for example the regulatory issues regarding nanomaterials for food contact application. The regulator (EFSA) is treating nanomaterial on a case-by-case basis. Risk assessment with nanomaterial is highly needed to address the nano-toxicity. Lately, the regulator has evaluated the request for using $\mathrm{ZnO}$ NPs food contact application. They issued their scientific opinion on this agent and expressed worries on the leaching of zinc ions especially under acidic conditions for the migration in food simulant B is close to the upper limit set by the toxicological studies. So the agent is not officially approved yet.

If we look at the nanoparticles already authorized by EFSA for food contact application, for example the TiN case, it can be noticed that the agent loading is far below the commonly accepted range for nanomaterials, shifting from pph (part per hundred) to ppm (part per million). But in the meanwhile such low loading enables good technical performance, which enables significant saving of energy and cost. Therefore, for successful authorization of $\mathrm{ZnO} \mathrm{NP}$, the key lies in suppressing the dissolution of NPs in acidic media and at the same time maintaining other desired properties, e.g. antimicrobial activity and UV-blocking. This implies challenges for future research.

There are limitations in this thesis and the origin is the sample material. In this study, the material is produced using solvent casting method on paper substrate. For this coating method, it is difficult to obtain a satisfactory coating concentration. Finally, the priority was given to the nanoparticle dispersion and runnability on the coating machine; polymer coating of low concentration was used $(10-15 \% \mathrm{w} / \mathrm{v})$. But the thin coating penetrates into paper structure in a less controlled manner, and this has caused the high reject rate in the recycling test. In the antimicrobial test, if the surface pores exist, the testing method JIS Z 2801 may fail and SEM analysis is necessary. For future study, it is recommended to produce the material with extrusion coating, and this will eliminate the above-mentioned problems and make the results more meaningful to the industry.

Another point that can be improved is the material validation. As the material has been shown effective in in-vitro test, the next step is to carry out in-vivo test with real food. This is important as reduced activity is often observed in the in-vivo test. Besides, as the antimicrobial mechanism of $\mathrm{ZnO} N \mathrm{NP}$ is complex, it is critical choose suitable foodstuffs, e.g. dry, half dry, or liquid, which could significantly influences the material's performance. 


\section{ACKNOWLEDGEMENT}

This thesis represents three years of effort in packaging research. Most of the work was carried out at the ITENE, Valencia, Spain, from 2013 to 2015.

This thesis would not have been possible without the help from many people. I would like to take this opportunity to thank them.

First I wish to thank my directors, Mercedes Hortal and Maria Jorda, for your guidance and support in carrying out this research. Thank you to Antonio Dobon, who showed me to the world of LCA.

Thank you to the workmates at the ITENE and the consortiums of the "NewGenPak" project. Needless to mention the numerous useful discussions and support in our meetings and workshops, all the wonderful dinners, parties and talks, have enriched my life. Many of us have become good friends.

I had three happy secondments. Thank you to the hosts, Prof. Julien Bras at the Grenoble INP-Pagora, Dr. Graziano Elegir at the paper division of the INNOVIHUB, and Prof. Chris Breen at the Sheffield Hallam University, for your kindness and hospitality.

I would like to thank Prof. Chris Breen and Dr. Francis Clegg at the Sheffield Hallam University for your support in the SEM measurement and the useful discussions in preparing the manuscript (Paper I). I also thank two colleagues at the ITENE, Mari Pau Balaguer, who provided her critical review to this manuscript, and Natalia Ortuño, who helped me with the TGA measurement.

It is a great pleasure to work with you, Graziano and Daniele. Thanks for your contribution and critical review to this manuscript (Paper II). Tullia Maifreni and Alessandra Boschi at the INNOVHUB-SSI are also acknowledged for performing the SEM-EDX experiments as reported in Paper II. Umicore is greatly acknowledged for providing the nanoparticles used in these studies (Paper I and II).

I want to thank the Seventh Framework Program of the European Union for providing the financial support (grant agreement No. 290098). Though I am a 
researcher from the outside of the EU, I was so lucky to receive the prestigious Marie Curie Fellowship. I really appreciate this open selection policy, and hopefully my work has generated satisfactory results and met the expectations.

I owe my deepest gratitude to my parents for your support and understanding. I am sorry that in the past three years I cannot stay by your side and take care of you. 


\section{LIST OF PUBLICATIONS:}

- PAPER I. ZnO-PLA nanocomposite coated paper for antimicrobial packaging application. Hai Zhang, Mercedes Hortal, Maria Jordá-Beneyto, Estela Rosa, Marta Lara-Lledo, Inmaculada Lorente. Submitted to the LWT-Food Science and Technology.

- PAPER II. PLA coated paper containing active inorganic nanoparticles: Material characterization and fate of nanoparticles in the paper recycling process. Hai Zhang, Daniele Bussini, Mercedes Hortal, Graziano Elegir, Joana Mendes, Maria Jordá-Beneyto. Published in the Waste Management, 2016, 52: 339-345.

- PAPER III. The effect of active packaging on minimising food losses: Life Cycle Assessment (LCA) of essential oil component enabled packaging for fresh beef. Hai Zhang, Mercedes Hortal, Antonio Dobon, Jose M. Bermudez and Marta Lara-Lledo. Published in the Packaging Technology and Science, 2015, 28 (9): 761-774.

- PAPER IV. Selection of nanomaterial-based active agents for packaging applications: Using Life Cycle Assessment (LCA) as a tool. Hai Zhang, Mercedes Hortal, Antonio Dobon, Maria Jorda-Beneyto, and Jose M. Bermudez. Accepted manuscript for the Packaging Technology and Science, 2016. 